\title{
3 Heimatkunde
}

Die Verknüpfungen von Heimat- und Wissensdiskursen zeigen sich historisch teils auch als Verknüpfungen von Heimat- und Wissenschaftsdiskursen: mit der Theologie (II.1.1), der Altphilologie (II.1.3) oder mit der Rechts- und Staatswissenschaft (II.2.1). Kaum eine Wissenschaft, die im Lauf des 19. Jahrhunderts nicht mit dem Heimatdiskurs in Berührung gekommen wäre: die Naturwissenschaften (zur Erdkunde siehe II.3.1.1), die Sozialwissenschaften (zur Volkskunde II.3.2, zur Pädagogik II.3.1), die Geisteswissenschaften (zur Germanistik und Geschichtswissenschaft II.3.3). Was hier der ausgedehnten Natur der Sache gemäß nur exemplarisch gezeigt werden kann, verdichtet sich in drei Punkten.

Erstens wird Heimat als Begriff in die Wissenschaftssprachen integriert: Die Geographiedidaktik entwirft Anfang des 19. Jahrhunderts eine ,Heimatkunde' und am Ende des Jahrhunderts prägen die Indogermanistik und die Sprachwissenschaft den Begriff der ,Urheimat' (II.3.3.1), um zwei Beispiele zu nennen. Mit der sprachlichen Einverleibung geht zweitens die teils emphatisch vorgetragene Annahme einher, dem Heimatbegriff komme in der Wissenschaft eine grundsätzliche Beschreibungskraft zu. Alexander von Humboldts Kosmos, einem zeitgenössisch als zentrale Schrift der Naturkunde angesehenen, gar als „Evangelium der Natur" bezeichneten Werk, wird beispielsweise - in offensichtlicher Analogie zu religiösen Bildern einer Heimat im Himmelreich - die Aufgabe zugeschrieben, dem Menschen sein Erdenreich zur Heimat zu erheben. Humboldt lehre mit seinem Werk, dass die „Naturwissenschaft [...] ihre Bedeutung und ihren Werth erst“ gewinne, ,indem sie ein Gemeingut der Menschheit wird und dabei als irdische Heimathskunde erscheint“.

Denn er lenkte zuerst den Blick der Naturforscher von der Aeußerlichkeit der einzelnen Gestalten und Erscheinungen auf ihr inneres Wesen und lehrte sie, daß die Naturwissenschaft ihr höchstes Ziel weder als Dienerin der Heilkunde und Gewerbe, noch als Lieferantin für die Naturalienkabinette, sondern erst als Erzieherin des Menschengeschlechts zur irdischen Heimathsangehörigkeit erreiche. ${ }^{1}$

Was hier Zuschreibung seitens eines anonymen Rezensenten des Kosmos ist, dass nämlich das eigentliche Telos der (Natur-)Wissenschaft Heimatkunde sei, und zwar in dem umfassenden Sinn einer Zugehörigkeit zur Welt, findet sich auch im Selbstverständnis der Wissenschaften selbst. Vertreter der Volkskunde, der Germanistik, der Geographie und anderer Fachdisziplinen gehen davon aus, dass Heimat ein belastbarer wissenschaftlicher Begriff, teils gar ein belastbares Er-

1 Anonym 1853, S. 397.

Ә OpenAccess. (c) 2021 Anja Oesterhelt, publiziert von De Gruyter. (cc)BY-ND Dieses Werk ist lizenziert unter der Creative Commons Attribution-NonCommercial-NoDerivatives 4.0 Lizenz.

https://doi.org/10.1515/9783110707847-006 
klärungs- und Begründungsmodell ihrer Wissenschaften abgeben könne, wie dieses Kapitel zeigen wird.

Diese sich zum größeren Teil nach der Jahrhundertmitte ausbildendenden wissenschaftlichen (oder vorsichtiger: von den Wissenschaften verwendeten) Begriffe von Heimat stehen drittens oft, wenn auch nicht immer, mit geschichtsteleologischen Vorstellungen in Zusammenhang, nach denen aus dem Heimatgefühl die Vaterlands- oder Nationalstaatsliebe erwachse (vgl. I.2.1). ${ }^{2}$ Geschichte erscheint etwa beim Althistoriker Ernst Curtius schon im antiken Griechenland als eine Bewegung von Heimat zu Nation. ${ }^{3}$ Solche Fortschritts- und Steigerungslogik, symptomatisch für den Liberalismus des 19. Jahrhunderts, verknüpfte sich unproblematisch mit dem kulturellen Klima des Historismus, das sich nicht in der (gleichwohl zentralen) Bedeutung der Geschichtswissenschaft für das 19. Jahrhundert erschöpfte. ${ }^{4}$ Ein sich an den vermeintlich eigenen historischen Ursprüngen ausbildendes Selbstverständnis prägte viele Wissenschaftsdisziplinen - in diesem Kapitel werden die Volkskunde, die Germanistik und ihre Didaktik sowie die Literaturgeschichtsschreibung im Mittelpunkt stehen -, betraf aber genauso die Kunst und damit auch die Literatur, die hier fokussiert wird. Legt man ein solches weites Verständnis eines alle gesellschaftlichen Bereiche prägenden Historismus zugrunde, in dem sich widerspiegelt, dass Geschichte vor allem für das liberale Bürgertum zu einem die eigenen Ordnungs- und Wertvorstellungen legitimierenden Argument wurde, kann das hier vorliegende Kapitel als Darstellung des Zusammenhangs von Historismus und Heimatdiskursen gelesen werden. Eine dieser Ordnungs- und Wertvorstellungen war die der Heimat, die dann in die Fortschrittskonstellation Heimat - Nation eingesetzt wurde. Dabei geht es nicht um die Vorstellung, die regionale und historische Heimat sei zugunsten der größeren Nation in der eigenen Gegenwart zu überwinden, vielmehr um die Vorstellung, der stets zu erneuernde Rückbezug auf regionale Heimaten konstituiere erst das nationale Ganze. ${ }^{5}$

\footnotetext{
2 Mollberg 1916, S. 7.

3 „Je freier der Horizont, desto kühner geht der Blick auf das Große und Ganze; aus der Heimath wird ein Vaterland, wo Leute aus verschiedenen Gauen sich mit einander einleben und ihrer großen Gemeinschaft bewußt werden.“ Curtius 1875, S. 376.

4 Zum Liberalismus und dem Stellenwert der Geschichtswissenschaften insgesamt vgl. Langewiesche 1988, S. 65-72.

5 Langewiesche: Föderativer Nationalismus, 2000, S. 241; Confino 1997. Und so ist es auch kein Widerspruch, dass sich etwa in den Geschichtswissenschaften die Landesgeschichte als Teildisziplin konstituiert. Der Historiker und liberale Politiker Ludwig Häusser als einer der Begründer eines neuen landesgeschichtlichen Denkens konnte die Geschichte der Rheinischen Pfalz (1856) schreiben, ohne in Konflikt mit seinen liberalen, auf die kleindeutsche Lösung unter preußischer Führung zielenden Vorstellungen zu geraten. Landesgeschichte nach Häusser will
} 
Chronologisch beginnt das Interesse der hier fokussierten wissenschaftlichen Disziplinen am Thema Heimat mit der Pädagogik. Zunächst werden Anfang des 19. Jahrhunderts Begriff und Programm einer Heimatkunde für den propädeutischen Geographieunterricht geprägt. Die aus der Pestalozzischule hervorgehende anschauungsbasierte Methodik, in der von der Nahwelt des Kindes ausgehend ein Verständnis auch der größeren Welt ausgebildet werden soll, erfährt über Jahrzehnte starke Widerstände. Schulpolitischen Aufwind erhält die inzwischen transformierte Heimatkunde erst ab 1871, zugleich werden heimatkundliche Methoden auf den Deutsch- und Geschichtsunterricht, ja schließlich auf ausnahmslos alle Unterrichtsfächer ausgedehnt. Nach der Jahrhundertwende gipfelt das gewandelte Verständnis der Heimatkunde in ihrer Rolle als Vermittlerin von inzwischen volkskundlich fundierten - „Heimatwerten“.6 Die Heimatkunde will zu Beginn des 20. Jahrhunderts kein einzelnes Fach mehr sein, sondern universaler Bildungsansatz. Pädagogisches Ziel ist die Heranbildung des national gesinnten ,Gemütsmenschen' geworden; es hat sich damit gegenüber den ursprünglich aufklärerischen Intentionen der Heimatkunde ins Gegenteil verkehrt (vgl. II.3.1).

Auch für das Selbst- und Wissenschaftsverständnis der Mitte des 19. Jahrhunderts sich formierenden Volkskunde ist Heimat ein Schlüsselbegriff. Heimat fungiert einerseits als objektivierbarer Beschreibungsgegenstand des Fachs und andererseits als dessen Ideal, das es zu erhalten, $\mathrm{zu}$ bewahren und wiederzubeleben gilt. Die Volkskunde nationalisiert Heimat, indem sie diese zum spezifisch deutschen Gemütswert erklärt. Der volkskundliche Heimatbegriff ist ungemein attraktiv für andere Disziplinen, für die Germanistik, für die Geschichtswissenschaft und für ihre Didaktiken. Insbesondere die Landesgeschichtsforschung bezieht sich auf die volkskundlichen Schriften Riehls (vgl. II.3.2). ${ }^{7}$

Der Anspruch auf Wissenschaftlichkeit, den die Volkskunde für ihren Umgang mit Heimat erhebt, wirkt ab 1900 auch auf die Literaturgeschichtsschrei-

nicht verklären, sondern den „glänzenden Nimbus“ abreißen, der durch den „servile[n] Jubel von Höflingen, käuflichen Beamten, bezahlten Künstlern und Gelehrten“ errichtet worden sei. Häusser will den grellen Gegensatz zeichnen „zwischen Prunkpalästen“ und den sozialen Gegebenheiten einer Zeit, in der „der Bauer hungernd sein Vaterland verließ und der Name ,Pfälzer ‘ lange identisch war mit einem Auswanderer und Heimathlosen“ (Häusser 1856, S. V).

6 Hofstaetter 1921, S. 5.

7 So begründet etwa die Schrift Die Ortschroniken, ihre kulturgeschichtliche Bedeutung und pädagogische Verwertung. Ein Beitrag zur richtigen Beurteilung des idyllischen Chronikkults (1886) des Historikers August Holder die Erforschung von Ortschroniken mit der Entwicklung des „heimatliche[n] Sinn[s]“, der zum „Ausharren und Überwinden“ anrege und vor „unüberlegtem Auswandern“ bewahre; die „Richtigkeit des Riehl'schen Prinzips, daß ,Land und Leute zusammen gehören““, werde durch die Beschäftigung mit Ortschroniken bestätigt. Holder 1886, S. 53. 
bung. Literaturhistorische Ansätze wie die von August Sauer oder Josef Nadler wären ohne das volkskundliche Heimatverständnis nicht denkbar. Zur wissenschaftlichen Leitkategorie wird Heimat bei Adolf Bartels, der die sogenannte Heimatkunstbewegung zum (vorläufigen) Telos der gesamten deutschen Literaturgeschichte erklärt (vgl. II.3.3).

Literatur spielt in all diesen vielfältig miteinander verwickelten wissenschaftlichen Heimatdiskursen eine herausgehobene Rolle. Erstens, insofern die Wissenschaften als Beleg für ihre Heimatthesen immer wieder die schöne Literatur heranziehen. Was in der Germanistik und Literaturgeschichtsschreibung kaum verwunderlich und in der Pädagogik nachvollziehbar ist, überrascht in der Volkskunde oder auch in der Geschichtswissenschaft. ${ }^{8}$ Als Beleg für die Behauptung, dass Heimatliebe wahlweise ein anthropologisches oder, im 19. Jahrhundert sehr viel verbreiteter, ein spezifisch deutsches Gefühl sei, werden in der Regel Gedichte zitiert, die diese Heimatliebe besingen. Dass diese Gedichte allesamt aus dem 19. Jahrhundert stammen, rief dabei keine Bedenklichkeiten hervor.

Zweitens ist Literatur in besonderer Weise mit den wissenschaftlichen Heimatdiskursen verknüpft, insofern die Wissenschaften, insbesondere die Didaktik, Literatur funktionalisieren, um Heimatliebe $\mathrm{zu}$ installieren. Andererseits bildet sich ein literarischer Markt aus, der diese Funktionszuschreibungen bedient oder sich in ein Verhältnis zu ihnen setzt. Die schöne Literatur spielt aus Perspektive der pädagogischen Bemühungen um Heimat insbesondere nach 1871 eine wesentliche Rolle, denn ihr soll eine Vermittlungsfunktion für die schulpolitisch geforderte Erziehung zur ,Heimatliebe‘ zukommen. Die Literatur des Realismus, die sich ohnehin in weiten Teilen einem pädagogischen Auftrag verpflichtet fühlt, wird in diesem ideellen Umfeld produziert, aber auch interpretiert und für die Schule verwertbar gemacht. Gustav Freytags ${ }^{9}$ Romanzyklus Die Ahnen, der von den Pädagogen wegen seiner ,Heimatwerte“ nachdrücklich schon während der achtjährigen Entstehungszeit empfohlen und für den Deutschunterricht aufbereitet wurde, zeigt prägnant die Interdependenzen zwischen literarischem und didaktischem Heimatdiskurs (II.3.1).

Drittens spielt Literatur für die folgenden Überlegungen eine herausgehobene Rolle, insofern es zahlreiche personelle und institutionelle Verknüpfungen zwischen den Wissenschaften und der Literatur gibt. Die Grenzen zwischen den

8 August Holder etwa meint, dass sich der „heimatliche Zug, der jedem innewohnt“, in einer „begründeten Bevorzugung des Eigenen, Örtlichen, Herkömmlichen, Alten, geschichtlich Gewordenen und einem bedächtigen Prüfen des Fremden, Neuen, willkürlich Gemachten, erst heute unvermittelt ins Leben Gestellten“ äußere, und will dies mit Gedichten von Emil Ritterhaus und Karl Wörmann und dem literarischen Werk Theodor Storms belegen. Holder 1886, S. 39.

9 Zu Freytag und dem Liberalismus vgl. Hahn 2016. 
Bereichen waren bis 1870 ohnehin durchlässig: Ein mit heutigen Standards der Quellenkritik, des spezifischen Verhältnisses von Subjekt und Objekt und anderen Faktoren vergleichbares stabiles Wissenschaftsparadigma bildete sich Michael Maurer zufolge für die Geschichtswissenschaften erst nach 1870 aus; ${ }^{10}$ und dies gilt ebenso etwa für die Volkskunde. Aus diesem Grund wurde es auch nicht als Widerspruch wahrgenommen, dass Wilhelm Heinrich Riehl als Begründer der Volkskunde galt und zugleich als Schriftsteller. Gustav Freytag war promovierter und habilitierter Germanist, betätigte sich als Historiker und war daneben Journalist, Romancier und Dramatiker. Riehls volkskundliche Schriften bedienen sich genauso literarischer Schreibweisen wie Freytags Bilder aus der deutschen Vergangenheit, ohne dadurch in Widerspruch $\mathrm{zu}$ ihren zeitgenössischen wissenschaftlichen Standards zu geraten. Und als Wissenschaft wahrgenommene Texte wie die von Riehl wurden von literarischen Kreisen stark rezipiert. Gustav Freytag bezieht sich auf Riehl, und auch Theodor Fontanes Wanderungen durch die Mark Brandenburg sind ohne Riehl nicht zu denken. Schließlich ist auch der völkische Literaturkritiker, -historiker und -produzent Adolf Bartels ein prägnantes Beispiel für die Verschränkungen des literarischen Feldes mit dem der (Populär-)wissenschaft. Bartels positioniert sich als Literaturhistoriker, -kritiker, -programmatiker und Autor auf dem literarischen Feld der Heimatkunstbewegung, das er durch seine vielfältigen Aktivitäten zu einem guten Teil erst selbst erschafft. Dessen normativer Kraft konnten sich die zeitgenössischen Autoren einerseits nicht vollständig entziehen, andererseits passt ihr Werk teils gar nicht in Kategorien wie die der Heimatkunst, wie das Prosawerk der seinerzeit populären Autorin Clara Viebig zeigen kann (II.3.3).

\subsection{Heimat und Pädagogik}

In Gottfried Kellers Martin Salander (1886) fragt der aus Südamerika in die Schweiz zurückgekehrte Protagonist: „Ich habe gelesen, daß in den letzten Jahren in der Schule eine Art Heimatkunde eingeführt worden sei; wie steht es damit?“11 Tatsächlich wurde der Lehrinhalt ,Heimatkunde“ im Kanton Zürich erstmals 1848 in den Lehrplan der vierten Volksschulklasse aufgenommen, ${ }^{12}$ in den 1870er

10 Vgl. Maurer 2003 und Maurer 2004.

11 Keller 1991, S. 440. Die Fiktion legt nahe, dass es sich um das Jahr 1866 handelt.

12 Der Kommentar der Sämtlichen Werke verweist auf: Die Zürcherischen Schulen seit der Regeneration. Festschrift zur Jahrhundertfeier, hg. vom Erziehungsrat des Kantons Zürich, Bd. 1, Zürich 1933, S. 622 und führt aus: „Ein solcher Unterricht, der aus Geographie, Geschichte und Naturkunde der engeren Heimat der Schüler bestand, wurde schon 1848 in den Lehrplan der vierten 
Jahren erhielt die Heimatkunde in der Schweiz genauso wie im Deutschen Reich verstärkte Aufmerksamkeit. Auch wenn sie erst im 20. Jahrhundert eigenständiges Schulfach wird, ${ }^{13}$ ist das 19 . Jahrhundert der pädagogikgeschichtlich relevante Zeitraum, in dem sich Programmatik, Schulpraxis und Schulpolitik der Heimatkunde ausbilden. Der Bedeutungswandel, dem Heimat in diesen pädagogischen Kontexten im Lauf des 19. Jahrhunderts unterliegt, zeigt die große semantische Spannbreite des Begriffs, der gerade im pädagogischen Feld im Lauf schon eines halben Jahrhunderts geradezu Gegensätzliches ausdrückt.

Die Literatur spielt dabei eine wachsende Rolle, wie schon der Blick darauf zeigt, welche Fächer für die Heimatkunde zuständig waren: Die realienbasierte Heimatkunde entwickelt sich Anfang des Jahrhunderts aus der Geographiedidaktik heraus; im letzten Jahrhundertdrittel findet dagegen vor allem im Deutschunterricht die Vermittlung von Heimat statt, und zwar im Medium der Literatur. Nicht mehr den Realien, sondern der Literatur wird von schulpolitischen Instanzen die Vermittlung von Heimat anvertraut. Nach dem Kriterium der Beförderung von ,Heimatliebe‘ wird ausgewählte Literatur auf die Lehrpläne gesetzt und zum Unterricht empfohlen, und sie wird vom Standpunkt des Heimatlichen aus kritisiert und interpretiert.

Literatur kann auf unterschiedliche Art und Weise darauf reagieren. Sie kann zu heimatkundlichen Zwecken verfasst werden, denn im Selbstverständnis einiger Autoren ist Literatur selbst so etwas wie Heimatkunde mit einem pädagogischen Auftrag - nämlich Heimatliebe zu lehren. Kellers Figur Martin Salander etwa war in einem früheren Beruf Lehrer und das Wirken des Heimgekehrten steht, auch ohne Lehramt, unter volkserzieherischem Vorzeichen, ja die Volkserziehung selbst wird ihm zur „wahre[n] Heimat““. ${ }^{14}$ Salanders volkserzieherische Sache ist zugleich die Kellers und dieser steht mit Jeremias Gotthelf, Charles Dickens, Lew Tolstoi, Berthold Auerbach, Gustav Freytag und vielen anderen in

\footnotetext{
Volksschulklasse aufgenommen. In den 1870er Jahren führte die Erneuerung verschiedener Schulbücher - mit der man das Scheitern der Schulreform von 1872 kompensieren wollte - zu einer Verbesserung des Realunterrichtes. Die Lehrmittel von Heinrich Wettstein fanden auf der Weltausstellung in Paris 1873 große Anerkennung. Es wurde neben der Vermehrung des Anschauungsmaterials darauf geachtet, daß die Inhalte des Realunterrichts auch als Übungsstoff in den Sprachunterricht Eingang fanden.“ Keller 1991, S. 1158.

13 Seit 1921 gibt es das Fach Heimatkunde in der Grundschule; schon 1908 liegt eine Ministerialanweisung zur Pflege der Heimatkunde vor. In den Richtlinien für die Lehrpläne der höheren Schulen Preußens von 1925 wird die Heimatkunde als fächerübergreifendes Unterrichtsprinzip starkgemacht.

14 „Sein Lieblingsfeld war aber die Volkserziehung; sie galt ihm als die wahre Heimat, in welcher er seinen frühen Abfall von der Schule gut machen müsse.“ Keller 1991, S. 567.
} 
einer Reihe von (früh-)realistischen Autoren, die programmatisch die pädagogische Funktion von Literatur betonen.

Die im frühen 19. Jahrhundert beginnende Geschichte der Heimatkunde und ihr weiterer Verlauf bis zum Beginn des 20. Jahrhunderts (II.3.1.1) sind der historische Hintergrund, auf dem exemplarisch die pädagogische Rezeption von Freytags Ahnen ab 1872 diskutiert werden kann. Mit dem Blick darauf, welche pädagogischen Interessen sich historisch an Heimat knüpften, kann besser verstanden werden, wie sich die spezifisch pädagogische Semantisierung von Heimat darstellt und warum Freytags Romanzyklus in dieser Hinsicht zu einem derart attraktiven Gegenstand werden konnte. Es wird gezeigt, wie die Pädagogik mittels des Romans ihren Heimatbegriff füllt und wie literarische und pädagogische Rede über Heimat miteinander verschränkt sind (II.3.1.2.1). Gustav Freytags Ahnen demonstrieren, wie ein literarischer Entwurf von Heimat mit explizit pädagogischer Funktion aussehen kann. Der Romanzyklus kommt zeitgenössischen pädagogischen Lesarten entgegen, ohne sich in diesen zu erschöpfen (II.3.1.2.2).

\subsubsection{Heimatkunde in Pädagogik und Unterrichtsdidaktik}

Der Begriff der Heimatkunde wird erstmals zu Beginn des 19. Jahrhunderts im Umfeld der Unterrichtsdidaktik, genauer in Bezug auf den Geographieunterricht für die Volksschule verwendet. ${ }^{15}$ Die Einführung der Schulpflicht, der damit verbundene Ausbau der Volksschule und die beginnende Anwendung des Realunterrichts im Elementarbereich stellen dafür die wesentlichen Rahmenbedingungen dar.

Den Begriff der Heimat führt Johann Wilhelm Matthias Henning in die Unterrichtsdidaktik ein. ${ }^{16}$ Sein 1812 erscheinender Leitfaden beim methodischen

15 Die Geschichte von realienbasierten, sich auf Anschauung gründenden pädagogischen Konzepten ist sehr viel länger. Einer der pädagogikgeschichtlich prominentesten Vorläufer des Realunterrichts ist die Gothaische Schulordnung von 1662, wobei diese nicht als repräsentativ für ihre Zeit gelten kann und die tatsächliche Umsetzung fraglich ist, vgl. Mitzlaff 1985, Bd. 1, S. 63-71. Hartmut Mitzlaffs dreibändige Studie zur Geschichte der Heimatkunde ist bis heute die umfassendste Arbeit zum Thema. Einen guten Überblick bietet auch der historische Teil des Artikels ,Heimatkunde‘ im Enzyklopädischen Handbuch der Pädagogik, vgl. Scholz 1897, S. 418 421. Zum Zusammenhang von Volkserziehung und Heimatforschung vgl. auch Greverus 1972, S. $296-299$.

16 Die Bedeutung Hennings wird in der gegenwärtigen Forschung nicht angemessen gewürdigt, meist wird er gar nicht genannt und Harnisch als Begründer der Heimatkunde genannt. Hartmut Mitzlaff weist zwar auf Henning hin, muss sich dabei aber auf ältere Forschung beziehen (Singer), 
Unterricht in der Geographie basiert auf seiner Lehrertätigkeit zwischen 1809 und 1812 am berühmten Institut Pestalozzis im schweizerischen Iferten (heute Yverdon-les-Bains) und ist den Ideen Pestalozzis verpflichtet. ${ }^{17}$ Jede Erkenntnis der Erde, so der Hauptgedanke, fange mit „der Erkenntniß der Heimath“ ${ }^{18}$ an. Zentral für Henning ist, dass der Mensch, „welcher den Wohnort seines Geschlechts, die Erde, kennen lernen will, diese Erkenntniß vor allen Dingen mit dem Theilchen anfangen müsse, das er selbst zunächst bewohnt und mit seinen Blicken überschaut“. Die Zöglinge müssten ,immer mehr heimisch werden, da, wo sie zu Hause sind“, 19 und diese Erkenntnis der „heimathlichen Gegend“20 dient im weiteren Lernen dann der Welterkenntnis; eine politische Geographie - und damit auch Fragen des Nationalen - möchte Henning hingegen ausdrücklich aus der Geographie ausschließen, mindestens aber anderen Fragen unterordnen. ${ }^{21}$ Heimat wird in der geographiepropädeutischen Unterrichtsspanne erforscht, dem aufbauenden Geographieunterricht ist dann die Lehre von der Welt, also den weiter entfernten Gegenden, vorbehalten. Der Ansatz ist menschheits- und individualpsychologisch begründet, insofern das Kind die Menschheitsentwicklung im Individuellen wiederhole. ${ }^{22}$ Nicht das Abstrakte, sondern das Konkrete, sinnlich Erfahrbare und lebensweltlich Relevante entspreche entwicklungspsychologisch den Bedürfnissen des jüngeren Kindes, wie Henning anschaulich an der eigenen Erfahrung erläutert:

da ihm der Text nicht zugänglich war. Da sämtliche jüngere Forschung sich auf Mitzlaff bezieht, entsteht nach meinem Eindruck ein Missverhältnis in der historischen Darstellung.

17 Vgl. schon die emphatische Widmung an Pestalozzi in Henning 1812. Einen zentralen Einfluss haben außerdem die Geographen Carl Ritter und Johann Georg Tobler, Letzterer ebenfalls an Pestalozzis Institut tätig und der unmittelbare Vorgänger im Amt für den Geographieunterricht in Iferten (Tobler unterrichtet zwischen 1800 und 1808, Henning zwischen 1809 und 1812 Geographie in Iferten). Henning zitiert beide ausführlich in seinem Leitfaden.

18 Henning 1812, S. 12.

19 Alle Henning 1812, Vorrede S. 41.

20 Henning 1812, Vorrede S. 30.

21 Vgl. Henning 1812, Vorrede S. 17, S. 34.

22 Der Ansatz beruhe auf der Erkenntnis, „daß der Mensch den Anfang seiner Erdkunde bey dem Theil der Erdoberfläche gemacht habe, und noch immer machen müsse, der ihm vor Augen liegt, - daß der elementargeographische Unterricht also das Kind seine heimathliche Gegend kennen lehren [...] müsse.“ Henning 1812, Vorrede S. 19. In diesem Sinn führt der Autor aus, „daß der erste Haupttheil der Elementargeographie schicklicher heißen könnte: ,Anweisung, wie Kinder in der Beobachtung und Erkenntniß der Natur ihrer heimathlichen Gegend zu führen sind, mit besondrer Beziehung, nicht etwa auf die Mineralogie oder Botanik etc., sondern auf die Kenntniß und Beschreibung des ihnen vor Augen liegenden Landes, als eines Theils der Erdoberfläche‘.“ Henning 1812, Vorrede S. 30. 
Ich mußte die Palmen und die Gewürzbäume beschreiben nach Beschreibungen, aber was Gerste und Hafer sey, wie die Eiche sich von der Tanne, die Buche von der Birke unterscheide, und welche Sträucher in den Wäldern und Gärten und an den Landstraßen ständen, das lehrte man mich nie. Ich kenne noch jetzt meine Heimath nicht; ich fühle den unersetzlichen Verlust; ich fühle und erkenne es klar, wie mein Geist leicht ohne Quaal für mich und den Lehrer und ohne Aufwand für die Eltern in rege frohe Thätigkeit hätte gesetzt werden können $\left[\ldots . . .{ }^{23}\right.$

Das Lernen durch selbständige Anschauung des Kindes ${ }^{24}$ - im Umfeld der Pestalozzischule erprobt, revolutionär in Bezug auf die gängige Unterrichtspraxis der Zeit ${ }^{25}$ - verbindet sich mit einem empirisch-rationalistischen Weltbild: Wahrheit, Wirklichkeit und Wissenschaftlichkeit werden ausdrücklich als Leitlinien genannt. ${ }^{26}$ Die Natur wird zum „Stoff der selbstthätigen Erkenntniß“ und ihre Erfahrung wird durch Wanderungen im Klassenverband gewährleistet. ${ }^{27}$ Heimat ist zusammengefasst also das Fundament eines anschauungsbasierten Unterrichts, auf das man dann die Vermittlung des weiter Entfernten, Abstrakteren aufsatteln kann. Schon die Geschichte der Geographie lehre, dass diese mit „der Erkenntniß der Heimath anfing, daß jeder Mensch sein Wissen um die Erde mit der Erkenntniß desjenigen Theils der Erdoberfläche beginnen muß, der innerhalb seines Horizontes vor seiner Anschauung da liegt“. ${ }^{28}$

Der Begriff Heimatkunde wird durch den Pädagogen Christian Wilhelm Harnisch (1787-1864) eingeführt, und zwar in seiner 1816/1817 veröffentlichten Weltkunde, deren erster Teil die sogenannte Heimathskunde bildet. Harnisch kennt Henning persönlich; beide nehmen 1812 ihre Lehrertätigkeit in Breslau auf und arbeiten eng zusammen; ${ }^{29}$ der Leitfaden Hennings wird zum Teil wörtlich von Harnisch aufgegriffen. ${ }^{30}$ Der Realunterricht für die Kleinsten wählt genau wie bei Henning aus entwicklungspsychologischen Gründen die nächste Umgebung zum

23 Henning 1812, S. 24.

24 Vgl. Henning 1812, S. 12-14.

25 Die Praxis des Auswendiglernens wird schon spätestens seit dem 17. Jahrhundert von Pädagogen beklagt und durch anschauungsbasierte Programmatiken kontrastiert, etwa bei Wolfgang Ratke, Johann Amos Comenius, Andreas Reyher, Johann Bernhard Basedow, August Herrmann Francke oder Christian Gotthilf Salzmann. Der Begriff der Heimat ist indes erst durch Henning, der Begriff der ,Heimatkunde‘ erst durch Harnisch eingeführt worden.

26 Vgl. Henning 1812, Vorrede S. 41.

27 Henning 1812, Vorrede S. 20.

28 Henning 1812, S. 12.

291814 gründen Harnisch und Henning gemeinsam den Breslauer Schullehrerverein, wie aus dem Handbuch der Berliner Vereine und Gesellschaften 1786-1815 hervorgeht, vgl. Motschmann 2015, S. 121.

30 Vgl. Singer 1914, S. 88. 
Anschauungsgegenstand: Da „die Kinder nur eine kleine Welt haben“, müsse „die Weltkunde auch mit dieser ihrer kleinen Welt anfangen“..31 Anschauung wird hier - radikaler noch als bei Henning - explizit gegen die Methoden des Auswendiglernens gestellt. Stattdessen sollen konkrete sinnliche Erfahrung und aktive Untersuchung das Lernen des Kindes befördern. Dazu verlässt man den Klassenraum, erkundet die Umgebung und ermutigt die Kinder zu selbständigem Forschen. Der konkrete Erfahrungshorizont des Kindes wird zum didaktischen Organisationsprinzip des Unterrichts, in dem die einzelnen Erkenntnisgegenstände auseinander folgen sollen. Die anschauungsbasierte Erkundung der Heimat, verstanden als unmittelbare lokale Umgebung, dient als Ausgangspunkt, um in den folgenden Schritten zur Weltkunde, zur Erkenntnis auch ferner, nicht mehr sinnlich erfahrbarer Gegenstände zu gelangen. Den Kindern solle gezeigt werden, „daß sich an die Heimath noch andere Länder anschließen, daß die Flüsse der Heimath in andere Länder hineinfließen, daß die Heimath nur ein kleiner Theil von dem Lande sei, in welchem man noch dieselbe Sprache spricht, daß dieses wieder ein kleiner Theil von der ganzen Erde sei etc. “. 32

Hatte Henning die Erweiterung von Heimat noch als Welt gefasst, differenziert Harnisch zwischen Heimat, Erde und Vaterland. Seine Weltkunde gliedert sich in drei Teile, die diese Reihenfolge einhalten: die Kunde von der Heimat, die Kunde von der Erde, die Kunde des Vaterlands. Und diese Reihenfolge ist durchaus als Steigerung gemeint: „Der Anfang der Weltkunde ist also die Heimath; das Ziel soll sein gottesfürchtiges Würken und Leben für das Vaterland.“33 Dieses Ziel des Wirkens und Lebens fürs Vaterland werde umso besser „erreicht werden, einen je

31 Beide Zitate Harnisch 1817, S. 5. Zuvor schon 1816 unter dem Titel „Leitfaden beim Unterricht in der Weltkunde“ in der Zeitschrift Der Schulrath an der Oder veröffentlicht.

32 Harnisch 1817, S. 69.

33 Harnisch 1817, S. 5. Dem Zitat unmittelbar voran steht folgender erläuternder Absatz: „Aus dem menschlichen Wesen scheint sich in Hinsicht der Weltkunde Folgendes zu ergeben. Je enger und beschränkter des Menschen Wesen ist, desto enger ist auch seine Welt. Dem Bauer ist oft sein Dorf mit einigen daran gränzenden die Welt. Und sehr richtig sagte in dieser Hinsicht ein Mal ein märkischer Drescher: ,Wie toll geht das jetzt nicht in der Welt her, wie mag dis nicht erst in Berlin sein!' Auch in allen Sprachen hat daher das Wort Welt einen sehr engen und einen sehr weiten Begriff nebst vielen dazwischen liegenden. Gerade aus diesem Grunde habe ich das Wort Weltkunde gewählt, weil sie soll allmälig dem Schüler die Welt in immer größern Umrissen kennen lehren. Zugleich ergibt sich aus den Vorigen, daß, da die Kinder nur eine kleine Welt haben, die Weltkunde auch mit dieser ihrer kleinen Welt anfangen muß. Denn jeder Unterricht muß ja an das Bekannte das Unbekannte schließen, damit es mit demselben verwachse als etwas Gleichartiges. Also nicht mit Allgemeinheiten, nicht mit der ganzen Erde kann die Weltkunde anfangen, sondern mit den nächsten Umgebungen des Schülers, mit des Schülers Welt und nicht mit der Welt des Lehrers.“ Harnisch 1817, S. 5. 
weitern Weg man durch die ganze Erde nimt. “34 Heimat und Vaterland, so merkt Harnisch noch einmal eigens an, verwende er „scharf unterschieden“: „Heimath ist die Geburtsgegend, als Geburtsort, Geburtskreis, Geburtsprovinz; das Vaterland geht so weit, als gemeinschaftliches Denken in gemeinschaftlicher Sprache reicht.“ Schon bei Harnisch kann damit die im späteren 19. Jahrhundert zentral werdende Idee gefunden werden, dass Heimatverständnis Fundament der Nationsbildung sei: „Der Schlesier, der Märker, der Würtemberger, der Westfale haben verschiedene Heimathen, aber nur ein Vaterland, nämlich Deutschland“35 (vgl. I.2.2.1). Diese Idee ist hier allerdings auf eine Weise kosmopolitisch abgefedert, wie es im weiteren Verlauf des Jahrhunderts immer seltener der Fall sein wird.

Ein pädagogisches Lexikon von 1835 schlägt im Artikel ,Erdbeschreibung“ zum Geographieunterricht eine andere Reihenfolge von Heimat, Nation und Erde vor, nämlich die vom Kleinsten zum Größten - und wieder zurück. Der Elementarunterricht müsse „sich, wenn er zweckmäßig seyn soll, an die Heimath anschließen“. ${ }^{36}$ Dabei hat die Heimat hier eine rein methodische Funktion, insofern sie dem unmittelbaren Erfahrungsbereich und der altersgemäßen Auffassungsgabe des Kindes entspricht. Die langsame Erweiterung des Lehrbereichs von „Wohnort“ zu „Amt“, „Kreis“, „Bezirk“, „Provinz“, „Vaterland“ geht über Europa zur Welt: „Außer unserem Staate gibt es noch mehrere andere, die ebenfalls deutsche Staaten sind, und welche zusammengenommen Deutschland bilden. Nun gibt es wieder viele andere Staaten und Länder auf der Oberfläche der Erde, und diese wird in 5 Erdtheile eingetheilt.“"37 Erst nach diesem mit der „Heimath“ beginnenden und dem „Globus“ endenden Elementarunterricht fange der eigentliche geographische Unterricht an. Dieser verfährt andersherum: Von der Erde als ganzer, den Weltteilen, Europa geht es wieder zurück zum „Heimathslande ${ }^{\text {،38 }}$ des lernenden Kindes, wobei damit dann nicht mehr die unmittelbare Umgebung, sondern der jeweilige deutsche (Klein-)Staat gemeint ist. Anders als bei Harnisch ist also nicht das - alle deutschen Staaten umfassende - Vaterland Zielpunkt der Didaktik, sondern das jeweilige Land, der jeweilige deutsche Staat.

34 Harnisch 1817, S. 6.

35 Alle Harnisch 1817, S. 5.

36 Anonym 1835, S. 263.

37 Anonym 1835, S. 264.

38 „Nach diesem hier aufgestellten Gang, knüpft sich also der Elementarunterricht an die Heimath an, und endet mit der Anschauung des Globus, um von dort aus erst ein eigentlicher geographischer Unterricht zu werden, das Nöthige aus der allgemeinen Geographie, dann die Kenntniß fremder Erdtheile und zuletzt die von Europa zu geben, und da bei dem Heimathslande ein nach dem Zwecke der Schule mehr oder weniger vollständige Heimathskunde zu werden.“ Anonym 1835, S. 266. 
Entsprechend ist der Nationalstaat gewissermaßen nur eine von vielen Durchgangsgrößen zwischen Heimat und Globus.

In der ersten Jahrhunderthälfte ist eine große Zahl heimatkundedidaktischer Modelle in der Geographiepropädeutik entwickelt worden. ${ }^{39}$ Vor allem Friedrich August Fingers (1808-1888) Heimatskunde von 1844 sticht durch die Radikalität des darin vertretenen Anschauungsprinzips heraus. Seine im Umfeld einer reformfreundlichen Weinheimer Real- und Bürgerschule entwickelte Methode basiert auf einem Unterrichtsverständnis, das sich am Kind orientiert und kausalanalytisches Denken auf der Grundlage selbständiger Erkenntnisprozesse fördern will. ${ }^{40}$ Finger grenzt die Heimatkunde mit seiner ausdrücklichen Beschränkung der Unterrichtsmethoden auf empirische Weltaneignung und -beschreibung von religiöser ebenso wie von nationaler Gesinnungsbildung ab und interpretiert das Anschauungsprinzip für seine Zeit sehr weitgehend in der Art, dass nur wissenschaftskonforme Aussagen zugelassen werden. Heimat lasse sich, so heißt es wörtlich, nicht „nach politischen Rücksichten“, ${ }^{41}$ sondern ausschließlich nach geographischen erkunden, und so sei es selbstverständlich, dass der Heimatkundeunterricht beispielsweise in Saarbrücken auch französisches Gebiet umfasse. Heimat zeigt sich hier nicht als die kleinste Einheit des (National-)Staates, sondern als eine nicht an politische Grenzen gebundene Größe. Finger ist damit einer der ganz wenigen Autoren, gleich welcher Disziplin, der das subversive Potential, das Heimat eigentlich in Bezug auf nationalstaatliche Interessen hat, erkennt und auch explizit macht. ${ }^{42}$

39 Vgl. Mitzlaff 1985, Bd. 2, S. 751.

40 „Heimatskunde ist eine auf Anschauung begründete Bekanntmachung mit der heimatlichen Gegend.“ Finger 1876, S. 4.

41 Finger 1876, S. 4. Schon Henning verweist nachdrücklich darauf, dass sich die politische Erdbeschreibung der geographischen Erdbeschreibung unterzuordnen habe: „[...] warf er endlich die wenigen Bücher, die er sonst benutzt hatte, weg, und fasste die so reiche Natur seines schweizerischen Vaterlandes allein in's Auge. Hier fand er nun 1) eine über alle Willkühr und allen Wechsel erhabene physische Eintheilung des Landes durch Gebirge etc., die sich nicht nur in seinem bergigen Vaterlande bis auf den väterlichen Hügel, bis auf das heimathliche Thal hinab bewährte, sondern über die ganze Erde sich gleichartig aussprach, und welcher sich auch die politische Erdbeschreibung aller Zeiten leicht und sicher unterordnete." Henning 1812, S. 12-13. 42 Finger geht im zeitgenössischen Vergleich weit. Aber auch in anderen Heimatkunden der Zeit ist zumindest die Gewichtung zwischen pragmatischen Interessen und dem Interesse an der Entwicklung von Vaterlandsliebe eine deutlich andere als später, vgl. etwa Schulzes Heimatkunde: „Unter allen Ländern Europa’s hat unser deutsches Vaterland für uns die größte Wichtigkeit. Darum ist es auch natürlich, daß wir demselben beim Unterrichte in der Geographie die größte Aufmerksamkeit widmen und mit seiner Beschaffenheit und Einrichtung uns gründlicher bekannt zu machen suchen, als mit der Beschaffenheit und Einrichtung anderer europäischer Länder. Unter den Staaten Deutschlands haben wir aus gleichem Grunde vorzüglich den kennen 
Die ursprünglichen Konzeptionen von Heimatkunde enthalten nichts von dem, was sich ab dem letzten Jahrhundertdrittel mit ihr zu verbinden beginnt sentimentale Erzählung, mythologisierende und antimodernistische Gesinnungsbildung des Nationalen. Heimat bedeutet im Kontext dieser geographiepropädeutischen Heimatkunden den konkreten Lebensort, nicht ein Surrogat des Nationalen. Harnischs und Fingers Heimatkunde haben in weiten Teilen einen aufklärerischen Ansatz, der von der Entwicklungspsychologie des Kindes ausgeht. Solche Ansätze waren von Anfang an Widerständen ausgesetzt. ${ }^{43}$ Schon nach Ende der oktroyierten Liberalisierung während der napoleonischen Besatzung verstärkten sich die politischen Maßnahmen gegen den Real- und damit auch den Heimatkundeunterricht. In einem Rundschreiben des Preußischen Ministeriums für Unterrichtsangelegenheiten von 1829 wird der Volksschulunterricht auf christliche Religion, Ehrfurcht und Folgsamkeit und die basalsten Fähigkeiten im Lesen, Schreiben und Rechnen beschränkt, Anschauungs- und Realunterricht dagegen ausdrücklich untersagt. 1841 wird für Preußen eine Anordnung erlassen, nach der Landschullehrer in Naturkunde und Geographie nur nach Lehrbüchern und nicht nach dem Prinzip der Anschauung zu unterrichten haben, in einem Folgeerlass von 1844 wird reale Anschauung ausdrücklich untersagt, Real-Lehrbücher werden verboten. Frühere schulpolitische Maßnahmen zugunsten des Anschauungs- und Realunterrichts werden nach dem Scheitern der bürgerlichen Revolution wieder zurückgenommen. Der Höhepunkt des forcierten Kampfes gegen die als atheistisch diffamierte Realbildung sind die sogenannten Stielschen Regulative von 1854, durch die der Realunterricht völlig aus der

zu lernen, in welchem wir wohnen, oder der unsre besondere Heimath, unser besonderes Vaterland bildet. Solche Heimathskunde ist namentlich für Den unentbehrlich, dem das Vaterland zum bleibenden Aufenthalte dienen und der in demselben einst dem von ihm erwählten Berufe leben soll. Da nun die Kinder in Volksschulen der überwiegenden Mehrzahl nach innerhalb der Grenzen des Vaterlandes leben und wirken sollen, so müssen sie auch weit eher und weit gründlicher mit den Eigenthümlichkeiten ihres Vaterlandes bekannt gemacht werden, als mit denen anderer Länder. Wie könnten sie bürgerliche Gewerbe einst erfolgreich betreiben, wenn sie mit den Producten und Fabrikaten des Inlandes unbekannt wären? Wie könnten sie einst in Amt und Würden auf das Wohl ihrer Mitbürger heilsam einwirken, wenn sie nichts wüssten von den Landeseigenthümlichkeiten, von den gesetzlichen Vorschriften, von den Bedürfnissen und Leistungen der Einwohner [...] von den zur Hebung des Volkswohles sich darbietenden Mitteln ihrer Heimath? / Für uns Gothaer hat aber eine genaue Kenntniß unsers Vaterlandes [d.i.: Gotha] noch den Nutzen, daß sie uns dasselbe achten und lieben lehrt. Denn so klein dasselbe im Verhältniß zu andern Ländern sein mag, so bietet es doch so viel des Guten dar, daß wir uns glücklich preisen können, ihm anzugehören." Schulze 1846, S. 1-2.

43 Ausführlicher vgl. Mitzlaff 1985, Bd. 2, S. 767-782. 
Volksschule verbannt wird und an dessen Stelle wieder alternativlos der Religionsunterricht rückt. ${ }^{44}$

Mit der Reichsgründung setzt eine Wende in der Schulpolitik ein. Diese Wende steht u.a. auch im weiteren Kontext des sogenannten Kulturkampfes, in dem das Ringen zwischen Staat und Kirche um den vorherrschenden Einfluss auf das gesellschaftliche Leben und eben auch auf die Bildungspolitik eskaliert. ${ }^{45}$ Mit den Allgemeinen Bestimmungen für die preußischen Volksschulen und Seminare von 1872 werden die Stielschen Regulative für Preußen revidiert. Vorgesehen ist nun die Anschauungsmethode für den Spracherwerb im Rahmen des Deutschunterrichts der Unterstufe, in der Mittel- und Oberstufe ein die ,Heimathskunde، einschließender Realunterricht, der die Lehrgegenstände Geschichte, Geographie, Naturbeschreibung und Naturlehre umfasst. ${ }^{46}$ Die Allgemeinen Bestimmungen legen fest: „Der geographische Unterricht beginnt mit der Heimathskunde; sein weiteres Pensum bilden das deutsche Vaterland und das Hauptsächlichste von der allgemeinen Weltkunde [...].“ Bei der Aufstellung des Lehrplans sei es vorzuziehen, „nöthigenfalls den Umfang des Lehrstoffes zu beschränken, statt auf dessen Veranschaulichung zu verzichten und den Unterricht in Mittheilung bloßer Nomenclatur ausarten zu lassen“. ${ }^{47}$ Somit werden sowohl der Begriff der Heimatkunde als auch Teile ihrer Methode aus der ersten Jahrhunderthälfte schulpolitisch implementiert. Insgesamt bleibt das Programm aber weit hinter seinen Vorgängern zurück: Unter Veranschaulichung wird ausschließlich der Einsatz von Bild- und Kartenmaterial verstanden, Wanderungen oder andere Formen aktiver Weltaneignung, wie sie Henning, Harnisch und Finger schon vorsahen, werden ausgeschlossen.

Auch wenn also von einem relativen Fortschritt gegenüber den Stielschen Regulativen gesprochen werden muss, ist das aktive Anschauungsverständnis der früheren Heimatkundemodelle nicht annähernd erreicht. Ja, die Neuauflage der Heimatkunde stellt bezogen auf ihre ideellen Voraussetzungen eine diametrale Verkehrung der früheren Intentionen dar. Denn die Idee des Anschauungsunterrichts wird zwar partiell aufgegriffen, dies geschieht aber unter dem geänderten,

$44 \mathrm{Zu}$ den nach Ferdinand Stiehl benannten Regulativen und ihren Auswirkungen auf die literarische und schulische Praxis (hier mit Schwerpunkt auf dem ,Klassikerverbot' der Regulative für die Volksschule) vgl. Parr/Wülfing 1996.

$45 \mathrm{Im}$ engeren Sinn bezieht sich der Begriff des Kulturkampfes auf die Auseinandersetzung zwischen Bismarck und Papst Pius IX., im weiteren Sinn wird er auch als Bezeichnung eines gesamteuropäischen Phänomens dieser Zeit verwendet, vgl. Clark/Kaiser 2003.

46 Einen Überblick über die Kontexte gibt Nipperdey 1990, S. 534; genauer vgl. Mitzlaff 1985, Bd. 2, S. 783-796; Frank 1976, Bd. 2, S. 487-494.

47 Alle Zitate: Anonym 1872, S. 596. 
der Methode der wertfreien Empirie grundsätzlich entgegenstehenden Vorzeichen der Gesinnungsbildung.

Geht es um Gesinnungsbildung, ist es folgerichtig, dass das programmatische Bildungsziel der Heimatkunde sich schwerpunktmäßig vom Fach Geographie auf den Deutschunterricht verlagert. ${ }^{48}$ In diese Richtung weist eine Preisschrift des Pädagogen Hugo Weber von 1872, die ein neues nationales Bildungsprogramm für die Volksschule ausruft. Zu ihren Leitthesen gehört, dass ,jede auf Kosmopolitismus berechnete Bildung“ entnationalisiere, dass sie „heimat- und ruhelos“ mache und „dem Individuum den innern Halt“ raube. ${ }^{49}$ Heimat und Welt werden zu Widersprüchen. Das Lesebuch der Volksschule soll für Weber zur nationalen Erbauungsschrift werden, indem es eine Brücke zur Heimatkunde schlage; „in schönen Schilderungen“ - mit anderen Worten mittels der Literatur - sollen der „deutsche Boden, die deutschen Kulturpflanzen, die deutschen Hausthiere, das einfache, friedliche und gemüthvolle Naturleben der Schäfer, Hirten und Jäger“, ferner „der Wein-, Berg- und Ackerbau, vor allem der deutsche Wald“50 dargestellt werden.

Nicht mehr Realien (wie im Realienteil des älteren vaterländischen Lesebuchs), sondern Literatur soll Heimat vermitteln; die Literatur selbst wird zur Heimatkunde. Das heißt, dass Heimat von den Schülern über literarische Darstellungen erfahren werden soll. Und Heimatkunde steht für Weber, auch dies diametral entgegengesetzt zu Fingers Intentionen, nicht mehr im Widerspruch zu religiösen und nationalen Ideen: „[E]s sei eine weltlich, eine nationale Bibel, die jeden Deutschen auf seinem Lebenswege begleite; es sei ein Buch, das, wie Bibel und Gesangbuch, ein jedes Haus besitze, aus dem ein jeder seine Sprache der Form nach bilden und veredeln, Herz und Gemüth erwärmen und erfrischen könne [...]. “51 Die soziale Wirklichkeit der im letzten Drittel des 19. Jahrhunderts vorwiegend städtischen Volksschüler mit ihren Mietskasernen, Fabriken, einer Arbeiterbewegung und einer Aktienbörse soll also gerade nicht beschrieben werden, vielmehr wird sie mit einer Ersatzwirklichkeit vertauscht. ${ }^{52}$ In diesem

48 Im Artikel ,Gesinnungsunterricht‘ des Pädagogischen Lexikons von Hermann Schwartz werden Religion, Deutsch und Geschichte zu den bevorzugten „Gesinnungsfächern“ gezählt, Anonym 1929, Sp. 468. Zur Geschichte des Deutschunterrichts vgl. umfassend Frank 1976.

49 Alle Zitate Weber 1872, S. 9.

50 Alle Zitate Weber 1872, S. 111.

51 Weber 1872, S. $110-111$.

52 Die Oppositionsbildung von Großstadt und Land innerhalb eines Heimatverständnisses, dem zufolge nur auf dem Land Heimat sein kann, findet sich ab dem letzten Jahrhundertdrittel und verstärkt dann zu Beginn des 20. Jahrhunderts; vgl. auch das Kapitel II.3.3. So heißt es in der Schrift des Schulrats Dr. A. Mollberg zu Heimat und Charakterbildung. Richtlinien für bodenständige Erziehung von 1916, „Erwerbssucht und äußerer Lebensgenuß“ locke die Menschen in 
Sinn kann hier von Heimat als Komplementärideologie gesprochen werden, einer die Realität verleugnenden Verheißung, die in manipulativer Absicht eingesetzt wird (vgl. I.1.3). ${ }^{53}$

Nicht nur im Volksschulbereich, sondern parallel auch hinsichtlich der höheren Schulen - Gymnasien, Oberrealschulen, Realgymnasien - ist diese didaktische Neusemantisierung von Heimat zu beobachten. So richtet sich etwa der Deutschlehrer und spätere Germanistikprofessor Rudolf Hildebrand in seiner erstmals 1867 erschienenen, nach 1871 in überarbeiteter Form große Verbreitung findenden Schrift Vom deutschen Sprachunterricht in der Schule und von deutscher Erziehung und Bildung überhaupt gegen die „Richtung zur Abstraktion“ und das „Übersehen des Wirklichen, das uns nahe und täglich umgibt““. ${ }^{54}$ Er steht damit vermeintlich in einer Linie mit der Heimatkunde des Jahrhundertbeginns, füllt die Forderung nach Anschauung und die Ablehnung von Abstraktion aber mit ganz anderen Inhalten. Sich zur Wirklichkeit hinzuwenden, bedeutet für ihn, sich auf das spezifisch Deutsche zu besinnen und von allem Fremden abzukehren. ${ }^{55}$ Aufgeklärter Kosmopolitismus wird als blutleere Abstraktion verworfen. „Aber im neunzehnten Jahrhundert ist die Zeit gekommen, daß wir von der weiten Lustreise wieder in die Heimat voll einziehen können, unsern Mittelpunkt wieder in uns

die Großstadt, deren Realität indes äußere und innere Verwahrlosung sei: „Das Familienleben mit seiner Leben erhaltenden Wärme ist gelockert, bald zerstört und verödet. Denn wo kein heimelnder Herd mehr ist, der Altar des Hauses von guten Geistern verlassen steht, da herrschen körperliches und sittliches Elend: Armut, hohle Wangen, Zank und Unfriede. - Und in der alten Heimat daheim gibt es Arbeit und Brot und ein eigen Häuschen am sonnigen, sauberen Garten. Da kann die Gesundheit spendende Sonne den ganzen Tag ins Zimmer, da erfreut die grüne Wiese das Auge und auch das kleinste Ährenfeld das Herz. Dort blüht das Leben. Da ist Gelegenheit geboten zu sparen und einzuheimsen, statt zu verschleudern, ein Stück Grund und Boden zu erwerben, einen Besitzstand zu sichern. Und ist das nicht ein edleres Vergnügen, wenn in trauter Feierstunde die Familie sich vor der Tür des Hauses zu friedlichem Gespräch versammelt, und wenn Sonntags Wald und Flur zu froher Wanderung laden? Wenn der Frühling zu unschuldigem Tanz unter der Linde und die Weihnachtsglocken zu beseligender Feier unter dem Christbaume die ganze Familie vereinigen?“ Mollberg 1916, S. 7-8.

53 So definiert der Politologe Kurt Lenk die Komplementärideologie. Vgl. Lenk 1994. Hartmut Mitzlaff verweist auf die Funktion der Heimat als „Ersatz- und Gegenwelt“ im pädagogischen Kontext, Mitzlaff 1985, Bd. 2, S. 794.

54 Beide Zitate Hildebrand 1910, S. 75. Zu Hildebrand vgl. auch Schneider 2005, S. 247-249. 55 „Das deutsche Volk ist ja förmlich dazu erzogen worden von dem Gange seiner Kultur, sich selbst und das Seine als im höhern Geistesleben der Welt nicht hoffähig anzusehen, sich seiner Ichheit nach Kräften zu entäußern und - sich ein neues, andres Ich weit draußen herzuholen auf einem Wege, der notwendig die ganzen schweren Gebrechen jener gelehrten und verkehrten Abstraktion an sich tragen mußte [...].“ Hildebrand 1910, S. 75. 
selbst versetzen [...]. “56 Das 19. Jahrhundert, so Hildebrand, sei das Jahrhundert der Heimat, und er versteht das als Ausdruck der nationalen Selbstbesinnung. Was an diesen an nationalen Idealen orientierter Vision von Schule anschaulich und nicht abstrakt sein soll, bleibt das Geheimnis Hildebrands.

Die Bildungstheoretiker, -praktiker und -politiker des Wilhelminischen Reiches kamen mit ihrer Neuauflage des Heimatkundeunterrichts dem gesellschaftlichen Bedürfnis nach Realwissen vermeintlich entgegen, das mit den technologischen und ökonomischen Entwicklungen gewachsen war und auch in der Gründung von Realschulen zum Ausdruck kam. So wird es möglich, dass der Heimatkundeunterricht erstmals 1876 nicht mehr als (propädeutisches) Fach, sondern als fächerübergreifendes methodisches Prinzip jedes anschauungsbasierten Unterrichts verstanden wird. ${ }^{57}$ Zugleich wurde die Heimatkunde nicht mehr als wertneutrale Methode verstanden, sondern als Möglichkeit der Erziehung zu nationalen Anschauungen. ${ }^{58}$

Eine neue Stufe des Verständnisses von Heimatkunde als Vermittlerin ideeller Werte wurde in den 1890er Jahren erreicht, eingeleitet durch den Erlass von 1889 zur Bekämpfung sozialistischer und kommunistischer Ideen durch die Schule im Rahmen der sogenannten Sozialistengesetze und die Ansprache Wilhelms II. auf der Berliner Schulkonferenz von 1890, fortgesetzt durch die Gymnasiallehrpläne von 1892, die den Deutschunterricht erklärtermaßen stärken, um das nationale Selbstbewusstsein als oberstes Bildungsziel der Schule durchzusetzen. Gerade unter den Deutschlehrern und Hochschullehrern der Germanistik fand die damit verbundene Heimatkundeidee begeisterte Gefolgsleute, etwa beim schon genannten Rudolf Hildebrand oder dessen Schüler Otto Lyon. Die radikalen völkischen Anschauungen, die Lyon neben anderen - etwa Hans Zimmer mit seiner „Volkstums-“ bzw. „Deutschtumspädagogik“59 (1904) - vertritt, entsprechen zu

56 Hildebrand 1910, S. 76.

57 Der Anschauungsunterricht, so der Leipziger Pädagogikprofessor Ziller, darf „nicht auf bestimmte Stufen und Jahre beschränkt sein [...] und ein besonderes Lehrfach kann er ebenso wenig bilden, weil er [...] bei Vorstellungen aller Art nothwendig ist. Er ist immer ein Theil der Analyse und schreitet an der Hand des Neuen fort, und so folglich auch der eine Zweig des Anschauungsunterrichts, der sich auf die äusseren Erfahrungsobjecte bezieht, die Heimathskunde.“ Ziller 1876, § 23, S. 219.

58 Das „konservative Dilemma: modernisieren zu müssen, aber die Folgen der Modernisierung auch begrenzen, einhegen und einbinden zu wollen“, wird so gemeistert. Nipperdey 1990, S. 538. 59 Zimmer 1904, S. 7. Hans Zimmer spricht in seiner Schrift Volkstumspädagogik für den deutschen Sprachraum von Deutschtumspädagogik; vgl. auch Zimmer 1903. Hans Zimmer schreibt an anderer Stelle über seine „Deutschtumspädagogik“: „Die geographische Bedingtheit der Pädagogik vom vaterländischen Boden wird zu beachten sein.“ Zimmer 1905, S. 55. Als Grundlage jeder Pädagogik will Zimmer nicht mehr wie Herbart die Philosophie, sondern das Prinzip des Volks- 
diesem Zeitpunkt wohl noch nicht der mehrheitlichen Ansicht der Pädagogen seiner Zeit, ${ }^{60}$ aber sie sind auch keine marginale Strömung. Schulrat Dr. A. Mollberg repräsentiert dann den pädagogischen Zeitgeist während des Ersten Weltkriegs, wenn er es 1916 in seiner Schrift Heimat und Charakterbildung als „heilige Aufgabe“ der Pädagogik bezeichnet, das Wort „Am deutschen Wesen soll die Welt genesen“ Wahrheit werden zu lassen. ${ }^{61}$ „Heimatbildung“ heißt für ihn: „Weniger Bücher und mehr Heimat!“62

Auf den Beginn des 20. Jahrhunderts lässt sich auch die zunehmende Ausrichtung der Deutschdidaktik auf die Disziplin der Volkskunde (II.3.2) datieren. ${ }^{63}$ Für eine Zusammenführung von Volkskunde und Deutschunterricht plädiert der promovierte Germanist Walther Hofstaetter mit seiner „Deutschkunde“ (1912 bzw. 1917), ${ }^{64}$ die eine regelrechte Deutschkundebewegung auslöste. ${ }^{65}$ Hofstaetters pädagogisches Programm will den Deutschunterricht nicht auf philologische und sprachliche Themen beschränkt, sondern als eine Erziehung zum ,Deutschsein“ verstanden wissen. Deutschkunde präsentiert sich sowohl als ein in Methoden

tums aufstellen. Pädagogische Methoden werden aus (so Zimmer) wissenschaftlich noch weiter $\mathrm{zu}$ fundierenden spezifisch deutschen Wesensmerkmalen abgeleitet. So ergebe sich aus der deutschen Naturliebe die Methode des Unterrichts in freier Natur, aus dem deutschen Freiheitsgefühl die Methode des unbeschränkten Fragerechts des Kindes. Vgl. Zimmer 1904, S. 18. Auch „die angeborene Anhänglichkeit an die heimische Scholle“ fordere eine andere Stoffauswahl: „Weniger griechische und römische Geschichte - mehr deutsche! Weniger Geographie von Asien und Australien - mehr deutsche!" Zimmer 1904, S. 18.

60 Ein 45-spaltiger Lexikoneintrag zur Heimatkunde im Enzyklopädischen Handbuch der Pädagogik von 1896 etwa knüpft insbesondere an Friedrich August Fingers Verständnis des Anschauungsprinzips an und enthält sich nationalistischer oder völkischer Auslegungen der Heimatkunde. Aber auch hier wird selbstverständlich der ,ganzheitliche‘, damit aber auch potentiell ideologieanfällige Ansatz vertreten: Über die methodische Bedeutung der Anschauung hinaus müsse es der Heimatkunde um die Entwicklung des Gemütslebens des Kindes und damit die „zukünftige sittliche Persönlichkeit des Zöglings“ gehen. Scholz 1897, S. 401.

61 Beide Zitate Mollberg 1916, S. 1.

62 Beide Zitate Mollberg 1916, S. 4.

63 Schon früher lässt sich eine Annäherung von Volkskunde und Deutschdidaktik nachweisen; so wird in der von Hildebrand ab 1887 herausgegebenen Zeitschrift für den deutschen Unterricht über die Stellung der Volkskunde zum Deutschunterricht diskutiert.

64 Hofstaetter schreibt, er habe den Begriff 1912 ,in die pädagogische Begriffssprache eingeführt“, weist dies aber nicht nach, Hofstaetter 1930, S. 236. Bei Horst Joachim Frank findet sich dieselbe Datierung, aber ebenfalls ohne Nachweis, vgl. Frank 1976, Bd. 2, S. 527. Ich finde den ersten Nachweis bei Hofstaetter 1917; vgl. weiterhin Hofstaetter/Hofmann 1923; Hofstaetter/Panzer 1925.

65 Der 1912 gegründete Deutsche Germanistenverband (bzw. nach Umbenennung 1920 die Gesellschaft für deutsche Bildung) versammelte viele Vertreter der Deutschkunde, u.a. Friedrich Panzer, Johann Georg Sprengel, Julius Petersen. Vgl. Peters 1972; Blessing 1996. 
und Stoffen erweiterter Deutschunterricht als auch als fächerübergreifende Methode. ${ }^{66}$ Dabei werden Bezüge zur Heimatkunde ${ }^{67}$ und zur Volkskunde ${ }^{68}$ explizit hergestellt. Die Deutschkunde will Universalwissenschaft des Deutschen sein und dem Unterricht der einzelnen Fächer einen Zusammenhang geben, ${ }^{69}$ und diesen Anspruch teilt sie, genauso wie den Bezug auf Heimat als Ausdruck dieses ganzheitlichen Ansatzes, mit der Volkskunde: „Erst die gemütvolle Erfassung des reichen Gutes unserer Vergangenheit, erst die gemütvolle Betrachtung aller der Heimatwerte, die auch die Gegenwart noch zu bieten hat, erzieht den deutschen Menschen, den wir brauchen, läßt ihn wirklich im Heimatboden, in der Mitte seines Volkes wurzeln.“70

Spätestens mit den Richtlinien für die Lehrpläne der höheren Schulen Preußens von 1925 ist die Heimatkunde in ihrer engen Verbindung von Volkskunde und Deutschunterricht legitimiert und in weiten Kreisen durchgesetzt. ${ }^{71}$ Das lässt der Professionalisierungsgrad der Publikationen zum Thema, etwa das Erscheinen von umfangreichen Handbüchern, vermuten, dem eine Professionalisierung in den Wissenschaften entspricht: Heimatkunde setzt sich als eigenständige Disziplin in den 1920er Jahren institutionell durch ${ }^{72}$ und in der Hochschulgermanistik ist sie schon lange angekommen (II.3.3). ${ }^{73}$ Auflistungen von ausgegebenen Auf-

66 Deutschkunde gilt dann „als Prinzip, das alle Fächer durchdringen soll“. Hofstaetter 1930, S. 237. Schon 1921 heißt es: „Deutschkunde ist kein Fach, sie umfaßt - im weitesten Sinne - alle Erscheinungen des deutschen Lebens in Vergangenheit und Gegenwart, sofern sie für deutsche Art bezeichnend sind. [...] Sie verfolgt alle Fragen des deutschen Volkslebens im Reich und im Ausland, sie will alles beleuchten, was deutsche Herzen bewegt - soweit es deutsch." Hofstaetter 1921, S. 3.

67 „Daraus erhellt, daß die Deutschkunde vieles heranziehen muß, was zur Heimatkunde, Erdkunde, Geschichte, Religion, Geisteskunde und anderen Fächern gehört, aber mit den Ergebnissen des besonderen Deutschunterrichts zu einem großen Gesamtbild des deutschen Wesens vereinigt werden muß.“ Hofstaetter 1921, S. 3.

68 Der Deutschunterricht müsse ,allerlei aufnehmen, wofür sich im Ausbau der Schule sonst nirgends ein Plätzchen findet: Volks- und Altertumskunde, Musik und Kunst und gar manches auch aus den Grenzgebieten zwischen Deutsch, Geschichte und Staatsbürgerkunde“. Hofstaetter 1921, S. 4.

69 Vgl. Walther Hofstaetter: Vorwort, in: Hofstaetter 1917, S. 3.

70 Hofstaetter 1921, S. 5.

71 Vgl. dazu Held 1928, S. 7.

721926 entstand am Pädagogischen Institut der Technischen Hochschule Dresden ein ,Seminar für wissenschaftliche Heimatkunde u und am Lehrstuhl für Landesgeschichte der Universität Leipzig das erste ,Institut für Heimatforschung‘, in Leipzig konnten Pädagogen und Volksschullehrer im Fach Heimatkunde promovieren, vgl. Faehndrich 2010, S. 64.

73 Im 19. Jahrhundert sind die Grenzen zwischen Schul- und Hochschulgermanistik insgesamt fließend; nicht selten wechseln Gymnasiallehrer im Lauf ihrer Karriere in den Hochschuldienst. Von den hier genannten heimat- und zugleich volkskundlich affizierten Germanisten agiert ein 
satzthemen legen nahe, dass die Programmatik der Heimatkunde auch tatsächlich in die Unterrichtspraxis Eingang fand. ${ }^{74}$ Die Aufsatztitel zeigen, dass der Deutschunterricht als Ort der Vermittlung von Heimat- und Volkskunde galt. Eine Gleichsetzung von Deutsch-, Heimat- und Volkskunde nimmt etwa der Aufsatz Volkskunde im Deutschunterricht vor: „Das Kernstück der Heimatkunde ist die Volkskunde“, ${ }^{75}$ heißt es; Zweck der Schule insgesamt sei die „Bildung zum deutschen Menschen“, ${ }^{76}$ Volkskunde und „Heimatschulgedanke“77 gelten als allgemeiner Unterrichtsgrundsatz. Daher müsse auch der Deutschunterricht die herkömmlichen Inhalte und Methoden weit überschreiten. Der Autor des Aufsatzes, Josef Klapper, definiert die intrinsische Motivation und innere Anteilnahme der Schüler als oberstes Ziel und will dies erreichen, indem „der Unterricht vom Eigenerlebnis, von der heimatlichen Anschauung “78 auszugehen habe. Nur der „Pauker“ mit seinem „Lehrbuch“, heißt es in einem anderen Aufsatz, brauche

Großteil sowohl im Bereich der Schule als auch in dem der Hochschule: Rudolf Hildebrand ist zunächst Lehrer, später Professor für Neuere deutsche Literatur, Otto Lyon Oberlehrer am Gymnasium mit Professorentitel und Josef Klapper sowohl promovierter Oberstudienrat als auch außerplanmäßiger Universitätsprofessor. Walther Hofstaetter ist Mitbegründer des deutschen Germanistenverbandes, der Schul- wie Hochschullehrern offenstand, und die von ihm ausgelöste Deutschkundebewegung wurde maßgeblich von der Hochschulgermanistik mitgetragen.

74 Im Handbuch der Heimaterziehung werden über mehrere Seiten vergebene Aufsatzthemen von namentlich genannten Schulen und Klassenstufen verzeichnet, die mit „Heimatpflege“ in Zusammenhang stehen, von „Warum können wir auf unsere engere Heimat stolz sein (Gymnasium und Oberrealschule Minden O II.)“ über „Heimat und Vaterland, eine Begriffsentwicklung (Bismarckgymnasium Berlin-Wilmersdorf U II.)“ bis zu „Wodurch können wir unser Interesse am Heimatschutz zeigen? (Oberrealschule Görlitz U II.)“. Heinrich Deckelmann: Heimatkunde und Heimatpflege im deutschen Unterricht, in: Schoenichen 1924, S. 73-112, hier S. 106-107.

75 Klapper 1928, S. 22.

76 Klapper 1928, S. 22.

77 „Volkskunde ist mehr Unterrichtsgrundsatz als stofflicher Sonderinhalt. Die Beschäftigung mit der Volkskunde beherrscht somit alle Schulfächer; sie wird als Heimatschulgedanke ihr einigendes Band, ihr Konzentrationsgedanke.“ Klapper 1928, S. 24. „Die Volkskunde als Heimatkunde in der Schule weist über sich selbst hinaus. Sie will nicht nur klärend und gefühlsweckend wirken. Sie will mithelfen, aus den als wesensecht erkannten deutschen Grundzügen die deutsche Welt $\mathrm{zu}$ bauen, sie will richtungsweisend und zielsetzend wirken für die arbeitsfähigen, arbeitsfreudigen, sittlich gesund empfindenden Teile des deutschen Volkes.“ Klapper 1928, S. 25. „Die Gliederung volkskundlicher Arbeitsstoffe beschränkt sich nicht auf die deutschkundlichen Fächer im engeren Sinne, sie umspannt die gesamte Heimatüberlieferung. Die Verteilung der Einzelfächer kann je nach der Eignung und Neigung der Lehrer vorgenommen werden; jeder grundsätzliche Versuch der Verteilung würde bei einem innerlich so einheitlichen Ganzen willkürlich bleiben, wie ja auch die heutige Stoffverteilung auf Unterrichtsfächer in vielen Fällen Willkür ist." Klapper 1928, S. 28.

78 Klapper 1928, S. 26. 
„die Heimat nicht zu kennen“, aber jeder Lehrer, der seine Schüler gewinnen wolle, schon. ${ }^{79}$ Bei aller ideellen Verbrämung, die auf Gesinnungsbildung zielte, schließt die Neuauflage der Heimatkunde der höheren Schulen des frühen 20. Jahrhunderts damit in einem wichtigen Punkt an die Idee des hundert Jahre zuvor entwickelten Heimatkundeunterrichts für die Volksschulen an: die Idee, dass ein Schüler überhaupt erst zu gewinnen sei, und zwar über anwendungsbezogene Methoden. Eben hierin liegt eine Erklärung für die Durchsetzungskraft des heimatkundlichen Ansatzes. Denn trotz aller komplementärideologischen Elemente schlossen die angewandten Methoden der Heimatkunde teils an die ,Pädagogik vom Kinde her' an, wie sie Henning, Harnisch und Finger für die Geographie entwickelt hatten und wie sie dann in der Reformpädagogik der Jahrhundertwende intensiv diskutiert und erprobt wurde. In diesem zwischen 1800 und 1900 kompliziert gebliebenen Gefüge von aufklärerischen und gesinnungsbildenden Elementen der Heimatkunde haben freilich letztere immer mehr an Einfluss gewonnen (und die Geschichte der Heimatkunde geht auch nach 1945 zunächst in diesem Sinne weiter). ${ }^{80}$ Der Artikel ,Heimaterziehung a aus dem Sachwörterbuch der Deutschkunde von 1930 sieht die frühe, „rein sachlich[e]“ Heimatkunde als geradezu schädlich an:

Der methodische Ausgangspunkt von Erfahrung und Umgang des Zöglings, vom Nahen zum Entfernten, vom Bekannten zum Unbekannten, vom Besonderen zum Allgemeinen, ließ an die rein sachlich als die zufällige Umgebung des Kindes aufgefaßte Heimat des Kindes anknüpfen, die ebenso auch unabhängig von Herbart bei den Pestalozzianern und bei Schülern

79 In einem Aufsatz über Heimatkunde im Deutschunterricht wird dem Lehrer empfohlen, sich Heimat durch Lektüre, den Besuch von Heimatmuseen und Wanderungen zu erschließen. Nur über diese Kenntnisse gewinne er den Schüler für sich: „Wer also [als versetzter Lehrer] in einen neuen Ort, in eine ihm unbekannte Landschaft kommt, der unterrichte sich sofort über das Schrifttum der neuen Heimat, das jede Lehrbücherei haben müßte. Er frage nach der geologischen, geschichtlichen Karte, er sehe sich statistische Aufstellungen an; er beschaffe sich die geschichtlichen, kunst- und kulturgeschichtlichen Werke; er besuche sofort die Heimatmuseen und sonstigen Bildungsmittel und mache sich bald daran, durch Wanderungen die Umgebung näher kennenzulernen. Nur so wird der Lehrer heimatvertraut und kann er den Forderungen neuzeitlicher Pädagogik, die so sehr den Wert der Anschauung und des Erlebnisses betont, die mit dem geistigen Besitz des Schülers wirtschaftet, gerecht werden. Nur so gewinnt er die Möglichkeit, das Mitteilungsbedürfnis des Schülers durch Anreizfragen und Hinweise auf das aus der Heimat Bekannte zu erschließen. Der ,Pauker freilich braucht die Heimat nicht zu kennen; er ist immer noch ohne sie ausgekommen; für ihn genügt das Lehrbuch mit seinem enzyklopädischen Inhalt.“ Held 1928, S. 8. Der Lehrer soll durch einen Bezug auf Heimat für möglichst erlebnisgesättigten Unterricht sorgen und die Schüler motivieren: „Das Heimaterlebnis drängt sich besonders freudig über die Lippen; es beschäftigt und fördert auch die Mitschüler und eint die Klasse am leichtesten zu einer Arbeitsgemeinschaft.“ Held 1928, S. 10.

80 Vgl. Röhrich 1961; Haug 1969. 
Humboldts in Geographie und Naturkunde, bei Biedermann für die Geschichte, zu Hilfe genommen wurde. Die daraus hervorgegangene „Heimatkunde“ als besonderes Unterrichtsfach scheint dem Heimatgedanken eher geschadet zu haben.

Laut dem Artikel gehe es gerade nicht um eine methodische, sondern um eine ideelle Bedeutungsgebung von Heimat und erst „die große kulturelle Heimatbewegung um die Jahrhundertwende und heute nach den Erfahrungen des Zusammenbruchs hat dem Heimatgedanken in der Schule Tiefe und Hintergrund gegeben [...].“ Die neue Tiefe des Heimatgedankens besteht darin, dass Heimat folgt man der folgenden Formulierung - gleichzeitig Fundament, Mittel, Ziel und Ideal nationaler Erziehung ist:

H. ist das große Mittel, das die Jugend heimisch macht in Volk und Vaterland und ihr den gemeinsamen geistigen Besitz des Volkes, die noch unerschütterten Fundamente des Volkstums überliefert. Heimat ist nicht mehr nur eine methodische Angelegenheit als von der Psychologie festzustellende Gegebenheit, sondern eine Aufgabe, eines der Bildungsziele unserer Schule, ein unverlierbarer Bestandteil des gegenwärtigen dt. Bildungsideals. ${ }^{81}$

Das vom Artikel als vermeintlich richtig identifizierte Verständnis von Heimatkunde, nämlich nicht nur als methodische, sondern als ideelle Bedeutungsgebung von Heimat, sei erst um die Jahrhundertwende und dann mit der Erfahrung des Ersten Weltkriegs möglich geworden. Heimat erscheint als „das große Mittel, das die Jugend heimisch macht in Volk und Vaterland“ (vgl. I.2.1). Heimat, expliziter könnte es nicht mehr sein, ist Mittel der Ideologie, nicht mehr Ausdruck der Methode der Anschauung.

Der schon genannte Otto Lyon dürfte in die „große kulturelle Heimatbewegung um die Jahrhundertwende“, von der im Artikel ,Heimaterziehung lobend die Rede ist, einzuordnen sein. Er ruft 1893 die neue Weltanschauung des ,Germanismus' aus und fordert zu diesem Zweck, Deutschunterricht und Heimatkunde eng miteinander $\mathrm{zu}$ verbinden. Der Zeit des einseitigen Humanismus werde nun eine solche folgen, in der nicht mehr Italien oder Griechenland, sondern Deutschland zur wahren Heimat der Auszubildenden werden könne. ${ }^{82}$ Für diesen Zweck empfiehlt Lyon unter anderem Gustav Freytags Ahnen.

81 Weniger 1930, Bd. 1, S. 526-527.

82 Lyon fordert, den Deutschunterricht der Realgymnasien ,aufs innigste mit der Heimatkunde zu verknüpfen“. Er fährt fort: „Dasselbe Gefühl, das der klassische Philolog und der klassisch Gebildete überhaupt empfindet, wenn er in Italien oder Griechenland auf dem Heimatboden der von ihm gepflegten klassischen Erinnerungen steht, wird mit seinem überwältigenden Zauber die junge Seele gefangen nehmen, wenn sie, ausgerüstet mit allen Mitteln einer deutschen Bildung, überall den Zeugen einer großen Vergangenheit in der deutschen Heimat begegnet.“ Lyon 1893, S. 720-721. 


\subsubsection{Freytags Ahnen-Zyklus}

Im Jahr 1886 hatte die öffentliche Aufmerksamkeit für Gustav Freytag ihren Höhepunkt erreicht. Keine deutsche Zeitung, die den Autor nicht zu seinem 70. Geburtstag würdigte und eine Besprechung seiner eben erschienenen Autobiografie veröffentlichte. Die Zeitungswelt schätzt Freytag einhellig als einen der besten Historiker und Dichter der Gegenwart, erhebt ihn gar zum „,bedeutendsten lebenden Dichter[ ]“. ${ }^{83}$ Seine Lebenserinnerungen gelten als die seit Jahren wichtigste literarische Novität ${ }^{84}$ und gehören, so das breite Urteil, „fortan zu den Büchern, die im Hausschrein der deutschen Familie nicht fehlen dürfen“. ${ }^{85}$

Fast immer wird dabei auch Freytags nationale Gesinnung hervorgehoben, ja, der eigentliche Grund der Auszeichnung scheint eben im nationalen Standpunkt Freytags zu bestehen. Zum „deutschen Klassiker“ mache ihn seine „Vaterlandsliebe“. ${ }^{86}$ „Kein Dichter der Welt“ sei „in gleichem Grade vom Bewußtsein des Staatsbürgerthums erfüllt““ ${ }^{87}$ Sein Werk ebenso wie seine Lebensführung seien eine „nationale That“. ${ }^{88}$ National ist diese Tat im Verständnis der Zeitgenossen doppelt: Für das Nationale werbend und zugleich auf die ganze Nation wirkend, ist es insbesondere die volkspädagogische Wirksamkeit, die man Freytag so hoch anrechnet. Ihm sei es, so wird im hegelschen Ton verkündet, zu verdanken, „das deutsche Volk zur Einkehr bei sich selbst gebracht [zu] haben“. ${ }^{89}$ Der Wertmaßstab für Werk und Persönlichkeit ist damit ganz und gar ein ideeller, erst sekundär werden aus diesem wissenschaftliche oder ästhetische Beurteilungskriterien abgeleitet: „Wir brauchen nicht mehr nach Griechenland zu gehen“, so ist zu lesen,

83 o.A., o.T., in: Die Presse 297 (26. Oktober 1886), Wien. Im Goethe- und Schiller-Archiv in Weimar (GSA) sind um die einhundert Freytag gewidmete Zeitungsartikel aus dem Jahr $1886 \mathrm{zu}$ finden. Alle hier und im Folgenden genannten Zeitungsartikel finden sich im GSA unter der Signatur 19/105, sie sind nicht noch einmal im Literaturverzeichnis aufgelistet. Sind Jahrgänge, Ausgabennummern oder Druckorte nicht angeben, handelt es sich um Zeitungsausschnitte ohne entsprechende Angaben. Dieses und das folgende Kapitel zu Freytags Ahnen und ihrer pädagogischen Rezeption basiert auf Oesterhelt: Heimatkunde, 2016.

84 Vgl. o.A., o.T., in: Der Westen 46, 32. Jg. (14. November 1886), Chicago, GSA 19/105.

85 Weisstein, Gotthilf: Gustav Freytags Lebenserinnerungen, in: Deutsches Montags-Blatt 45, 10. Jg. (8. November 1886), S. 4-5, hier S. 5, GSA 19/105.

86 o.A., o.T., in: Schlesische Zeitung 772 (4. November 1886), GSA 19/105.

87 Johannes Proelß, o.T., in: Wochenblatt der Frankfurter Zeitung 44 ,13. Jg. (31. Oktober 1886). Hervorhebung im Original, GSA 19/105.

88 o.A., o.T., in: Der Bund 312, 37. Jg. (12. November 1886), Bern, GSA 19/105.

89 o.A., o.T., in: Kölnische Zeitung 298 (27. Oktober 1886), GSA 19/105. 
denn Freytags „Verherrlichung des deutschen Volksthums“ sei von „einer wahrhaft klassischen Ruhe erfüllt““.90

Aus der Presseschau des Jahres 1886 ergibt sich das Bild eines Mannes, der als herausragende Persönlichkeit des öffentlichen Lebens wahrgenommen wird. Person und Werk werden weitgehend analogisiert und nach dem Wertmaßstab des Nationalen beurteilt. Freytag erscheint als Repräsentant und zugleich als volkspädagogisch wirksamer Akteur eines nationalen Selbstbewusstseins. Popularität und Erziehungsfunktion von Freytags schriftstellerischem Werk stehen für die Zeitgenossen nicht im Widerspruch zur literarischen Qualität des Autors, selbstverständlich zählt Freytag für sie zu den Vertretern der hohen Literatur.

Freytag ist als promovierter und habilitierter Germanist, Bühnen- und Romanautor, populärer Historiograph, Journalist und leitender Redakteur in einer der wirkmächtigsten nationalliberalen Zeitschriften sowie als Abgeordneter der Nationalliberalen Partei und Vorstand eines Arbeiterwohlfahrtvereins ein ungewöhnlich vielseitig agierender Vertreter der Intelligenz seiner Zeit, der mit zahlreichen Protagonisten des Hochschul-, Literatur- und Politikbetriebs in engem Kontakt steht. Er begreift sich in all seinen Tätigkeiten als öffentlich wirksamer Vertreter der bürgerlichen Bildungselite und auch seine literarische Produktion entspricht diesem Selbstverständnis. ${ }^{91}$ Engagement heißt für einen Nationalliberalen in der zweiten Hälfte des 19. Jahrhunderts die Verbreitung der Idee der nationalen Einheit und für einen Vertreter des repräsentativen Realismus ${ }^{92}$ (mit einem seiner Schlagworte) deren objektivierende ,Verklärung'. Selbstverständnis und zeitgenössische Rezeption stehen also in diesem Punkt durchaus im Einklang.

90 A.R., o.T., in: Erste Beilage zur ,Post', 21. Jg. (27. Oktober 1886), GSA 19/105.

91 In seiner Autobiographie koppelt Freytag den Beginn seines Engagements an die Barrikadenkämpfe des Jahres 1848. Er habe seine Theaterarbeit sofort beiseitegelegt und sich dem Journalismus verschrieben (vgl. Freytag 1896, Bd. 1, S. 145). In einer den Lebenserinnerungen parallelen Läuterungsszene des letzten Helden seiner fiktiven Ahnengalerie heißt es in den $A h$ nen, nicht mehr der „Säbel“, sondern „das gesprochene und gedruckte Wort“ sei die zeitgemäße Form der Erhebung für die nationale Sache (Freytag: Ahnen, 1897, Bd.13, S. 302). In beiden Szenen der Umkehr, der autobiographischen wie der fiktiven, steht das Schreiben fortan im Zeichen eines Sendungsbewusstseins, das die eigene Tätigkeit dem nationalen Kollektiv zugutekommen lassen will. Bezogen auf Freytags Biographie gilt das nicht nur für seine journalistische Arbeit, sondern auch für das gesamte weitere schriftstellerische und historiographische Euvre.

92 So die Kategorisierung von Lothar Schneider. Schneider arbeitet heraus, dass für Freytag der „Bildungsimpetus im Zentrum der Poesie“ stehe. Schneider 2005, S. 55. Nicht eine engagierte Literatur in der Tradition des Vormärz werde von ihm entworfen; Realismus nach Freytag bedeute vielmehr „einen ästhetisch-beschreibenden Nachweis der Realitätsfähigkeit des liberal-idealistischen Entwurfs bürgerlicher Subjektivität“. Schneider 2005, S. 71. 
Die „stille Agitation“93 für die nationale Sache gründet sich in Freytags literarischer, journalistischer und historiographischer Produktion unter anderem auf die Vermittlung von Werten, die für spezifisch deutsch gehalten werden. In Freytags literarischer Figurenwelt sind die Träger solcher Werte leicht zu identifizieren: Traugott Schröter und Anton Wohlfart bewähren sich in Soll und Haben durch Ehrbewusstsein, Arbeitsamkeit und Bürgerstolz, Sabine Schröter und Ilse, Letztere in der Verlorenen Handschrift, durch Pflichttreue gegenüber dem Ehemann. In den Ahnen verkörpern alle Vertreter der fiktiven Familiendynastie vom Vandalenkrieger Ingo bis zum Zeitungsredakteur Victor Tapferkeit und Fleiß, Freiheitsliebe, Ehrlichkeit, Treue, Willensstärke und Opferbereitschaft. Dieser ,bürgerliche Wertehimmel ${ }^{64}$ wird $\mathrm{zu}$ einem spezifisch nationalen, insofern die durch stete Wiederholungsschleifen erzeugte Überlagerung der einzelnen Heldengestalten ein idealisiertes Subjekt der deutschen Geschichte zum Vorschein bringt.

$\mathrm{Zu}$ den Eigenschaften dieses ,Ideal-Deutschen' gehört auch die Heimatliebe. Unverschuldete Heimatlosigkeit ist Schicksal des tragischen Helden, bewusst in Kauf genommene charakterisiert die Verwerflichen: Es sind „verlorene Menschen“ und „Frevler“, „welche sich von dem Segen der Heimat lös[]en“, 95 es sind „Räuber, welche heimatlos über die Erde“96 irren oder „zuchtlose Kreuzfahrer“, die in Wahrheit nicht ihrem Glauben dienen, sondern sich als „heimatlose Abenteurer, nur auf den eigenen Vortheil bedacht“97 erweisen. Um die Idee der Heimatliebe als eines nationalkonstitutiven Wertes in den Ahnen und deren Rezeption soll es hier nun gehen.

Seit dem Erscheinen des ersten Bandes 1872 bis zum Abschluss 1880 mit dem sechsten - verkaufsstrategisch geschickt immer kurz vor Weihnachten auf den

93 Freytag 1896, Bd. 1, S. 213. Das Zitat bezieht sich auf die „Belehrung der Nation und eine allmähliche Erziehung der öffentlichen Meinung durch die Presse“, lässt sich aber problemlos auch auf das Selbstverständnis als Belletristen übertragen. Auf die nationalpädagogische Wirksamkeit Freytags wird immer wieder hingewiesen, vgl. von Essen 2000, S. 165. Philipp Böttcher zeigt, dass Freytag sowohl als Journalist wie als Historiker in der Presse „nicht bloß eine Artikulationsinstanz des allgemeinen Willens, sondern immer auch ein Instrument, Einfluss auf diesen auszuüben“ sah. Böttcher 2018, S. 249. Einfluss auszuüben, kam in Freytags Selbstverständnis ihm selbst und dem liberalen Journalismus als der Spitze der öffentlichen Meinung selbstverständlich zu. Gleichzeitig wurde dieser Einfluss auch auf die Gefahr von Repressalien hin gegen die staatliche Zensur erstritten; vgl. Böttcher 2018, S. 348-261. Gegen Freytag wurde in diesem Zusammenhang 1854 Haftbefehl durch Preußen erlassen; vgl. auch Mühlen 2016, S. 130. 94 Vgl. Hettling/Hoffmann 2000.

95 Alle Zitate Freytag: Ahnen, 1897, Bd. 8, S. 155.

96 Freytag: Ahnen, 1897, Bd. 8, S. 348.

97 Beide Zitate Freytag: Ahnen, 1897, Bd. 10, S. 137. 
Markt gebracht - werden die Ahnen von den Zeitgenossen als „Nationalangelegenheit“98 wahrgenommen, und zwar sowohl im Sinn der breiten Leserschichten, die der Romanzyklus erreicht - bis 1920 wurde der erste (und erfolgreichste) Teil über eine halbe Million mal verkauft,$-{ }^{99}$ als auch im Sinn seines Gegenstands, der über einen Zeitraum von 357 v.Chr. bis 1848 anhand einer fiktiven Ahnengalerie ein Epos der Deutschen erzählt. Vom Vandalenkrieger Ingo, der in Thüringen ein Adelsgeschlecht begründet, über die Zeit der Christianisierung, die Reformationskriege bis in die eigene Zeitgenossenschaft wird die männliche Genealogie einer fiktiven Familie verfolgt, innerhalb derer sich immer wieder bestimmte Charaktere, Konstellationen und Ereignisse scheinbar schicksalhaft wiederholen. Zugleich flicht der Historiker Freytag reale Zeitgeschichte mit ein: Der römischdeutsche Kaiser Friedrich II., Martin Luther und Friedrich II. von Preußen treten beispielsweise als Nebenfiguren auf.

Ein monumentales Nationalepos sind die Ahnen im Hinblick auf ihren Umfang - in der hier genutzten Werkausgabe umfassen die sechs Abteilungen mit zwölf Teilen über zweitausend Seiten -, aber auch im Hinblick auf die Ausdehnung der erzählten Zeit und die episch breite Erzählweise. Die Intellektuellen der Zeit von Wilhelm Scherer über Paul Lindau bis Berthold Auerbach bedenken die ersten Abteilungen der Ahnen mit ausführlichen Rezensionen und Stilanalysen; selbst Theodor Fontanes Verriss stellt die Bedeutung des Romans nicht in Frage. ${ }^{100}$

Die Auseinandersetzung mit den Ahnen ist nicht nur Sache der Literaturkritik und Literaturwissenschaft. Sie findet im letzten Jahrhundertdrittel auch innerhalb der Unterrichtsdidaktik statt. Dieser bisher nicht untersuchte Teil der Rezeption spricht dem Romanzyklus eine klare Funktion zu: die Ausbildung von Heimatliebe. Der Heimatliebe kommt seit der Reichsgründung 1871, wie dargestellt, eine schulpolitische Aufgabe zu. Sie wird von Bildungspolitikern und Pädagogen zugleich als Bildungsmethode, Bildungsgegenstand und Bildungsziel empfohlen, um auf diesem Weg Vaterlandsliebe und Staatstreue zu fördern. Die historischen Bedingungen dafür, dass Heimat und Heimatliebe diese Vermittlungsfunktion zugeschrieben werden konnte, sind mit der Vorgeschichte zu dieser Entwicklung schon skizziert worden. Freytags Schriften gehen, und dies zeichnet sie aus, nicht

98 Beim Erscheinen des fünften Bandes freut sich ein Rezensent, er verfolge das „Wachsthum“ des Werkes „nun seit fünf Jahren wie eine Nationalangelegenheit“. Kreyßig 1879, S. 314.

99 Genaueres zu Auflagenzahlen und -höhen für die einzelnen Bände vgl. Eggert 1971, S. 182. 100 Vgl. Lindau 1872; Auerbach 1981 (die Rezension erschien zuerst 1873); Scherer 1873; Lindau 1881; und Fontanes Rezension zum ersten bis dritten Band der Ahnen, die in der Sonntagsbeilage der Vossischen Zeitung, Nr. 7 und 8 vom 14. und 21.2.1875 erschien, vgl. Theodor Fontane: Die Ahnen, in: Fontane 1969, S. 308-325. 
vollständig in der hier vorgestellten Rezeptionslinie auf. Auch wenn andererseits sicher nicht von einer gänzlichen Fehllektüre der Zeitgenossen gesprochen werden kann, ist davon auszugehen, dass Freytags Schriften bestimmte zeitgenössische Bedürfnisse bedienen, ohne sich in diesen zu erschöpfen. An dem Umgang mit Heimat im Romanzyklus selbst lässt sich das zeigen.

\section{Pädagogische Ahnen-Rezeption 1872 -1897}

Als Quellen für die pädagogische Rezeption der Ahnen dienen hier Aufsätze in pädagogischen Zeitschriften und vor allem wissenschaftliche Abhandlungen in Schulprogrammschriften. ${ }^{101}$ Ihre Autoren sind, so sieht es das Genre der Programmschrift vor, als Lehrer an den herausgebenden höheren Schulen tätig. Sie sind überwiegend promoviert, viele tragen den Professorentitel. Die Übergänge zwischen dem höheren Schulwesen und der Universität sind im 19. Jahrhundert fließend und viele der Gymnasiallehrer sind zugleich Privatdozenten an den Universitäten oder wechseln im Lauf ihrer Karriere in den Hochschuldienst. Die Aufsätze in den Programmschriften dienen der Reputation der höheren Schulen und sollen das öffentliche Interesse an ihnen wecken, sie dienen ihren Autoren aber auch dazu, sich wissenschaftlich zu profilieren. ${ }^{102}$ Sie verbinden also die pädagogischen Interessen des Schulwesens mit der wissenschaftlichen universitären Forschung. ${ }^{103}$

Den Reigen des Lobs der Schulmänner auf Freytags erzieherischen Wert eröffnet ein Aufsatz des Gymnasiallehrers und späteren Professors Dr. Adalbert Heinrich Horawitz, in dem es über Freytags Bilder aus der deutschen Vergangenheit heißt, sie seien geeignet, die Nation zu erziehen. ${ }^{104}$ Nach 1872 findet sich dieses Lob dann vor allem bezogen auf die im Erscheinen begriffenen Ahnen. In

101 Die Bedeutung der Textsorte Schulprogrammschrift für die Erforschung der Pädagogik- und Kanonisierungsgeschichte wurde besonders von Hermann Korte und Carsten Gansel erforscht, vgl. Korte/Zimmer/Jakob 2005 und Gansel/Ächtler/Siwczyk 2017.

$102 \mathrm{Zu}$ diesem Dilemma vgl. Ullrich 1908, S. 138-139.

103 Für den betreffenden Zeitraum können die Schulprogrammschriften zu Freytag geradezu in einer Vorreiterrolle für die universitäre Forschung zu Freytag gesehen werden, denn die Germanistik etabliert sich überhaupt erst seit der Reichsgründung als eine sich auch der Gegenwartsliteratur öffnende Literaturwissenschaft, mit Wilhelm Scherer als einem ihrer ersten Repräsentanten. Überblicksartig zu den historischen Kontexten vgl. Nipperdey 1990, S. 633-654. Eine rein universitäre germanistische Forschung entsteht im Rahmen von Dissertationen zu Freytag erst mit Beginn des 20. Jahrhunderts. Insofern können die hier vorgestellten Schriften zum geringeren Teil als pragmatisch-pädagogische Texte, zum größeren dagegen als wissenschaftsgeschichtlich der germanistischen Forschung zugehörig behandelt werden.

104 Vgl. Horawitz 1871, S. 13-14. 
einer begeisterten Besprechung der ersten Abteilung durch den Gymnasiallehrer Dr. Otto Frick wird das Romanprojekt 1873 als „pädagogische That im höchsten Sinne des Wortes“ bezeichnet; es trage „vielleicht mehr und Wirksameres zur Erziehung des Volkes bei, als bändereiche Werke über Culturgeschichte oder Pädagogik thun könnten“. Einem Schulmeister springe das Herz vor Freude bei dem Gedanken, „dass der Jugend unserer höheren Schulen eine solche Gabe geboten wird, aus welcher ihr die Herrlichkeit unseres deutschen Volkes, seine Gesundheit, seine Tiefen, sein ethischer Gehalt in solchem Reichthum entgegentritt““ ${ }^{105}$ Die pädagogische Leistung wird also in der Vermittlung eines Nationalbewusstseins erblickt, ohne dass in diesem Zusammenhang aber das Stichwort Heimat fallen würde - das wird sich ändern, und zwar auch beim Pädagogen Frick selbst.

Dabei wird der herausragende Stellenwert des Motivs der Heimatliebe von Anfang an bemerkt, zunächst im Zusammenhang mit den vielfältigen Analogien zwischen dem heimatlosen Helden Ingo und dem homerischen Odysseus (vgl. II.1.3.1). Auf die Bezüge zur Odyssee hatte schon der Germanist und Hochschulprofessor Wilhelm Scherer aufmerksam gemacht. ${ }^{106}$ Die pädagogische Literatur verweist immer wieder auf Scherers ausführliche Besprechung in den Preußischen Jahrbüchern von 1873, in der Ingo als ein ,deutscher Odysseus, der heimatlos an den gastlichen Heerd kommt“ gedeutet wird. ${ }^{107}$ Wilhelm Scherer lobt in seiner motivgeschichtlichen Einordnung des Textes, die neben der Odyssee auch die Nibelungen, Beowulf und andere mythische Texte einbezieht, dass Freytags Ahnen die Heimatliebe als charakteristisches Gefühl der deutschen Stammväter darstelle: „Die größte Weichheit, die ein germanisches Männerherz in sich birgt, kommt gegenüber dem Gefolgsherren zu Tage. Und nur das Heimatgefühl kann an Intensität und Tiefe damit wetteifern. “ ${ }^{108}$ Heimatgefühl und Gefolgstreue kommen im ersten Teil von Freytags Romanzyklus laut Scherer praktisch zur Deckung: „Heimat aber, das ist die Halle, in der sie um den Herrn versammelt waren, das sind die liebreichen Genossen, der Jubel und Gesang beim Trunk, der den Saal durchtönt, und der Hochsitz, der Thron des Herrn, von dem er die Gaben vertheilt. “109

105 Alle Zitate Frick 1873, S. 154-155.

$106 \mathrm{Zu}$ den verschiedenen Stellungnahmen Scherers zu den Ahnen vgl. Schneider 2005. Zur Beziehung zwischen Scherer und Freytag vgl. auch Müller/Nottscheid 2015.

107 Scherer 1873, S. 485. Vgl. auch Heußner 1892, S. 25.

108 Scherer 1873, S. 492.

109 Scherer 1874, S. 19. 
Zur volkspädagogischen Funktion der Ahnen wird in den Folgejahren viel geschrieben, ${ }^{110}$ zur Bedeutung von Heimat in Bezug auf die Ahnen erst wieder 1882 - inzwischen liegt der ganze Ahnen-Zyklus vor - vom Pfarrer Wilhelm Daniel Friedrich Felgenträger. Für ihn stellt Heimat das zentrale verbindende Motiv des Zyklus dar:

Unverkennbar ist die Bedeutung, welche der Heimath der Ahnen beigelegt wird. Ingo's Ansiedlung auf dem Idisberge, die Wiege des Geschlechtes, bleibt zwar nicht der Wohnort der Nachkommen, wohl aber ein Heiligthum, zu welchem sie Jahrhunderte hindurch in schweren Tagen wandern. Die späteren Enkel wissen nicht mehr, wo ihr Geschlecht seinen Ursprung genommen hat, doch führt sie immer wieder ein geheimnißvoller Zug dorthin zurück. Immo gewinnt auf der Idisburg Hildegard zur Braut. Marcus hat zornig die Heimath an der Weichsel verlassen, um in der Fremde zu sterben, und er schließt die Augen auf der alten Heimstätte seines eigenen Geschlechtes. Und Ernst König, der in grauem Haar zum ersten Male mit den Seinen die Koburg betritt, fühlt sich heimisch auf dem anmuthigen Stück Erde, als hätte er's immer geschaut. ${ }^{111}$

Im Verlauf des Zyklus sei allerdings zu beobachten, dass die Bindung an Heimat, Landschaft und Stamm gegenüber einer neuen Bindung in den Hintergrund trete, der Bindung an die Nation: „Der Grundgedanke der Dichtung fordert, daß die fortschreitende Entwickelung des Geschlechts nicht an die Schranken der Landschaft und des Volksstammes gebunden bleibt. In demselben Maße, wie die Beziehungen der Ahnen zur engeren Heimath und zur besonderen Stammesart sich lockern, wächst für sie die Bedeutung des gemeinsamen Vaterlandes und Volksthums. “112 Diesen Grundgedanken sieht Felgenträger dann in allen einzelnen Romanen des Zyklus verwirklicht, wie er in der Folge detailliert ausführt, immer wieder entfalte sich für die Helden im Handlungsverlauf ,bei aller Anhänglichkeit an den heimischen Gau und Stamm ein stärkeres Nationalbewußtsein“. ${ }^{113}$ Heimatund Vaterlandsliebe erweisen sich bei Felgenträger sowohl innerhalb der Logik des Romanzyklus als auch historisch gesehen als aufeinander aufbauende Prinzipien.

Mit der pädagogischen Funktion von Heimat, so wie sie in den Ahnen dargestellt sei, beschäftigt sich der Geheime Schulrat Oscar Adalbert Grüllich. Was

110 Die volkspädagogische, insbesondere die „Volksjugend zur Ehrfurcht gegen Staat und Monarch“ erziehende Funktion der Ahnen hebt der Literaturhistoriker Franz Hirsch 1882 hervor, der ausdrücklich alle Teilbände zur ,nationalen Erziehung' empfiehlt. Hirsch: Geschichte und nationale Erziehung, in: Der Salon 2 (1882), S. 1455-1461, hier zitiert nach Bucher/Hahl/Jäger/ Wittmann 1981, S. 491-492.

111 Felgenträger 1882/1883, S. 605-606.

112 Felgenträger 1882/1883, S. 606.

113 Felgenträger 1882/1883, S. 606. 
bei Scherer 1872 und Felgenträger 1882 schon formuliert ist, dass nämlich Heimatliebe bzw. -gefühl ein Kernmotiv des Ganzen sei, das ein spezifisch Deutsches zum Ausdruck bringe, das wird 1888 bei Grüllich zum Dreh- und Angelpunkt der Interpretation. Freytag habe in seinen Ahnen die „Grundstimmung des deutschen Wesens“ darzustellen gesucht. Dieses deutsche Wesen zeichne sich aus als „deutsche Mannhaftigkeit und Hochherzigkeit“, als „deutsche Treue und Hingebung“, als „dem Zuge zur Freiheit und Ungebundenheit“, als „Liebe zu Heimat und Haus“, als „die edle, zarte Minne“ und als der „Zug des deutschen Gemüts zu wahrer, innerlicher Frömmigkeit““ ${ }^{114}$ Freytags ,Sprache der Ahnen“, zu der die Heimatliebe gehöre, so die Behauptung des Schulrats, sei eine spezifisch der deutschen Nation zugehörige und nur ihr verständliche. Auch er geht wie Scherer davon aus, dass Liebe zur Heimat zum archaischen Gefühlshaushalt der Deutschen zähle:

\begin{abstract}
Selbst in der Wanderzeit der Deutschen - so zeigt uns der Historiker - hatte der Deutsche eine tiefe Anhänglichkeit an die Heimat, an den heimischen Boden. Die Not trieb sie nur fort oder die rauhe Poesie der Gefolgschaften, aber rechtlich ließen sie auch in der Fremde den Anspruch auf den heimischen Boden sich nicht rauben. Wandersinn und Heimgefühl - beides kämpft im deutschen Gemüt seit Jahrtausenden. Diese Liebe zur Heimat und Seßhaftigkeit, die Liebe zum heimischen Herde weht uns auch allenthalben aus den Gestalten der Dichtung entgegen. ${ }^{115}$
\end{abstract}

Empfiehlt Grüllich die Ahnen noch vorrangig dem Lehrer selbst zur Lektüre, um sich „das Herz am Brunnquell der Poesie zu erfrischen, und zwar an einer Poesie, die in jedem Zuge deutsches Gemüt, das deutsche Wesen in seiner Edelart zum Ausdruck bringt“, und sich so gestärkt seiner Aufgabe zu widmen, „den guten Geist der Ahnen in der Jugend weiter zu pflanzen“, ${ }^{116}$ so liefert der Gymnasialdirektor Dr. Friedrich Heußner 1892 einen regelrecht ausgearbeiteten Leitfaden zur schulischen Nutzung der Ahnen ab dem Ende der Obersekunda, in dem er „den didaktischen Wert und die didaktische Berechtigung des Romans“117 erweisen will. Er formuliert Vorschläge, in welcher Klassenstufe und in Kombination mit welchen Lernstoffen der Text zu behandeln sei, gibt Handreichungen in Form von Inhaltsangaben und Hinweise zu intertextuellen Bezügen und den wichtigsten Besprechungen. Im ersten Teil der Schulprogrammschrift entwickelt er ausführlich die Verbindung von Heimatliebe und Nationalgefühl: „Welchen größern und würdigern Gedankenkreis können wir uns nun nächst dem religiösen denken, als

114 Alle Zitate Grüllich 1888, S. 21.

115 Grüllich 1888, S. 25.

116 Beide Zitate Grüllich 1888, S. 31.

117 Heußner 1892, S. 8. 
die Kenntnis unseres deutschen Volkslebens, und welcher möchte unmittelbarer herauswachsen aus den die jugendliche Seele von früh auf nährenden Mächten, nämlich dem deutschen Familien-, Heimats- und Vaterlandsgefühle?“ Der rhetorischen Frage folgt die Ausführung. „In der Tiefe der Seele“ seien diese Gefühle „von früh unbewusst wirksam, brechen aus ihr hervor wie Quellen ursprünglichen Lebens und teilen allem, was sich mit ihnen verbindet, etwas mit von ihrer Ursprünglichkeit, ihrer Innerlichkeit, ihrem zeugungskräftigen Wesen“. Über den didaktischen Wert speziell des Heimatgefühls heißt es im Folgenden:

Das Heimatsgefühl [...] vermag auch eine gewaltige erziehende Macht zu üben. Darum sollen wir in die heimatliche Welt, den fruchtbaren Gehalt von Anschauungen, den Landschaft, Sage und Dichtung, Geschichte und Sitte der Heimat darbieten, die jugendlichen Gemüter auch in den höheren Schulen von früh auf bis zu den oberen Stufen recht allseitig, tief und ganz hineinsenken, daß dieselben für sie zu einer wirklichen Lebensmacht werden, Sinn und Verständnis für deutsches Wesen und deutsche Sitte recht allseitig wecken, bilden, kräftigen und pflegen, unserer Jugend und somit dem gesamten Volkstum selbst zu größtem Gewinn und Segen. ${ }^{118}$

Einerseits wird Heimatgefühl, zu dem Freytags Ahnen laut Heußner in hervorragender Weise anregen, mit den Begriffen der ,Anschauung' und der ,Wirklichkeit‘ assoziiert - andererseits mit den Begriffen des ,Unbewussten', der ,Innerlichkeit‘, des ,Gefühls‘ und der ,Tiefe der Seele‘. Hinzu kommt die Metaphorik des Organischen (,nährende Macht‘, ,Quelle‘, ,zeugungskräftiges Wesens‘, ,Fruchtbarkeit‘), deren Verwendung in Bezug auf Heimat auf Wilhelm Heinrich Riehl zurückgeht (vgl. II.3.2.1). ${ }^{119}$ Heimat wird hier mittels zweier unterschiedlicher Sinnbereiche konzipiert, des Bereichs des Realen und seiner Anschauung einerseits, des Bereichs des Gefühls und der Innerlichkeit andererseits. Auf rhetorischer Ebene ist die zeitgenössische Wandlung des pädagogischen Heimatbegriffs ablesbar: Der Anschauungsbegriff erinnert an das frühe Verständnis der Heimatkunde, wird aber durch die irrationalen Komponenten überformt, so dass sich die Zielrichtung der neu verstandenen Heimatkunde nicht mehr mit der alten in Deckung bringen lässt.

Heußner entwickelt im Folgenden die Ausbildung von Heimatliebe als das Zentrum des Lehrplansystems überhaupt; Heimat sei „ein machtvolles, lebendig wirkendes Centrum des Unterrichts, von dem aus gleichsam unzählige Saugwurzeln und Arme den neu sich darbietenden Stoffen aus der Sinnen- und Geisteswelt

118 Heußner 1892, S. 3-4.

119 Der biologische Begriff des Organismus wird schon bei Rousseau auf Gesellschaftsmodelle übertragen; vgl. Metzger 2002 und Töpfer 2011; in Bezug auf Heimat aber erst in der zweiten Hälfte des 19. Jahrhunderts. 
[...] sich entgegenrecken“. Von Heimat ausgehend könne der Lehrer vordringen „zu vollerer, vertiefter und geläuterter Auffassung und zu vollerem Verständnis vaterländischen Lebens und Wesens" ${ }^{120}$ Auffällig ist die aufsteigende Linie, die zwischen „Heimats- und Vaterlandsgefühlen“ hergestellt wird. Das ,Heimatgefühl' steht im Zentrum der pädagogischen Bemühung, deren Ziel die Entwicklung von Vaterlandsgefühl ist (vgl. I.2.1). Durch die Metaphorik des Spinnens, Streckens, Fassens und Saugens wird suggeriert, es handle sich um einen organischen, also natürlichen und sich zwingend vollziehenden Vorgang. Heußner bettet diese Überlegungen dann in sein pädagogisches Konzept der Heimatkunde ein und entwickelt ein ausgefeiltes Heimatkundeprogramm, das Naturkunde-, Geographie-, Geschichts- und Deutschunterricht umfasst.

Offensichtlich ist 1892, im Erscheinungsjahr von Heußners Text, ein Punkt erreicht, wo Heimat nicht mehr vorrangig als Romanmotiv wahrgenommen wird, wie bei Scherer, und nicht mehr als bloßer Erbauungsstoff für den Lehrer wie bei Grüllich. Jetzt wird sie Teil eines fächerübergreifenden pädagogischen Ansatzes, der sich Heimatkunde nennt und Zwecken dient, die sich weit von der konkreten Romanexegese entfernt haben.

Die pädagogische Rezeption der Ahnen in den ersten dreißig Jahren nach Erscheinen des Zyklus ist Teil einer Geschichte der Heimatkunde zwischen den 1870er und 1890er Jahren, wie sie in 3.1.1 skizziert wurde: Der Beginn des AhnenProjekts 1872 fällt ins gleiche Jahr wie der Erlass der Allgemeinen Bestimmungen, die den Heimatkundeunterricht fortan nicht mehr verboten, sondern unter modifizierten Bedingungen zuließen. Heimat wird seitens der Bildungspolitik somit nicht mehr als potentiell subversiv eingestuft - das neue Heimatkundeprogramm erzieht ohnehin vornehmlich den kaisertreuen und national gesinnten Untertanen und nicht den wissbegierigen Forscher. ${ }^{121}$

Die seit der Reichsgründung immer wieder eingeforderte Ausdehnung dieser neu verstandenen Heimatkunde auf den Deutschunterricht ${ }^{122}$ erhält Anfang der

120 Beide Zitate Heußner 1892, S. 4.

121 Bis zur staatlichen Einführung als eigenständiges Schulfach dauert es noch einmal fast fünfzig Jahre: Seit 1921 gibt es das Fach Heimatkunde in der Grundschule; schon 1908 liegt eine Ministerialanweisung zur Pflege der Heimatkunde vor; vgl. Anonym: Heimatkunde, 1927, S. 209; wichtiger für Fragen der Ideologisierung sind aber die Versuche, die Heimatkundeidee als fächerübergreifendes Konzept zu etablieren.

122 Etwas später folgen die Geschichtsdidaktiker: August Tecklenburg, der Begründer der historischen Heimatkunde, sieht diese als Fundament des nationalerzieherischen Unterrichts: „National bilden auf und aus dem Grunde der Heimat!“ Tecklenburg 1909, S. 20. Mit Tecklenburg, der mit der Heimatschutzbewegung und der Heimatkunstbewegung der Jahrhundertwende eng verknüpft war, eröffnen sich noch einmal neue Kapitel einer militarisierten, expansionistischen Heimatkunde, die davon träumt, so ,in der Heimat und im Vaterlande wurzelnd [...] dauernd und 
1890er Jahre einen neuen Schub. Dies korreliert mit einer deutlichen Horizontverschiebung der Ahnen-Rezeption: Spielte Heimat vorher für das als zentral angesehene Moment des Romanzyklus - die Entstehung der Nation - eine Rolle unter vielen, rückt Heimat, eingeleitet mit dem Aufsatz Grüllichs von 1888, ab 1892 mit den Schriften Heußners, Lyons und Fricks ins Zentrum der Auslegung.

Die Zuspitzung der pädagogischen Bemühungen um Heimat innerhalb von zwanzig Jahren lässt sich bei Otto Frick besonders gut beobachten: Frick ist jener Pädagoge, der 1873 die Ahnen emphatisch als „pädagogische Tat“ im Sinn der Stärkung des Nationalbewusstseins begrüßt hatte, ohne aber die Heimatidee in diesem Zusammenhang besonders hervorzuheben. In verschiedenen Schriften von 1892 wird Heimat für Frick, der inzwischen zum Leiter der Franckeschen Stiftungen in Halle und laut Neuer deutscher Biographie zu einem der ,bedeutendsten Schulmänner[ ] des ausgehenden 19. Jahrhunderts“123 aufgerückt ist, zum zentralen pädagogischen Gegenstand.

Ein pädagogischer Text Fricks von 1892 verdeutlicht ein weiteres Mal die zeittypische begriffliche Annäherung an Heimat. Wieder lassen sich die unterschiedlichen, ineinandergreifenden Begriffskomplexe des Empirischen, der Innerlichkeit und des Organischen identifizieren:

Jeder Punkt der heimatlichen Umgebung wird ein Anknüpfungs- oder Stützpunkt für die geistige Aneignung, ein Träger innerer Erfahrungen und Erlebnisse; an jede heftet sich eine kleine Welt von Vorstellungen und Empfindungen, ein Stück innerer Teilnahme des Gemüts, und der Niederschlag der an die Heimat sich knüpfenden Erfahrung und Teilnahme wird zum fruchtbarsten Grundstock des ganzen Innenlebens, vor allem des Gemütslebens. Und so bilden in der That die Eindrücke der Heimat vornehmlich den inneren Organismus des Menschen, ebenso wie die Speise seinen äußeren Organismus bildet. Anschauung und Phantasie, Vorstellung und Verstand, Gefühl und Gemüt - alle Seiten der geistigen Thätigkeit empfangen ihr erstes Werden und frühstes Wachstum aus der Heimat; diese wird die Geburtsstätte auch des geistigen Menschen. ${ }^{124}$

Die Begriffe Erfahrung, Verstand und Anschauung, die an das Vokabular der früheren Heimatkundemodelle aus der ersten Hälfte des 19. Jahrhunderts erinnern, werden auch hier bezogen auf Heimat verwendet. Aber sie dienen nicht

mit starkem Arm unsere Stellung unter den Völkern zu behaupten, neue Heimaten für unsere Volksgenossen in fremden Erdteilen zu begründen, Weltpolitik zu treiben und uns den gewünschten Platz an der Sonnenseite zu erwerben“ (Tecklenburg 1909, S. 72). Für Tecklenburg ist die Heimatkunde keine Angelegenheit einzelner Fächer mehr; vielmehr solle der gesamte Schulunterricht den „Erdgeruch der Heimat“ (Tecklenburg 1909, S. 199) an sich tragen. Zu Tecklenburg vgl. Mitzlaff 1985, Bd. 2, S. $830-843$.

123 Asmus 1961.

124 Frick: Heimatgefühl, 1892, S. 14-15. 
mehr vornehmlich der Idee eines anschauungsbasierten Realienunterrichts, sondern werden im Zeichen des (im Zitat dreimal genannten) „Gemüts“ in eine Reihe mit den Begriffen Phantasie, Empfindung und Gefühl gestellt.

Die begriffliche Zusammenführung von Ratio und Emotion übernimmt in der Pädagogik und angewandten Psychologie schon Mitte des 19. Jahrhunderts das ,Gemüt', in der zweiten Hälfte des 19. Jahrhunderts immer öfter das ,deutsche Gemüt' ${ }^{125}$ Der Gemütsbildung und -erziehung kommt etwa in der Allgemeinen Pädagogik (1852) des Herbartianers Theodor Waitz noch vor der intellektuellen Bildung hervorragende Bedeutung zu, denn das Gemüt bezeichne die Gesamtheit der Gefühle, Interessen und Bestrebungen des Menschen, also sowohl die sinnlichen wie die intellektuellen Aspekte des Menschen: ${ }^{126}$ „Laufen demnach alle Fäden des Erziehungsgeschäftes in der Gemütsbildung als ihrem gemeinsamen Mittelpunkte zusammen, so folgt, daß die Entwicklung der Intelligenz ebenso wie die Kultur des sinnlichen Vorstellungskreises sich jener unterzuordnen hat und ihr dienstbar werden muß.“127 Rudolf Hildebrand, Verfechter der gesinnungsformenden Funktion der Heimat für den Deutschunterricht und Verfasser des Artikels „Gemüt“ im Grimmschen Wörterbuch, sieht als Ziel des Unterrichts „nicht die Entwicklung intellektueller Vermögen, sondern die Prägung der ganzen Person in ihrem intellektuellen wie affektiven Haushalt“ “. ${ }^{128}$ Und der Heimatkundeverfechter Otto Frick lässt keinen Zweifel, dass sich insbesondere die Deutschen durch ihre ,Gemütstiefe‘ auszeichnen. ${ }^{129}$

Heimat ist, so lässt sich zusammenfassen, in der zweiten Jahrhunderthälfte ein Schlüsselbegriff der Pädagogik, insbesondere der Deutschdidaktik. In Verbund mit dem Begriff des Gemüts wird Heimat als Ziel- und Angelpunkt der erzieherischen Bemühungen aufgefasst, weil der Bezug auf sie eine personale Ganzheit zu bewahren bzw. wiederherzustellen verspricht, die laut der Modernekritik ihrer Verfechter zu verschwinden drohe.

Die Idee der frühen Heimatkunde, die konkrete Anschauung zu schulen, wird von der neuen Heimatkunde nach 1871 partiell adaptiert. Mit der Überlagerung des eher nüchternen Gehalts, den der Begriff der Heimat in den früheren Hei-

125 Vgl. Schneider 2007, besonders S. 226-231.

126 Waitz greift insbesondere auf die Schriften von Jakob Friedrich Fries zurück, vgl. Waitz 1910, S. 115.

127 Waitz 1910, S. 117-118.

128 Die Ganzheitsbestrebungen sind dabei mit klar benannten Inhalten besetzt: So wie durch den Lehrer vermeintlich deutsche Werte wie Pflichttreue, Opferbereitschaft und Ehrlichkeit in das Gemüt des Schülers zu senken seien, so ist das Gemüt selbst eine spezifisch deutsche Eigenschaft. Vgl. Schneider 2007, S. 231.

129 Frick: Naturgefühl, 1892, S. 3. 
matkundemodellen hatte, durch emphatische und ideelle Qualitäten kann Heimat nun die angestrebte ,Ganzheit' verkörpern, die auch in den Ahnen entdeckt wird. Eine zunehmende Zahl von Schulprogrammschriften und Aufsätzen in pädagogischen Zeitschriften zu Freytag belegen in den 1890er Jahren eine Verfestigung dieser Entwicklung. Neben pathetischen Gleichsetzungen der Ahnen mit der Bibel und Homer, nun eben nur für die Deutschen, ${ }^{130}$ werden die Ahnen auch weiterhin für den Unterricht empfohlen, um mit ihrer Hilfe die Heimatliebe als deutsche Eigenschaft zu vermitteln. ${ }^{131}$ Die Gabe zum „Lokalkolorit“ in den Ahnen zeichne Freytag als Mann von „Heimatgefühl und Vaterlandsliebe“ aus, die mit dem „nationalen Empfinden“ der Deutschen so eng verbunden seien. ${ }^{132}$ Und immer wieder wird die im Ahnen-Epos gefeierte „Anhänglichkeit an die Heimat“ als vorbildlich hervorgehoben. ${ }^{133}$

Freytags Ahnen, so lässt sich resümieren, werden mit Beginn der 1890er Jahre massiv für eine Ausbildung von Heimat liebe als Gesinnung in Anspruch genommen. Die pädagogische Rezeption trifft auf einen Autor, der die nationalerzieherische Funktion seiner literarischen Produktion selbst immer wieder betont hat. So liegt es besonders nahe, auch das Heimatmotiv der Ahnen auf seinen Ort im Umfeld der Rede von Heimat nach $1871 \mathrm{zu}$ befragen. Tatsächlich decken sich die Ahnen vielfach mit dem nach der Reichsgründung vorherrschenden Verständnis von Heimat.

130 Karl Landmann setzt die Ahnen auf eine Stufe mit der Bibel und Homer. Sie ragten deswegen aus der Gegenwartsliteratur heraus, „weil in ihnen deutsches Leben, deutsches Denken und Fühlen so ganz vortrefflich, so recht als Herzensgeheimnis des eignen Hauses zur Darstellung gebracht ist“. Landmann 1892, S. 81.

131 Professor Lepp empfiehlt die Ahnen ausdrücklich für den Unterricht: „Unbegründet ist die Annahme, dass die Germanen nicht an ihrem heimischen Boden hingen und zäher Liebe zur Scholle der Ahnen ermangelten [...].“ Lepp 1895, S. 9.

132 Schuldirektor a.D. Neubauer empfiehlt 1896 Freytag als einen Autor vom Rang Goethes und Schillers, die Ahnen als das wichtigste Werk. Neubauer 1896, S. 93 (zu den Ahnen vgl. insbesondere Neubauer 1896, S. 106-109).

133 Über Freytags Ahnen schreibt Prof. Dr. Roth: „In der Jugend hauptsächlich muss es die wärmste Vaterlandsliebe entzünden und das lebhafte Streben wecken, sich den Ahnen würdig anzureihen, wenn sie hier die edelsten Eigenschaften des deutschen Volks verkörpert sieht: Freiheitssinn, Furchtlosigkeit, Anhänglichkeit an die Heimat, Keuschheit in der Auffassung des Weibs und vor allem das in der mannigfaltigsten Weise sich äussernde Streben, die Welt mit dem Gemüte zu erfassen.“ Roth 1896/97, S. 42-43. 


\section{Heimat als historische Integrationsformel}

Freytags Romanzyklus ist im Kontext seiner Zeit und der Gattungsgeschichte ein bemerkenswertes Dokument. Der zeittypische Wunsch nach einem deutschen Nationalepos ${ }^{134}$ wird hier erstmals durch eine neu geschaffene Fiktion eingelöst. Für das Genre des historischen Romans sind die Ahnen in Bezug auf Reflexion und literarische Umsetzung des Verhältnisses von Historiographie und Dichtung ausgesprochen innovativ. ${ }^{135} \mathrm{Neu}$ ist etwa die Entscheidung, historisch verbürgte Personen nur am äußersten Rand der Erzählung auftreten zu lassen (so geschieht es mit Heinrich IV., Luther, Napoleon), die fiktiven Helden aber in einer historisch detailliert rekonstruierten Welt agieren zu lassen und auf diese Weise hohe historische Plausibilität innerhalb eines fiktionalen Rahmens herzustellen. Die Randstellung realer Personen hat den Effekt, historische Spekulation zu reduzieren, ist aber auch als Teil des freytagschen historiographischen Programms zu lesen, nicht mit dem Fokus auf die ,großen Männer‘, sondern auf den ,Durchschnittsmenschen' Geschichte zu erzählen, wie es auch in den Bildern aus der deutschen Vergangenheit sichtbar wird. ${ }^{136}$ Der „Herold des deutschen Bürgerthums“, zu dem die Gartenlaube Freytag erklärt, ${ }^{137}$ wird von den Zeitgenossen seit Soll und Haben dafür geschätzt, das bürgerliche Leben poesiefähig gemacht zu haben, ${ }^{138}$ und auch der historische Roman Freytags schreibt ja einen spezifisch bürgerlichen Werthorizont in die Vergangenheit ein. ${ }^{139}$

Bemerkenswert auf konzeptioneller Ebene ist auch der Versuch, die Sprache dem je erzählten Jahrhundert anzuverwandeln. Gezielt eingesetzte Anachronismen, Neologismen oder die auf dem Stabreim basierende Rhythmik der ersten Abteilungen verwandeln sich über die weiteren Abteilungen stufenweise in eine

134 Zeittypisch ist dieser Wunsch europaweit, vgl. Detering/Hoffmann/Pasewalck/Pormeister 2011.

135 Nicht Faktentreue, sondern die ästhetische Komposition habe den Romanaufbau zu leiten, so Freytag in seinen Kritiken der zeitgenössischen historischen Romane von Victor von Scheffel und Willibald Alexis, wobei dies nicht bedeute, dass man gegen historische Fakten verstoßen dürfe. Vgl. dazu auch Eggert 1971, S. 77-79.

$136 \mathrm{Zu}$ „dem historiographischen Meisterwerk der Bilder aus der deutschen Vergangenheit“ im Kontext der zeitgenössischen Kulturgeschichtsschreibung vgl. Maurer 2016, hier S. 88. Geschichte wird hier nicht als Galerie der großen Männer, sondern als Leistung der vielen Namenlosen dargestellt.

137 Alberti 1886, S. 514.

138 Vgl. dazu Böttcher 2018, S. 3-29, besonders S. 8-9.

139 Im Nest der Zaunkönige, dessen Handlung um das Jahr 1000 spielt, ist es ebenfalls das höchste Ziel der Figuren, als „Herr auf freiem Eigen“ zu stehen und nach Erwerb des eigenen Grund und Bodens dazu noch „die liebe Hausfrau“ gewonnen zu haben. Beide Zitate Freytag: Ahnen, 1897, Bd. 9, S. 320. 
moderne Erzählsprache. ${ }^{140}$ Der inhaltliche Zusammenhang wird durch unterschiedlichste narrative Elemente der Wiederholung hergestellt. Durch variierende Wiederholungen biographischer Details und zwischenmenschlicher Konstellationen, durch Rekursionen von Geschehnissen in Traumsequenzen oder in mündlichen und schriftlichen Tradierungen werden zyklische Strukturen geschaffen und wird zugleich die Frage nach dem Status von verschütteten, um- und neuerzählten, ja falsch erzählten Erinnerungen innerhalb des fiktiven Tradierungsvorgangs reflektiert.

Heimat wird in den Ahnen von der ersten Abteilung an als eines der schon quantitativ wichtigsten Romanmotive entfaltet. Immer wird es in die Nähe von Innerlichkeit, Gefühl und Gemüt gerückt und zugleich dem Tragischen und Heroischen angenähert. Ihr Korrelat, die Heimatlosigkeit, ist meist mit Unehrenhaftigkeit, Falschheit und Schwäche assoziiert und deutlich negativ konnotiert, oder aber ein schicksalhafter Zustand, wie ihn der Urheld Ingo zur Zeit der Völkerwanderung in Analogie zum homerischen Odysseus (vgl. II.1.3.1) durchleiden muss. Die konsequente Heimatliebe führt mehrfach in die Katastrophe, etwa wenn die heimwehkranken, eben in die Heimat zurückkehrenden Liebenden in der fünften Abteilung an deren Schwelle und damit an der Schwelle zum erhofften gemeinsamen Glück in den Wirren des gerade endenden Dreißigjährigen Krieges umkommen. ${ }^{141}$ Immer ist der Tod der auf ihrer Heimat Beharrenden aber mit dem Überleben des erstgeborenen Sohnes und damit der Aufrechterhaltung der männlichen Genealogie verbunden. Kriegerische Auseinandersetzungen oder der Tod werden als Beharren auf Heimat legitimiert und heroisiert.

Heimat motiviert sich darüber hinaus als ein wichtiges erzählstrategisches Moment. Die Heimatlosigkeit des Vandalenfürsten Ingo, seine Wanderschaft und Eroberung einer neuen Heimat sind die handlungsauslösenden und schließlich in den heroischen Tod führenden Momente der ersten Abteilung. Das unstillbare Heimweh des Priesteranwärters Immo und sein Entschluss, gegen den Willen des Klosters und der Mutter in die Heimat zurückzukehren und Krieger zu werden,

140 Am ausführlichsten hierzu Lindau 1872.

141 Nur in der „Heimat“ glaubt Judith in Der Rittmeister von Alt-Rosen gesunden zu können. Zu ihrem Geliebten Bernhard sagt sie: „Seht dort in der Ferne die grauen Berge, dort liegt unser Hof. Seit ich den Knaben habe, träumt mir wieder von der Kinderzeit. Dann erfaßt mich die Sehnsucht. Ich sehe die Höhen im Morgenlicht und das Haus des Vaters, und ich hoffe, was mich jetzt krank macht und zur Last für meinen lieben Herrn, das wird schwinden, wenn ich dahin komme." Eine innere Stimme rufe ihr zu, dass sie „dort den Frieden wiederfinden werde“ (Freytag: Ahnen, 1897, Bd. 12, S. 170). Dieser Wunsch erfüllt sich wenige Seiten später auf doppeldeutige Weise im Tod des Paares: „So kam den Liebenden der Friede. Und wer von ihnen erzählt, der weiß nicht, soll er sie glücklich preisen oder beklagen.“ Freytag: Ahnen, 1897, Bd. 12, S. 173. 
initiieren die Handlung der dritten Abteilung; für fast alle Abteilungen ließen sich solche konfliktgenerierenden, -beschleunigenden und -lösenden Funktionen beschreiben und ließe sich damit zeigen, wie der Dramentheoretiker und Bühnenautor Freytag seine Romanthemen und -motive in Szene setzt.

Heimatliebe und die daraus hervorgehenden Konflikte gewährleisten im Romangefüge nicht nur den Fortgang der Handlung innerhalb der einzelnen Erzählungen, sondern auch die Kontinuität der Gesamterzählung. Indem das bis zur eigenen physischen Vernichtung reichende Beharren auf der Heimat die Familiengenealogie gefährdet, aber nie beendet (etwa, wenn Ingo im Kampf um seine Heimat stirbt, sein Sohn aber gerettet wird), wird zugleich das Erzählkontinuum gewährleistet. Die zugrundeliegende Behauptung ist, im Einklang mit der sich in der zweiten Hälfte des 19. Jahrhunderts etablierenden Volkskunde (vgl. II.3.2), dass Heimatgefühl, oder, synonym verwendet, Heimatliebe, eine ethnische Konstante der Deutschen sei. Ein Nationalbewusstsein hat sich in der Geschichtsauffassung sowohl der Bilder aus der deutschen Vergangenheit als auch der Ahnen demgegenüber erst über die Jahrhunderte herausgebildet. Heimat zeigt sich als überzeitliches, zugleich ethnisch spezifisches Kontinuum, in das historisch die daraus hervorgehende Vaterlandsliebe eingetragen werden kann - die zeitgenössische Vorstellung von Heimat als ,Wurzelboden' der Nation also.

Die Kontinuitätsbildung geht, zunächst scheinbar widersprüchlich, mit einer Dezentrierung einher. In mehreren Hinsichten wird im Romanzyklus ein Standpunkt der Peripherie eingenommen, nicht einer des Zentrums: Nicht die großen historischen Persönlichkeiten stehen im Mittelpunkt, sondern Vertreter der vielen unbekannt Gebliebenen; nicht die großen historischen Ereignisse und Zentren der Macht, sondern der Blick auf sie vom Rand aus wird gewählt. Die Akzentuierung der provinziellen Heimat als jeweiliger Schauplatz des Geschehens, die Entscheidung für die regionale ,Verwurzelung' der Charaktere und die detailliert geschilderte lokale Topographie lassen sich im Einklang mit Aussagen Freytags darstellungspragmatisch erklären. Über die Arbeitsweise beim historischen Roman schreibt er: „[...] so muß man sich nach meiner Ueberzeugung auf ein kleines Gebiet beschränken und durch Reichthum des Details zu fesseln suchen“. ${ }^{142}$ Darüber hinaus ist der forcierte Provinzialismus im Anschluss an Celia Applegate $^{143}$ wiederholt als Versuch gedeutet worden, einen gegenüber der Nationalidee potentiell widerständigen Regionalismus für die Nationalstaatsidee gefügig zu machen und aus der Zusammenschau der vielen Heimaten weniger das jeweils

142 Freytag 1904, S. 256. Brief Gustav Freytags an Ernst II. vom 8.12.1873.

143 Vgl. Applegate 1990. Auf Celia Applegate, in deren Studie A Nation of Provincials. The German Idea of Heimat Freytag freilich nicht vorkommt, beziehen sich Tatlock 2002, Woodford 2004, Griffiths 2004. 
Einzigartige als vielmehr die universalen deutschen Werte aufscheinen zu lassen, um identitätsbildend zu wirken. Heimat wird zur Integrationsformel. Sie vermittelt zwischen dem Regionalen und dem Nationalen, zwischen dem Individuellen und dem Kollektiven, zwischen dem Konkreten und dem Abstrakten und zwischen dem Besonderen und dem Typischen. Dabei setzt Freytag Heimat und Nation keinesfalls gleich. So beharren einzelne positiv gezeichnete Figuren auf dem Regionalen, ohne sich der Idee des Nationalen zu öffnen. Der damit angedeutete Konflikt wird allerdings durch verschiedene erzählerische Verfahren harmonisiert, etwa indem sich die individuelle Figurenperspektive gegenüber der (den objektiven Gang der Geschichte repräsentierenden) Erzählerstimme als anachronistisch bzw. nicht zukunftsfähig erweist. ${ }^{144}$ Die Wahl der Provinz als Ausgangspunkt kann als Strategie gedeutet werden, nationaler Integration eine affektive Grundlage zu geben, indem das Besondere mehr als das Allgemeine zur Identifikation herausfordert und auf diese Weise den gemeinsamen Grund des Nationalen zu etablieren hilft. ${ }^{145}$

Symptomatisch ist in diesem Zusammenhang, dass Thüringen als wichtigste aller Heimatregionen gewählt wurde - der Zyklus beginnt und endet dort und verschiedene Generationen kehren im Verlauf der Erzählung immer wieder dorthin zurück. ${ }^{146}$ Wenn Freytag Thüringen im Romanzyklus als „Herzland“147 bezeichnet, greift er einen Sprachgebrauch auf, der Thüringen mit seinen nationalen protestantischen Symbolen wie Wartburg und Lutherbibel, aber auch wegen seiner geographisch zentralen Lage als symbolische Verkörperung ganz

144 „It undercuts the supposed dichotomy between nationalism and provincialism by showing how national feeling is born from the provinces.“ Griffiths 2004, S. 229. Laut Griffiths wird die Harmonisierung der Dichotomie erzählerisch erreicht, indem die das Regionale dem Nationalen vorziehenden Figuren zwar vordergründig mit Sympathie bedacht, durch den Erzählungsverlauf aber als unzeitgemäß disqualifiziert werden. Vgl. Griffiths 2004, S. 230.

145 Diese These entwickelt Lynne Tatlock sowohl für die Bilder (vgl. Tatlock 2000) als auch für die Ahnen (vgl. Tatlock 2002, bes. S. 87-88).

146 Als „Zufall“ und darüber hinaus rein biographisch motiviert deutet Jürgen Matoni die auf Thüringen fallende Wahl, vgl. Matoni 1995, S. 16. Auch Charlotte Woodford erkennt trotz ihrer thematischen Fokussierung auf den Heimat- und Nationaldiskurs im Anschluss an Applegates These nur den Aspekt der Austauschbarkeit des Regionalen. Vgl. Woodford 2004, S. 259.

147 Über Thüringen sagt der Held: „Denn wie ein Herzland liegt es in der Mitte und die größte Kraft ist hier gesammelt, ich darf das zum Lobe meiner Heimat wohl sagen. “ Freytag: Ahnen, 1897, Bd. 10, S. 137. Im unmittelbaren Anschluss wird die Nationalehre im Helden wach: „Zum erstenmal, seit er lebt, wurde er gerufen, weil er ein Deutscher war [...] er fühlte, daß eine Kränkung seines Volkes auch Kränkung seiner eigenen Ehre war [...]“.. Freytag: Ahnen, 1897, Bd. 10, S. 138. 
Deutschlands auffasst und die Region so für den Nationalstaatsdiskurs funktionalisiert. ${ }^{148}$

Eine kontinuitätsstiftende Funktion von Heimat, die durchaus nicht ganz in der Nationalidee aufgeht, eröffnet sich in Bezug auf die zeitgenössische Volksidee (vgl. I.2.2 und II.3.2), die auch Freytags Denken bestimmt und in den Ahnen durch die Vorstellung einer überindividuellen und überhistorischen ,Volksseele“ Ausdruck findet. Die Gleichförmigkeit der Einzelschicksale, die Freytag durch wiederkehrende Handlungen und Konstellationen vorführt und mittels derer er das Erleben seiner Helden über Jahrhunderte abseits rationaler Erklärbarkeit miteinander verknüpft, konstruieren eine überindividuell wirksame, zwar nicht von den Romanfiguren, dafür aber von den Lesern als solche erkannte gemeinschaftsbildende Kraft. In der Verbindung von Individuellem und Allgemeinem hat Heimat eine ihrer zentralen Funktionen bei Freytag: Sie stiftet einen individuell und historisch konkret erfahrbaren, aber überindividuell und transhistorisch wirksamen gemeinschaftlichen Raum, der Kontinuität gewährleistet. Auf diese Weise erfährt die Idee des Nationalen eine Ergänzung, welche die Anbindung ans Konkret-Individuelle ermöglicht.

Die nationale Reichsgründung steht in einem mindestens ambivalenten Bezug zum Romanprojekt. Vordergründig ist sie Ursprung und Telos der Ahnen, beim zweiten Blick stellt sich ihre Bewertung zwiespältig dar. Schon der Entstehungsmythos, der von Freytag in seinen (insgesamt vor allem als Dokument der Auslassungen und Glättungen interessanten) Erinnerungen um die Textgenese gewoben wurde, erweist sich als brüchig. Denn die Eindrücke des preußischen Feldzuges gegen Frankreich von 1870 dürften für die Entstehung nicht so ausschlaggebend gewesen sein, wie Freytag behauptet. ${ }^{149}$

Uneindeutig in Bezug auf Freytags Stellung zur nationalen Reichsgründung ist auch der Schluss der Ahnen. Anders als in der Widmung von 1872 nahegelegt und allgemein bis zum Erscheinen des letzten Bandes angenommen, endet das scheinbar teleologisch auf die nationale Erfüllung in der Reichsgründung angelegte Epos nämlich nicht 1871, sondern, wie vielfach von den Zeitgenossen moniert, mit einem wenig herausragenden Helden in der mittelmäßigen Zeit nach 1848. ${ }^{150}$ Freytag selbst gibt in seinen Erinnerungen nur wenig überzeugende

148 Vgl. Tatlock 2002, S. 89-92; vgl. zur Thematik insgesamt: Haufe/Gibas 2005, sowie Haufe 2008.

149 Die Grundidee ist vielmehr schon in der Verlorenen Handschrift (1864) zu finden, vgl. Sellmann 1906, S. 2- 3. Gegenüber Moritz Haupt datiert Freytag die erste Konzeption auf das Jahr 1867, vgl. Eggert 1971, S. 77. Vgl. schon Dove 1879, S. 276 und Ulrich 1907, S. 15. Anders sieht das Pegiel 2000, S. $182-183$.

150 Grundsätzlich zur zunehmend skeptischen Aufnahme vgl. Holz 1983, S. 104-113. 
Gründe für diese Entscheidung an, wenn er behauptet, die Großartigkeit des Ereignisses lasse sich durch keine Fiktion überbieten und unmittelbare Gegenwartsdarstellung sei für den historischen Roman unangemessen. ${ }^{151}$ Claus Holz nimmt Freytag diese Worte mit guten Gründen nicht ab und rekonstruiert biographisch, wie der nationalliberale Optimismus von 1848 bei Freytag zunehmend von Vorbehalten abgelöst wird. Zu Beginn des Romanprojekts hält Freytag die Gattung des historischen Romans noch für geeignet, dem mittlerweile skeptischen Verhältnis zur eigenen Gegenwart eine ideale historische Welt entgegenzuhalten. ${ }^{152}$

Die Reichsgründung konnte Freytag schon zu diesem Zeitpunkt nur sehr eingeschränkt als die Erfüllung seiner nationalpatriotischen Träume auffassen, da sie in seinen Augen unter falschen Vorzeichen durchgeführt wurde. Anders als viele Nationalliberale kann sich Freytag auch nach 1871 nicht mit Bismarcks Politik arrangieren, lehnt dessen politische Ziele genauso wie seinen autoritären Politikstil ab. ${ }^{153}$ Bismarcks Revolution von oben schalte das Volk als treibende Kraft des Einigungsprozesses aus, kritisiert Freytag. Seine zunehmende Unzufriedenheit mit der Fortsetzung des Romanprojekts, so rekonstruiert Holz überzeugend, spiegele die politischen Frustrationen des Liberalen über die von Bismarck angeführte Hohenzollern-Nation und über die Korrumpierbarkeit des bürgerlichen Standes, der sein Selbstwertgefühl zugunsten der Kaiserhörigkeit aufzugeben bereit gewesen sei. ${ }^{154}$ Die Niederschrift des Schlussbandes 1879 falle bezeichnenderweise zusammen mit dem endgültigen politischen Ende der Nationalliberalen.

Der von den Zeitgenossen als defizitär wahrgenommene Schluss ist als kalkulierte Leerstelle oder auch als fehlende Antwort des Autors lesbar, die das Verhältnis des Nationalliberalen zum Zeitgeschehen indirekt zum Ausdruck bringt: Die nationale Reichsgründung, so wie sie sich tatsächlich ereignet hat, kann demnach eben nicht als Telos von Freytags Epos fungieren, obwohl der ganze Romanzyklus darauf zuzulaufen schien. ${ }^{155}$

151 Eggert und von Essen schließen sich in ihrer Deutung des Endes weitgehend Freytags Selbstdarstellung an. Gesa von Essen fügt hinzu, dass das Identifizierungsangebot stärker sei, da sich der Leser durch die bewusst gesetzte Leerstelle selbst in die Geschichte einschreiben könne. Vgl. Eggert 1971, S. 82-83, von Essen 2000, S. 181-182.

152 Vgl. Holz 1983, S. 66.

153 Das zeigt Peter Sprengel. Insgesamt deutet Sprengel die Ahnen funktional als Wunsch- und Gegenbild zur aktuellen Erfahrung, vgl. Sprengel 1996, S. 153-181. Zu Freytags Ablehnung Bismarcks vgl. Herrmann 1974; Holz 1983, S. 185.

154 Vgl. Holz 1983, S. $76-87$.

155 Vgl. Holz 1983, S. 99. Daniel Fulda schließt sich der Deutung von Holz an, vgl. Fulda 1993, S. 202-204. Auch Tatlocks und Griffiths' Deutungen basieren, anders als behauptet, wesentlich 
Im Zusammenhang mit diesen Beobachtungen gewinnt Freytags Heimat eine gewisse Resistenz im Verhältnis zur Nation. Denn es fällt auf, dass in die Leerstelle des Schlusses Heimatliebe, Volkskraft, Volksseele, nicht Kaiser- und Staatstreue gesetzt werden. Heimat erweist sich in der Perspektive des Nationalliberalen Freytag als immer schon eingelöste Größe; die von Freytag erhoffte Nationenbildung, nämlich die durch das ,Volk‘, bleibt für ihn aber ein offenes Projekt deswegen der offene Schluss.

Vor diesem Hintergrund macht Freytags Text eine etwas andere Auslegung von Heimat möglich als die der zum großen Teil kaiser- und bismarcktreuen Bildungspolitiker und Pädagogen, von denen oben die Rede war. Heimat wäre dann nicht mehr nur als natürlicher ,Wurzelboden“ der Nation zu verstehen, sondern auch als stete Infragestellung der Realisierungsformen des Nationalen. Im zeitgenössischen kulturellen Klima des Historismus kann Heimat als Ursprungskonzept eigene Ordnungsvorstellungen legitimieren, ja wird selbst zur vermeintlich historisch konstanten - Ordnungsgröße, die Orientierung für die eigene Gegenwart bietet. Heimat ist, so erzählt Freytag, immer schon da - um die Nation hingegen muss gerungen werden.

Die Erzählung von Heimat ist bei Freytag somit nicht in eine Verlustgeschichte eingebettet. Es geht nicht um die nostalgische Erinnerung an etwas Verlorenes, wie in vielen anderen Heimatentwürfen des 19. Jahrhunderts, sondern um die historisch je eigene Realisierung einer vermeintlich anthropologischen oder eher, das gilt auch für den liberalen Freytag: einer spezifisch deutschen Grundkonstante. Für die eigene Gegenwart entwirft Freytag entsprechend in seinem Bestsellerroman Soll und Haben ein Modell von Heimat, das sich weder mit dem Ländlich-Regionalen noch mit einem Vergangenen oder Vermissten verknüpft. Heimat erscheint vielmehr als fortschrittsoptimistisches Modell bür-

auf Holz. Tatlock akzentuiert stärker die kulturelle Signifikanz des offenen Endes, vgl. Tatlock 2002, S. 101-102. Griffiths streicht heraus, es handele sich weniger um eine Flucht vor als eine Antwort auf die für Freytag enttäuschende Realität des Kaiserreichs. Vgl. Griffiths 2004, S. 40. Sohns versucht einen Neuansatz mit seiner Deutung, das ,fehlende Ende“ stehe für das Ende der historischen Repräsentation schlechthin. „Erinnerungs-, Erkenntnis- und Darstellungskrise erscheinen ineinander verschränkt. “ Sohns 2004, hier S. 232. Im jüngsten Beitrag zur Frage arbeitet Daniel Fulda den engen „Zusammenhang zwischen politischer Motivation und ästhetischen Instrumenten im nationalliberalen Historismus“ heraus. „Die Zukunft, in deren Dienst Freytags Erzählungen von der Herkunft durchweg stehen“ kann demnach nicht dargestellt werden, „obwohl sie beim Erscheinen des Romans keine Projektion mehr gewesen wäre, sondern schon eingetreten war“. Für die Frage des Verhältnisses von Vergangenheit, Gegenwart und Zukunft hätten demnach neue Antworten gefunden werden müssen, die der nationalliberale historische Roman insgesamt aber nicht bereitstellt. Alle Zitate Fulda 2016, S. 124-125. 
gerlich-kapitalistischer Ordnung und findet im Handelskontor seinen Ort (vgl. II.3.2.2).

\subsection{Heimat und Volkskunde}

Die Transformationen des Heimat(kunde)begriffs in Literatur und Pädagogik wären ohne den parallel sich etablierenden Heimatbegriff der Volkskunde nicht denkbar. Als akademische Disziplin 1919 mit dem ersten Lehrstuhl für Volkskunde an der Universität Hamburg endgültig anerkannt, wird der wissenschaftliche Status volkskundlicher Bemühungen schon sehr viel früher diskutiert. In den späten 1850er Jahren wird die Volkskunde erstmals als akademisches Fach eingefordert, und schon hier ist Heimat ein Schlüsselbegriff.

Die jüngere volkskundliche Forschung, die mit der neuen Ausrichtung des Fachs seit dem letzten Drittel des 20. Jahrhunderts und der damit einhergehenden Aufarbeitung der eigenen Geschichte entstanden ist, stellt die Frage nach dem Zusammenhang von Volkskunde und Heimat bisher noch nicht mit dem Nachdruck, der seiner historischen Bedeutung angemessen wäre. ${ }^{156}$ Allerdings lassen sich die zahlreichen volkskundlichen Forschungen zur Heimat, auch wenn sie nicht immer ausdrücklich auf die eigene Fachgeschichte eingehen, als indirekter Versuch einer fachlichen und terminologischen Neuverortung begreifen. ${ }^{157}$

156 Einen unkritischen Zugriff auf den Anteil des eigenen Fachs an der Entwicklung des Heimatbegriffs bietet das 1996 unverändert nachgedruckte Wörterbuch der deutschen Volkskunde von 1974 mit seinen Artikeln zu „Heimat“, „Heimatkunde, „Heimatmuseen“ und „Heimatschutz“, vgl. Oswald/Beitl 1996. Der historischen Aufarbeitung des eigenen Faches - damit aber auch der Idee von Volkskultur und Heimat - widmet sich dagegen Wolfgang Kaschuba (Kaschuba 1988; Kaschuba 2012). Zur österreichischen Fachgeschichte vgl. Jacobeit/Lixfeld/Bockhorn 1994; zur schweizerischen Fachgeschichte vgl. Schürch/Eggmann/Risi 2010.

157 Ein breites wissenschaftliches Interesse am Thema begründet, nach soziologischen Arbeiten von Wilhelm Brepohl (Brepohl 1952/53, Brepohl 1954, Brepohl 1965), vor allem die Volkskunde der 1960er Jahre (Bausinger 1961, Treinen 1965, Wiegelmann 1965) und die Kulturanthropologie der 1970er und frühen 1980er Jahre (Greverus 1972, 1979, 1982). Insbesondere die Tübinger Empirische Kulturwissenschaft hat sich dem Thema von den 1970er Jahren an bis heute intensiv gewidmet (Bausinger 1977, 1984, 1990, Scheer 2014). Nicht nur hier ist eine der Hauptfragen die Funktion der Heimat für territoriale Identitätsbildung (Bausinger 1980, 1982, 1986, 1999, Dürrmann 1994, Gmür 1997, Kaschuba 1979, Köstlin 1989, 1991, 1996, Stark 1992, Seifert 2014). Insgesamt dominiert deutlich ein Forschungsinteresse, das sich auf die je unmittelbare Gegenwart richtet, zuletzt unter den Vorzeichen von Regionalisierung (Schilling 1995), von Spät- und Postmoderne (Seifert 2010, Huber 1999), von Globalisierung (Daxelmüller 2003, Klose/Lindner/Seifert 2012, Köstlin 2002, Seifert 2011/2012, 2012, Tauschek 2005) und Migration (Binder 2008, Fischer 2013, Scheer 2014). Neuerdings gibt es auch wieder phänomenologische Ansätze, die das ,Heimatgefühl` als an- 
Die ,Väter der Volkskunde، werden, obwohl die Volkskunde terminologisch ihre Ursprünge in der aufklärerischen Statistik und Staatenkunde hatte (die Begriffe Volks- und Völkerkunde kommen um 1780 in diesem Kontext auf), meist um 1800 in diesem Sinn tätig: Herder mit seinem Aufruf zur Sammlung deutscher Volkslieder, die Grimms mit ihren vielfältigen Bemühungen um Märchen, Sagen und Volkslieder, auch Achim von Arnim und Clemens Brentano mit ihrer Volksliedersammlung Des Knaben Wunderhorn. Die Geburtsstunde des Fachs im engeren Sinn wird gewöhnlich in dem von Wilhelm Heinrich Riehl 1858 gehaltenen Vortrag „Volkskunde als Wissenschaft“ gesehen, worin der studierte Theologe die Grundzüge einer Volkskunde als wissenschaftliche Disziplin entwirft. ${ }^{158}$ Als Begründer der Volkskunde wird Riehl in den folgenden Kapiteln im Mittelpunkt der Frage nach dem Verhältnis von Volkskunde und Heimat stehen (II.3.2.1 und II.3.2.2). So wichtig die Impulse einzelner Männer wie Riehl waren, wichtiger noch im Zusammenhang mit der Entstehung der Volkskunde ist die Tatsache, dass sie auf eine breite, vornehmlich von einem heterogen professionalisierten Bildungsbürgertum (vgl. I.2.5) getragene Bewegung zurückgreift bzw. direkt aus ihr hervorgeht; sie lässt sich andererseits nicht von der Entstehung der Geschichtswissenschaft und hier insbesondere der Landesgeschichte ${ }^{159}$ trennen, die ebenfalls ihren Weg hin zur Professionalisierung über die Museumskultur und das Ver-

thropologische Konstante untersuchen (Klose 2013). - Zur Herkunftsgeschichte von Heimat aus volkskundlicher Sicht vgl. (Kaschuba 1979, Zimmermann 1991, Treiber 2015). Auf die rechtliche Dimension von Heimat gehen eine größere volkskundliche Arbeit zur Situation der Armen im Westfalen des 19. Jahrhunderts (Lerche 2009) und eine Arbeit zur Geschichte der sozialen Fürsorge in schleswig-holsteinischen Städten ein (Sievers/Zimmermann 1994).

158 Vgl. Kaschuba 1988.

159 Landesgeschichtliche Aktivitäten historischer Vereine gab es seit dem frühen 19. Jahrhundert; ein Verwissenschaftlichungsschub trat nach 1871 in diesen auf über 250 angewachsenen Vereinen mit dem Zuwachs ihrer Mitglieder im Bereich universitär ausgebildeter Fachhistoriker ein. Regionale Forschung wurde, beginnend 1876 mit der Historischen Kommission für die Provinz Sachsen, auch von den zahlreichen Historischen Kommissionen betrieben. Als eigene historische Disziplin begann sich Landesgeschichte mit der Einrichtung erster Lehrstühle am Ende des 19. Jahrhunderts zu etablieren. Schon für Karl Lamprecht (1856 -1915) heißt Landesgeschichte seit den 1890er Jahren die Analyse der „heimischen Zustände“ (zitiert nach Werner 2018, S. 5); sein Schüler Rudolf Kötzschke (1867-1949) leitete in diesem Sinn seit 1906 das „Seminar für Landesgeschichte und Siedlungskunde“ in Leipzig. Hermann Aubin (1885-1969) gründete 1920 ein landeskundliches Institut in Bonn, Adolf Herlbok (1883-1968) 1923 das Insitut für geschichtliche Siedlungs- und Heimatkunde der Alpenländer, viele weitere folgten in den 1920er und 1930er Jahren. Vgl. Werner 2018; zu Kötzschkes Beziehungen zum Heimatdiskurs vgl. auch Müller/Steber 2018, S. 654-655. 
einswesen nahm. ${ }^{160} 1852$ wird das Germanische Nationalmuseum in Nürnberg von Hans von und zu Aufseß gegründet, 1889 von Rudolf Virchow und anderen Mitgliedern der Berliner Anthropologischen Gesellschaft das Museum für deutsche Volkstrachten und Erzeugnisse des Hausgewerbes. ${ }^{161}$ Diese in Umfang und öffentlicher Aufmerksamkeit herausragenden Projekte sind ab Mitte des 19. Jahrhunderts begleitet von zahllosen kleinen Regionalsammlungen zur eigenen Geschichte und Kultur, gegen Jahrhundertende als Heimatmuseen bezeichnet. ${ }^{162}$ Neben solchen Sammeltätigkeiten publizieren viele Geschichts- und Altertumsvereine für das gebildete Publikum. Ab Mitte des 19. Jahrhunderts tauchen in diesen Veröffentlichungen volkskundliche Themen auf ${ }^{163}$ und der Begriff der Volkskunde findet in Vereinsnamen Verwendung ${ }^{164}$ - zeitgleich mit dem ersten Verein für ,Heimatkunde، ${ }^{165}$ Die Anzahl der Gründungen nun explizit so genannter volks- und heimatkundlicher Vereine und der von ihnen herausgegebenen Jahrbücher und Monatsschriften wird ab den späten 1880er Jahren unüberschaubar, ${ }^{166}$ wobei der Begriff der Volkskunde meist den der Heimat im Schlepptau führt und andersherum: Das Kränzchen für Gothaische Geschichte und Altertumsforschung (gegr. 1894) gibt die Blätter Aus der Heimat heraus, der Ba-

160 Einer der ersten dieser Vereine ist der 1822 gegründete Verein für Vaterlandskunde in Stuttgart. $\mathrm{Zu}$ diesen und folgenden Informationen zum Vereinswesen vgl. den sogenannten ,Vereinsmüller': Müller 1883-1917. Zur These der Vereine als Wegbereiter und direkten Einfluss ausübenden Partner der universitären Disziplin vgl. Brückner/Beitl 1983.

161 Die private Sammlung wird ab 1904 als „Königliche Sammlung für Deutsche Volkskunde“ Teil der Königlich Preußischen Museen zu Berlin und ab 1929 Teil des Staatlichen Museums für Deutsche Volkskunde.

162 Vgl. Roth 1990, S. 32-33. Die Vorgeschichte des Heimatmuseums ist kaum erforscht. Roth gibt nur einzelne Hinweise, sein Schwerpunkt liegt auf der Zeit ab der Weimarer Republik. Vgl. auch Ringbeck 1991; als zeithistorische Quelle vgl. Lehner 1928, S. 1-25.

163 Vgl. Rumpf 1992, S. 245.

164 Mit der Gesellschaft für Beförderung der Geschichts-, Althertums- und Volkskunde von Freiburg, dem Breisgau und den angrenzenden Landschaften erstmals 1866 in Freiburg/Brsg., vgl. Rumpf 1992, S. 246.

1651865 wurde ein Verein für Heimatkunde in Wittenberg und 1865 in Müncheberg gegründet; vgl. Müller 1883-1917.

166 Einen Überblick bietet Rumpf 1992; hier werden u. a. folgende Heimatschutzvereine für den Zeitraum 1886 - 1910 genannt: 1886 Verein für Orts- und Heimatkunde in der Grafschaft Mark mit Jahrbuch; 1890 Verein zur Pflege der Natur- und Landeskunde in Schleswig-Holstein, Hamburg und Lübeck mit Sitz in Kiel mit der Monatszeitschrift Die Heimat; 1897 Verein für Naturkunde an der Unterweser mit dem Jahrbuch Aus der Heimat - für die Heimat; 1902 Verein für ländliche Wohlfahrtspflege auf dem Lande, später Deutscher Verein für ländliche Wohlfahrt und Heimatpflege, mit der Schriftenreihe Wegweiser für ländliche Wohlfahrts- und Heimatpflege und der Buchreihe Bücherschatz des deutschen Dorfboten, in der u.a. Titel wie Vom Heimatacker. Geschichten eines hessischen Bauersmannes (21904) erscheinen. 
dische Verein für Volkskunde und ländliche Wohlfahrtspflege ab 1903 die Monatsblätter Dorf und Heimat, der Bayerische Verein für Volkskunst und Volkskunde 1912 die Schrift Bayerischer Heimatschutz und so weiter. ${ }^{167}$ In den Gründungstexten der wissenschaftlichen Volkskunde um 1900 wird immer wieder über die das Fach gefährdenden Dilettanten geklagt, ${ }^{168}$ teilweise aber auch anerkannt, dass das Fach auf diese angewiesen sei. ${ }^{169}$

Volks- und Heimatkunde ist vor allem Sache der gebildeten Laien, die Heimatmuseen und Vereine gründen und Heimat im Sammeln, Bewahren und Vermitteln erlebbar machen. Heimat ist in diesem Umfeld regelrecht als Summe von Praktiken zu verstehen. Es sind insbesondere unzählige Landschullehrer, die sich volkskundlich inspiriert mit Heimat beschäftigen. Symptomatisch ist etwa die Schrift Der Lehrer auf der Heimatscholle von dem bayerischen Volksschullehrer Hans Stieglitz, die sich als eine Anleitung versteht, wie der an einen neuen Wirkungsort versetzte Lehrer ,Heimatkunde، vor Ort betreiben soll. Das Buch wolle zeigen, ,wie es der Lehrer als Mensch und Lehrer anfangen kann, um auf der Heimatscholle wirklich daheim zu sein“170 - nicht primär ein Lehrinhalt, sondern vor allem ein Erfahrungsinhalt soll also vermittelt werden. Heimat ist hier eine Sache der Praxis, nicht der Theorie. Der Lehrer müsse sich selbst Heimat aneignen, indem er die Heimatgeschichte, die Sitten und Bräuche, die Natur und alles andere, was die unmittelbare Umgebung betreffe, erforsche und sinnlich erlebe Riehl wird als wichtigstes Vorbild genannt. ${ }^{171}$ Nur wenn der Lehrer selbst durchdrungen sei von Heimatliebe, könne er diese auch seinen Schülern vermitteln und damit die Grundlage für jegliches Lernen ausbilden.

Ziel dieser vielfältigen Bemühungen ist das Sammeln, Bewahren und Beschreiben von Erzeugnissen der eigenen Kultur, die zumeist als gefährdet und deswegen schutzbedürftig betrachtet wird. Dies drückt sich symptomatisch in den Komposita der ,Heimatpflege‘ und des ,Heimatschutzes‘ aus, die um die Jahrhundertwende im Umfeld volks- und heimatkundlicher Vereine aufkommen. Die sogenannte ,Heimatschutzbewegung“, deren Gründungsaufruf u.a. von dem Komponisten und Professor für Klavier Ernst Rudorff, von dem Volkskundler Robert Mielke (1914 habilitiert über ein volkskundliches Thema), von den Architekten Paul Schultze-Naumburg und Oskar Hossfeld und auch von vielen

167 Vgl. Rumpf 1992, S. 246.

168 Vgl. Karl Weinholds Aufsatz Was heißt Volkskunde?, der zuerst 1890 im 20. Jg. der Zeitschrift für Völkerpsychologie und Sprachwissenschaft erschien: Weinhold 1937, S. 11; ähnlich Eduard Hoffmann-Krayer in Die Volkskunde als Wissenschaft von 1902, vgl. Hoffmann-Krayer 1946, S. 1. 169 Vgl. Hoffmann-Krayer 1946, S. 1.

170 Stieglitz 1909, S. V.

171 Vgl. Stieglitz 1909, S. 25 und S. 32. 
Schriftstellern wie Heinrich Sohnrey, Peter Rosegger, Friedrich Lienhard, Ernst von Wildenbruch, Wilhelm Bölsche und Felix Dahn unterzeichnet wird, führt 1904 zur Gründung des „Bundes Heimatschutz“ als eines Dachverbandes der Heimatvereine mit schätzungsweise 100.000 Mitgliedern. ${ }^{172}$ Die Gründung reiht sich in eine gesamteuropäische Bewegung des Schutzes von Natur und Kultur vor den Auswirkungen der Industrialisierung und den durch sie bewirkten Transformationsprozessen ein. ${ }^{173}$

Ernst Rudorff, die zentrale Gründergestalt von 1904, ${ }^{174}$ veröffentlicht 1897 in den Grenzboten - aus der liberalen Zeitschrift unter Gustav Freytag und Julian Schmidt ist zu diesem Zeitpunkt schon lange eine ausgeprägt konservative geworden - verschiedene Beiträge, in denen die Heimatschutzbewegung als volkskundliche deklariert wird. ${ }^{175}$,Deutsche Heimat' und ,deutsches Volkstum sind für Rudorff unzertrennliche Größen, die im Verein geschützt und erhalten, oder, wo sie schon verloren gingen, zurückerobert werden müssen. ${ }^{176}$ Heimat ist

172 Als zeitgenössische Quelle vgl. Mielke 1906; zu neuerer Forschung vgl. Rumpf 1992, S. 252. Zur Rolle der Vereine im Kontext der Heimatbewegung im Kaiserreich vgl. Ditt 1990, S. 136-143. Das Programm des 1914 in Deutscher Bund Heimatschutz umbenannten Vereins wird hier beurteilt als „eine gegenwarts- und zukunftsorientierte kulturpolitische Konzeption aus neoromantischem Geist. Damit gehörten die Heimatvereine zu der breiten Reform- und Erziehungsbewegung, die in Gestalt von Dürerbund, Körperkultur-, Bodenreform-, Naturheilkunde- und anderen Vereinen seit der Jahrhundertwende in Reaktion auf die Kulturkrise entstand." Ditt 1990, S.141. Ditt schlägt von der Jahrhundertwende um 1900 den historischen Bogen bis zur Eingliederung der regionalen Heimatbünde in die sogenannten ,Gauheimatwerke' der NSDAP, vgl. Ditt 1990, S. 152. Zu den Verbindungslinien von Heimatschutzbewegung und Nationalsozialismus vgl. auch Koshar 1996. Willi Oberkrome verfolgt Heimatkonzepte in Naturschutz und Kulturpolitik von 1900 bis in die 1960er Jahre in Ost und West, vgl. Oberkrome 2004.

1731895 wurde der National Trust for Places of Historic Interest or Natural Beauty in England gegründet, 1901 die Societé pour la Protection des Paysages de France in Frankreich, 1909 fand der erste internationale Heimatschutzkongress in Paris statt, 1912 der zweite in Stuttgart. Vgl. Sieferle 1985, S. 40 und Scharnowski: Heimat, 2019, S. 75. Zur gesamteuropäischen Perspektive vgl. auch Mai 2006.

$174 \mathrm{Zu}$ Rudorff als Protagonist der Heimatschutzbewegung vgl. Rollins 1996.

175 „Dem Pfarrer Hansjakob in Freiburg im Breisgau ist es gelungen, einen Verein zur Erhaltung der Volkstrachten ins Leben zu rufen, der offenbaren Erfolg aufzuweisen hat. Seine Schrift über diesen Gegenstand enthält eine Fülle goldner Worte. Von der Volkstracht aber zu den überkommnen Sitten und Gebräuchen des Volkes und zu volkstümlicher Bauart, deren Wiederbelebung die unerläßlichste Forderung ist, wenn von der Eigenart deutschen Landes überhaupt noch die Rede sein soll, ist nur ein Schritt.“ Rudorff 1897, S. 468. Vgl. auch Knaut 1991.

176 „Keine einzige Vereinigung aber würde in ihrer Bedeutung schwerer wiegen, ist dringender nötig als eine Zusammenscharung aller Gleichgesinnten, denen es darum zu thun ist, deutsches Volkstum ungeschwächt und unverdorben zu erhalten, und was davon unzertrennlich ist, die 
bei Rudorff die Grundlage jeder deutschen Kultur, ,Heimatschutz‘ ist ihre Verteidigung gegen die sozialen Fliehkräfte der sich industrialisierenden Gesellschaft:

Es ist bezeichnend, daß die Vaterlandslosigkeit fast ausschließlich in den Fabrikbezirken großgezogen wird. Was giebt es auch an vaterländischen Gütern besondres zu schützen, wofür das Leben einzusetzen wäre, wenn jede Eigenart der Heimat in ihrem landschaftlichen und geschichtlich gewordenen Charakter, jede Volkstümlichkeit und Besonderheit in Wesen, Sitte und Erscheinung vertilgt wird? ${ }^{177}$

Rudorff geht es nicht nur um ein sammelndes und archivierendes Verhältnis zur Heimat, sondern darum, ihr Verschwinden aufzuhalten: Er wendet sich gegen die Begradigung der Flüsse und der Felder, gegen die Abholzung der Alleebäume, gegen die restlose Erschließung der Wälder für Forstwirtschaft und Tourismus, setzt sich für den Erhalt und die Wiederbelebung älterer Kulturlandschaften, Wirtschaftsmethoden und Bauweisen ein - später wird Letzteres in der sogenannten Heimatschutzarchitektur Paul Schultze-Naumburgs seine Fortsetzung finden. ${ }^{178}$ Trotz der sehr konkreten Ansätze dieses frühen Naturschutzes (die Rudorff mit dem Kauf von bedrohtem Land auch tatsächlich im Kleinen umgesetzt hat ${ }^{179}$ und der ausführlichen Erörterung so pragmatischer Fragen wie der nach „Verkoppelung und Gemeinheitsteilung“ und anderen Maßnahmen in der Landwirtschaft ist bemerkenswert, dass in den Texten Rudorffs nicht die Natur um ihrer selbst willen als schützenswert erscheint. Vielmehr ist der Naturschutz nur Teil eines größeren Kampfes gegen Materialismus und für Heimat als Ausdruck aller „Güter des Gemüts und des Geistes“. Heimatschutz sei der Aufruf gegen eine materialistische Gesinnung, die „das Gefühl für das, was wir in dem Wort ,Heimat“ zusammenfassen, vernichten will“. ${ }^{180}$ Heimat impliziert einen ideellen Überbau, der weit über die Idee des Naturschutzes hinausgeht. Letztlich

deutsche Heimat mit ihren Denkmälern und der Poesie ihrer Natur vor weiterer Verunglimpfung zu schützen. Denn hier und nirgends anders liegen die Wurzeln unsrer Kraft.“ Rudorff 1897, S. 466. 177 Rudorff 1897, S. $466-467$.

178 Zur Illustration der ambivalenten Bewertung der Heimatschutzarchitektur in der Gegenwart verweist Christiane Nowak auf die Diskussion um den Begriff der Moderne, den die Ausstellung Moderne Architektur in Deutschland 1900 bis 1950. Reform und Tradition auslöste. Der Kurator Vittorio Magnago Lampugnani hatte hier auch Bauprojekte im Umfeld der Heimatschutzbewegung von Heinrich Tessenow und Paul Schultze-Naumburg präsentiert, deren Rückgriff auf traditionelle Bauformen unter den Bedingungen moderner Produktionsbedingungen er ebenfalls als Antworten auf die Herausforderungen der Moderne begriff, stieß damit aber auf heftige Kritik. Vgl. Nowak 2013, S. 20-21. Zum Zusammenhang von Heimat und Architektur vgl. auch Umbach/ Hüppauf 2005.

179 Rudorff selbst äußert sich dazu: Rudorff, Abermals zum Heimatschutz, 1897, S. 113.

180 Rudorff, Abermals zum Heimatschutz, 1897, S. 115. 
geht es Rudorff zufolge um den Erhalt der ,Schöpferkraft' eines ganzen Volkes: „Fahren wir fort, so zu wirtschaften, wie bisher, so werden wir bald ein ausgelebtes Volk sein, dessen religiöses Empfinden samt allen übrigen Kräften des Gemüts verdorrt oder verflacht, das keines geistigen Aufschwungs mehr fähig ist [...].“ Keine „wahrhaft schöpferische Persönlichkeit“ könne das Volk unter solchen Bedingungen mehr hervorbringen. ${ }^{181}$ Die metaphorisch verstandene Gesundheit des Volkes lässt sich nicht an einem gesunden Wald messen, wie Rudorff es durch Analogiebildung suggeriert, sondern nur an einem ideellen Maßstab. In unzähligen volkskundlichen Arbeiten um 1900 findet sich die gleiche Argumentationsfigur: Heimat steht für Gesundheit und gesund ist das Ländliche, krank das Städtische, gesund der Bauer, krank der Städter vom Arbeiter über den Feuilletonisten bis zum Spekulanten. Oder: Gesund das einfache Volk, krank die Gebildeten, wie beim klassischen Philologen und Volkskundler Albrecht Dieterich:

\footnotetext{
Wenn wir alle, die Gebildeten und Gebildetsten, wieder fühlen könnten, daß wir zum Volke mit Leib und Seele gehören, daß das Volk unserer Heimat Fleisch ist von unserem Fleisch, Blut von unserem Blut, dann fühlten wir es auch, daß aus dem Heimatboden und dem Heimatvolke jedem Sproß dieser Heimat neue gesunde Kraft kommt: allein von unten in diesem Sinne konnte von je nur gesunden die krank gewordene Bildung. ${ }^{182}$
}

Dieterichs in religiöse Metaphorik gekleidete Vorstellung, Heimat versöhne die gespaltene Gesellschaft, lasse das deutsche Volk gesunden, ist zentral für die Rede über Heimat um 1900: Heimat wird, wie bei Rudorff oder Dieterich, als spirituelle Kraftquelle der Deutschen aufgefasst und an einen Prozess der Gesundung gebunden.

„Heimatliebe‘ soll der Kitt für die auseinanderdriftenden Gesellschaftsschichten sein. Die „nationalste und zugleich sozialste Aufgabe der Volkskunde“ sei es, so Dieterich, „den Riß zwischen Volk und Gebildeten, zwischen den

181 Beide Rudorff 1897, S. 466- 467.

182 Dieterich 1902, S. 3-4. Zum Begriffspaar, gesund - krank' als Wertungskriterium im Umfeld von Heimatschutz und Heimatkunst um 1900 vgl. Rossbacher 1975, S. 52-56 sowie mit weiteren Literaturverweisen das Kapitel dieser Studie zu Adolf Bartels. Heimat verbindet sich in diesem Kontext mit Gesundheit, Vitalität und Kraft - und auch schon um 1900 mit dem ,Blut ${ }^{\star}$ - speziell des deutschen ,Volkes', wie ein Zitat des einflussreichen Reformkatholiken, Langbehn-Apologeten und späteren Herausgebers der Zeitschrift Hochland Carl Muth veranschaulichen kann, der „die frische, unverbrauchte Kraft unseres Volksthums, die stillnährende Poesie unserer deutschen Heimatherde und die Erinnerung an jene hehren Sonn- und Feiertage unseres Nationallebens [...], da aus den herrlichsten Söhnen unseres Blutes die reckenhafte, frische, stählerne und gesunde Urwüchsigkeit des deutschen Genius sprach“, als die Garanten zukünftiger deutscher Kunst erkennen will. Muth 1893, S. 366. 
Ständen eines Volkes zu mildern“. ${ }^{183}$ Dieser Riss lasse sich durch Heimatliebe überwinden:

Die treue und ehrliche Liebe zur engsten Heimat, deren Boden und Bäume und Wege und Wiesen und Menschen uns teuer sind, ist die tiefste und festeste Wurzel echter Vaterlandsliebe, fester als manches Nationalbewußtsein, das manchem wandernden Bureaukraten, dem weder Ost noch West eine Heimat ward, ein jammervoll abstraktes Ding geworden ist, und seinen Kindern, die nirgends von Herzen zu Hause sind, noch viel blasser und schemenhafter überliefert wird. ${ }^{184}$

Viele Vertreter der Volkskunde verstehen ihre Arbeit genau wie die ihrer ,dilettantischen' Schwester, der Heimatschutzbewegung, als aktiven Beitrag zum Prozess dieser ,Gesundung‘. Volkskunde sieht sich aus dieser Perspektive als gesellschaftliche Kraft, die Antworten auf die Moderne geben, Gesellschaft mitgestalten will. Heimat ist das Schlüsselwort dieses alles andere als wertfreien Wissenschaftsverständnisses. Nicht nur mit Blick auf Rudorffs ,Heimatschutz', auch mit Blick auf die Ansätze mit dezidiert wissenschaftlichem Anspruch kann diese aktive Gestaltungsfunktion als weiteres zentrales Element der Rede über Heimat gelten. So spricht etwa der Volksökonom und Volkskundler Robert Wuttke 1909 davon, dass es der ,innerste Kern“ von Volkskunde und Heimatschutz sei, „eine Gegenströmung gegen den Industrialismus“ $\mathrm{zu}$ sein. ${ }^{185}$ Und der Theologe Paul Drews, der Begründer der ,Religiösen Volkskunde‘, geht davon aus, dass „die Pflege der Religion ohne eine ,kirchliche Heimatpflege“ nicht möglich“ sei und dass es daher „bodenständiger Pfarrer“ bedürfe. ${ }^{186}$

183 Beide Zitate Dieterich 1902, S. 4.

184 Dieterich 1902, S. 4.

185 „Volkskunde wie Heimatschutz arbeiten auf das gleiche Ziel hin: die von unseren Vorfahren geschaffenen Werte zu schätzen. [...] Es muß davor gewarnt werden, daß wir die volkstümliche alte Habe industriell in der Gegenwart verwerten und damit entwerten. Die Liebe zu der Vergangenheit soll geweckt werden, nicht aber die Nachahmung vergangener Formen. Gerade in dem Gegensatz des jederzeit wirtschaftlich Verwertbaren, mit dem Erhalten des Überlieferten liegt die Bedeutung der Volkskunde und des Heimatschutzes. Diese bedeuten in ihrem inneren Kern eine Gegenströmung gegen den Industrialismus.“ Wuttke 1909, S. 176.

186 So Paul Drews in seinem Artikel zur ,Religiösen Volkskunde‘ im RGG (Die Religion in Geschichte und Gegenwart. Handwörterbuch in gemeinverständlicher Darstellung) von 1913, hier zitiert nach Drews 2016, S. 387-393, hier S. 393. Religion und Volkskunde sind Anfang des 20. Jahrhunderts eng verknüpft. Zur durch Heinrich Sohnrey mitinitiierten Dorfkirchenbewegung und weiterer Zusammenhänge von Volkskunde und evangelischer Theologie vgl. Treiber 2004. Der Artikel zu ,Heimatkunst“ in der zweiten Auflage des RGG von 1928 sieht die Kirche in der Pflicht, im Schulterschluss mit der Volkskunde Heimat zu pflegen und zu erhalten: „Schon die Verwandtschaft der Pietät mit der Religion und das darin beschlossene Gemeinschaftsband zieht die Kirche zur Pflege der H. Auch hat jedenfalls die evg. Kirche Heimatboden vor allem in dem 
Als drittes zentrales Element der Rede über Heimat um 1900 gilt für den Wissenschaftsdiskurs der Volkskunde genauso wie für den pragmatisch orientierten Heimatschutz, dass Literatur sehr häufig eine legitimatorische Funktion für die Rede über Heimat übernimmt. Die Programmatik des Heimatschutzes Ernst Rudorffs etwa - der selbst auch literarisch tätig war ${ }^{187}$ - beglaubigt ihren Gegenstand maßgeblich über literarische Texte. Schon als Motto seiner Programmschrift Heimatschutz von 1897 wählt er Verse Friedrich Rückerts: „Die Welt ist rauh und dumpf geworden, / Die Stimm' entfiel ihr nach und nach, / Die einst in tönenden Akkorden / Zum off'nen Ohr des Menschen sprach. "188 Die Verse sind dem Gedicht Zum Schluß entnommen, das eine Abstiegsgeschichte des menschlichen Weltverhältnisses erzählt. Darin erweist sich die ursprüngliche Beziehung von Mensch und Welt als vollendet harmonische: „Die Brust ein Spiegel ungetrübet / Gefühl ein reiner Widerhall / Gesang durch keine Kunst geübet, / Der Dichter eine Nachtigall“. Diese Ganzheit in „,jenen goldnen Tagen“189 wandelt sich unter Einfluss des Verstandes in einen von Kampf, Leidenschaft, Zerstörung geprägten Weltbezug, innerhalb dessen der Dichter unter Qualen um Ausdruck ringen muss.

Interessant ist, dass hier dezidiert ein literarischer Text an die Spitze einer Programmatik der Heimatliebe und des Heimatschutzes gesetzt wird und dass dieser eine Ursprungs- und Verlustgeschichte erzählt, wie sie schon in der romantischen Begriffsbildung von Heimat enthalten ist (vgl. II.1.2). Der romantische Vorbehalt gegenüber der Wiederherstellbarkeit solcher Ursprungsphantasien wird dabei übersehen, wie sich dann im weiteren Verlauf des Textes erweist. Rudorffs beglaubigt seine Ausführungen durch fast ausschließlich der Romantik entnommene literarische Zitate: Mit Uhland, Schwab und Eichendorff, Tieck, Arnim und Brentano wird eine Heimat beschworen, die es so nicht mehr gebe und damit angenommen, die romantischen Dichter hätten eine Realität der Hei-

Lebenskreis, den die H. widerspiegelt. Sie hat Bundesgenossen in dieser Arbeit in den Bestrebungen der Volkskunde, Ortsgeschichte, Sittengeschichte, Sagenkunde, (Natur-)Denkmalpflege, Heimatmuseen, dem Volksbildungswesen; die Dorfkirchenbewegung geht sie unmittelbar an, und das Laienspiel sowie die neue Singbewegung haben Beziehungen zu ihr. Die kath. Kirche hat in ihren Diözsanmuseen, die die heimische Kirchenkunst der Vergangenheit sammeln, eine bemerkenswerte Einrichtung getroffen." Günther 1928, Sp. 1768.

187 So Paul Schultze-Naumburg in seinem lobenden Vorwort zur Neuauflage von Rudorffs Texten (1926). Rudorff sei in Einigem romantisch, übertrieben und überholt und müsse an die Zeitforderungen angepasst werden. Vgl. Paul Schultze-Naumburg: Vorwort, in: Rudorff 1928.

188 Rudorff 1897, o.S.; wiedergegeben sind hier Teile von Friedrich Rückerts Gedicht Zum Schluß. 189 Alle Zitate Rudorff 1897, o.S. 
mat abgebildet, die $\mathrm{zu}$ ihrer Zeit noch existiert habe. ${ }^{190}$ Es werden auch Verse Hoffmann von Fallerslebens ${ }^{191}$ und immer wieder Eichendorffs ${ }^{192}$ zitiert. Auch sonst spielt Literatur eine wichtige Rolle für die Programmatik Rudorffs, allerdings nur deren vermeintlich volksnahe Varianten. So wird das „echte, treuherzige Volkslied“ in drastischen Worten gegen die Operettenmelodie gehalten, die „das Gift der Entsittlichung in das Volk“ trage. ${ }^{193}$ Und Beispiele für die ursprüngliche Heimatliebe des einfachen Volkes entnimmt Rudorff den Texten der Schriftsteller Heinrich Hansjakob und Peter Rosegger, ohne die Belegkraft solcher Verweise zu reflektieren. ${ }^{194}$ Andererseits zeigen Schriftsteller wie Wilhelm von Kügelgen, die über Heimatliebe spötteln, aus Rudorffs Perspektive nur, dass sie sich dem „Empfindungsleben des Landvolks“ entfremdet haben. ${ }^{195}$ Die Dichtung ist Rudorff auch Beleg, dass Heimatliebe etwas spezifisch Deutsches sei. ${ }^{196}$

Auch die wissenschaftliche Volkskunde ist ohne ihren Bezug zur Dichtung nicht zu denken: Karl Weinhold, der Herausgeber der Zeitschrift des Vereins für Volkskunde, zählt die Poesie und insbesondere die Volkspoesie zu den natürlichen Gegenständen der Volkskunde, ${ }^{197}$ genauso der Schweizer Volkskundler Eduard Hoffmann-Krayer. ${ }^{198}$ Hoffmann-Krayer verwendet, wie zahlreiche weitere Volkskundler, insbesondere die literarischen Texte Jeremias Gotthelfs als

190 „Was ist aus unserer schönen, herrlichen Heimat mit ihren malerischen Bergen, Strömen, Burgen und alten Städten geworden, seitdem sie Dichter wie Uhland, Schwab und Eichendorff zu unvergänglichen Liedern begeistert, seit Ludwig Tieck, Arnim und Brentano die Wunderwildnis des Heidelberger Schlosses gepriesen haben!“ Rudorff 1897, S. 401.

191 Rudorff 1897, S. 407; vgl. auch: „Und der Winter war vergangen, / Und der Sommer ging herum, / Und es zog mich heiß Verlangen / Nach der Heimat wiederum.“ Rudorff 1928, S. 34-35. 192 Rudorff 1897, S. 456.

193 Beide Zitate Rudorff 1897, S. 466.

194 Vgl. Rudorff, Abermals zum Heimatschutz, 1897, S. 116.

195 „Und wenn Kügelgen in seinen Jugenderinnerungen von einer braven esthnischen Dienstmagd berichtet, die mit seiner Familie von Esthland nach Dresden übergesiedelt war, schließlich aber, trotz aller Annehmlichkeiten, trotz aller Güte und Freundlichkeit, die sie dort erfuhr, und obwohl ihre sämtlichen Angehörigen in der Heimat gestorben waren, dennoch vom ,Bohrwurm ihres Heimwehs‘ getrieben nach dem ,wilden, unfruchtbaren, abgelegnen‘ Lande ihrer Jugend zurückkehrte, so beweist der spöttelnde Ton, in dem er das vorträgt, nur, daß in der Bauernmagd ein tieferes, innigeres Heimatsgefühl steckte, als in dem gebildeten Allerweltsstädter, der das Empfindungsleben des Landvolks zu verstehen verlernt hatte.“ Rudorff, Abermals zum Heimatschutz, 1897, S. 116.

196 „Es ist nicht ohne Grund, wenn kein Volk der Erde Dichter der Landschaft, der Naturempfindung aufzuweisen hat von solcher Kraft und Innigkeit wie das deutsche.“ Rudorff, Abermals zum Heimatschutz, 1897, S. 116.

197 Vgl. Weinhold 1937, S. 13. Zu Weinhold vgl. Kaschuba 2012, S. 47-48.

198 Vgl. Hoffmann-Krayer 1946. 
Grundlage ihrer Forschung. ${ }^{199}$ Bei Albrecht Dieterich steht der Bezug auf die Dichtung darüber hinaus unter dem Vorzeichen seines Heimatverständnisses (s.o.), wenn er die Überwindung der Trennung von höheren und unteren Schichten, „die keinen Mittelpunkt mehr“ hätten, als Aufgabe der Volkskunde ansieht. Die Volkskunde solle sich hierbei die Dichtung zum Vorbild nehmen: „An der Verschmelzung der beiden Mittelpunkte arbeite die Dichtung nun schon lange; die Wissenschaft beginne damit“, zitiert Dieterich zustimmend den Germanisten Rudolf Hildebrand, den er als „Meister der echten Volkskunde“ ${ }^{\text {200 }}$ verehrt. Die von Dietrich so bezeichnete Wiederentdeckung der Volkspoesie im 18. Jahrhundert ist ihm Keimzelle der Literatur und der Philologie; die herausragende Rolle Jacob und Wilhelm Grimms für die Entstehung der Volkskunde aus dem Geist der philologischen Beschäftigung mit der Volkspoesie wird gewürdigt. $^{201}$

Wilhelm Heinrich Riehls Mitte des 19. Jahrhunderts entstandene Schriften stellen den Ausgangspunkt dieses wissenschaftlichen Verständnisses von Heimat in den hier skizzierten Positionen der Volkskunde um 1900 dar. Diese Schriften, ohne die auch zahlreiche literarische Produktionen der zweiten Jahrhunderthälfte nicht zu denken wären, sollen nun näher betrachtet werden.

\subsubsection{Riehls volkskundliche Heimat}

Den studierten Theologen Wilhelm Heinrich Riehl (1823-1897) prägten die Vorlesungen von Ernst Moritz Arndt am historischen Seminar der Universität Bonn mehr als die theologischen. ${ }^{202}$ Und statt eine Dorfpfarre zu übernehmen, betätigt er sich seit 1841 schriftstellerisch und journalistisch. 1854 wird er (ohne Promotion und Habilitation) Honorarprofessor, 1859 ordentlicher Professor für Staatswissenschaft und Kulturgeschichte in München und Herausgeber der Bavaria - einer fünfbändigen Landes- und Volkskunde des Königreiches Bayern (1860 - 68) -, 1885 Direktor des Bayerischen Nationalmuseums und Generalkonservator der Kunst-

199 Hoffmann-Krayer 1914. Es handelt sich hierbei um eine Stellensammlung aus Gotthelfs Roman Bauernspiegel und seiner Erzählung Wie fünf Mädchen im Branntwein jämmerlich umkommen. Zur Rolle von Gotthelfs Werk für volkskundliche Untersuchungen u.a. bei Karl Geiser und Albert Brüschweiler vgl. Mettenleiter 1974, S. 195.

200 Alle Zitate Dieterich 1902, S. 4-5.

201 Vgl. Dieterich 1902, S. 10-12.

202 So Viktor von Geramb in seiner ausführlichen, allerdings hagiographischen Biographie, vgl. Geramb 1954. Zur jüngeren Forschungsliteratur zu Riehl vgl. Applegate 1990; Altenbockum 1994; Lövenich 1992; Mollenhauer 2002; Zinnecker 1996. 
denkmäler und Altertümer Bayerns. Seine Karriere beruht auf der vierbändigen Naturgeschichte des Volkes als Grundlage einer deutschen Socialpolitik (18511869). In einer neuartigen Verbindung aus geographischen, kulturgeschichtlichen, alltagskulturellen und soziologischen Studien will Riehl das ,deutsche Volk ${ }^{*}$ erforschen, das er als individualisierbare, leibliche Einheit betrachtet, als „Organismus einer ganzen Volkspersönlichkeit“. ${ }^{203}$ Das aus Landschaft, Geschichte, Lebenswelt und Milieu destillierte Spezifikum dieses Volkskörpers erklärt Riehl zum Fundament der sozialpolitischen Neuordnung der Gesellschaft. Die große Popularität von Riehl in der gebildeten Öffentlichkeit - er hielt an die 500 Vorträge vor geschätzt 180.000 Zuhörern ${ }^{204}$ und seine Naturgeschichte erreichte hohe Auflagen - basiert auf mehreren Aspekten. Alle hängen mit seiner Auffassung des Heimatbegriffs zusammen.

\section{Narrative des Natürlichen}

Riehl erklärt in seinem Vortrag Volkskunde als Wissenschaft das ,Volk‘ zum Zentrum eines neuen wissenschaftlichen Erkenntnisinteresses. ${ }^{205}$ Auch für den Nationaldiskurs, um den es vordergründig gar nicht geht, ist das Jahr des Vortrags, 1858, ein wichtiges Datum. Denn zwischen der Rede von ,Nation“ und der von ,Volk ${ }^{`}$ besteht ein wichtiger Unterschied: Die Nation ist eine politische Einheit, das Volk ein anthropologisch aufgefasstes Kollektiv (vgl. I.2.2). Riehl ersetzt mit seiner Idee des Volkes zehn Jahre nach den politischen Bewegungen von 1848 die politische Idee der Freiheit des selbstbestimmten Individuums durch die Idee der naturwüchsigen Gemeinschaft. Heimat wird in diesem Zusammenhang als zwar regional divergierend, aber zugleich als nur eine von vielen zusammengehörigen deutschen Heimaten verstanden.

Riehl macht mit dieser Bestimmung der spezifischen Heimat als Teil des gesamtnationalen Ganzen auch ein Angebot, den ,deutschen Sonderweg‘ positiv zu deuten, und wird so zu einem der Wegbereiter einer zentralen Selbstbeschreibung der Deutschen. Heimatverbundenheit wird von Riehl als unterschiedlich ausgebildet beschrieben, je nach Region komme es zu großen Differenzen. ${ }^{206}$ Er grenzt

203 Riehl 1859, S. 215.

204 „Bis 1885 hatte er während 14 Jahren in 487 Wandervorträgen und 106 deutschen Städten über 112 verschiedene Stoffe vor 180.000 Zuhörern gehandelt.“ Nadler 1928, S. 452. Nadler schreibt in seiner Literaturgeschichte über Wilhelm Heinrich Riehls Kulturgeschichte der Deutschen, sie habe beispiellos auf das Selbstbewusstsein des deutschen Bürgertums gewirkt.

205 Vgl. Riehl 1859, S. 206. Zum Volksbegriff bei Riehl vgl. Mollenhauer 2002.

206 Vgl. Riehls Schrift Land und Leute von 1853, hier zitiert nach der dritten Auflage 1856. Hier spricht er beispielsweise vom „Heimathsgefühl und Heimathsstolz des Westerwälders“ (Riehl 
sie aber vom politischen Partikularismus ab, deutet sie vielmehr als natürlichen, vorpolitischen, gleichsam kindlichen Gefühls- und Bewusstseinszustand, der nicht notwendig vom Bewusstsein eines Zusammenhangs mit dem größeren Ganzen begleitet sein muss, gleichwohl aber in diesem Zusammenhang steht. ${ }^{207}$ Die notwendige Verbindung eines so verstandenen ,natürlichen' Partikularismus (Riehl unterscheidet „naturwidriges Sondergelüste“ und „naturnotwendige Besonderung“(208) mit der zwingend daraus hervorwachsenden nationalen Einheit leitet Riehl aus der spezifisch deutschen politischen Situation ab. In der Ausbildung des Regionalbewusstseins, wie es Riehl mit seinen volkskundlichen Studien zu einzelnen Orten und Landstrichen befördern will, liegt nach seiner Meinung zugleich der Schlüssel für das Selbstbewusstsein, ja die Lebensfähigkeit der Nation.

\section{Sozialpolitik und Ethik}

Die Aufgabe der Volkskunde sieht Riehl nicht nur im Beschreiben, sondern im ,Erhalten' und ,Weiterbilden' des ,Volkslebens', also einer aktiven Mitgestaltung von Gesellschaft. Seine Studien versteht er auch als sozialpolitische Handlungsanweisungen für die brennenden gesellschaftlichen Probleme seiner Zeit. Die Bewahrung von Heimat, die Besinnung auf die hergebrachte ständisch gegliederte Gesellschaft und patriarchalische Familienmodelle kennzeichnen den vom Zeitgenossen Paul Heyse als ,reaktionär` eingeschätzten - zugrundeliegenden Gesellschaftsentwurf. Heyse schreibt rückblickend:

Damals hatte Riehl eben erst seine reiche Arbeitskraft entfaltet und große Erfolge gehabt. Seine Bücher über ,Die Familie‘, „Die Arbeit', ,Land und Leute‘, ,Die Pfälzer‘ waren so voll geistreicher Paradoxen [sic], so reich an charakteristischen Zügen und so farbig im Stil, daß auch wir sie aufrichtig bewunderten und gern über gewisse ,reaktionäre‘ Tendenzen darin hinwegsahen. Wohl wurden auch wir bald inne, wie wenig diese Bücher des Volkswirtschaftslehrers zur Lösung der schweren sozialen Probleme beitrugen, die damals die Zeit zu bewegen anfingen. Sein Ideal einer ,Familie' paßte nicht in die von so ganz anderen, freieren Bedürfnissen erfüllte, an Verkehrsmitteln reichere Gegenwart hinein. Und wer von der ,Arbeit' im Grunde nicht viel mehr zu sagen wußte, als daß sie einen sittlichen Wert habe, war nicht dazu geeignet, in die moderne Bewegung der breiten Volksschichten einzugreifen. ${ }^{209}$

1856, S. 237). Das „süddeutsche“ Volk habe in Abweichung von anderen Regionen ein „fröhliches Heimatbewußtsein“ (Riehl 1856, S. 151). Nord- und Süddeutsche hätten einen ausgeprägteren „Heimatstolz“ (Riehl 1856, S. 170) als Mitteldeutsche; dies erklärt Riehl ausführlich unter Rückgriff auf geschichtliche Zusammenhänge (vgl. Riehl 1856, S. 170).

207 Vgl. Riehl 1856, S. 213-214.

208 Beide Zitate Riehl 1856, S. 304.

209 Heyse 1912, S. 222. 
Während Marx und Engels schon 1848 im Kommunistischen Manifest die Entstehung des Vierten Standes als Produkt ökonomischer Prozesse analysieren, hält Riehl 1855 die soziale Ungleichheit für ein Naturgesetz und deren zeitgenössische Auswüchse für selbstverschuldet ${ }^{210}$ - und vor allem: für reversibel. Die soziale Desintegration des Proletariats bezeichnet er mehrfach als ,Heimatlosigkeit“, der durch die Rückbesinnung auf familiärere Arbeitsverhältnisse entgegengearbeitet werden müsse, „damit der proletarische Arbeiter in dem beschränkten Kreise dieser Familie das finde, was er in dem Phantasiebild der socialistischen Familie der Menschheit vergeblich sucht“. Gelinge es der Fabrik, nach Vorbild der alten zünftigen Werkstatt, Heimat für den Arbeiter zu schaffen, werde auch der ,vaterländische Boden' nicht vergessen, auf dem sich diese Heimat befinde. Der Fabrikarbeiter sei ,in der Regel familienlos [...], heimathlos“. Es gelte deswegen,

ihm allmählich eine Geschichte zu schaffen, eine Heimath, eine sociale Schranke, und das alles findet sich von selber, wenn man ihm eine Familie schafft, nicht eine solche Familie, wie er sie wohl öfters leider besitzt, nämlich ein hungerndes Weib und verkümmernde Kinder, sondern ein Familienbewußtseyn, wie es auch der Handwerksbursche besitzt, der darum doch nicht mit Kindergeschleppe durch die Welt zieht.

So wie der Handwerksbursche ein Stück Heimat in der Werkstatt und Familie seines Meisters finden könne, müsse auch die Fabrik diese Form der sekundären Beheimatung bieten:

Der ewige Handwerksbursche [...] wandert freilich heimathlos von Land zu Land, aber überall findet er in der Familie seines Meisters auch für sich ein Stück Familienleben wieder und in jeder Werkstatt ein Stück Heimath. Er vergißt darüber doch seinen ursprünglichen vaterländischen Boden nicht [...]. Wenn dieses genossenschaftliche Leben der Familie auch in jeder Fabrik heimisch würde, dann könnte der Fabrikarbeiter nicht mehr um deßwillen proletarisch werden, weil er keine Familie, kein Vaterland, keine Geschichte besitzt. ${ }^{211}$

210 Vor allem im Ausland radikalisiere sich das deutsche Proletariat: „Die Auswanderung ganzer Massen verkommener Leute nach außerdeutschen europäischen Hauptstädten wirkt gar traurig auf die Heimath zurück. Diese Verstoßenen sind die Dolmetscher, welche die Theorien der auswärtigen Social-Demokraten dem gemeinen Manne in Deutschland erst verdeutscht haben." So Riehl in Die bürgerliche Gesellschaft von 1851, hier zitiert nach der dritten Auflage: Riehl 1855, S. 342-343. Entgegen der nachträglichen Systematik der vierbändigen Naturgeschichte des Volkes, zu der Land und Leute (als Teil 1), Die bürgerliche Gesellschaft (als Teil 2), Die Familie (als Teil 3) und Das Wanderbuch (als Teil 4) gehören, erschien Die bürgerliche Gesellschaft chronologisch zuerst (1851). Auch in Die Familie ist die Auswanderung für Riehl ein „heimathliches Unglück“, das Volk fliehe vor sich selbst. Riehl 1862, S. 284.

211 Alle Zitate Riehl 1855, S. 350-351. 
Heimat steht in Riehls Sprache für gelungene soziale Integration in die bürgerliche Gesellschaft, eine Gesellschaft indes, die er in ihrer Existenz gefährdet sieht. Riehl analysiert diese Gefährdung vor dem Hintergrund seines sich am vorindustriellen Zeitalter orientierenden Gesellschaftsmodells und will mit der Volkskunde ein Gegenmittel zur Verfügung stellen. Er versteht die Volkskunde als gesellschaftlich wirksame Wissenschaft, ja als ethische Handlung: „[J]ede ächte Volkskunde ist eine Sittenpredigt.“212 In der Rekonstruktion deutscher ,Sitte“ meint Riehl zugleich einen Beitrag zur ,Sittlichkeit‘ zu leisten und sieht sich als Volkserzieher im Geist Justus Mösers. Heimat wird im Sinn dieser Volkserziehung zum ethischen Prinzip.

\section{Anschauung und Zusammenschau}

Als bahnbrechend ist Riehl aufgrund seiner Methode der Feldforschung und seines interdisziplinären Ansatzes anzusehen, ${ }^{213}$ ohne den die Volkskunde nicht zur Leitwissenschaft um 1900 hätte aufsteigen können. In seinem Wanderbuch (1869) resümiert Riehl seine „Handwerksgeheimnisse des Volksstudiums“, 214 die er schon im 1853 vorausgehenden Band Land und Leute angewandt hatte: Der Erforscher des Volkslebens müsse auf Reisen gehen. Dabei sollen nicht die Kutsche und die Eisenbahn, sondern nur die eigenen Füße benutzt werden. Gewandert werden solle allein: „Wandern heißt auf eigenen Füßen gehen, um mit eignen Augen zu sehn, mit eigenen Ohren zu hören.“215 Das Quellenstudium habe immer erst an zweiter Stelle zu stehen, ${ }^{216}$ an erster die leibliche Erfahrung am Objekt. Der Ruf des Romantikers, der Riehl anhing, beruht zum Teil wohl auf der

212 Riehl 1859, S. 212.

213 Riehl entwickelt seine Fragestellung nicht aus einer innerdisziplinären Logik, sondern formiert um seine Fragestellung eine neue Disziplin. Indem er die hergebrachten Disziplinen vom Standpunkt des eigenen Erkenntnisinteresses als dienende Wissenschaften interpretiert, stellt er die Rangfolge der Wissenschaften in Frage (die Volkskunde sollte nach Riehl beispielsweise zur Grundlage der Staats- und Rechtswissenschaft werden) und formuliert zugleich einen interdisziplinären Ansatz, denn ohne historische, geographische oder germanistische Forschung ist für ihn auch keine Volkskunde zu denken. Volkskunde wird also als Integrationswissenschaft unter der Leitfrage des Volksbegriffs verstanden. Jasper von Altenbockum liest Riehl nicht als Volkskundler, sondern als interdisziplinär arbeitenden Kulturhistoriker (vgl. Altenbockum 1994). Er verdeckt mit dem Alternativbegriff das historische Selbstverständnis der Volkskunde als interdisziplinäre Leitwissenschaft.

214 Riehl 1869, S. 1.

215 Riehl 1869, S. 4.

216 Vgl. Riehl 1869, S. 5. 
Assoziierung von Wanderung und Romantik, ${ }^{217}$ tatsächlich aber weist Riehl die Romantik als Orientierungsmodell zurück. Er ziele nicht auf Subjektives, sondern auf Objektives, nicht auf Vergangenheit, sondern auf Gegenwart: ${ }^{218}$, ,W]elch frischeren Stoff gäbe es als das eigene Volk, die eigene Heimath. “219 Riehl etabliert einen volkskundlichen Erkenntnisbegriff, der Anschauung an die erste Stelle setzt: „Durch’s Wandern können uns Bücher und Acten nicht entbehrlich werden, aber wir lernen Bücher und Acten lesen durch’s Wandern. “220 Es gehe um die „unmittelbare Anschauung des Lebens“, heißt es schon in Die Volkskunde als Wissenschaft, und die Volkskunde ziele auf die Erfahrung von Heimat. Ein „Bild das Leben athmet“ bedürfe „der unmittelbaren Quellen, zu deren Aufsuchung man auf den eigenen Beinen durch's Land gehen muß. Und gerade diese Neuheit eines noch nicht von Hunderten abgeschriebenen sondern zum erstenmale auf's Papier geworfenen Stoffes ist es, die der auf die heimische Gegenwart zielenden Volkskunde ein so jugendliches und frisches Gesicht verleiht.“221 Quellenforschung wird von Riehl dementsprechend nicht nur als Studium von überlieferten Schriften, sondern auch als das ,aus der unmittelbaren Anschauung des Lebens mit nach Hause“ Gebrachte verstanden. ${ }^{222}$

Analog zu den Entwicklungen in der Pädagogik richtet sich dieser Anschauungsbegriff auf das Naheliegende im wörtlichen Sinn des nahe Liegenden und folgt einem dezidiert (wissenschafts-)kritischen Impuls (vgl. II.3.1). Räumlich soll sich das Erkenntnisinteresse von der Ferne in die Nähe verlagern, zeitlich von der Vergangenheit in die unmittelbare Gegenwart. ${ }^{223}$ Dabei wird das Fremde und Vergangene durchaus als wesentliches Konstitutionsmoment des Eigenen ge-

217 Wandern ist für Riehl mehr als Forschungsreise, es ist auch poetischer Vollzug eigener Innerlichkeit: „Vollends aber einen Führer mitzunehmen, zerstört alle Poesie des Wanderns, denn die tiefste Wander-Poesie ist Selbstsuchen, Selbstfinden, Selbstverfehlen, kurzum durchaus auf eigenen Füßen gehen und sein eigener Herr seyn.“ Riehl 1869, S. 8. Auch sonst sind die Anknüpfungspunkte an die Romantik zahlreich, von der Suche nach dem ,Volksgeist" bis zum bewahrenden und poetisierenden Sammeln historischer Zeugnisse.

218 Vgl. Riehl 1869, S. 33.

219 Riehl 1869, S. 33.

220 Riehl 1869, S. 23.

221 Riehl 1859, S. 219.

222 „Doch meinen noch immer manche gelehrte Leute, wenn Einer etwa auf einem alten Schweinsleder eine neue Notiz über das Volksleben unserer Urahnen aufspürt, so sey das allerdings Quellenforschung; wenn aber Einer eine gleich wichtige und neue Notiz über das Volksleben unserer Zeitgenossen aus der unmittelbaren Anschauung des Lebens mit nach Hause bringt, so könne man dies doch nie und nimmer Quellenforschung heißen. Genau genommen finde ich aber zwischen Beidem doch eigentlich nichts Unterscheidendes als das Schweinsleder.“ Riehl 1859, S. 220.

223 Vgl. Riehl 1859, S. 217-218. 
würdigt: „Wäre Amerika nicht entdeckt worden, - wir wüßten heute gewiß noch nicht halb so gut, wie es mitten in Deutschland aussieht.“224 Der „Entwicklungsgang der Volkskunde“, so heißt es unmittelbar vorher, sei „durch die Erkenntniß fremder und vorzeitlicher Gegensätze erst zum Heimischen und Gegenwärtigen hindurchgedrungen“. Diese historische Entwicklung habe auch jeder einzelne „Volksforscher“ für sich persönlich zu vollziehen: „[D]er ächte Volksforscher reist, nicht blos um das zu schildern, was draußen ist, sondern vielmehr um die rechte Sehweite für die Zustände seiner Heimath zu gewinnen. “225 Die Einforderung von Gegenwärtigkeit auch im Wissenschaftsverständnis entspricht jener Öffnung gegenüber den Realitäten - und zwar auch gegenüber den profanen Alltagsrealitäten -, welche die eine Seite des zeitgleich mit Riehls Theorien entstehenden literarischen Realismus ausmacht.

Auch die andere unmittelbar damit zusammenhängende Seite des Selbstverständnisses der Programmatiker des Realismus findet sich bei Riehl: die Auffassung, der genaue Blick auf die empirischen Details müsse verklärend in eine sinnvolle und in diesem Sinn schöne Einheit überführt werden, das ungeordnete Chaos der Welt in ein wohlgeordnetes Ganzes. Der Realist stelle, so Gustav Freytag in seinem Nachruf auf das große Vorbild Charles Dickens, „modernes Leben [dar], im Grunde alltägliche Wirklichkeit [...] nur verklärt durch das liebevolle Gemüth eines echten Dichters““.226 Gelungene Dichtung habe „die ungeheure, furchtbare, unverständliche Welt ins Menschliche umgedeutet nach den Bedürfnissen eines edlen und sehnsuchtsvollen Gemüthes“. 227 Der Weltentwurf der Realisten ist ein empirisch gesättigter, zugleich aber idealistisch überformter genauso wie bei Riehl. Mit Beobachtung allein sei noch nichts erreicht, solange das Detail nicht in eine größere Ordnung eingebunden sei: „Zu beobachten was man findet, ist leicht, aber das zu finden, was man beobachten will, das ist die feinere Kunst. [...] Die feinste Kunst aber ist dann weiter das Beobachtete im Moment des Beobachtens selber schon zu ordnen, zu sichten, im Zusammenhang zu ahnen, vom Theil aufs Ganze, vom Ganzen auf den Theil zu schließen. “228 Die hier von Riehl skizzierte, an die divinatorische Hermeneutik Schleiermachers erinnernde Methode geht von einem prozesshaften Verstehen aus, das die Erkenntnis des Einzelnen immer an die zeitgleiche Erkenntnis des Ganzen bindet.

224 Riehl 1859, S. 218.

225 Beide Zitate Riehl 1859, S. 218.

226 Freytag: Dickens, 1897, S. 241.

227 Freytag: Dickens, 1897, S. 244.

228 Riehl 1869, S. 12-13. 
Das Ganze mache erst den Blick fürs Einzelne, das Einzelne den fürs Ganze frei. ${ }^{229}$ Dieses Ganze aber ist für Riehl die ,Volkspersönlichkeit‘ und sein Verstehen eine ,feine Kunst', die nicht jedem gegeben ist, eher einem schöpferischen, ja künstlerischen Akt gleichkommt, der eines Geistes bedarf, der ,ahnen“ können muss, statt zu wissen. Die große „Ueberschau“, ${ }^{230}$ der Rückbezug aufs große Ganze ist ein zugleich wissenschaftlicher und poetischer Akt, wie es explizit heißt: „Diese Studien über oft höchst kindische und widersinnige Sitten und Bräuche, über Haus und Hof, Rock und Kamisol und Küche und Keller [...] erhalten erst ihre wissenschaftliche wie ihre poetische Weihe durch ihre Beziehung auf den wunderbaren Organismus einer ganzen Volkspersönlichkeit [...]. “231 Während aber bei Schleiermacher die Vorstellung des Textsinns als eines Ganzen, auf welches das Verständnis des Einzelnen immer wieder rückbezogen werden muss, prinzipiell offen bleibt, ist das Ganze bei Riehl eine vorher schon festgelegte Größe - eben der ,wunderbare Organismus einer ganzen Volkspersönlichkeit‘. Aus dem Verstehensmodell der wechselseitigen Bedingtheit ist also eines geworden, in dem das sinnvolle Ganze immer schon feststeht: das deutsche Volk.

Eine weitere methodisch so problematische wie charakteristische Vorannahme von Riehls Volkskunde ist es, dass nur der liebende Blick Erkenntnis hervorbringen könne. Wer Heimat beschreiben und verstehen will, müsse, so heißt es immer wieder, ,Heimatgefühl` haben. ${ }^{232}$ Wird der Erkenntnisgegenstand Heimat geliebt, kann er erst verstanden werden, und wird er verstanden, vermag er sittlich zu erheben und geistige Heimat zu geben. Demselben Zirkelschluss unterliegt Riehls Heilsversprechen für den Volkskundler. Wer seine Heimat in der Volkskunde gefunden habe, könne geistig nicht mehr heimatlos sein:

Allein die Wissenschaft, der wir dienen, ist unsere geistige Heimath, und jeder rechte Mann hält seine Heimath für die schönste der ganzen Welt und spricht gerne von ihr und meint, es müßten auch Andere gerne davon sprechen hören. Und weil wir die veredelnde, sittigende Kraft eines kräftigen und fröhlichen Heimathsbewußtseyns würdigen, hören wir ihm mit

229 Für Riehl gilt zugleich, dass das Ideal erst den Blick für die (entscheidenden) empirischen Tatsachen freimache, vgl. Riehl 1869, S. 24.

230 Riehl 1869, S. 19.

231 Riehl 1859, S. 215.

232 „Der forschende Wanderer [...] hat sich Muth und Kraft und Begeisterung erwandert, um selbst durch die pfadlose Wildniß solcher Abhandlungen zu dringen, weil er eben Heimathsgefühl mitbringt für das Land, dessen Geschichte der allzu gelehrte Monographist untersuchte, und in dem Heimathsgefühl zugleich die Geduld für das Kleine, Dürftige und Trockene und das Verständniß Verworrenes zu entwirren, ohne daß ihm, dem bloßen Wanderer, darum der unbefangene freiere Ueberblick verloren gegangen wäre, dessen Mangel den Eingeborenen so oft verführt Wichtiges und Nichtiges gleich zu achten und des Stoffes kein Ende zu finden.“ Riehl 1869, S. 30. 
Nachsicht zu, mit derselben Nachsicht, welche ich mir von Ihnen erbitten möchte für diesen Vortrag, der Ihnen ja nur darthun wollte, daß, wer seine Heimath in der Volkskunde gefunden zu haben wähnt, doch nicht eigentlich wissenschaftlich heimathlos ist. ${ }^{233}$

Heimat ist hier also nicht mehr nur Gegenstand der Volkskunde, sondern darüber hinaus ihr Nukleus und Telos. Und auch die Methodik Riehls arbeitet daran, Heimat als objektivierbaren Gegenstand zugleich $\mathrm{zu}$ behaupten und $\mathrm{zu}$ untergraben.

\section{Zwischen Wissenschaft und Literatur}

Heimat ist bei Riehl nicht auf einen bestimmten Ort (der Herkunft oder des Wohnsitzes) oder eine bestimmte Praxis (der Alltagskultur, der Riten und Gebräuche) zu reduzieren. Sie weist bei Riehl - trotz seines Anspruchs, sie wissenschaftlich zu greifen - vielmehr eine Mehrdeutigkeit auf, die Ethisches, Emotionales, aber auch Schöpferisches umfasst, das Riehl mehrfach mit einem ,Poetischen' assoziiert. Nicht nur seinen Gegenstand Heimat, sondern auch seine Untersuchungs- und Verstehensmethode begreift Riehl zugleich als objektivierbar und als spezifisch ästhetisch.

Riehl verbindet eine naturwissenschaftlich-empirische Methodik mit dem Ziel einer idealistischen Zusammenschau und ordnenden Fügung zu einem sinnvollen und in diesem Sinn auch schönen Ganzen. Was in der realistischen Literatur als ordnender Schöpfungsakt des Autors angesehen wird, ist in Riehls Auffassung der Volkskunde die außergewöhnliche Forscherpersönlichkeit, deren Freiheit es ist, im Akt des Erzählens zu einer höheren Wahrheit vorzudringen: „Und zuletzt kommt es bei derlei kleinen Geschichten“ - Riehl meint hier die Berichte über Sitten und Bräuche in seinen volkskundlichen Schriften - ,auch kaum darauf an, ob sie wirklich so vorgefallen sind, sondern vielmehr ob der Landeskundige zustimmend sagt, daß sie so und nicht anders einmal vorfallen müßten, wenn es gleich noch gar nicht geschehen wäre. “234 Riehls überaus einflussreiche Vorstellung von Heimat (vgl. 3.2.2 und 3.3) ist somit eine, die nicht nur ihren Untersuchungsgegenstand, sondern auch ihre Untersuchungsmethode als spezifisch ästhetisch ansieht.

Vor diesem Hintergrund nimmt es kaum wunder, dass Riehl selbst passionierter Schriftsteller war und Heimat ein wesentlicher Bezugspunkt seiner literarischen Produktion ist. Er wird durch zeitgenössische Autoren rezipiert, die ihrerseits über Heimat schreiben: Theodor Fontane und Gustav Freytag gehören

233 Riehl 1859, S. 229.

234 Riehl 1869, S. 28. 
neben Peter Rosegger, Berthold Auerbach und E. Marlitt ${ }^{235}$ dazu. Einige Spuren dieses riehlschen Verständnisses von Heimat im Literarischen sollen im Folgenden rekonstruiert werden.

\subsubsection{Heimat als soziale und ästhetische Integrationsformel}

Heimat erhält in Riehls volkskundlichen Schriften unter anderem eine sozialpolitische Funktion. Heimat steht für die Befriedung der sozialen Frage, wobei Vergangenes unter den Bedingungen der Moderne erhalten bzw. rekonstruiert werden soll. Diese Dialektik von Bewahrung und Neuschöpfung von Heimat beinhaltet auch, dass die Neuschöpfung von Heimat eine Sache der Literatur ist.

Insgesamt, und insofern sind Riehl und die literarische Riehl-Rezeption eines Freytag und Fontane hier exemplarisch, wird die volkskundliche Idee von Heimat ab der Mitte des 19. Jahrhunderts zu einem Leitnarrativ, auch für die Literatur. Sich an der volkskundlichen Idee von Heimat zu orientieren, heißt mit Riehl immer auch, Heimat vor allem in Form von literarischen Texten zu zeigen und zu interpretieren. Peter Roseggers Monatsschrift Heimgarten ist dafür ein gutes Beispiel. Die 1877 von Rosegger gegründete und bis 1911 von ihm, danach von einem seiner Söhne geleitete Zeitschrift bietet eine Mischung aus fiktiven Erzählungen, Gedichten und volkskundlichen Beobachtungen; schon die Rubriken der Zeitschrift deuten das an: „Novellen und Erzählungen“, „Alpines und Volksthümliches aus den Alpen“, „Cultur- und Naturgeschichtliches, Essays, Plaudereien“, „Land und Leute, Charakterbilder“ - der Verweis auf Riehls Buchtitel ist sicher nicht zufällig ${ }^{236}$ - „Kleine Geschichten, Sagen, Märchen, Schwänke“ und so weiter. Die Grenze zwischen literarischer Fiktion und volkskundlicher Beobachtung wird hier ins Fließen gebracht. Die Zeitschrift will Brücken schlagen zwischen Gebildeten und Ungebildeten, Stadt und Land, Tradition und Moderne. ${ }^{237}$

235 Eugenie John (1825-1887) avancierte unter dem Pseudonym E. Marlitt zu einer der wichtigsten Autorinnen der Gartenlaube und $\mathrm{zu}$ einer der prominentesten Unterhaltungsschriftstellerinnen der zweiten Jahrhunderthälfte überhaupt. Tobias Klein vertritt in seiner dieser Autorin geltenden Studie Von deutschen Herzen - Familie, Heimat und Nation in den Romanen und Erzählungen E. Marlitts die These, dass sich in den marlittschen Romanen ein von Riehl geprägtes organisches Verständnis von Gesellschaft ausdrücke, in dem Familie und Heimat als ,Wurzelgrund' der Nation dienten. Vgl. Klein 2012.

236 Rosegger hat das gleichnamige Buch von Riehl nachweislich gelesen, vgl. Wagner 1991, S. 96. 237 „Der Heimgarten nun soll eine Schrift für’s Volk werden, zur Unterhaltung, Erhebung des Gemütes u. Belehrung. Er soll die Liebe zur Einfachheit, Häuslichkeit, zum Vaterlande fördern, u. den Glauben an die grossen Ideale der Menschheit überhaupt. Er soll aber so gehalten sein, daß er als Organ des Volksthumes in den Alpen auch den Gebildeten interessirt. Neugesamelte Volks- 
Wie sehr dieser mit dem Ziel sozialer Integration antretende und sich zwischen volkskundlicher und literarischer Heimat vollziehende Brückenschlag mit Riehls Denken verbunden ist, zeigt sich etwa auch in dem zeitgenössischen Bestseller Soll und Haben.

\section{Freytags Soll und Haben}

Riehl hat sich aus sozialpolitischer Perspektive auch über die Aufgabe zeitgenössischer Literatur geäußert. In Form des ,socialen Romans‘ sei Literatur unverzichtbar für die Analyse der eigenen Gegenwart, schreibt er 1851: „Die Zeit ist da, wo Staatsmänner zu ihrer Instruction auch Romane lesen müssen. “238 So wie zur Kenntnis sozialer Realitäten zukünftig auch die Romanlektüre beitragen werde, müsse sich andersherum die Literatur den sozialen Realitäten öffnen. Zeitgemäß sei es beispielsweise, das Bauerntum nicht mehr als Genrebild „private[r] Gemüthlichkeit“ darzustellen, wie Hebel und Jung-Stilling, sondern als gesellschaftlichen Stand, wie bei Auerbach und Gotthelf. ${ }^{239}$ Mit seinen Beispielen aus der europäischen Romanliteratur weist Riehl aber auch auf die im Deutschen noch weitgehend ausstehende literarische Darstellung der städtischen gesellschaftlichen Schichten hin, wie sie Dickens' und Sues Romane zu diesem Zeitpunkt schon leisteten.

Wenige Jahre nach Riehls Ausführungen zum sozialen Roman wird ein deutschsprachiger Text zum Bestseller, ${ }^{240}$ der Riehls Ansprüchen in vielerlei Hinsichten entsprochen haben dürfte - gerade auch in seinen Abweichungen von Dickens und Sue. ${ }^{241}$ Gustav Freytags Roman Soll und Haben (1855) will Antworten

sagen, Volksschwänke, Volksmärchen, Volkslieder, Schilderungen von Volkssitten u. Unsitten soll er bringen, usw. Dem Dorfe, dem schlichten Leser soll der ,Heimgarten“ die Vorzüge u. Errungenschaften der gebildeten Welt in einfacher Schreibweise offenbaren; dem Salon soll er die Ursprünglichkeit u. Kraft der Volksseele vermitteln. Der ungeschulte Leser soll im ,Heimgarten das finden, was ihn von der Welt; der Gebildete das, was ihn vom Volke, vom Dorfe, vom Walde u.s.w. interessirt.“ Rosegger an seinen Verleger Gustav Heckenast am 24.1.1876, hier zitiert nach Wagner 1991, S. 117-118.

238 Wilhelm Heinrich Riehl: Der sociale Roman, in: Beilage zur [Augsburger] Allgemeinen Zeitung Nr. 159 vom 8. Juni 1851, S. 2537-2538, zitiert nach: Adler 1990, S. 312.

239 Adler 1990, S. 313.

240 Schon im Jahr der Ersterscheinung, 1855, wurden fünf Auflagen in einer Auflagenhöhe von je tausend, teils tausendfünfhundert Exemplaren produziert, die erste preiswerte Volksausgabe erschien 1858 in der Erstauflage mit fünftausend Exemplaren; vgl. Mühlen 2016, S. 143-158.

241 Freytag hat sich nicht öffentlich zu Riehl geäußert, kannte aber dessen Schriften, die regelmäßig in Die Grenzboten gedruckt wurden. Zeitgenossen bringen Freytag und Riehl in Bezug auf ihre Auffassung der Kulturgeschichte immer wieder in Zusammenhang, vgl. Steinhausen 1898. 
auf die sozialpolitischen Umwälzungen der eigenen Gegenwart geben und wird auch in diesem Sinn rezipiert, etwa in Theodor Fontanes überschwänglicher Rezension. ${ }^{242}$

Das städtische Handelsbürgertum ist das positive Wertezentrum des Romans. Gezeigt werden soll, wie Ökonomie und Soziales durch die Kraft dieses gesellschaftlichen Standes zusammenkommen können. Nicht die Schrecken des Proletarierdaseins werden wie im zeitgenössischen englisch- und französischsprachigen Realismus entworfen, sondern die Verheißungen einer auf ökonomischen Fortschritt bauenden Bürgerwelt, in der sich die soziale Frage lösen lässt. ${ }^{243}$

Heimat ist dabei, wie bei Riehl, eine zentrale Antwort auf das Problem der sozialen Frage. Und Heimat ist, wie bei Riehl, unter den Bedingungen der eigenen Gegenwart zu aktualisieren. Das heißt für Freytags Roman etwa, dass Heimat selbstgewählt sein und ihren Ort in der Stadt finden kann, und das heißt, dass sie Tradition und Fortschritt, Emotion und Ökonomie miteinander verbinden kann. Der Romanheld Anton Wohlfahrt, dessen Geburtsort in der schlesischen Provinz Nebensache bleibt, findet seine Heimat in einem Breslauer Kolonialwarengeschäft: „[E]r hatte jetzt eine Heimat, er gehörte in das Geschäft.““244 Heimat, Haus und Geschäft werden in Soll und Haben zu Synonymen, und zwar genau im Sinn von Riehls Ideal des patriarchalisch geführten Betriebes. Heimat ist nicht sentimentale Erinnerung, sondern gegenwärtig und pragmatisch, sie bindet sich zunächst an die Arbeit und über die Arbeit wird am Ende auch das private Glück gemacht. In Riehls Gesellschaftsutopie von 1851 ist es - nach dem Vorbild des

242 Fontanes Rezension erschien 1855 im Literaturblatt des deutschen Kunstblattes, Nr. 15 vom 26.7.1855. Vgl. Theodor Fontane: Soll und Haben. Ein Roman in drei Bänden, in: Fontane 1969, S. 293-308. Die aktuellste und umfassendste Studie zu Gustav Freytag legt Philipp Böttcher vor; neben den Journalisten und Soll und Haben steht die Literaturpolitik der Grenzboten im Zentrum der Studie, vgl. Böttcher 2018.

243 Diese Welt des Handels ist der bäuerlichen Welt aufgesattelt, die sich ihrerseits den ökonomischen Prinzipien der eigenen Gegenwart anpasst: Die „uralte Pflugschar“ und der „neue Dampfkessel“ werden in einem Erzählerkommentar von Soll und Haben ins Bild der „brüderlich“ sich ergänzenden Arbeit gefasst, die die Menschen „reicher“, aber auch „weiser“ mache: Bäuerliche Arbeit und industrielles Zeitalter bilden eine harmonisch sich ergänzende Einheit, die ökonomischen und ideellen Fortschritt zur Folge hat. Während der Horizont des Bauern sich früher nur bis zu den Preisen „auf dem nächsten Wochenmarkt“ erstreckte, beobachte der moderne Bauer nun „viele Strömungen des menschlichen Geistes auch außerhalb seiner Feldmark“. Die immer weiteren Kreise, in die ihn sein ökonomisches Interesse zieht, weiten seine Welt. Und die industrielle Landwirtschaft birgt die Lösung des sozialen Problems: „Neben dem ländlichen Tagelöhner baut ein neues Geschlecht arbeitsamer Menschen seine Hütten auf den Ackerboden, in jeder Abstufung von Wissen und Bildung; allen kann er gerecht und allen zum Heil werden.“ Freytag 1896, Bd. 4, S. 463.

244 Freytag 1896, Bd. 4, S. 42. 
Handwerks, wo „in jeder Werkstatt ein Stück Heimath“ zu finden sei - die Arbeit, die Heimat geben soll. ${ }^{245}$ Bei Freytag ist es das Handelshaus T. O. Schröter. Dieses repräsentiert zugleich Arbeits- und Privatwelt: Im Haus befindet sich das Geschäft, zugleich wohnen die Familie und sämtliche (unverheiratete) höhere Angestellte dort. Das Handelshaus ist „Heimat“ der „Herzen“ und zugleich der „Geschäfte“;246 es nimmt den Protagonisten am Ziel- und Endpunkt seiner Entwicklung und seiner Bewährung in der Fremde als moralisch, sozial und ökonomisch gefestigten Bürger, Kaufmann und Ehemann auf. „,Willkommen in der Heimat!‘ ,Willkommen im Hause!' rief Sabine. Da sagte er leise: ,Ich habe eine Heimat, ich habe ein Haus, in dem ich mich wohl fühle. Durch Ihre Güte habe ich Beides gewonnen.“ “247

Der Held des Entwicklungsromans muss sich freilich erst bewähren, bis ihn das Haus endgültig aufnimmt, denn dieses Haus ist eine über Arbeit - und eben auch Arbeit an sich selbst - definierte Heimat. Erst die Erfahrung der Fremde lehrt ihn diese arbeitsame Heimat schätzen: „Ich habe gute Gesellen auch in der Fremde gefunden, und doch ist mir bei Vielem, was ich erlebte, die Ueberzeugung gekommen, daß es kein größeres Glück gibt, als sich in seiner Heimat mitten unter seinen Landsleuten tüchtig zu rühren." ${ }^{248}$ Diese in das Strukturmodell des Bildungsromans eingebundene Bewegung von der Heimat in die Fremde und zurück in die Heimat ist bei Freytag eine spezifisch national ausgerichtete: Weltgewandtheit und Weltoffenheit sind Ideale des Kaufmanns, aber sie gründen in der Heimat- und Vaterlandsliebe und festigen diese. Der Erkenntnisgewinn des Zurückgekehrten besteht vor allem darin, das Verlassene noch besser schätzen zu können; seine ,Männlichkeit‘ beweist er darin, sich nicht der Fremde anverwandelt zu haben:

Wer immer in den gebahnten Wegen des Lebens fortgegangen ist, begrenzt durch das Gesetz, bestimmt durch Ordnung, Sitte und Form, welche in seiner Heimat als tausendjährige Gewohnheit von Geschlecht zu Geschlecht vererbt sind, und wer plötzlich als Einzelner unter Fremde geworfen wird, wo das Gesetz seine Rechte nur unvollkommen zu schützen vermag, und wo er durch eigene Kraft die Berechtigung zu leben sich alle Tage erkämpfen muß, der erst erkennt den Segen der heiligen Kreise, welche um jeden einzelnen Menschen Tausende der Mitlebenden bilden, die Familie, seine Arbeitsgenossen, sein Volksstamm, sein Staat. Ob er in der Fremde verliere oder gewinne, er wird ein Anderer. Ist er ein Schwächling, so wird er die eigene Art den fremden Gewalten opfern, in deren Bannkreis er getreten ist. Hat er Stoff

245 Riehl 1855, S. 350 - 351.

246 Freytag 1896, Bd. 5, S. 313.

247 Freytag 1896, Bd. 4, S. 492.

248 Freytag 1896, Bd. 4, S. 508-509. 
zu einem Manne, jetzt wird er einer. [...]. Erst im Auslande lernt man den Reiz des Heimatdialekts genießen, erst in der Fremde erkennt man, was das Vaterland ist. ${ }^{249}$

Der Roman endet mit der Aussicht, dass Anton Ehemann von Sabine Schröter und zugleich Kompagnon ihres Bruders Traugott und damit zum Vorstand des Hauses wird, in dem Privat- und Geschäftsleben eins sind. Das Haus agiert dabei als eine über das einzelne Menschenleben hinaus wirksame Kraft, in der Familiarität und Geschäftstüchtigkeit, Tradition und Fortschritt eine ideale Einheit eingehen. In der Prosaik des Hauses liegt der Grund seiner Beständigkeit: „Dies Haus ist ein gutes Haus, aber es ist keins, wo man poetisch fühlt und sich leicht rühren läßt, die Arme schnell öffnet und den ans Herz drückt, der gerade kommt, um herein zu fallen. Es ist ein nüchternes, prosaisches Haus! [...] Und es ist ein stolzes und strenges Haus.“250 Mit dieser prosaischen Heimat verbindet sich Anton nun geschäftlich und privat, Ausdruck des höchsten Glücks innerhalb des freytagschen ,bürgerlichen Wertehimmels‘.

Heimat ist selbstgewählt und das Ergebnis der eigenen Arbeit. Das streng patriarchal geführte städtische Handelshaus ist, wie bei Riehl, eine sozial integrierende Heimat unter den ökonomischen Bedingungen der Moderne. Sie versichert sich ihrer Wurzeln nicht im Regionalen oder Ruralen, sondern im bürgerlichen Wertekodex von Arbeit, Ehre und Verlässlichkeit, den der Roman als spezifisch deutsch ausweist. Der Antisemitismus ${ }^{251}$ des Romans ist Teil eines ,kulturellen Codes' (Shulamit Volkov), der sich zeitgenössisch zu etablieren beginnt. Er spielt den ,Deutschen' gegen den ,Juden` aus und stärkt so die Vorstellung von Heimat als spezifisch ,deutsch“ und das Gegenteil des ,Jüdischen` (vgl. II.1.3.2). Das dem Handelshaus T. O. Schröter negativ kontrastierende Haus des Wucherers Ehrental wird in seinem Interieur als Luxusimitat beschrieben, unter deren glänzender Oberfläche der Dreck hervorschimmert. Der heimatlose Jude, diese Schlussfolgerung will Freytag dem Leser wohl nahelegen, kann Heimat höchstens schlecht kopieren. Bernhard, der beste, aber lebensunfähige Bewohner des Hauses, wohnt zwischen Bücherregalen voll orientalischer Poesie, seine schöne Schwester spielt im Salon Klavier, aber ohne eigentliches Gefühl. Der Vater geht in dunklen Zimmern ebenso dunklen Geldgeschäften nach. Die negativste jüdische Figur, Veitel Itzig, hat schließlich nicht einmal mehr ein Haus, er treibt sich überall und nirgends herum und lebt, ohne ,ehrlicher' Arbeit nachzugehen, in zwielichtigen Herbergen. Diese ,Wurzellosigkeit‘ entspricht seiner Unfähigkeit,

249 Freytag 1896, Bd. 5, S. 19-20.

250 Freytag 1896, Bd. 5, S. 311.

251 Über literarischen Antisemitismus bei Gustav Freytag vgl. Gubser 1998, Hopp 2016 und Stenzel 2016. 
Ideale wie Aufrichtigkeit und Treue überhaupt nur zu verstehen. Die ab Beginn des 19. Jahrhunderts neu semantisierte Heimat und ihr Korrelat, die ,Heimatlosigkeit‘, das lässt sich auch hier beobachten, muss somit auch im Kontext eines neuen, zeitgleich entstehenden Antisemitismus gelesen werden (vgl. II.1.3.2).

\section{Fontanes Wanderungen durch die Mark Brandenburg und Der Stechlin}

Freytags Roman fasst Riehls Idee von Heimat als Synthese des Sozialen und Ökonomischen in das markante Bild des Handelshauses T. O. Schröter. Fontane geht weiter: Er übernimmt in seinen Wanderungen durch die Mark Brandenburg Riehls Programm des Erwanderns und, damit verbunden, der poetischen Schöpfung von Heimat. Heimat ist dabei gleichzeitig Gegenstand und Produkt der literarischen Darstellung.

Das Rezeptionsverhältnis zwischen Fontane und Riehl, die sich 1859 in München trafen, ist - anders als in der Fontane-Forschung teilweise behauptet klar. ${ }^{252}$ Denn obwohl Fontanes Wanderungen in Buchform schon ab 1862 (bis 1889) erscheinen, Riehls Wanderbuch dagegen erst 1869 auf den Markt kommt, ${ }^{253}$ ist das Wanderbuch eine methodische Explikation dessen, was bereits Riehls Buch Land und Leute (1853) vorführt. Der erste Teil der insgesamt vierbändigen Naturgeschichte Riehls, zu der Land und Leute und das Wanderbuch gehören, geht sogar schon 1851 in Druck. Land und Leute hat Fontane nachweislich zur Kenntnis genommen. ${ }^{254}$ Fontanes Wanderungen sind also vor dem Hintergrund von Riehl zu lesen, nicht umgekehrt.

Das erzählende Ich der Wanderungen steht im Dienst der kulturhistorischen Archivierung einer Welt, die dabei ist, sich zu verändern. Dabei gilt die Sympathie deutlich der verschwindenden, nicht der neu entstehenden Welt. Diese alte Welt ist eine scheinbar zeit- und bewegungslose, in dem Ort und Mensch eine Einheit bilden. Interesse wecke gerade „die poetische, beinahe absolute Stille“ und „die stillste Stelle dieses stillen Landes“. „Durchreisende gibt es hier nicht, und jeder dem man begegnet, der ist hier zu Haus [...]. Noch einmal also, keine ,Passanten“. Es legt hier nur an, wer landen will“. ${ }^{255}$ An solchen nicht von Eisenbahnlinien

252 „Fast zeitgleich zu Fontanes erstem Wanderungen-Band hat Wilhelm Heinrich Riehl in seinem Wanderbuch von 1869 ähnliche Absichten programmatisch expliziert“, heißt es etwa bei Wolfgang Albrecht. Mit dem Bezug auf die Erscheinungsdaten der beiden Bücher wird suggeriert, Fontane sei Riehl vorangegangen, was nicht stimmt. Albrecht 2003, S. 103.

253 Der Inhalt beider Bücher ist teilweise schon vorher, im Fall Fontanes in Zeitungsvorabdrucken (ab 1859), im Fall Riehls in Form von Aufsätzen erschienen (ab 1864).

254 Vgl. Heinrich 2003, S. 17.

255 Fontane: Wanderungen, 2002, S. 44-45. 
gekreuzten Orten wird der „Zauber des Natürlichen und Lebendigen“256 gesucht. Wie bei Riehl kann dieses Authentische nur gefunden werden, indem es abseits der ausgetretenen Pfade aufgesucht wird, indem es leiblich erfahren und nicht nur den Büchern entnommen wird - nicht das auswendig Gelernte zähle. ${ }^{257}$ Das Wandern ist die bevorzugte Reiseform des erzählenden Ich (tatsächlich, man weiß es, hat Fontane viel mehr von Eisenbahn und Kutsche Gebrauch gemacht, als er zugab) und auch andere Fortbewegungsformen lassen sich in eine alte und eine neue Welt teilen:

[S]o werden sich die beiden Passagierboote, die jetzt das Bedürfnis decken, noch längere Zeit mit dem Publikum behelfen müssen, das jetzt zu ihnen hält. Dies Publikum, wenn auch nicht zahlreich, ist immerhin mannigfach genug. Tagelöhner, die auf die Güter, Handwerker, die zu Markte ziehen, dazu Kaufleute und Gutsbesitzer, auch gelegentlich Badereisende, besonders solche, die in den schlesischen Bädern waren. Nur eine Klasse fehlt, der man sonst wohl auf den Flußdampfern unserer Heimat, besonders im Westen und Süden, zu begegnen pflegt: der Tourist von Fach, der eigentliche Reisende, der keinen andern Zweck verfolgt, als Land und Leute kennenzulernen. ${ }^{258}$

Die feine Ironie der Textpassage sagt nichts Schlechtes über den Touristen - allein deswegen nicht, weil das Gros der Leserschaft von Fontanes Wanderungen unter Zeitgenossen eben touristisch interessiert war (und bis heute ist). Aber der Fortgang macht deutlich, dass die Authentizität der folgenden Erlebnisse dem ,Touristen von Fach' auf seinen ausgetretenen Pfaden nicht auffindbar gewesen wäre. Gleichwohl ist auch hier die alte Welt schon im Verschwinden, wie das Gespräch mit einem ehemaligen Glockengießer ergibt, der die Zeiten des „reellen Glockenguß[es]“ zur Vergangenheit zählt: Jetzt herrsche Profitgier, billigere Materialien würden verwendet, die Qualität leide, die Glocken klängen nicht mehr schön. ${ }^{259}$

Anliegen Fontanes ist es nicht, die alte Welt zu rekonstruieren, sondern ihr Verschwinden zu dokumentieren, neutraler, den Transformationsprozess selbst zum Gegenstand der Beschreibung zu erheben. Heimat hat an diesem Transformationsprozess teil, ist aktualisierbar und kann daher auch unter den Bedingungen der Gegenwart Bestand haben - im Zitat oben wird Heimat eben auch mit den Touristen auf den modernen Flussdampfern assoziiert. ${ }^{260}$

256 Fontane: Wanderungen, 2002, S. 14.

257 Vgl. Fontane: Wanderungen, 2002, S. 14.

258 Fontane: Wanderungen, 2002, S. 553-554.

259 Fontane: Wanderungen, 2002, S. 556.

260 Walter Erhart liest die Wanderungen insgesamt unter der Perspektive des touristischen Blicks, vgl. Erhart 2000, S. 840-843. Zur Spannung zwischen touristischem und historischem Interesse des Textes, die zumindest teilweise auch für die Widersprüchlichkeit des Umgangs der Forschung mit den Wanderungen verantwortlich ist, vgl. auch Erhart 1992. 
Wie Riehls ist es auch Fontanes methodischer Anspruch, das heterogene Material des Chronisten und des Archivars in ein Ganzes zu überführen und auf diese Weise ästhetisch zu transzendieren; beide verstehen sich als Grenzgänger zwischen Wissenschaft und Kunst. ${ }^{261}$ Dieses Programm wird von beiden ausführlich reflektiert. In diesem Sinn versteht sich Riehl nicht als detailversessener Gelehrter, sondern als „wissenschaftlicher Schriftsteller“, der aus Fragmenten ein „harmonisch gefügtes Ganzes“ zu formen versteht. Er strebe eine „Doppelkunst“ an, deren Resultat „nicht blos der Wissenschaft, sondern auch der Literatur“ ${ }^{\prime 262}$ angehöre.

Fontanes Wanderungen stehen ihrerseits auf der Grenze zwischen enzyklopädischem Archiv und historischer Materialsammlung auf der einen, essayistischer, episodischer und anekdotischer Reiseprosa auf der anderen Seite und wollen beides, das Enzyklopädische und das Anekdotische, in ein literarisches Ganzes überführen. ${ }^{263}$ Fontane schreibt über die „Grundidee“ der Wanderungen: „Es ist alles auf ein Ganzes hin angelegt“, es komme ihm auf die „Belebung des Lokalen, die Poetisierung des Geschehnen“ an. Aber „nicht Verherrlichung des Einzelnen, sondern Liebesweckung für das Ganze“ sei das Ziel. ${ }^{264}$ Die ,Liebe‘, die Fontane hier als intendierten Leseeffekt angibt, ist zugleich Bedingung der Produktion. Ausdrücklich ist es die „Liebe und Anhänglichkeit an die Heimat“, ${ }^{265}$ die es ermöglicht, die Heterogenität der einzelnen Reisebeobachtungen zum Ganzen hin zu transzendieren.

In der Passage über den Freienwalder Lokaldichter Karl Weise (1813-1888), der wohl insbesondere aufgrund von Fontanes Porträt bis heute nicht ganz vergessen ist, verdichten sich diese Überlegungen. Schon die Wohnung des Hei-

261 So auch bei Lepenies 2002, S. 239-243 und Kalazny 2003. Kalaznys Thesen zur Landschaftsauffassung Riehls passen gut zu den hier entwickelten. Entgegen dem Titel „Zum Sehen und Wandern in Wilhelm Heinrich Riehls Wanderbuch im Vergleich mit Fontanes Wanderungen durch die Mark Brandenburg“ bleibt Kalaznys vergleichende Bezugnahme auf Fontane allerdings marginal. Zum Vorwurf der Ästhetisierung in der Naturgeschichte, den Heinrich von Treitschke erhoben hat, vgl. Kalazny 2002.

262 Alle Zitate Riehl 1873, S. 4.

263 Den Anspruch des Literarischen stellen schon die Motti aus, die u.a. von Goethe, Uhland, Heine, Platen, Wilhelm Müller, Mörike, Storm und Heyse stammen.

264 So Fontane an Ernst von Pfuel in einem Brief vom 18. Januar 1864, in: Fontane 1909, S. 239240.

265 „Es ist ein Buntes, Mannigfaches, das ich zusammengestellt habe: Landschaftliches und Historisches, Sitten- und Charakterschilderung, - und verschieden wie die Dinge, so verschieden ist auch die Behandlung, die sie gefunden. Aber wie abweichend in Form und Inhalt die einzelnen Kapitel voneinander sein mögen, darin sind sie sich gleich, daß sie aus Liebe und Anhänglichkeit an die Heimat geboren wurden." Fontane: Wanderungen, 2002, S. 11. Der liebende Blick wird mehrfach als Erkenntnisvoraussetzung benannt, vgl. Fontane: Wanderungen, 2002, S. 12-13. 
matdichters verkörpert die Einheit von Heimatliebe und Poesie (vgl. I.2.5). ${ }^{266}$ Die Lebensgeschichte Weises lässt keine sentimentalisierende Heimat-Reminiszenz aus, von der armen, gleichwohl glücklichen und von Gesang erfüllten Kindheit ${ }^{267}$ bis zur Wanderschaft, die mit der Rückkehr in die Heimat endet. ${ }^{268}$

Das literarische Porträt Karl Weises übernimmt in Fontanes Text die Funktion, zwei verschiedene Schreibweisen - den akribischen Detailrealismus und die verklärende Synthese - biographisch zu erproben. Weise scheitert dabei nach Fontanes Darstellung an dem Versuch, ,jeder Kuppe, jedem landschaftlichen Punkt einen poetischen Zettel umzuhängen““. ${ }^{269}$ In welchem Maß Fontanes Text in der Gefahr stand, in derselben Weise in die Schilderung von Details zu zerfallen, zeigt sein zeitweiliger Plan, die überbordenden Textmassen alphabetisch anzuordnen. Es schien keinen Standpunkt jenseits des Alphabets zu geben, der es erlaubt hätte, die Tendenz des Textkonvoluts zum Enzyklopädischen zu bändigen (in der Werkausgabe umfassen alle den Wanderungen zugehörigen Texte ohne Kommentare ca. 2700 Seiten). Zum genauen Blick aufs Einzelne muss also eine bewusste Beschränkung hinzukommen.

Bezogen auf Karl Weises dichterisches Schaffen entfaltet Fontane solch eine gelingende Schreibtechnik. Sie geht ebenfalls vom Einzelnen aus, verbindet dieses aber mit den Werten des Häuslichen, der Liebe und der Einfachheit - mit einer thematischen Beschränkung also, die gleichwohl auf ein Ganzes zielt. „Geh vom Häuslichen aus und verbreite dich so gut du kannst über die Welt.“ Dies sei der „Leitstern“ von Weises poetischem Schaffen: „Alles, was uns ein Menschenherz

266 „Das Ganze hat das Anheimelnde einer Poetenwohnung alten Stils und wir treten guten Mutes ein.“ Fontane: Wanderungen, 2002, S. 617.

267 „Er beginnt mit Schilderungen aus seiner Heimat, seiner Kindheit. Am Giebichenstein spielt er herum; er singt und klettert unter Felsen und Trümmern, und tut unbewußt seinen ersten Trunk aus Romantik und Märchenwelt. Er singt ,des Knaben Berglied‘, er hat eine klare Kinderstimme; aber was frommt ,armer Leute Kind' Lied und Gesang, wenn beide nicht zu erwerben verstehen? [...] Glückliche Jahre waren das [...].“ Fontane: Wanderungen, 2002, S. 619.

268 „Er wanderte mit Lust, und seine Lieder selbst haben uns ein paar Klänge davon aufbewahrt. Er zog weit umher, arm, glücklich, liederfroh, bis er plötzlich, wie mancher vor ihm, eine Leere und eine Sehnsucht in seinem Herzen wachwerden und wachsen fühlte, die ihn nun wieder heimwärts trieb.“ Fontane: Wanderungen, 2002, S. 620.

269 „Es handelt sich in diesen Liedern um eine Verherrlichung der Freienwalder Natur, und die ursprüngliche Absicht des Dichters scheint auf nichts Geringeres ausgegangen zu sein, als in einem wahrhaft beängstigenden Drange nach Vollständigkeit jeder Kuppe, jedem landschaftlichen Punkt einen poetischen Zettel umzuhängen. Das glückt aber nie. Eine solche Aufgabe ist unpoetisch in sich, und in derselben Weise wie es unmöglich ist, auf sämtliche Schiffe der englischen Flotte, oder auf sämtliche Regimenter der preußischen Armee einen Sonettenzyklus zu machen, so verbietet es sich auch, die weitausgespannte Freienwalder Landschaft Nummer für Nummer zu besingen.“ Fontane: Wanderungen, 2002, S. 621. 
lieb und wert machen kann, das klingt hier zusammen: Genügsamkeit, kindlicheinfacher Sinn, Liebe, Pietät und Gottvertrauen. “270 Häuslichkeit steht hier für das Bei-sich-Sein des Poeten und für die Authentizität seiner Dichtung. Die Erzählerfigur der Wanderungen ist außenstehender Beobachter des naiven Poetenidylls, an dem sie selbst nicht teilhat.

Entsprechend ist die Stelle auch nicht eins zu eins als poetologisches Programm von Fontanes Wanderungen lesbar. Analogisierbar sind beide Schreibweisen, insofern das Häusliche bzw. regional Beschränkte beschrieben wird, insofern die Darstellung auf tatsächlicher Beobachtung und akribischer Detailgenauigkeit beruht und insofern die Heimatliebe zum einheitsbildenden Modus der Schöpfung und zugleich zum Rezeptionseffekt wird. Die Syntheseleistung, die Heimat hier erbringt, steht im Einklang mit dem Prinzip der Verklärung, wie es Fontane in seinem Aufsatz Unsere lyrische und epische Poesie seit 1848 (1853) entwickelte, dem zufolge der Literatur die Funktion zukomme, Wirklichkeit poetisch $\mathrm{zu}$ überhöhen. ${ }^{271}$ Die Wanderungen unterscheiden sich allerdings von der Dichtung Karl Weises und auch von den riehlschen Intentionen in ihrem Umgang mit ,Welt‘. ${ }^{272}$ Indem sie Heimat und ,Welt' in ein Spannungsverhältnis setzen, ermöglichen sie Distanz zu eben der Heimatliebe, die im Vorwort so hochgehalten wird.

Auch bei Riehl wird die Bedingtheit von Heimat und Fremde thematisiert (vgl. I.2.3) - wäre Amerika nicht entdeckt worden, so heißt es bei ihm, hätte sich nie ein Interesse für das Naheliegende ausgebildet. Nur wer in der Fremde gewesen sei, vermöge die Heimat objektiv zu erfassen, und der echte Volksforscher reise nicht

270 Alle Zitate Fontane: Wanderungen, 2002, S. 622.

271 Vgl. Theodor Fontane: Unsere lyrische und epische Poesie seit 1848, in: Fontane 1969, S. 236-260. Zur realistischen Programmatik der Verklärung vgl. Plumpe 1996, S. 50 - 57; Becker 2003, S. 103-110; sowie einführend Stockinger 2010, S. 10-11. Besonders Becker pointiert die Doppelgesichtigkeit realistischer Verklärung: Als Leistung der Realisten ist demnach herauszustellen, dass sie ,prosaische“ Gegenstände mithilfe der Verklärungsidee literaturfähig machten. Zugleich führt das Verklärungspostulat aber auch zu einem selektiven Verfahren, das bestimmte Sujets als nicht literaturfähig ausschließt. Für Fontane war die Darstellung „eines sterbenden Proletariers, den hungernde Kinder umstehen“ nicht literaturfähig (Fontane, Unsere lyrische und epische Poesie, 1969, S. 241).

272 Es ist typisch, dass Fontane unter den romantischen gerade ein Heimat-Gedicht Adelbert von Chamissos auswählt, des Deutschen mit französischen Wurzeln also, der sein Gedicht bei seiner Rückkehr von der „Reise um die Welt“ verfasste. Fontane zitiert das 1818 entstandene Gedicht Chamissos vollständig: „Heimkehret fernher, aus den fremden Landen, / In seiner Seele tief bewegt der Wanderer; / Er legt von sich den Stab und knieet nieder, / Und feuchtet deinen Schoß mit stillen Tränen, / O deutsche Heimat! - Woll' ihm nicht versagen / Für viele Liebe nur die eine Bitte: / Wann müd' am Abend seine Augen sinken, / Auf deinem Grunde laß den Stein ihn finden, / Darunter er zum Schlaf sein Haupt verberge.“ Fontane: Wanderungen, 2002, S. 723-724. 
bloß, um das zu schildern, was draußen sei, sondern vielmehr um die richtige Sehweise für die Zustände seiner Heimat zu gewinnen. ${ }^{273}$ Was bei Riehl anklingt, wird zum zentralen Thema und Darstellungsmodus bei Fontane. Denn von Anfang an spricht immer auch der Kosmopolit, der englische Redensarten genauso selbstverständlich in den Text flicht, ${ }^{274}$ wie seine Motti der europäischen Literatur entstammen.

Schon der Entstehungskontext der Wanderungen steht im Zeichen des Kosmopolitischen. Unmittelbar vorangegangen waren den Wanderungen die England- und Schottlandstudien - Ein Sommer in London und Jenseit des Tweed. Fontanes Vorwort zur ersten Auflage der Wanderungen weist darauf hin: „,Erst die Fremde lehrt uns, was wir an der Heimat besitzen.' Das hab' ich an mir selber erfahren und die ersten Anregungen zu diesen Wanderungen durch die Mark sind mir auf Streifereien in der Fremde gekommen." Auf der Wasserfläche des schottischen Sees Loch Leven sei es gewesen, als die „Einbildungskraft“ einsetzte und „plötzlich unsre Phantasie weiter in ihre Erinnerungen zurückgriff und ältere Bilder vor die Bilder dieser Stunde schob. Es waren Erinnerungen aus der Heimat, ein unvergessener Tag [...].“"275 Die Eindrücke vom Loch Leven Castle und vom Rheinsberger Schloss überlagern sich und diese imaginäre Synthese lässt den Wunsch entstehen, auch die eigene Heimat zu beschreiben. ${ }^{276}$

Die ausführliche Künstlerbiographie des Orient-Malers Wilhelm Gentz (18221890) im Abschnitt zur Grafschaft Ruppin ist in diesem Sinn als Kontrapunkt zur Passage über den Heimatdichter Karl Weise zu lesen. Gentz erscheint vorbildlich in seiner Lebenshaltung und als Künstler, er gehöre, so Fontane, zu den wenigen, die ihn ermutigten. ${ }^{277}$ Zitiert werden aus Gentz' Briefen mehrfach diejenigen Passagen, in denen ihm die Welt zusammenzurücken scheint. In Schweden „ist vor allem interessant [...] zu beobachten, wie wenig Unterschied zwischen hier und bei uns besteht“. ${ }^{278}$ Die Kenntnis großer kultureller und geographischer Differenzen relativiert die europäischen Unterschiede, und so zeigt sich ihm nach

273 Vgl. Riehl 1859, S. 218.

274 Vgl. Fontane: Wanderungen, 2002, S. 536.

275 Alle Zitate Fontane: Wanderungen, 2002, S. 9-10.

276 Stefan Neuhaus betont in seiner Interpretation von Fontanes Vorwort die Phantasie als eigentliche Konstrukteurin von Heimat: „Es wird nicht, wie es der Topos der Forschung will, eine Rekonstruktionsarbeit begonnen, sondern eine Konstruktionsarbeit. Es ist nicht die Erinnerung, die sich Bahn bricht - das Vergangene ist vergangen und von begrenztem Wert für die Gegenwart, wenn nicht ,die Phantasie، dazu kommt, die eine Adaption im Hier und Jetzt überhaupt erst möglich macht.“ Neuhaus 2018, S. 65.

277 Vgl. Fontane: Wanderungen, 2002, S. 168.

278 Fontane: Wanderungen, 2002, S. 168, zitiert ist ein Brief von Wilhelm Gentz. 
seiner Rückkehr aus Afrika selbst Spanien als „Heimat“. ${ }^{279}$ Gentz verbindet auf natürliche Weise die Liebe zur eigenen Nation mit Kosmopolitismus. ${ }^{280}$ Dieser Standpunkt hat direkte Auswirkungen auf sein Verständnis vom künstlerischen Sujet. Gentz' bekannte Bilder stellen denn auch alles andere als Naheliegendes dar, zu ihnen zählen Nillandschaft mit Flamingos, Schlangenbeschwörer, Sklaventransport durch die Wüste: „Es ist natürlich, daß ein Künstler das Naheliegende, das Heimatliche, das Vaterländische vollendeter als das Fremde zu schildern vermag. Sollte aber nicht, wie die Wissenschaft, so auch die Kunst dazu berechtigt sein, den ganzen Erdball in ihr Gebiet zu ziehen?“281

,Welt' wird also zum einen in Form von Porträts kosmopolitisch gesinnter Brandenburger in die Wanderungen hineingetragen. Wichtiger noch ist der humorvolle Darstellungsmodus, in dem sich die Liebe zum Ländlichen immer auch als liebenswerte Provinzialität erweist. Etwa, wenn es um den Badeort Freienwalde geht, in den sich kein Fremder verirrt:

Freienwalde ist ein Badeort, eine Fremdenstadt und trägt es auf Schritt und Tritt zur Schau; was ihm aber ein ganz eigentümliches Gepräge gibt, das ist das, daß alle Bade- und Brunnengäste, alle Fremden, die sich hier zusammenfinden, eigentlich keine Fremden, sondern märkische Nachbarn, Fremde aus nächster Nähe sind. [...] Der breite Stempel, den die echten und unechten Engländer seit fünfzig Jahren allen europäischen Badeörtern aufzudrücken wußten, hier fehlt er noch, hier ist der komplizierte „Breakfast-Tisch“ noch ein kaum geahntes Geheimnis, hier wird noch gefrühstückt, hier sucht noch kein grüner und schwarzer Tee die alte Herrschaft des Morgenkaffees zu untergraben, hier herrscht noch die vaterländische Semmel und weiß nichts von Buttertoast und Muffin, des Luftbrodes (aërated bread) und anderer Neuerungen von jenseits des Kanals ganz zu geschweigen. [...] Während überall sonst ein gewisser Kosmopolitismus die Eigenart jener Städte, die das zweifelhafte Glück haben „Badeörter“ zu sein, abzuschwächen oder ganz zu verwischen wußte, ist Freienwalde eine märkische Stadt geblieben. Kein Wunder. Nicht der Welttourismus, nur die Mark selber kehrt hier zum Besuche bei sich ein. ${ }^{282}$

279 „Nach Spanien zurückgekehrt, glaube ich mich in meine Heimat versetzt, so groß war der Unterschied zwischen europäischem und afrikanischem Leben.“ Fontane: Wanderungen, 2002, S. 156.

280 „Ich halte es für selbstverständlich, daß jeder, der unter bestimmten Einflüssen seines Lebens groß geworden ist, dies Land und seine Nation mehr liebt als andere Nationen. Ich hasse aber die Kirchturmpolitik. Da andere Völker die leuchtendsten Vorbilder hervorgebracht haben: Homer, Äschylus und Phidias, Christus, Shakespeare, Michelangelo und Tizian, so kann ich nicht einsehen, warum man das Fremde geringer achten soll.“ Fontane: Wanderungen, 2002, S. 156. 281 Fontane: Wanderungen, 2002, S. 188.

282 Fontane: Wanderungen, 2002, S. 591-592. 
Die „vaterländische Semmel“ ist eine Idee, die auch vom alten Stechlin aus Fontanes letztem Roman Der Stechlin (1897/98) hätte stammen können. Hier ist das Verhältnis von Provinz und Welt noch einmal das Zentrum eines fontaneschen Textes und Heimatliebe wird ganz ähnlich im Stil humorvoll-kosmopolitischer Reserve behandelt.

Die sich zwischen Berliner Hauptstadt und brandenburgischer Provinz bewegenden Figuren in Der Stechlin unterhalten sich ständig über die Vorzüge und Nachteile des Lebensortes. Die einen finden es traurig, abseits der Stadt „versauern zu müssen“, ${ }^{283}$ die anderen fühlen sich vom Ländlichen ,angeheimelt", ${ }^{284}$ teilweise, so wie hier der Superintendent Koseleger, beides zugleich. Gleich das erste längere Gespräch (zwischen Rex, Katzler und Lorenzen) behandelt die Frage kontrovers, ob dem „Globetrotter“ und dessen „Leben draußen in der Welt“ oder der „Stabilisierung“, dem „Sichzurückziehen aus der Welt“ der Vorzug zu geben sei. Der Gesprächsverlauf gibt schon die Antwort des Romans vor: Es ist der (wie immer bei Fontane ambivalente) Sympathieträger Lorenzen, der dem Vorurteil widerspricht, dass sich im engeren Kreis notwendig auch der Sinn verengen müsse. ${ }^{285}$

Es sind gerade die weltoffenen Charaktere, die der Provinz etwas abgewinnen können: „In unsrer sogenannten großen Welt gibt es so wenig, was sich zu sehen und zu hören verlohnt; das meiste hat sich in die stillen Winkel der Erde zurückgezogen“, ${ }^{286}$ sagt die vielgereiste Melusine. Und der alte Stechlin erinnert sich gern der Zeit, in der er „Fühlung mit der großen Welt“ gehabt hat, und ist doch seinem Landgut verhaftet: „Es heißt immer, der Adel gehöre auf seine Scholle, und je mehr er mit der verwachse, desto besser sei es. Das ist auch richtig. Aber etwas ganz Richtiges gib es nicht.“287 Woldemar charakterisiert den alten Stechlin entsprechend als „echten alten Junker“ und zugleich als „Weltmann“: „Er weiß was sie hierzulande nicht wissen oder nicht wissen wollen -, daß hinterm Berge auch noch Leute wohnen. Und mitunter noch ganz andre.“288

Die zwiespältigen Bedürfnisse zwischen Dableiben und Reisen werden vom Grafen Barby als Effekt einer zunehmend zusammenrückenden Welt beschrieben: „Jeder lebt zu Hause mehr oder weniger wie in einem Gefängnis und will weg. Und doch bin ich eigentlich gegen das Reisen überhaupt. [...] Und wozu denn auch? [...]

283 Fontane: Stechlin, 2002, S. 172.

284 Fontane: Stechlin, 2002, S. 173.

285 Alle Zitate Fontane: Stechlin, 2002, S. 29-30; Lorenzen will dem „Weltfremde[n]“ Vorzüge abgewinnen.

286 Fontane: Stechlin, 2002, S. 136.

287 Beide Zitate Fontane: Stechlin, 2002, S. 305.

288 Alle Zitate Fontane: Stechlin, 2002, S. 117. 
Das Beste vom Parthenon sieht man in London und das Beste von Pergamum [sic] in Berlin [...].“289 Symbolisch wird diese neue Welthaltung repräsentiert durch den Stechlinsee, der, „wenn's sein muß, mit Java telephoniert““. ${ }^{290}$ Der See als Inbegriff des Unverrückbaren ist nach einer Sage der Gegend mit dem anderen Ende der Welt verbunden: „,wenn es in Java oder auf Island rumort [...] dann springt auch in unserm Stechlin ein Wasserstrahl auf“. ${ }^{291}$ Auch im vermeintlich unbedeutenden See ist also ein Geheimnis zu finden. Dass der See nach Java „telephoniert“, ist ebenfalls wichtig. Die modernen Kommunikationsmedien schaffen eine neue Konstellation von Nähe und Distanz, An- und Abwesenheit, Region und Welt. ${ }^{292}$ Wie der Graf Barby, der nicht mehr reisen will, weil die Kunstschätze sich zu ihm bewegen, kann auch in der Provinz der Kosmopolit sitzen.

Der See „hat Weltbeziehungen“, 293 so wird mehrfach nicht ganz ernsthaft gesagt. Ganz unironisch führt Melusine dann aus: „Alles Alte, soweit es Anspruch darauf hat, sollen wir lieben, aber für das Neue sollen wir recht eigentlich leben. Und vor allem sollen wir, wie der Stechlin uns lehrt, den großen Zusammenhang der Dinge nie vergessen. Sich abschließen, heißt sich einmauern, und sich einmauern ist Tod.“294 Abgesetzt wird dieses kosmopolitische Bekenntnis zur Provinzialität von der wirklichen Provinzialität, die auch beim Großstädter gefunden werden kann. Gerade dem Berliner sei „die Gabe wirklichen Vergleichenkönnens völlig versagt““ ${ }^{295}$ Die Ironie, die gegenüber solcher Großstadt-Provinzialität gutmütig bleibt, stößt mit der Figur der Adelheid an ihre Grenzen und wird beißend gegenüber einer Selbstgerechten, die sich zugutehält, dass ihr alles Fremde widerstehe. Aus der Perspektive des Romans spricht das entschieden gegen sie. ${ }^{296}$ Gerade ihr, die geistige Beschränktheit und moralische Enge repräsentiert, wird dann mehrfach der - sonst sehr sparsam verwendete - Begriff der Heimat in den

289 Fontane: Stechlin, 2002, S. 308.

290 Fontane: Stechlin, 2002, S. 57.

291 Fontane: Stechlin, 2002, S. 136.

292 Vgl. Vogl 2010.

293 Fontane: Stechlin, 2002, S. 135.

294 Fontane: Stechlin, 2002, S. $270-271$.

295 „Wie beinah jedem hierlandes Geborenen, war auch ihr die Gabe wirklichen Vergleichenkönnens völlig versagt, weil jeder echte, mit Spreewasser getaufte Berliner, männlich oder weiblich, seinen Zustand nur an seiner eigenen kleinen Vergangenheit, nie aber an der Welt draußen mißt, von der er, wenn er ganz echt ist, weder eine Vorstellung hat noch überhaupt haben will. Der autochthone ,Kellerwurm;, wenn er fünfzig Jahre später in eine Steglitzer Villa zieht, bildet - auch wenn er seiner Natur nach eigentlich der bescheidenste Mensch ist - eine gewisse naive Krösusvorstellung in sich aus und glaubt ganz ernsthaft, jenen Gold- und Silberkönigen zuzugehören, die die Welt regieren.“ Fontane: Stechlin, 2002, S. 121.

296 Vgl. Fontane: Stechlin, 2002, S. 283. 
Mund gelegt. In der Heiratsfrage gibt sie ihrem Neffen Woldemar den Rat: „[G]ib auch in dieser Frage die Heimat nicht auf, halte Dich, wenn es sein kann, an das Nächste“;297 und noch einmal: „[H]eirate heimisch und heirate lutherisch.“298 Woldemar hält sich nicht an den Rat. Aber er zieht am Ende mit seiner Frau von Berlin auf das Schloss Stechlin und bereut seine Entscheidung nicht: „Die Scholle daheim, die dir Freiheit gibt, ist doch das Beste. “299 Es steht also am Ende eins zu eins für und gegen die Heimat.

\section{Riehls Die Dichterprobe und Ein ganzer Mann}

Über Wilhelm Heinrich Riehls - heute so gut wie unbekanntes - schriftstellerisches Werk ${ }^{300}$ fällte selbst der sonst dem Deutsch-Redlichen durchaus aufgeschlossene Fritz Martini ein deutliches Urteil: „Das Gemüthaft-Tüchtige, DeutschRedliche, Humoristisch-Genrehafte führte künstlerisch zu populärer Anspruchslosigkeit." ${ }^{301}$ Riehls von ihm selbst so betitelte Kulturgeschichtliche Novellen sind hier gleichwohl interessant, und zwar deswegen, weil sie eng mit seinem volkskundlichen Heimatprogramm zusammenhängen. ${ }^{302}$ Eine dezent humoristische, teilweise selbstironische Figurengestaltung des Heimatforschers geht dabei mit einem gesellschaftliche Friktionen harmonisierenden Anspruch an Heimat einher.

Die ,Heimatforscher', die auch in Riehls literarischen Texten immer wieder auftauchen, sind meist ein wenig weltfremd und wunderlich, wie der Schulmeister Philipp Balzer in Burg Neideck. Er wird von seiner Umgebung als „halber Narr“303 wahrgenommen und erscheint „mitunter komisch, wenn er recht ernst-

297 Fontane: Stechlin, 2002, S. 160.

298 Fontane: Stechlin, 2002, S. 162.

299 Fontane: Stechlin, 2002, S. 387.

300 Riehl als Schriftsteller wurde in der Literaturwissenschaft nur vereinzelt behandelt, vgl. Janke 1910; Schrott 1944; MacCort 1974; Schwarz 1997; Wiese 2007. Wiese behandelt Riehls Wanderbuch mit mehr kultur- als literaturwissenschaftlichem Interesse.

301 Martini 1974, S. 451. Die nach dem Nationalsozialismus bruchlos fortgesetzte Karriere des einflussreichen Germanisten Fritz Martini harrt noch der Aufarbeitung. Der im Nachkriegsdeutschland u. a. für die Realismusforschung bedeutsame Germanist war bei den beiden eng mit der völkischen Ideologie verbundenen Germanisten Julius Petersen und Robert Petsch mit einer Arbeit zu Wilhelm Raabe promoviert und der Arbeit Das Bauerntum im deutschen Schrifttum (1944) habilitiert worden; vgl. König 2003, Bd. 2, S. 1164-1166.

302 Anna Schrott liest die späte Novellistik Riehls im Kontext seiner volkskundlichen Studien, vgl. Schrott 1944, S. 92. Dieser sinnvolle Ansatz wurde in der Folge nicht mehr aufgenommen. 303 Riehl: Burg Neideck (1876), in: Riehl 1937, Bd. 3, S. 165-204, hier S. 198. 
haft sein wollte“. ${ }^{304}$ Am Ende ist es aber seine selbstverfasste Regionalchronik, die dazu führt, dass eine gelangweilte Prinzessin überhaupt an etwas Interesse entwickelt. Bisher war sie von ihrer Erzieherin Martigny nur mit französischen Büchern über ferne Orte traktiert worden; ,es tat der Prinzessin so wohl, zum erstenmal auch über die nächste Heimat, über das Rätsel, welches vor ihrem Fenster lag, Gedrucktes zu lesen“. ${ }^{305}$ Das Buch des Schulmeisters zeigt der Prinzessin die Möglichkeit des Perspektivwechsels und ein „ganz neuer Geist der Widersetzlichkeit erwachte in ihr“; ${ }^{306}$ am Ende führt dies dazu, dass sie den richtigen Mann heiratet (der ebenfalls die Schrift des Schulmeisters kennt und schätzt) und sogar die Burg Neideck vor dem Abriss bewahrt. Es ist also gerade der etwas wunderliche ,Heimatpfleger‘, der für den guten Ausgang der Novelle sorgt.

Die Dichterprobe (1865), die chronologisch letzte Novelle aus Riehls zyklisch konzipierter Novellensammlung ${ }^{307}$ (und als letzte im Zyklus topischer Ort für poetologische Reflexionen) beleuchtet Heimat als Motiv und Telos der Novellensammlung. In der Rahmenhandlung unterhalten sich mehrere Freunde über Volksdichtung und die Frage, wie „große Poeten [...] eigentlich in den Volksmund kommen?“308 Die sich anschließende Erzählung Richard Märkers bietet eine Antwort auf diese Frage. Märker erzählt, dass er eine Chronik seiner eigenen Herkunftsgegend verfasst habe. Diese Chronik soll seine „schönsten Jugenderinnerungen verklären und verewigen. “" ${ }^{309}$ Dabei habe er seiner Phantasie ziemlich freien Lauf gelassen und beruft sich mit dieser Auffassung von dichterischer Freiheit auf Berthold Auerbach, ${ }^{310}$ Heinrich Heine und Heinrich von Kleist. ${ }^{311}$

304 Riehl 1937, Bd. 3, S. 190.

305 Riehl 1937, Bd. 3, S. 190.

306 Riehl 1937, Bd. 3, S. 191.

307 Die fünfzig Novellen, die vom 9. bis zum 19. Jahrhundert deutsche Kulturgeschichte behandeln, sind vom Autor als Gesamtwerk konzipiert, aber erst nach seinem Tod in der von ihm gewünschten chronologischen Reihung als Sammlung erschienen, so dass sie, wie von ihm erhofft, auch „als ein Ganzes beurteilt“ werden können. Vgl. das Nachwort in Riehl 1937, Bd. 3, S. 355-369, hier S. 369. Das Zitat von Riehl ist dort nicht näher nachgewiesen. Riehl selbst nahm auch die Einteilung der Novellen in sieben Zeitepochen vor; so zählt die hier besprochene Novelle Vergelt’s Gott etwa zum Abschnitt „Reformation und Renaissance“, die Novelle Burg Neideck zum Abschnitt „Rokokozeit“ und Die Dichterprobe zum Abschnitt „Das 19. Jahrhundert“.

308 „Wenn nämlich der gemeine Mann spricht, so sagt der Demokrat: das ist die Stimme des Volkes, und wenn der Gebildete einen Dichter liest, so sagt der Literat: dieser Glückliche wird vom Volke gelesen. Der eine blickt von unten hinauf und merkt nicht, was oben geschieht, der andere von oben hinab und ahnt nicht, was unten vorgeht." Riehl: Die Dichterprobe. Als Epilog (1865), in: Riehl 1937, Bd. 4, S. 301-327.

309 Riehl 1937, Bd. 4, S. 304.

310 Er hatte das Hohen-Isenecker Tal „durch die Poesie geographisch berühmt machen wollen wie Auerbach sein Nordstetten, ich hegte eine volle Jugendfreundschaft für Hohen-Iseneck und 
Nachdem er durch einen Brief des Hohen-Isenecker Pfarrers erfährt, dass seine Geschichten im ,Hinterbrunner Wochenblatt' gedruckt und von den Talbewohnern gelesen würden, macht er sich auf den Weg ins Tal, „um zu erforschen, wie weit ich bereits ins Volk gedrungen“. ${ }^{312}$ Die Pointe der Geschichte besteht nun in einer gänzlichen Desillusionierung dieses Vorhabens: Auf seine Geschichten angesprochen, kennen die Talbewohner diese gar nicht, solche Geschichten seien nur „für die alten Weiber“. ${ }^{313}$ Die Heimatliebe, die er zunächst unter den Talbewohnern zu erkennen glaubt, hat ihre Ursachen nicht in der Lektüre seiner Texte. Den ersten Menschen, dem er begegnet und der sein Bedauern über den bevorstehenden Abbruch einer alten Burgruine äußert, denkt er sich sogleich als Leser seiner Geschichten:

Der Mann scheint ein Herz zu haben für die Denkmale seiner Heimat, und die Sagen der Burg waren ihm gewiß nicht fremd; vielleicht hatte er sogar meine Geschichte von Herrn von Hohen-Iseneck und seinen zwei Kartaunen im Hinterbrunner Wochenblatt gelesen. Also frage ich ihn, warum er denn den Abbruch des alten Gemäuers bedauere. ${ }^{314}$

Es stellt sich heraus, dass das Gegenüber ein Landstreicher ist, der die Burgruine bisher als Unterschlupf benutzt hat: „Jetzt wußte ich klar, daß dieser Freund der Burgruinen dennoch kein eigentlicher Romantiker sei und meine Geschichte des tollen Herrn von Hohen-Iseneck schwerlich gelesen habe.“315 Wie wenig der volkskundlich-poetisierende Blick auf Heimat mit den Realitäten zu tun hat, zeigt auch, wie Märker, der fortwährend Poetisches sieht, wo nur Schmutz und Un-

hatte meine Novellenstaffagen fast nur gezeichnet, um die Landschaft malen zu dürfen. Denn mit Naturheimweh und Naturpoesie beginnt der Jüngling, mit Menschenheimweh und Menschenpoesie schließt der reife Mann.“ Riehl 1937, Bd. 4, S. 305.

311 „Und wenn nun gar jene Geschichten, die ich eigens der Landschaft auf den Leib geschrieben und neu erfunden hatte, dort sich einpflanzten, umbildeten, vom Volksmund aufgenommen, selbst wieder Volkssage wurden, war das nicht ein seltenerer Ruhm, als ihn die größte Leserschar und das lauteste Lob der Kritik zu bieten vermag? Gibt es einen beneidenswerteren Nachruhm für Heine, als daß er seine Loreley, von welcher vordem nicht einmal die St. Goarshäuser das mindeste gewußt, dem ganzen deutschen Volke so fest in den Mund gedichtet, daß man diesem literarischen Gespenste sogar schon einmal eine überlebensgroße Statue hat setzen wollen? Und mit welchem Stolze müßte es Heinrich von Kleist erfüllen, wenn er jetzt nach Heilbronn käme und sähe, wie man dem Fremden das Haus seines Kätchens von Heilbronn zeigt, welches doch niemals woanders hauste als in seinem Buch und auf den Brettern?“ Riehl 1937, Bd. 4, S. 306.

312 Riehl 1937, Bd. 4, S. 305.

313 Riehl 1937, Bd. 4, S. 312.

314 Riehl 1937, Bd. 4, S. 308.

315 Riehl 1937, Bd. 4, S. 310. 
wirtlichkeit herrscht, ${ }^{316}$ selbst die Grobheiten des Wirts als erforschenswerte Authentizität umdeutet: „Der Wirt empfing mich zwar etwas grob, allein seine Mundart war so echt, daß man die halb gebrummten, halb gesprochenen Antworten sogleich als Sprachproben für Firmenichs deutsche Völkerstimmen hätte aufschreiben können." ${ }^{317}$ Der Wirt erweist sich schließlich als einziger Leser von Richard Märkers Heimatchronik, verwünscht sie allerdings aufgrund ihrer Unwahrheit, so dass sich Märker lieber als deren Autor verleugnet, um nicht „die volkstümlichsten Grobheiten“318 vom Wirt erfahren zu müssen. Durchaus selbstironisch wird hier also die poetisierende Heimatauffassung des gebildeten Städters aufs Korn genommen (vgl. I.2.4). Es findet aber auch eine Läuterung Richard Märkers während seiner Reise durchs Hohen-Isenecker Tal statt: Ein von ihm miterlebter Totschlag und die Begegnung mit einer schillerschen Karl-Moor-Gestalt in einer Umgebung, in der niemand den Namen Schillers kennt, zeigen ihm den wahren Stoff für seine Dichtung, die der Erfindung gar nicht bedarf. In einer zweiten Rahmenerzählung räsoniert die Erzählinstanz, ein Freund Richard Märkers, über Märkers Veranlagung zum Dichter, denn das „Rohe und Wüste“ habe sich ihm „im Goldschimmer des Humors verklärt“ und „die tatsächliche Ironie des wirklichen Lebens auf sein ideales Streben ward ihm sogar wieder zum dichterischen Motiv““. ${ }^{319}$ Das dichterische Potential liegt hier in der Verklärung des Gegenstandes. Das ideale Streben muss sich mit dem wirklichen Leben verbinden, und dies gelingt über den Humor. Heimat wird also durch die Binnengeschichte des selbstironisch die eigene Naivität eingestehenden Heimatdichters nicht desavouiert, vielmehr gehen Humor und Heimat durch die rahmende Invektive am Ende eine harmonische Allianz ein. ${ }^{320}$

Genauso verhält es sich noch in Riehls letztem Roman Ein ganzer Mann (1897), der „den Leser auf gewinnendste Weise für die Gedanken der Heimatpflege und für die Wertschätzung der Denkmäler erzieht“, wie 1954 Riehls Biograph

316 Vgl. Riehl 1937, Bd. 4, S. 315, S. 317.

317 Riehl 1937, Bd. 4, S. 314.

318 Riehl 1937, Bd. 4, S. 318.

319 Riehl 1937, Bd. 4, S. 327.

320 Es ist symptomatisch für die realistische Literatur insgesamt, dass dieser auf Verklärung zielende Humor die einzige Spielart des Komischen ist, mit der sich Heimat verbindet. Wilhelm Raabes Texte sind ein weiteres Beispiel dafür. Heimat als Gegenstand von Parodie, Satire, Witz, Ironie oder anderen Spielformen der Komik (vgl. Wirth 2017) sucht man in der Literatur des 19. Jahrhunderts in Bezug auf Heimat (auch vor dem Realismus) fast vergeblich; eine Ausnahme ist E.T.A. Hoffmanns Goldener Topf (vgl. II.1.3). Zur Ironiefreiheit von Heimat vgl. auch Blickle 2002, S. 40-42. 
Viktor von Geramb meint. ${ }^{321}$ Wie von Geramb diesen Roman, dessen programmatischer Auftakt sich deutlich genug von den literarischen Entwicklungen seiner Zeit absetzt, ${ }^{322}$ als ,packend ${ }^{6323}$ bezeichnen kann, bleibt schleierhaft, von Interesse ist hier aber die Darstellung von Heimat als heilender Kraft, die es vermag, Tourismus und antiquarische Interessen genauso zu versöhnen wie den Ewigen Juden (vgl. II.1.3.2) zu überwinden.

Der Konflikt des Romans entspinnt sich um den Haderturm des Städtchens Frankenfeld - es ist symptomatisch, dass es sich hier um eine Kleinstadt handelt $^{324}$ - und die Frage, ob er zugunsten der Ansprüche der neuen Zeit abgerissen oder aber erhalten werden soll. Der ,Verein zur Hebung des Fremdenverkehrs` kämpft für seinen Abriss. Dieser Verein wird durch den Entwurf eines Reklamebildes charakterisiert, welches das Stadtbild für den touristischen Geschmack veredelt, etwa indem sie mit einer Bergsilhouette umgeben wird, obwohl die Berge von der Stadt aus nicht zu sehen sind: „Wir dürfen unsere Stadt rühmen: das ist kein Selbstlob sondern Heimatliebe. “325 Die hier in polemischer Absicht gezeigte ,falsche“ Heimatliebe, die eigentlich ökonomische Absichten verfolgt, wird im Romanverlauf in eine ,echte ${ }^{6}$ Heimatliebe überführt: Der Haderturm wird in Friedensturm umbenannt und die der Heimat bisher Entfremdeten geraten über die Errichtung eines Heimatmuseums wieder in Kontakt mit ihr; zudem wird eine Ehe gestiftet und dem sich bisher „heimatlos“326 fühlenden Fräulein von Rohda ein Zuhause gegeben. Der Konflikt zwischen ökonomisch motivierter und richtig verstandener Heimatliebe wird im rahmenden Endkapitel noch einmal aufge-

321 Geschildert wird in diesem „Museumsroman“, wie der Großindustrielle Alfred Saß zum „Schöpfer und Gestalter eines feinen“ Museums „und gleichzeitig zu einem überzeugten Freund und Hüter heimatlichen Lebens heranreift. Alle Erfahrungen, die Riehl als Direktor des Bayerischen Nationalmuseums und als Generalkonservator der bayerischen Altertümer durch zwölf Jahre gewonnen hatte, sind in diesem Roman in packender Weise dargelegt. “ Alle Zitate Geramb 1954, S. 524-525.

322 Das Ideal eines Romans ist hier charakterisiert durch „gemütliche Stimmung“ und „ein behagliches Lächeln“, eine Kunst, „die mehr anregt als aufregt“ und die mehr „das Sonntagsgesicht der Menschen“ als „Marterbilder“ zeigt; kurz, ein „gesunder Roman, bei dessen Lektüre es dem Leser recht von Herzen wohl wird“, sei „der zeitgemäßeste“. Alle Zitate Riehl: Aus dem Begleitschreiben bei Uebersendung des Buches an eine Freundin, in: Riehl 1897, S. V-VIII.

323 Vgl. Geramb 1954, S. 525.

324 Christiane Nowak arbeitet in ihrer Studie zum Topos Kleinstadt zwischen 1900 und 1933 die enge Verbindung von Heimat- und Kleinstadtbildern in der deutschen Literatur heraus. Die Kleinstadt verbindet sich, wie Nowak anhand von Autoren im Umfeld der Zeitschrift Der Kunstwart zeigt, mit einem Sozialmodell des Zusammenhalts und einem Wertemodell des spezifisch Deutschen, vgl. Nowak 2013, S. 133-140.

325 Riehl 1897, S. 28.

326 Riehl 1897, S. 271. 
nommen, als der Erzähler, „Professor Wilhelm Heinrich Riehl aus München“, ${ }^{327}$ der das Städtchen Frankenfeld besucht, vom Wirt für den inkognito reisenden Karl Baedeker gehalten wird. Dass jemand sich für Frankenfeld interessieren könne, kann der Wirt sich höchstens so erklären. Riehl will aber, genau wie Fontane, nicht als Baedeker missverstanden werden. Die latente Aporie, die das anachronistische Heimatbegehren in Zeiten des modernen Tourismus in sich birgt und die Fontane in seinen Wanderungen reflektiert, wird auch von Riehl thematisiert, aber gleich wieder in harmloses Wohlgefallen überführt.

Diese starke Harmonisierungstendenz des Romans kann auch die Art und Weise zeigen, wie die Ahasver-Geschichte verarbeitet wird. Es ist ein Jude und genauer die ihm anhaftende Geschichte des Ewigen Juden, die der Verwirklichung des Heimatmuseums zunächst im Weg steht. Der Roman besteht zu einem guten Teil aus der Entwirrung der Intrige, die die jüdische Figur spinnt, um das Heimatmuseum zu verhindern.

Im Zuge der Sichtung historischer Akten für das zukünftige Museum entdeckt der Ratsdiener Kaspar Zuckmeyer, dass er Nachfahre des wandernden „Trödeljuden Levi“328 ist, der sein Geld damit verdiente, „als der wahrhaftige Ewige Jude den dummen Bauern zu erscheinen“, ${ }^{329}$ um von der Mischung aus Mitleid und Entsetzen, das er damit produzierte, zu profitieren. Levi „spielte meisterlich Ahasver, den Ewigen Juden“, ${ }^{330}$ wurde schließlich doch überführt und zum Tod verurteilt, behielt sein Leben aber, weil er die Richter überzeugen konnte, Christ geworden zu sein. Kaspar Zuckmeyer ist entsetzt, genealogisch mit einem Juden und dazu mit einem solchen in Verbindung gesetzt zu werden, verbrennt die Akten und spinnt Intrigen, um die Verwirklichung des Museums und damit auch die Sichtung der Akten und die mögliche Entdeckung seiner Tat zu verhindern. Am Ende wird er von Hermine von Rohda und Alfred Saß überführt, sie versprechen aber, sein Geheimnis nicht preiszugeben.

Der Jude sorgt bei Riehl für einige böse Verwirrungen - nicht für den tödlich endenden Ruin wie in Freytags Soll und Haben oder Polenz' Büttnerbauern -, am Ende fungiert er aber auch als Katalysator für den glücklichen Ausgang. Er selbst stirbt am Ende, wie es die literarischen Ausgestaltungen des Ahasver-Mythos im 19. Jahrhundert immer vorsehen; aber die eigentliche Versöhnung hat schon vor seinem Tod stattgefunden. Kaspar Zuckmeyer sei durchs Heimatmuseum erzogen worden und habe indirekt dafür gesorgt, dass Vergangenheit und Gegenwart, Altes und Modernes, Mann und Frau in harmonische Verbindung getreten seien,

327 Riehl 1897, S. 399.

328 Riehl 1897, S. 153.

329 Riehl 1897, S. 158.

330 Riehl 1897, S. 159. 
wie Alfred Saß, der Gründer des Museums, gegenüber der Erzählerfigur ,Professor Wilhelm Heinrich Riehl aus München' resümiert. Der Jude Zuckmeyer wird dem Museum in der Bildlichkeit von Saß einverleibt, er sei zum „Inventarstück des Museums“ geworden. Die integrierende Kraft des Heimatmuseums ist zugleich eine erzieherische: „Nachdem er eine einzige große Untreue begangen, deren wir ihn, Fräulein von Rohda und ich, ebenso sanft als zwingend überführten, wurde er der tadellos treueste Diener, der für uns Beide durchs Feuer gegangen wäre. “331 Auch Alfred Saß selbst, so führt er weiter aus, sei durch das Museum erzogen worden:

„Das Museum übte an ihm eine erziehende Kraft; - es hat sie auch an mir geübt. Es lehrte mich Gerechtigkeit. Früher nur für neueste Kunst und neues Schrifttum begeistert, wurde ich's jetzt auch für unserer Väter Werke. Als Hüter meiner Altertümer wurde ich zuletzt so gerecht gegen die alte Zeit, daß ich auf dem Punkte war, ungerecht zu werden gegen die neue. Da trat meine Hermine dazwischen, ein echtes Kind der Gegenwart wie die meisten Frauen, und indem ich für sie schwärmte, begann ich auch wieder für die Gegenwart zu schwärmen, ohne meiner Freude am Alten untreu zu werden.““332

Das Heimatmuseum wird in Riehls Roman damit zum Ort der Integration: Das Alte und das Neue, Frau und Mann, das Erhaltende und das Zukunftsweisende verbinden sich hier. ${ }^{33}$ Die jüdische Figur dagegen, wie so oft in literarischen Darstellungen des 19. Jahrhunderts, kann noch Läuterung erfahren, muss am Romanende aber sterben.

Auch wenn Riehls literarische Produktion somit als ein Beispiel für die soziale und politische Friktionen verharmlosende, ja negierende Funktion von Heimat

331 Riehl 1897, S. 404.

332 Beide Zitate Riehl 1897, S. 404-405.

333 Diese integrative Funktion hat - und nur insofern vergleichbar - auch das in der Literatur des 20. Jahrhunderts berühmt gewordene Heimatmuseum Siegfried Lenz' in dessen gleichnamigem Roman von 1978. Der Protagonist Zygmunt Rogalla widmet sein ganzes Leben dem Heimatmuseum eines masurischen Städtchens und muss es doch am Ende in Flammen aufgehen lassen, um es vor seiner fortwährenden ideologischen Vereinnahmung zu bewahren. Der Kern des im Heimatmuseum lebenden Gedankens bleibt davon aber unangetastet. Über das Wort ,Heimat‘ sagt Rogalla: „Ein schlimmes Wort? Ein belastetes Wort? [...] ich gebe zu, daß dies Wort in Verruf gekommen ist, daß es mißbraucht wurde, so schwerwiegend mißbraucht, daß man es heute kaum ohne Risiko aussprechen kann [...] was spricht gegen den Versuch, dieses Wort von seinen Belastungen zu befreien? Im seine Unbescholtenheit zurückzugeben? [...] Heimat, das ist für mich nicht allein der Ort, an dem die Toten liegen; es ist der Winkel vielfältiger Geborgenheit, es ist der Platz, an dem man aufgehoben ist, in der Sprache, im Gefühl, ja selbst im Schweigen aufgehoben, und es ist der Flecken, an dem man wiedererkannt wird; und das möchte doch wohl jeder eines Tages: wiedererkannt, und das heißt: aufgenommen werden [...].“ Lenz 1978, S. 119-120. Zu Lenz vgl. Fries 1987, Schaal 2006, McIsaac 2007, S. 223-254. 
gelten muss und sie auch die Tragweite der von ihm selbst eröffneten Frage nach dem Verhältnis von objektivierbarer und literarischer Heimat nicht einholen kann, bleiben seine volkskundlichen Arbeiten auch im historischen Rückblick die wichtigste zeitgenössische Referenz für eben diese Fragen. Freytags Soll und Haben zeigt sich als Versuch, Antworten auf die sozialpolitischen Umwälzungen der eigenen Gegenwart mit dem Mittel einer Aktualisierung von Heimat als Sitz eines sich über Arbeit und Ehrenkodex definierenden Bürgertums zu geben und schließt damit vielfältig an Riehls Ideen an. Und Fontane greift in seinen Wanderungen durch die Mark Brandenburg Riehls Programm des Erwanderns und, damit verbunden, der poetischen Schöpfung von Heimat auf. Denn Riehls Verstehensmethode der Zusammenschau und Fiktionalisierung will zu einer Wahrheit vordringen, die das Objektivierbare übersteigt, und so lässt sich für ihn auch Heimat nur mit einer von ihm als spezifisch poetisch ausgewiesenen Untersuchungsmethode erfassen. Kein Wunder, dass sich Wissenschafts- und Literaturgeschichte in Bezug auf Heimat hier kaum mehr trennen lassen.

\subsection{Heimatkunst und Literaturgeschichte}

Die Germanistik integriert Heimat ab dem letzten Drittel des 19. und stärker noch mit Beginn des 20. Jahrhunderts in ihre Wissenschaftssprache, zeitgleich mit ihrer neuerlichen Ausrichtung auf volkskundliche Ansätze. Schon im Verlauf des 19. Jahrhunderts sind Germanistik und Volkskunde eng miteinander verbunden: Die deutsche Sprachforschung und die germanische Altertumskunde als Teilgebiete der Hochschulgermanistik sind personell mit der Volkskunde verknüpft. ${ }^{334}$ Die Arbeiten von Jacob und Wilhelm Grimm wurden als Vorläufer volkskundlicher Forschung verstanden. ${ }^{335}$ Und der Wissenschaftler Karl Weinhold, habilitierter germanistischer Mediävist, trug mit der Gründung des Vereins für Berliner Volks-

334 Vgl. Weber-Kellermann 1969; vgl. Emmerich 1972. Emmerichs Studie erschien unter dem Titel Germanistische Volkstumsideologie. Genese und Kritik der Volksforschung im Dritten Reich 1968 als Dissertation, die überarbeitete Fassung von 1972 dann unter dem Titel Zur Kritik der Volkstumsideologie.

335 So etwa bei Riehl: Neben anderen Wissenschaften wie der Statistik, der Nationalökonomie, Geographie, Ethnographie, Geschichte, der Staats- und Rechtskunde greife die Volkskunde „ganz besonders auf die mythologischen, antiquarischen und philologischen Forschungen der sogenannten Germanisten“ zurück, wo „nur die Namen der Gebrüder Grimm“ ausreichend seien, um „unmittelbar zu veranschaulichen, daß wir von einer neuen Wissenschaft der Volkskunde selbst dann reden könnten, wenn wir auch gar nichts weiteres besäßen, als was diese beiden Männer zur Erkenntniß des deutschen Volkes ausgesonnen und ausgearbeitet haben.“ Riehl 1859, S. 228. 
kunde und der Herausgabe der Zeitschrift des Vereins für Volkskunde (ab 1891) mit zur Institutionalisierung des Faches Volkskunde bei. ${ }^{336}$

Wie für die Philologien schon des 19. Jahrhunderts insgesamt typisch in Bezug auf Volk und Nation ${ }^{337}$ wird auch Heimat ab dem letzten Drittel des 19. Jahrhunderts zugleich zum zentralen historischen Gegenstand und wertgeleiteten Telos des germanistischen Wissenschaftsverständnisses. Die Deutschdidaktik forderte, wie gezeigt, seit den 1870er Jahren heimatkundliche Konzepte für den Deutschunterricht, in denen Heimat zugleich Objekt, Methode und Ziel der Didaktik ist: Germanisten wie Rudolf Hildebrand (1871), Hugo Weber (1872) und Otto Lyon (1893) beziehen sich dabei stets auf die Volkskunde (vgl. II.3.1.1).

Für die literaturgeschichtliche Forschung gilt es dann um die Jahrhundertwende als innovativ, sich der volkskundlichen Forschung $\mathrm{zu}$ öffnen und dabei deren holistisches Heimatverständnis in Anspruch zu nehmen. Der österreichische Germanist August Sauer fordert in Literaturgeschichte und Volkskunde (1907), den „Zusammenhang der deutschen Literatur mit dem deutschen Volkstum als solchem, also die eigentlich nationale Seite unserer Literaturgeschichte“ stärker $\mathrm{zu}$ beleuchten und dabei insbesondere auf die volkskundliche Forschung zurückzugreifen, ${ }^{338}$ wobei er auf eine reiche Auswahl an schon vorliegenden lokalen und mundartlichen Anthologien und regionalen Literaturgeschichten der vergangenen Jahrzehnte verweisen kann. Letztes Ziel der Germanistik sei es, „die wissenschaftliche Formel für den Begriff Volksseele zu finden““. ${ }^{339}$ Es sei evident, dass die sich an einen bestimmten „Heimatsboden“ knüpfenden „Stammesmerkmale“ das Fundament bildeten, auf dem dann alle anderen Einflüsse aufsattelten, ohne die auch ein literaturhistorisches Verständnis nicht möglich sei. ${ }^{340}$ Sauer will einer Auffassung entgegenarbeiten, der zufolge die Nähe zur Heimat

336 Auch der als Professor für deutsche Literatur tätige germanistische Mediävist Karl Müllenhoff beeinflusste mit seiner Deutschen Altertumskunde die Volkskunde.

337 Vgl. Dehrmann 2015; dort insbesondere das Kapitel „Konkurrenz um den ,Volksgeist““, S. $67-79$.

338 Sauer 1907, S. 20. Sauer verweist u. a. auf Adolf Hauffens Einführung in die deutsch-böhmische Volkskunde (1896), Alfred Kirchhoffs Die deutschen Landschaften und Stämme (1903) und Gustav Meyers Essays und Studien zur Sprachgeschichte und Volkskunde (1885).

339 Sauer 1907, S. 33. Sauer zitiert hier aus Adolf Hauffens Einführung in die deutsch-böhmische Volkskunde von 1896.

340 Beide Zitate Sauer 1907, S. 21: „[...] darf man doch an die ganz unverkennbaren, deutlich ersichtlichen Merkmale anknüpfen, die jeder mit seinem Volksstamm gemeinsam hat und welche die demselben Heimatsboden entstammenden Menschen der verschiedensten Lebens- und Berufskreise sowie aller Altersstufen einander naherücken. Diese Stammesmerkmale bilden die älteste und festeste Schicht, auf welcher alle anderen Einflüsse und Eindrücke, wie sie Erziehung, Bildung und Leben mit sich bringen, sich aufbauen [...].“ 
eine Rangfolge der Dichter bezeichne. Denn ,je höher [...] ein Dichter steht, desto mehr meint man ihn dem Nährboden der Heimat entwachsen zu sehen“. Dies sei falsch: Auch das Genie, so versucht er ausführlich an Goethe zu belegen, sei „mit tausend Wurzeln in dem Boden seiner Heimat verankert“ und habe daher „mit den übrigen Stammesangehörigen zahlreiche völkische Merkmale gemein, die ihn erst zum nationalen Dichter stempeln“.341

Sauers Schüler Josef Nadler setzt dessen Forderung nach einer neuen Literaturgeschichtsschreibung auf der ,wissenschaftlichen' Grundlage der Volkskunde um. In seiner Literaturgeschichte der deutschen Stämme und Landschaften von 1912 - zwei Jahre später wird Nadler wohl auch aufgrund dieser ersten Fassung seiner später weiter ausgebauten Literaturgeschichte zum Professor in Fribourg/Schweiz - geht es ihm um angewandte Philologie, um „Dialektforschung, Stammeskunde, Familiengeschichte, Anthropologie“ und „eine Literaturgeographie, die die Erde nach unsern Bedürfnissen suchend abgeht“. ${ }^{342}$ Der Raum müsse neben der Zeit ein neues Gewicht bekommen. ${ }^{343}$ Um den einzelnen Dichter zu verstehen, müsse man die „Menschen seiner Heimat zur Erklärung heranziehen“. ${ }^{344}$ Denn Heimat sei der Nährboden für alles andere. Literatur und Kunst könnten „nur dort erklärt und begriffen werden, wo der Mensch mit tausend Fasern an einem bestimmten Erdfleck festgewachsen ist, wieder nur aus der Gesamtheit aller Wirkungen, die zwischen Heimat und Abkunft spielen. “345

341 Beide Zitate Sauer 1907, S. 28. „[D]ass sie mit den besten und höchsten Schöpfungen ihrer Muse im heimatlichen Boden wurzeln und ohne diesen Heimatsduft und -dunst nicht zu denken sind“, gelte nicht nur für Keller, Eichendorff, Pichler, Reuter, Storm, sondern auch für „Kleist, Hebbel, Grillparzer, Schiller und selbst Goethe“. Sauer 1907, S. 28.

342 Beide Zitate Nadler 1912, S. VII und VIII. Zu Nadlers Literaturgeschichte hat Irene Ranzmaier eine Monographie vorgelegt, in der u. a. auch der Einfluss der Volkskunde auf Nadlers Wissenschaftsverständnis behandelt wird, vgl. Ranzmaier 2008.

343 „Raum und Zeit! Zum zweiten auch das erste! Nicht eine Landschaft als Tummelplatz zufällig zusammengewürfelter Einzelner, sondern als Nährboden, als Materielles, als Trägerin eines ganz bestimmten Menschenschlages, von der aus beidem, aus Blut und Erde, das Feinste, das Geistigste wie in goldnen Dämpfen aufsteigt. Es gibt auch in den Geisteswissenschaften eine Spektralanalyse." Nadler 1912, S. VIII.

344 Nadler 1912, S. VII. Stamm, Sippe, Landschaft als „Zwischenglieder“, „Zwischeneinheit“ „zwischen dem Einzelnen und der letzten Einheit“; „Mit dem ererbten Blute rollt eine Fülle erblicher Güter von Geschlecht zu Geschlecht. Neben den Einzelnen tritt Fluch und Segen der Sippe. Und weil sich die Geschichte der Abfolge nur in seltenen Fällen lückenlos feststellen läßt, müssen wir zur unvollkommenen Auskunft greifen, die nächst Verwandten dieses Einzelnen, seinen Stamm, seine Umgebung, den Menschen seiner Heimat zur Erklärung heranziehen, falls wir wissen, daß er wenigstens in weiterer Folge mit ihm verwandt ist.“

345 Nadler 1912, S. VI. 
Heimat steht bei Nadler im Einklang mit der Nation - oder, um die Terminologie der Zeit aufzunehmen, zum ,Völkischen‘: „Der große Reichtum unserer Literatur“, so paraphrasiert Nadler zustimmend Sauer, hänge damit zusammen, „daß die einzelnen Landschaften nach fruchtbaren Sonderentwicklungen im rechten Augenblick in die Gesamtbewegung einträten“. ${ }^{346}$ Regionale Verschiedenheiten sind die systematische Größe seiner Literaturgeschichte, mit dem Anspruch, das je Spezifische der ,Landschaften' als individuelle Ausformung einer Gesamtheit des deutschen Volkes zu begreifen. Die ,Landschaft“ ist dabei ein zeitgenössisch viel verwendetes Schlagwort in der Debatte um Metropole und Provinz, ${ }^{347}$ und das eigentlich Deutsche wird von Vertretern wie Nadler eben gerade nicht in den Metropolen gesucht. Zu begreifen, „was in dem allen deutsch ist““, ${ }^{348}$ das ist die drängende Frage der Zeit, von der man annimmt - immer mit dem Zugeständnis, erst auf dem Weg dahin zu sein und nur Vorläufiges leisten zu können -, man könne sie analytisch-wissenschaftlich lösen. Der zentrale Heimatbegriff, das fällt bei Sauer und Nadler auf, wird dabei als wissenschaftlich gesättigter Begriff etabliert, als einer, der von der volkskundlichen Forschung abgesichert und zu dessen Erforschung nun auch aus literaturhistorischer Perspektive beizutragen sei. Auch Riehl wird als Ahnherr dieses Ansatzes gewürdigt. $^{349}$

Nadlers Literaturgeschichte setzt mit einer alttestamentliche Züge tragenden Schöpfungsgeschichte der deutschen Nation ein, in der eine chaotische Phase der Heimatlosigkeit in einen Zustand der Harmonie übergeht, sobald Heimat sich herausbildet:

346 Nadler 1912, S. VI.

347 Zum Landschaftsbegriff bei Josef Nadler vgl. Apel 1998, S. 187-196. Zum Schlagwort der Landschaft innerhalb der zeitgenössischen Debatte um Metropole und Provinz, die sich auch noch in der Weimarer Republik als Debatte um Berlin versus ,Landschaft' entfaltete, vgl. Oschmann 2008. Aufstand der Landschaft gegen Berlin ist der Titel eines programmatischen Textes von Wilhelm Stapel von 1930, der sich explizit auf Friedrich Lienhard als Ahnherrn des Gedankens bezieht. Vgl. Oschmann 2008, S. 305. Vgl. weiterhin Haß 1995, Werner 2003 und die Studie von Christiane Nowak zum Topos Kleinstadt, der die Dichotomie von Metropole und Provinz in Frage stellt, vgl. Nowak 2013. Zum Verhältnis von Metropole und Provinz in der österreichischen Literatur vgl. Dusini/Wagner 1994.

348 „So fehlt unseren Gebildeten nur zu oft der klare Überblick über unsere Gesamtentwicklung, es fehlen die inneren Zusammenhänge und die Erkenntnis, was in dem allen deutsch ist. “Walther Hofstaetter: Vorwort, in: Hofstaetter 1917, S. 3.

349 Vgl. Nadler 1912, S. 451. Nadler vereinnahmt ihn für sein eigenes Projekt: „Denn tatsächlich war ihm Grundaufgabe der Volkskunde die Naturgesetze des Volkslebens zu erhellen und es in seiner Notwendigkeit zu begreifen. Volk ist ihm die Ganzheit aus Stamm, Sprache, Sitte, Siedlung.“ Nadler 1912, S. 451. 
Im ersten Jahrhundert vor Beginn unserer Zeitrechnung war der Germane noch heimatlos; denn wie in unruhigen Morgenträumen suchten die Stämme, sich drängend und in überreicher Fruchtbarkeit, Wohnsitz um Wohnsitz; er war noch einsam, denn wie Schneeflocken wirbelten die Völker und Sippen durcheinander, oft losgerissen vom großen Verbande, heute noch uralter Kulturgemeinschaften sich bewußt, und über Nacht Todfeinde um ein Stück Erde. Ein halbes Jahrtausend später hat sich das Angesicht der deutschen Lande verwandelt; jedem war eine Heimat geworden; die Landschaft, so charakteristisch jede und nur für einen ganz bestimmten Stammestypus geschaffen, hat nun ihren Menschen erhalten, der durch Jahrhunderte mit seiner Seele an dieser Scholle festwachsen sollte. Und aus den zahllosen Einzelnen waren Einheiten geworden, aus Gegensätzen vom Schicksal zusammengeschweißt; aus Verwandtem und Gleichem erwachsen, wie wohl zwei, drei Stämme im tiefen Forst sich zu einer Krone verschlingen; oder nach weiser Fügung sich trennend was verwandt war und doch so verschieden. / Wen aber einmal die Scholle ernährt, der hängt an ihr, der reißt sich von ihr nur mit blutendem Herzen. Der Germane begann mit seiner Landschaft zu verwachsen. Ein neues Gefühl ward ihm vertraut, ein neues Wort: Vaterland, Heimat. ${ }^{350}$

Die Verknüpfung der Erzählung vom Ursprung der Nation mit derjenigen von der Entstehung des Heimatgefühls der Deutschen - vorgestellt als gleichsam pflanzenhaftes Verwachsen mit Boden und Landschaft - ist der Zeit vertraut, etwa durch Freytags und Riehls kulturhistorische Entwürfe. Und sowohl Sauer als auch Nadler beziehen sich, wie nicht anders zu erwarten, positiv auf Riehl, ${ }^{351}$ auch Freytag widmet Nadler in späteren Auflagen seiner Literaturgeschichte sehr positive Passagen. Nadler ergänzt seine Ursprungserzählung um die Ideen der neueren Rassenforschung. Heimat dient demnach als Vergegenwärtigung des eigenen ,Volkstums“ insbesondere dort, wo dieses ,Volkstum“ mit anderen „Rassen, Sprachsippen und Einzelstämme[n]" in Berührung komme. Heimat ist im Sinn solcher Rassenlehre keine Frage der Wahl, sondern biologisch feststellbar und unhintergehbar: „Das macht die Heimat, und wir können nicht anders.“352

350 Nadler 1912, S. $3-4$.

351 Vgl. Sauer 1907, S. 34; Nadler 1912, S. 451.

352 Über die starke Wirkung von Sauers „Literaturgeschichte und Volkskunde“ auf ihn und seine Kommilitonen der Prager Germanistik berichtet Nadler: „Die Beziehungen der Stadt [gemeint ist Prag] und der weiteren Heimat zu diesem Buche waren uns selbstverständlich. Es war der Geist, der wie ein Weggenosse von Fleisch und Blut mit jedem über die alte Prager Brücke wandert, der Geist des Volkstums, dessen Nähe nicht überall, weil ihn kein Gegensatz weckt, so unmittelbar anschaulich ist. Wer wie wir alle Not, allen Schmerz und jede Freude geistigen Lebens aus dem Drängen, Stoßen und Reiben der Rassen, Sprachsippen und Einzelstämme schöpft, die in eine Welt für sich in den Bergkesseln von Orsowa bis zur Elbpforte, bis Trient und bis zur Adria geworfen sind, all denen bedeutet das Volkstum den Schlüssel zu jeder Offenbarung, ein täglich neues Erlebnis, eine dauernde Gegenwart. Das macht die Heimat, und wir können nicht anders.“ Nadler 1912, S.V-VI. Im Luther-Gestus vorgetragen, erscheint die Berufung auf Heimat als eine Art ,Reformation' der Literaturgeschichtsschreibung. 
Weiter noch als Nadler geht der völkische Literaturhistoriker Adolf Bartels in der Amalgamierung von Heimat und Rasse. Insbesondere mit seiner populären, erstmals 1901/02 und dann in vielen weiteren Auflagen erschienenen Geschichte der deutschen Literatur fand diese Idee Verbreitung. Der polarisierende Bartels wurde von der völkischen Bewegung zur Führergestalt stilisiert und seine Ideen fanden durch eine Unzahl von Publikationen und Vorträgen große Verbreitung. 1905 wurde er durch Großherzog Wilhelm Ernst von Weimar mit dem Professorentitel ausgezeichnet; er hielt einen guten Teil seiner zahlreichen Vorträge in Universitäten. Legt man die Pressestimmen als Maßstab für die öffentliche Meinung zugrunde, fällt hingegen auf, dass er von liberalen Blättern als nicht satisfaktionsfähiger Extremist eingestuft wurde. Als Privatgelehrter ohne akademische Laufbahn wurde er auch von Teilen des Wissenschaftsestablishments abgelehnt. Andererseits beziehen sich einschlägige wissenschaftliche Arbeiten der Zeit selbstverständlich auf Bartels' Arbeiten. ${ }^{353}$ Trotz seiner ambivalenten Stellung im Wissenschaftsbetrieb kann gerade der Blick auf Bartels das historische Verhältnis von Literaturgeschichtsschreibung und Literatur in Bezug auf Heimat klären helfen, und das aus mehreren Gründen. Denn auch wenn Bartels' literaturhistorische Arbeiten zeitgenössisch im wissenschaftlichen Zwielicht stehen - sie wurden spätestens ab 1933 als seriöse wissenschaftliche Forschung behandelt. Vor 1933 stellen sie eine zwar radikalisierte, im Kern aber der engeren Fachgermanistik vergleichbare Form der Literaturgeschichtsschreibung dar, wie Nadlers Literaturgeschichte zeigt. Aus heutiger Perspektive werden Bartels’ Texte gern als „pseudo-scholarly“354 bezeichnet, bei Nadler wird dagegen eher von einem zeittypischen Wissenschaftsverständnis gesprochen. Dabei lässt sich Nadlers von Bartels’ Wissenschaftsverständnis höchstens graduell unterscheiden als Nadlers Literaturgeschichte 1912 erscheint, liegt schon seit sechs Jahren Bartels' Handbuch zur Geschichte der deutschen Literatur mit demselben Ordnungsprinzip vor, das Dichter nach Herkunftsregionen präsentiert. ${ }^{355}$

Eine zentrale Funktion kommt Bartels in Bezug auf die sogenannte Heimatkunstbewegung zu. Es ist Bartels, der diese Strömung zuerst beschreibt und damit, so die hier vertretene These, als literaturhistorisch bis heute beschriebene ,Epoche‘ überhaupt erst hervorbringt. Durch die Vereinnahmung unterschiedlichster Autoren als Vertreter der von ihm ,entdeckten' Bewegung konstruiert Bartels eine homogene ,Heimatliteratur`als vorläufigen Höhepunkt einer litera-

353 Vgl. etwa das ausführliche Lemma ,Heimatkunst' in der zweiten Auflage von Die Religion in Geschichte und Gegenwart (RGG) von 1928, in dem in den insgesamt drei Spalten neben Friedrich Lienhard ausschließlich (positiv) auf Adolf Bartels Arbeiten referiert wird; vgl. Günther 1928.

354 Kater 2014, S. 173.

355 Vgl. Bartels: Handbuch, 1906. 
turhistorischen Entwicklung, die er minutiös aus den Anfängen der deutschsprachigen Literatur herleitet. Bartels schreibt die gesamte deutschsprachige Literaturgeschichte neu als Bewegung auf ein Telos - die Heimatkunst -, in dem die deutsche Literatur gleichsam zu sich selbst findet. Er ist nicht nur literaturhistorischer Chronist, sondern zugleich tageskritischer Kommentator und programmatische Autorität der ,Bewegung;, in die er sich auch selbst als Autor literarischer ,Heimatkunst‘ einordnet. In diesen vielfältigen Funktionen beschreibt und erschafft er zugleich ein literarisches Feld, auf das die zeitgenössischen Schriftstellerkollegen Bezug nehmen, sei es durch Abgrenzung, sei es durch Zugehörigkeitserklärungen. Die Proklamation der ,Heimatkunstbewegung‘ hatte direkte Auswirkungen auf die Produktion von Literatur, genauso wie auf ihre Distribution (etwa in Form von Heimatverlagen und Heimat-Reihen, die wiederum einen Bedarf an entsprechender Literatur erzeugten) $)^{356}$ und ihre Rezeption - ein Text wird als der ,Heimatkunstbewegung` zugehörig oder nicht zugehörig wahrgenommen, auch gegen den Willen seiner Autoren (II.3.3.1).

Was dies für die Literatur um 1900 heißt, kann exemplarisch an der seinerzeit bekannten und viel gelesenen Schriftstellerin Clara Viebig gezeigt werden. Viebig fühlte sich der Heimatkunst auf ambivalente Weise zugehörig. In einem Brief Viebigs an Bartels ist es ihr wichtig, sich selbst in die Nähe der Heimatkunst zu stellen; ihr eigenes Werk bezeichnet sie als ,in erster Linie aus der Liebe zur Heimat geboren[ ]“. ${ }^{357}$ Der Programmatiker und Historiograph der ,Heimatliteratur` verwehrt ihr aber diese Zuordnung, jedenfalls zu diesem Zeitpunkt. Angesichts der alles andere als heimattümelnden Texte von Viebig stellt sich die Frage, inwieweit die Kriterien einer Heimatkunstbewegung, die teils mehr private Idiosynkrasie Bartels als Beschreibung einer real existierenden Literatur war, Geltung beanspruchen dürfen, um Texte wie die Viebigs zu erfassen. Viebigs Texte be-

356 Vgl. etwa den Heimatverlag von Georg Heinrich Meyer (Leipzig/Berlin). Mehrere Texte von Friedrich Lienhard und Adolf Bartels wurden hier veröffentlicht, u. a. in der Reihe Flugschriften der Heimat; auch die erstmals im Jahr 1900 erschienene Zeitschrift Heimat. Blätter für Litteratur und Volkstum (später umbenannt in Deutsche Heimat) wurde in Meyers Verlag herausgebracht. Auch Heinrich Sohnreys 1907 in Berlin gegründeter Verlag Deutsche Landbuchhandlung verstand sich mit seinem Verlagsprogramm als Organ der Heimatkunstbewegung; Sohnrey brachte Belletristik wie Heinrich Naumanns Vom Heimatacker. Geschichten eines hessischen Bauersmannes (1909) heraus, vor allem aber auch eigene Schriften wie Wegweiser für Ländliche Wohlfahrts- und Heimatpflege (1908), Osterfeuer. Ein Ostergruß für Heimat und Heer (1917) oder Herzen der Heimat. Geschichten aus Groß-Berlin und Kleinen Dörfern (1919). Zu Sohnreys Anteil an der Heimatbewegung und dem Verein für ländliche Wohlfahrts- und Heimatpflege vgl. Hartung 1991 und Stöcker 2011.

357 Viebig 1900, o.S. Der unveröffentlichte Brief stammt vom 9.12.1900 und befindet sich unter der Signatur GSA 147/863 im Goethe- und Schiller-Archiv in Weimar. 
schreiben unter anderem das Regionale und Ländliche und bedienen sich der Mundart, aber sie zeigen keine intakte Welt, und genauso oft wie das Dorf wird die Großstadt Berlin beschrieben. Der Begriff der Heimat wird in ihren Texten stets gleichsam experimentell auf diese literarischen Welten angewandt, doch die Versuche gehen immer zuungunsten dessen aus, der ihn benutzt: Heimat zeigt immer nur ein Bedürfnis an, das nicht befriedigt werden kann (II.3.3.2).

\subsubsection{Bartels' völkische Heimat}

Adolf Bartels ist einer der bekanntesten Propagandisten der völkischen und antisemitischen Ideen in der wilhelminischen Ära; er verbreitet sie in der Rolle als Literaturhistoriker und -kritiker, Schriftsteller und Pamphletist. ${ }^{358}$ Immer Person des öffentlichen Interesses, wird er den einen zum völkischen Hoffnungsträger, den anderen zum „bestgehaßte[n] Mann Deutschlands“. ${ }^{359} \mathrm{Zu}$ einem solchen Gehassten stilisieren ihn jedenfalls die deutschnationalen Zeitungen. Tatsächlich überwiegt in den liberalen Zeitungen eher der Spott über einen lächerlichen Eiferer. $^{360}$ In den 1920er Jahren ist der angeschlagene Ton ein schärferer: Von Kurt Tucholsky wird er in einer Rezension einer seiner Literaturgeschichten als ein „im Irrgarten der deutschen Literatur herumtaumelnde[r] Pogromdepp“ und „Hakenkreuzpolichinell“ mit „leicht angekümmelte[m] Antisemitismus“361 bezeichnet.

Die Ablehnung von Bartels' Person durch die journalistische Kritik, die es sich auch nicht nehmen lässt, auf das fehlende Abitur (der Vater konnte das Schulgeld

358 Zu Adolf Bartels vgl. Rösner 1996; Fuller 1996; Brändle 1997; Ulbrich 1998, S. 160 -162; Kater 2014; sowie verschiedene problematische Veröffentlichungen von Manfred Stoppel, die aufgrund ihrer revisionistischen Haltung nicht als seriöse Forschungsliteratur zu behandeln sind, vgl. etwa Manfred Stoppel: Adolf Bartels' Weg zur Heimatkunst. Eine revisionistische Betrachtung nebst einem Band von ,Adolf Bartels Auswahlbibliographie‘. Innsbruck 1989. Bartels’ Nachlass ist meines Wissens nur von Thomas Neumann in seiner Studie zur völkisch-nationalen Hebbelrezeption bearbeitet worden (vgl. Neumann 1997).

359 Anonym: o.T., in: Das Land (1. Dezember 1921) (GSA 147/41). Das Goethe- und Schiller-Archiv in Weimar (GSA) beherbergt ein großes Konvolut von Zeitungsartikeln zu Adolf Bartels. Sind hier und im Folgenden Jahrgänge, Ausgabennummern oder Seitenzahlen nicht angegeben, handelt es sich um Zeitungsausschnitte ohne entsprechende Angaben. Die hier zitierten Artikel der Signatur GSA 147 sind nicht noch einmal im Literaturverzeichnis aufgelistet.

360 Vgl. einen Artikel über Adolf Bartels im Hamburger Fremdenblatt vom 8. Juli 1910, GSA 147/ 41.

361 Alle Zitate Tucholsky 1922. Tucholsky veröffentlichte die Rezension unter seinem Pseudonym Ignaz Wrobel. 
nicht aufbringen) und den fehlenden Hochschulabschluss des (später gleichwohl mit dem Professorentitel ausgezeichneten) Autodidakten hinzuweisen, ist eine nicht unwichtige Prämisse für Bartels unermüdliche Produktion in Sachen ,Heimatkunst': Sie erfolgt in der Selbstwahrnehmung Bartels' aus der Opposition gegen das journalistische und wissenschaftliche Establishment heraus und kann sich auf diese Weise als eine vom herrschenden System unterdrückte, angeblich den eigentlichen Interessen des ,Volkes“ aber näherstehende erneuernde Kraft darstellen. Die deutsch-völkischen Netzwerke, an denen der ab 1896 von Weimar aus wirkende Bartels wesentlich teilhat, ${ }^{362}$ arbeiten am Sturz dieses vermeintlichen Establishments. Die Errichtung des NS-Staats wird von Bartels als Wiedergutmachung für die erlittenen Demütigungen empfunden. ${ }^{363}$

Die von Bartels beschriebene und protegierte oder, wie zu zeigen sein wird, in Teilen durch ihn überhaupt erst generierte ,Heimatkunstbewegung ${ }^{634}$ macht

362 In Bartels' Weimarer Jahre bis zum Ersten Weltkrieg gehören seine Mitgliedschaften im Deutschbund und im Werdandi-Bund ab 1907 sowie im Deutsch-völkischen Schriftstellerverband mit Sitz in Weimar ab 1910. 1913 organisiert Bartels maßgeblich den sogenannten Deutschen Tag in Eisenach, eine Art Heerschau völkischer Vereinigungen und Verbände. Er wird einer der Vorsitzenden der in der Folge entstehenden deutsch-völkischen Vereinigung und Mitglied der von 1914 bis 1918 bestehenden Deutsch-völkischen Partei. Er gehört zum sogenannten Judenausschuss des Alldeutschen Verbandes, eines der größten Agitationsverbände des deutschen Kaiserreiches, der die Gründung des Deutschvölkischen Schutz- und Trutzbundes betreibt, dessen Mitglied Bartels dann ebenfalls ist. Bartels ist ein gefragter Redner vor Studentenbünden und Germanisten-Vereinen von Berlin bis Wien, vor allem mit der Bitte um Beiträge „über germanische Weltanschauung in der Literatur“ wird er überhäuft (Brief der Schriftleitung der Ostdeutschen Rundschau an Adolf Bartels, 16. März 1914, GSA 147/1183). Fritz Stern bezeichnet Bartels 1961 als eine der „bedeutendsten und zugleich widerlichsten Gestalten der völkischen Bewegung“. Stern 2005, S. 232.

363 Vgl. Oesterhelt: Große deutsche Heimat, 2014. Zum soziologischen Profil der Heimatkunstprogrammatiker und -autoren vgl. Rossbacher 1975, S. 65-90. Sie gehören zum größten Teil „ins ländliche wirtschaftende Kleinbürgertum“ (Rossbacher 1975, S. 74). Sie sind „nicht Bauern, aber auch nicht etwa zivilisationsmüde Großbürgernachkommen; man kann sie als Bildungsaufsteiger innerhalb des Mittelstandes bezeichnen“ (Rossbacher 1975, S. 72), wobei sie von diesem Bildungsaufstieg - typischerweise zum Volksschullehrer - kaum ökonomisch profitieren und die „Abstiegserfahrung ihrer Herkunftsschicht“ mit sich tragen (Rossbacher 1975, S. 77). Isolationserfahrung, das Bewusstsein der Existenzbedrohung der eigenen (kleinbürgerlichen) Herkunftsschicht und Ressentiment aufgrund der als nicht angemessen anerkannt empfundenen eigenen sozialen Position gehören daher nach Rossbacher zum Profil der Gruppe.

364 Karlheinz Rossbachers Heimatkunstbewegung und Heimatroman. Zu einer Literatursoziologie der Jahrhundertwende von 1975 eröffnet eine Reihe sehr guter literaturwissenschaftlicher Studien, die sich mit der Heimat- bzw. Regionalkunst im Spannungsfeld der Moderne um 1900 beschäftigen, vgl. Rossbacher 1975; Mecklenburg 1982; Werner 2003; Kramer 2006 und die Studie von Christiane Nowak, welche die langfristige Wirkung herausarbeitet, die die Heimatkunstbewegung 
Heimat zum inhaltlichen wie ästhetischen Paradigma ihres Schreibens. Bartels verwendet den Begriff der Heimatkunst erstmals 1898, um Entwicklungen der neuesten Gegenwartsliteratur zu beschreiben. ${ }^{365}$ Mit seiner Literaturgeschichte, verschiedenen ,Gründungstexten' und eigenen literarischen Arbeiten wird Bartels zu einem Initiator der neuen Bewegung und stilisiert sich selbst als Gründerfigur, ${ }^{366}$ auch in Abgrenzung von Friedrich Lienhard, einem weiteren Programmatiker der Heimatkunst. ${ }^{367}$ Auch wenn Lienhard des Gegenteil behauptet, ist tatsächlich Bartels der Erste, der den Begriff verwendet - zwei Jahre vor Lienhard. ${ }^{368}$ Das Verhältnis zwischen Bartels und Lienhard scheint von Beginn an gespannt; die Zusammenarbeit an der Zeitschrift Heimat, in deren erster Ausgabe vom Januar 1900 die beiden die einleitenden programmatischen Aufsätze verfassen, wird schon mit der zweiten Nummer beendet, als Lienhard die Leitung der Zeitschrift niederlegt. ${ }^{369}$ Bartels versteht sich in der Folge als legitimer Historiker und Repräsentant der Heimatkunstbewegung und äußert sich öffentlich negativ über Lienhard. ${ }^{370}$

Der Großteil der unzähligen in der Folge erscheinenden Programmschriften (Abb. 38), literaturgeschichtlichen Abhandlungen und Beiträge zur Heimatkunst ist von Adolf Bartels verfasst - ohne Bartels, so könnte man es etwas überpoin-

auch noch auf die 1930er Jahre hatte, vgl. Nowak 2013. Geschichtswissenschaftliche Beiträge zur Heimatkunstbewegung versammelt der Band Antimodernismus und Reform. Beiträge zur Geschichte der deutschen Heimatbewegung von Edeltraut Klueting, vgl. Klueting 1991. Zur Malerei der Heimatkunstbewegung vgl. zuletzt Laufer 2019.

365 Vgl. Bartels: Neue Erzählende Literatur, 1898; hier heißt es noch „Heimatskunst“, S. 104. 366 Vgl. Bartels 1938, S. 263-265. „Den Ausdruck ,Heimatkunst“ brachte ich auf (2. Auflage meiner Deutschen Geschichte der Gegenwart, 1898), doch hatten schon Julius Langbehn in seinem Rembrandt als Erzieher (1890) und Caesar Flaischlen in seinem Neuland (1894) den Wunsch nach ihr ausgesprochen, und mir stand zunächst Fritz Lienhard, der Verfasser der Schrift Los von Berlin!, zur Seite.“ Bartels 1938, S. 264.

367 Vgl. Bartels 1938, S. V. Zu Friedrich Lienhards Heimatbegriff und seinem Anteil an der Heimatkunstbewegung vgl. Krauß-Theim 1992; Kramer 2006, S. $43-47$ und 65-82 (hier zu Friedrich Lienhards Einfluss auf René Schickeles literarisches Programm); Nowak 2013, S. 124-133; Oesterhelt 2019.

368 Andreas Kramer irrt, wenn er mit Verweis auf Lienhards Wasgaufahrten Lienhard zum Erfinder des Begriffs macht (vgl. Kramer 2006, S. 43). Kramer zitiert die dritte Auflage der Wasgaufahrten von 1902, in der das Wort im Vorwort und in einer Fußnote fällt (vgl. Lienhard 1902, S. 179). In der ersten Auflage von 1895 vermisst man das Wort aber an der entsprechenden Stelle (vgl. Lienhard 1895, S. 161). Lienhards Schriften, die explizit von ,Heimatkunst` sprechen, erscheinen ab dem Jahr 1900 (z. B. Lienhard: Hochland, 1900) und lassen von Anfang an Vorbehalte gegenüber der ,Bewegung“ erkennen. Vgl. Lienhard 1901, S. 193.

369 Vgl. dazu Bülow 1923, S. 155.

370 Vgl. etwa Bartels 1912, S. 95. 
tieren, hätte es die bis heute in der Literaturgeschichte als literarische Strömung behandelte Heimatkunstbewegung ${ }^{371}$ gar nicht gegeben. Natürlich gab es unabhängig von Bartels die vielfältigen Phänomene einer Literatur, die teils bis heute als ,Heimatliteratur' subsumiert werden: Es gab die aufs Regionale setzende Literatur, solche, die die Mundart literaturfähig machte, es gab die Literatur, die das ,einfache Volk' zum Gegenstand (seltener zum Adressaten) ihres Schreibens machte. Das alles lässt sich als zeitcharakteristische, teilweise gesamteuropäische literarische Phänomene im Spannungsfeld von Regionalismus und Moderne beschreiben. ${ }^{372}$ Aber in diesen Kriterien erschöpft sich nicht die Bewegung, die Bartels ausrief. Das, was er als Strömung der zeitgenössischen Literaturproduktion erkennen wollte, war mehr als das Regionale, Einfache, Volksnahe, und mit diesem ,Mehr‘, mit dem er den Begriff der Heimat versah, konstruierte er eine Bewegung, die vorrangig von seiner eigenen Programmatik ihren Ausgang nahm und dauerhaft in einem Spannungsverhältnis zur Breite der tatsächlich produzierten Literatur stand.

Die ,Heimatkunstbewegung‘ beruht somit erstens auf Bartels’ Agieren im zeitgenössischen Feld der Literatur mittels programmatischen Schriften, Literaturkritik und eigener Literaturproduktion, aber auch eigener Zeitschriften, Hausverlage etc., und zweitens auf einer literaturhistorischen Konstruktion, die er vor allem durch seine Literaturgeschichte popularisiert. ${ }^{373}$ Diesem zweiten Aspekt gilt hier die Aufmerksamkeit.

371 Vgl. Sprengel 2004, S. 103-107.

372 In dieser Perspektive gehören dann auch viele gewöhnlich der Moderne zugerechnete Autoren zum Phänomen, wie Andreas Kramer überzeugend zeigt: „Moderne Autoren wie Heinrich und Thomas Mann oder Rilke partizipieren am Regional-Diskurs. Lienhard wird zum Anreger und Förderer des jungen René Schickele, dessen Autorengruppe aus dem Elsass kurz nach 1900 ein regionalistisches Kulturerneuerungsprogramm formuliert, das paradigmatische Bedeutung in der literarischen Moderne haben wird.“ Kramer 2006, S. 40. Kramers Studie zu Regionalismus und Moderne. Studien zur deutschen Literatur 1900-1933 erforscht die Heimatkunstbewegung der Jahrhundertwende im Kontext von expressionistischen und avantgardistischen Regionalismen und zeigt die Verwobenheit von Regionalismus und Moderne auf. Der „Diskurs des Regionalen“ trage sich „in eine doppelte Matrix ein. Auf einer horizontalen Achse ist das Regionale dabei gegen die großstädtische Moderne gerichtet, gegen die es eine ,landschaftliche‘ Gegen-Moderne konstituieren möchte, [...]. Auf einer vertikalen Achse ist der Regional-Diskurs aber stets auf nationalkulturelle Gedanken, d.h. auf die Gesundung und Erneuerung deutscher Kultur und deutschen Volkstums bezogen. Innerhalb dieser doppelten Matrix wird der Diskurs des Regionalen äußerst vielgestaltig. Das macht ihn für die literarisch-ästhetischen Bewegungen attraktiv“ (Kramer 2006, S. 33-34). „Die Heimatkunstbewegung gilt als antimoderne Bewegung, doch hat ihr Diskurs entscheidenden Anteil an der kulturellen Moderne“ (Kramer 2006, S. 40).

373 Organe für Bartels' Beiträge waren u.a. die 1900 gegründete und von ihm herausgegebene Zeitschrift Heimat. Blätter für Literatur und Volkstum, die auflagenstarke Zeitschrift Der Kunstwart, 


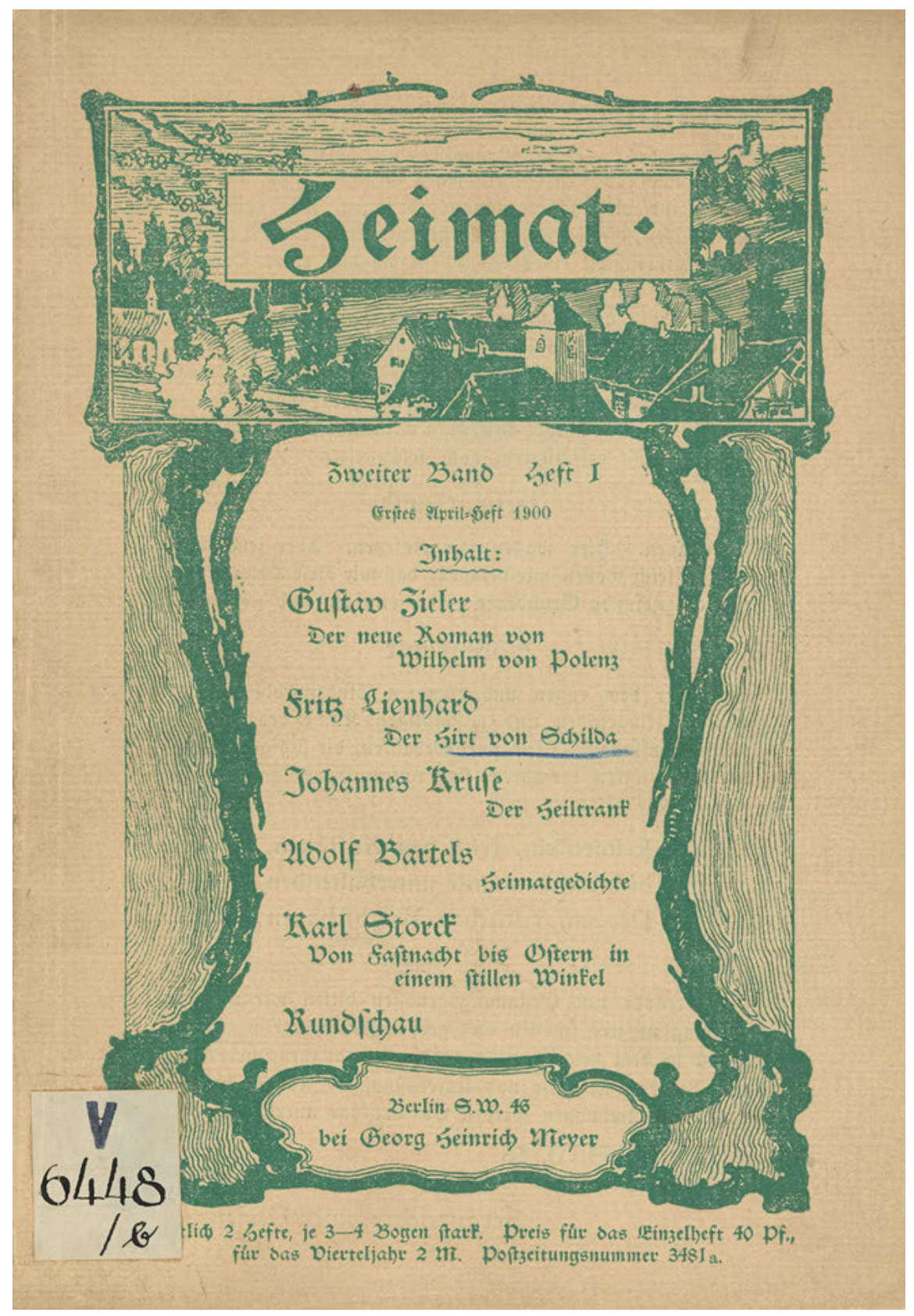

Abb. 38: Heimat. Zweiter Band, Heft 1 (1900), Zeitschrift hg. von Adolf Bartels und Fritz Lienhard (Klassik Stiftung Weimar) 
Bartels ist als enorm produktiver Literaturkritiker ausgezeichneter Kenner der Literatur des 19. Jahrhunderts bis hin zu seiner unmittelbaren Gegenwart, und das unterscheidet ihn von der institutionalisierten Germanistik seiner Zeit. Mit Recht kann er deswegen selbstbewusst im Vorwort seiner Geschichte der deutschen Literatur hervorheben, erstmals sei die Literatur des 19. Jahrhunderts literaturgeschichtlich angemessen gewürdigt. ${ }^{374}$ Tatsächlich widmet die zweibändige Literaturgeschichte den ersten Band der gesamten Literatur bis zum 19. Jahrhundert. Der zweite Band beschäftigt sich mit der Literatur des 19. Jahrhunderts. Während die zeitgenössischen Literaturgeschichten mit Goethe endeten, wolle er selbst vom „Standpunkte der Gegenwart“ aus schreiben und auch jüngere Literaturgeschichte als wissenschaftswürdig erklären. ${ }^{375}$ Daran, dass er seine Literaturgeschichte als Beitrag zur Wissenschaft versteht, lässt Bartels keinen Zweifel, und sie ist mitunter auch in diesem Sinn rezipiert worden. ${ }^{376}$

Bartels beschreibt die deutsche Literaturgeschichte ab Ende des 18. Jahrhunderts in den Epochen der Klassik und Romantik, der Nachklassik und Nachromantik, des Jungen Deutschland, des Realismus, des Eklektizismus, der Décadence, des Symbolismus, des Naturalismus und der Heimatkunst. All diese literaturhistorischen Epochen gewinnen an Wert und Unwert durch ihren Bezug zur Heimatkunst, die zum Telos der gesamten Literaturgeschichte wird. Anhand dieses Bewertungsmaßstabs konstruiert Bartels drei große Perioden deutscher Heimatdichtung: Die Heimatkunst beginnt nach Bartels mit Jeremias Gotthelf. ${ }^{377}$ Vorbereitet durch Johann Heinrich Pestalozzi ${ }^{378}$ und Johann Peter Hebel ${ }^{379}$ über-

in der Bartels Mitarbeiter für die Abteilung Literatur war, und die ab 1909 von Bartels in Weimar vertriebene und von ihm in den ersten Jahren allein geschriebene Zeitschrift Deutsches Schrifttum sowie die Reihe Grüne Blätter für Kunst und Volkstum. Zum Verhältnis von Heimatkunstbewegung und Publizistik vgl. Rossbacher 1975, S. 16-19. Die wichtigsten literaturgeschichtlichen Schriften Bartels' sind seine erstmals 1901/1902 erschienene Geschichte der Deutschen Literatur, im Folgenden zitiert in der fünften Auflage: Bartels 1909; sowie seine Thüringische Literaturgeschichte von 1938/42: Bartels 1942.

374 Vgl. Bartels 1909, Bd. 1, S. VI.

375 Bartels 1909, Bd. 1, S. VII.

376 Vgl. Adolf Bartels: Vorwort zur dritten und vierten Auflage, Bartels 1909, Bd. 1, S. VIII-XI. 377 Zur Gotthelf-Renaissance ab Mitte der 1880er Jahre und der Rolle Adolf Bartels' bei dieser Wiederentdeckung vgl. Mettenleiter 1974, S. 344. Auch Mettenleiter attestiert Gotthelfs Bauernromanen, wenn auch auf der Grundlage gänzlich anderer Kriterien, „,vollendete Beispiele gültiger Heimatdichtung“ zu sein (Mettenleiter 1974, S. 348). Die „Implikationen des Heimatlichen“ - bei Mettenleiter ist damit u.a. die regionale Begrenzung und Darstellung des bäuerlichen Lebens gemeint - seien Mittel der „Welterhellung“: „Heimatdichtung wird hier legitimes Beispiel dichterischer Weltgestaltung.“ Mettenleiter 1974, S. 349.

378 Pestalozzi habe mit Lienhard und Gertrud „den ersten wahren Volksroman“ geschaffen. Bartels 1909, Bd. 1, S. 525. 
winde Gotthelf die tendenziösen Züge des einen und die idyllisierenden des anderen. Gotthelfs Literatur sei „Heimatkunst“, weil er fast vierzig Jahre unter den Menschen und Zuständen gelebt habe, die er schildert. Unter allen Volksschriftstellern habe er die größte Kenntnis des Volkes gehabt, mit ihm beginne der Naturalismus, insofern „nicht die Poesie der Dinge, sondern die Dinge selbst“ gezeigt würden, mit ihm beginne auch „die ernst zu nehmende soziale Dichtung““. ${ }^{380}$ Bartels kürt Gotthelf zum germanischen Tolstoi und Balzac, und Gotthelfs Konkurrent Berthold Auerbach habe unverdient jenen Ruhm in Anspruch genommen, der eigentlich Gotthelf hätte zukommen müssen. ${ }^{381}$ Auerbachs jüdische Abstammung verhindere notwendig einen qualifizierten Beitrag zur Heimatliteratur (zu Auerbach vgl. II.2.2.2).

Die zweite Periode der Heimatdichtung bilden Bartels zufolge die Realisten. Alle realistischen Dichter und Dichterinnen des 19. Jahrhunderts seien immer auch Heimat- oder Stammesdichter, wobei Heimat und Stamm (wie bei Sauer und Nadler) teils synonym verwendet werden: ${ }^{382}$ Annette von Droste-Hülshoff, Willibald Alexis, Adalbert Stifter, Wilhelm Raabe, ${ }^{383}$ Theodor Fontane, Gerhart Hauptmann. ${ }^{384}$ Der Thüringer Otto Ludwig stehe in der vorderen Reihe der großen „Stammesdichter“, u.a. weil er die Dorfgeschichte „wahrhaft zum Kunstwerk erhöht“ habe. ${ }^{385}$ Der Nordfriese Theodor Storm sei „ein echter Heimatdichter“, denn das Heimweh sei „die Seele seiner Poesie“. ${ }^{386}$ Der Dithmarscher Klaus Groth wird immer wieder als idealer Vertreter der Heimatdichtung gepriesen. ${ }^{387}$ Auch der Schweizer Gottfried Keller ist „Stammesdichter“, der sich „vom heimischen We-

379 Hebels Schriften entsprängen „dem engen Anschluß an die Natur und das Volksleben seiner Heimat“, Bartels 1909, Bd. 1, S. 528.

380 Alle Zitate Bartels 1909, Bd. 2, S. 315.

381 Vgl. Bartels 1909, Bd. 2, S. 418.

382 August Sauer führt die Kategorie des Stammes in die akademische Literaturgeschichtsschreibung ein, sein Schüler Josef Nadler folgt diesem Weg in seiner Literaturgeschichte von 1912 (vgl. II.3.3). Schon 1901/02 druckt die Zeitschrift Deutsche Heimat in sechs aufeinanderfolgenden Nummern Ernst Otto Eichlers Die deutschen Stämme im Hausgewande, den Versuch, den Schlesiern, Niedersachsen, Mecklenburgern etc. bestimmte Stammesmerkmale zuzuordnen.

383 In einem höheren Sinn sei selbst Wilhelm Raabe der Heimatdichtung zuzuordnen: „In gewisser Beziehung kann man Raabe den deutschesten unserer Dichter nennen; kein bloßer Heimatdichter, ist er doch der Dichter der deutschen Heimat.“ Bartels 1909, Bd. 2, S. 415.

$384 \mathrm{Zu}$ allen Genannten vgl. komprimiert: Bartels 1920, S. 45.

385 Beide Zitate Bartels 1909, Bd. 2, S. 359.

386 Beide Zitate Bartels 1909, Bd. 2, S. 378.

387 „Klaus Groth gehörte seinem Volke und seiner Heimat, er schritt auch mit festen Füßen über die Fluren der Heimat hin, und seine Augen sahen alles, aber seine zugleich männliche und weiche, stolze und liebeerfüllte Seele hatte doch nur für das Reine, Schöne und Tüchtige Raum, er konnte nur mit Herz und Gemüt erfassen und darstellen.“ Bartels 1909, Bd. 2, S. 388. 
sen nie gelöst und den sichern Grund heimischen Lebens nie verlassen“388 habe, ein „Sohn des Volkes“389 zudem. Als andere große Talente des 19. Jahrhunderts, „die ihre beste Kraft aus dem Heimatboden gesogen, örtliche Kunst, die wirkliche Kunst, oft Kunst großen Stils war“, ${ }^{390}$ werden zudem der Mecklenburger Fritz Reuter und die Österreicher Ludwig Anzengruber und Peter Rosegger genannt. Für alle Aufgezählten gilt aber einschränkend, dass bei ihnen Heimat typisiert werde und „Mittel zum Zweck“ sei, insofern sie „individuell-ästhetische Zwecke“391 befriedige.

Die Heimatkunst im engen Sinn ist der dritten von Bartels identifizierten Periode vorbehalten. Seit der Jahrhundertwende, so Bartels, sei eine neue „Unmittelbarkeit“ in der Literatur zum Durchbruch gelangt, die „ästhetischem Spiel und subjektiver Willkür“ ein Ende mache. ${ }^{392}$ Diese neue Tendenz verbinde Heimatkunst und Naturalismus. In seinem Kampf um die Hoheit der Avantgarde erklärt Bartels den Naturalismus zum bloßen Teilbereich der übergeordneten Heimatkunst. Guter Naturalismus ist nach der bartelsschen Logik eigentlich Heimatkunst, schlechter Naturalismus bloß Naturalismus. Außerhalb der Schnittmenge von Naturalismus und Heimatkunst sei der Naturalismus nicht zukunftsfähig. ${ }^{393}$

Die Heimatkunst überbiete den Naturalismus, so Bartels, insofern sie den genauen Blick des Naturalismus und die Wahrhaftigkeit seiner Darstellung mit dem ,liebenden Blick' $\mathrm{zu}$ verbinden verstehe. Nicht mehr die verklärende Liebe des Realismus, aber auch nicht der lieblose Blick von Teilen des Naturalismus,

388 Beide Zitate Bartels 1909, Bd. 2, S. 394.

389 Bartels 1909, Bd. 2, S. 395.

390 Bartels 1904, S. 10.

391 Beide Zitate Bartels 1904, S. 11.

392 Beide Zitate Bartels 1904, S. 11.

393 „Wir können es schon heute bestimmt aussprechen, daß die wahre und dauernde Bedeutung des Naturalismus nicht, wie man es zuerst glaubte, auf seiner neuen Technik, sondern auf seinem volkstümlichen (nicht in dem Sinne von populär gemeint) Lebensgehalt beruht, daß nur das von ihm leben wird, was wahrhafte Stammes- und Heimatkunst geworden, und daß er also, vom Standpunkte der deutschen Gesamtliteratur aus gesehen, weiter nichts als die dritte Periode deutscher Volks-, Stammes- und Heimatdichtung seit Pestalozzi und J. P. Hebel ist, trotz seiner hohen ,Allüren'. Man wird dies natürlich heute noch bestreiten, aber die Zukunft wird es ausweisen, Gerhart Hauptmann beispielsweise wird vor allem als schlesischer Stammespoet, nicht anders wie Reuter als mecklenburgischer und Anzengruber als österreichischer, leben." Bartels 1909, Bd. 2, S. 545. Auch Arthur Moeller van den Bruck arbeitet in seinem Buch Unser aller Heimat an einer Verhältnisbestimmung von Heimatkunst und Naturalismus, und er kommt zu anderen Ergebnissen; ihm gelten Johannes Schlaf, Max Halbe, Wilhelm Schäfer und Hermann Stehr als vorbildliche moderne Heimatdichter. Vgl. Moeller-Bruck 1900. 
sondern die ,sehende“ Liebe bezeichne das neue Weltverhältnis. ${ }^{394}$ Heimat erhält damit bei Bartels eine Heilungsfunktion, Heimatkunst kann die Moderne heilen.

Als Vertreter werden - je nach Veröffentlichungszeitpunkt seiner vielfältigen Schriften zur Heimatkunst und dem gerade gepflegten Verhältnis zu den Genannten - u. a. Helene Böhlau, Gabriele Reuter, Friedrich Lienhard und Ludwig Ganghofer (alle veröffentlichen ihre ersten Texte in den 1880er Jahren) sowie Wilhelm von Polenz, Hans Nikolaus Krauß, Julius Petri, Clara Viebig, Gustav Frenssen (diese veröffentlichen ihre ersten Texte in den 1890er Jahren) behandelt. Auch sein eigenes Euvre im Zusammenhang mit der Heimatkunstbewegung wohlwollend zu erwähnen, vergisst Bartels nie. Er muss zugeben, dass es keine überragenden ,Großen` unter den Genannten gibt, ${ }^{395}$ die Unterhaltungskunst überwiege. ${ }^{396}$ Einigen Rezensionen des Literaturkritikers Bartels ist die Enttäuschung über die Erzeugnisse ,seiner“ Bewegung anzumerken. ${ }^{397}$ Es gibt verschiedene Strategien von Bartels, mit diesem Befund umzugehen, die je nach dem Zeitpunkt seiner Äußerungen variieren.

Eine immer wieder angewendete Argumentationsfigur besagt, die Heimatkunst sei nur Durchgangsstadium für eine Entwicklung, an deren Ende die Nationalkunst stehe. Heimatkunst helfe demnach nur, den Boden für die höhere nationale Kunst zu bereiten: „Heimatkunst ist nicht große Kunst, das haben wir

394 Vgl. Bartels 1904, S. 13.

395 Vgl. Bartels 1909, Bd. 2, S. 588.

396 Bartels 1909, Bd. 2., S. 587-588.

397 Immer wieder muss Bartels konstatieren, dass es noch keinen repräsentativen Vertreter der Bewegung gebe, und anlässlich der Besprechungen verschiedener Heimatautoren kann er nicht selten die Enttäuschung über die unbefriedigenden Ergebnisse der Heimatkunst und damit über die Differenz von eigener Programmatik und tatsächlichen Resultaten nur schlecht verhehlen. So kann Bartels Walther Siegfrieds Novelle Um der Heimat willen „nur lokale Bedeutung zusprechen [...]. Ich habe, notabene, durchaus nichts dagegen, daß jedes deutsche Nest seinen Dichter hat, doch muß man ihm die wahre Empfindung anmerken, und in der Form muß er einigermaßen auf der Höhe der Zeit stehen.“ Bartels: Kritischer Kehraus, 1898, S. 363, oder in einer anderen Besprechung: „Daraus folgt, dass man zwar Ernst Muellenbach Glück wünschen darf, wenn er auf dem betretenen Wege, dem deutschen Volke gesunde Unterhaltungsliteratur zu liefern, fortschreitet, daß man aber zugleich die Olga Januszcka oder Marie Janitscheck oder irgend einen Modernen oder eine Moderne nicht aus den Augen verlieren soll. Denn vielleicht kommt bei der ,intimen Feinheit moderner Neurotik und Psychologie doch einmal etwas heraus, was Ernst Muellenbach nicht machen kann und was doch wahre Kunst oder wenigstens für die Entwicklung der Kunst wertvoll ist. Gesundheit allein thut es eben auch nicht, die Gesundheit ist ja überhaupt keine ästhetische Eigenschaft, sie ist nur die Grundlage vieler, aber nicht anders als wie sie zugleich die Grundlage der Lebensbethätigung eines Goethe und eines beliebigen Bauernknechtes ist. So viel, um keine Irrtümer aufkommen zu lassen; mir persönlich ist die Weise E. M.s sympathischer als die von O. J. und Genossen.“ Bartels: Neue Erzählende Literatur, 1898, S. 105-106. 
immer gesagt, aber sie kann der großen Kunst den Boden bereiten. “398 Die Heimatkunst an sich wirke „national sehr günstig“, ${ }^{399}$ insofern sie „gesunde Lebensdarstellung für alle“400 biete. Dies sei „eine neue Grundlegung für ein von der Zukunft zu errichtendes stolzes Kunstgebäude“.401 Bartels glaubt, dass sich, „wenn wir durch eine Periode der Heimatkunst hindurchgegangen sein werden, eine neue deutsche Menschheitskunst entwickeln wird“. ${ }^{402}$ Von dieser ,Höhenkunst‘, wie Friedrich Lienhard sie nannte, wird noch zu sprechen sein.

Die andere wiederholt angewandte Argumentationsstrategie besteht darin, die Heimatkunst-Literatur einer Vergleichbarkeit und damit auch Marginalisierbarkeit zu entziehen, indem sie als über alle literarischen Richtungen erhaben erscheint: ,Heimatkunst“ sei „im Grunde keine Richtung“, keine spezifische literarische Strömung, keine literarische Partei, sondern vertrete die gesamte ,wertvolle literarische Produktion der Zeitgenossenschaft - also insbesondere sämtliche ,wertvolle“ naturalistische Dichtung. ${ }^{403}$ Damit zusammenhängend zielt die Argumentationsstrategie auf Selbstnobilitierung durch Vereinnahmung. Dem Vorwurf der Enge und Beschränktheit wird durch die Aneignung der ,Großen“ des 19. Jahrhunderts entgegengearbeitet. Denn die Literatur des 19. Jahrhunderts zeichne sich insgesamt dadurch aus, stärker aus dem Regionalen hervorgewachsen zu sein: „[V]on nun an ist fast jeder große deutsche Dichter Heimatdichter. “404 Dem möglichen Einwand gegen diese Inbesitznahme der deutschen Literatur für die eigene Programmatik begegnet Bartels offensiv:

Ja, höre ich nun die modernen Literaturweisen reden, wenn du alle Dichter, die sich auf dem Heimatboden bewegen, ganz abgesehen von ihrer sonstigen Bedeutung, Heimatdichter nennst! Was haben wir denn mit eurer engen, beschränkten Heimatkunst gemein? Meine verehrungswürdigsten Literaturweisen, die enge beschränkte Heimatkunst hat immer nur in Ihren engen beschränkten Schädeln existiert - wir, die Vorkämpfer der Heimatkunst, haben allezeit sehr deutlich erklärt, daß wir die Kunst Jeremias Gotthelfs und Otto Ludwigs, Ludwig Anzengrubers und Theodor Fontanes meinten, nur freilich diese Kunst noch „intimer“ ausgestaltet, gemäß der durch die neueste Literaturentwicklung noch stärker ausgebildeten Fähigkeit des Sehens und der ebenfalls durch sie reicher entwickelten Technik, die freilich keineswegs immer die schulmäßig naturalistische zu sein braucht. ${ }^{405}$

398 Bartels 1904, S. 17.

399 Bartels 1909, Bd. 2, S. 587.

400 Bartels 1909, Bd. 2, S. 588.

401 Bartels 1909, Bd. 2, S. 589.

402 Bartels 1920, S. 47.

403 Bartels 1904, S. 1.

404 Bartels 1920, S. 45.

405 Bartels 1920, S. 45-46. 
Auch wenn die zeitgenössische Heimatkunst - also alles, was laut Bartels zur Periode nach Gotthelf und Fontane zu zählen ist - nichts Gleichrangiges zu bieten habe: Für die „Gegner“, wie Bartels alle Literaturströmungen nennt, die sich nicht der Heimatkunst zuordnen lassen, gelte das schließlich ebenso. ${ }^{406} \mathrm{Zu}$ dieser Strategie der Selbstnobilitierung gehört es schließlich auch, die Heimatkunstbewegung als europäisches Phänomen zu würdigen: Maxim Gorki, Selma Lagerlöf, Gabriele d'Annunzio werden genannt. ${ }^{407}$ Dies steht allerdings im offenen Widerspruch zur rhetorischen Strategie, Heimat als spezifisch deutschen Gemütswert, der gleichwohl nicht auf Regionalismus, sondern auf Nationalismus ziele, darzustellen. Heimat sei das „deutsche Urgefühl“, das aber immer „das ganze Deutschland“ meine. ${ }^{408}$ Eine dritte Argumentationsfigur, die begründen soll, warum die Heimatkunst keine ,Großen' zu bieten habe, besagt, dass die Juden den Aufstieg der Heimatkunst verhindert hätten. ${ }^{409}$

Bis hierher lässt sich resümieren: Bartels sichtet als erster Literaturhistoriker die Geschichte der deutschsprachigen Literatur unter dem Gesichtspunkt der Heimat und kommt dabei teilweise zu Ergebnissen, die noch heute standhalten. Dazu gehört die Feststellung, dass für die Aufklärung und Klassik Heimat noch eine untergeordnete Rolle gespielt habe (Schiller wird geradezu als „Anti-Heimatdichter“ bezeichnet, viel mehr als Goethe sei er noch „Sohn des 18. Jahrhun-

406 Bartels bezeichnet Gotthelf und Fontane als ,größte‘ Heimatdichter. Bei anderen Autoren wie Detlev von Liliencron und Gerhart Hauptmann differenziert er in Werkgruppen, die zur Heimatkunst, und solche, die nicht dazu zählen. Vgl. Bartels 1904, S. 15-16.

407 Vgl. Bartels 1920, S. 47.

408 Bartels argumentiert, „der Deutsche“ sei immer „ein großer Individualist“ gewesen, „,immer verstand er es, das Besondere aus dem Allgemeinen herauszubauen, niemals konnte er trotz Wanderlust und Wagemut glücklich sein, wenn er nicht eine Heimat hatte. An dies deutsche Urgefühl schließt sich unsere Heimatkunst an, aber sie will doch das ganze Deutschland, sie will die Einheit über der Mannigfaltigkeit, in der Mannigfaltigkeit die Einheit.“ Alle Zitate Bartels 1904, S. 19.

409 „Darüber wollen wir uns freilich nicht verhehlen, daß ein vollständiger Sieg der Heimatkunst trotz der großen Erfolge, die einzelne Werke errangen, nicht erfolgt ist: Das Judentum hatte in ihr den gefährlichen Feind seines dekadenten Literaturtreibens recht wohl erkannt, und es gelang ihm, die öffentliche Meinung gegen sie einzunehmen und selbst manche Vorkämpfer einzuschüchtern, so daß sie bescheiden nur noch von der ,sogenannten Heimatkunst‘ zu reden wagten.“ Bartels 1909, Bd. 2, S. 588-589. Antisemitismus, wenn auch etwas verbrämter, findet sich auch in Friedrich Lienhards Äußerungen zur Heimatkunst. Friedrich Lienhards ,idealistischer Antisemitismus‘ besagt, dass es nur ein ,geistiges Judentum` zu bekämpfen gelte. Vgl. Puschner 2001, S. 54-57; zu Lienhards Rassentheorie der ,großen Seelen` vgl. Puschner 2001, S. 71-76; Oesterhelt 2019. Antisemitismus als Teil der Heimatkunstbewegung weist Karlheinz Rossbacher auch bei Julius Langbehn, Ernst Wachler, Gustav Frenssen und Carl Muth nach, vgl. Rossbacher 1975, S. 36-40. 
derts“410), Herder sei der erste „Prophet der Heimatdichtung“, ${ }^{411}$ bei Bürger, Hölty, Voß und in Goethes Jugenddichtung (Götz, Werther) und bei Jung-Stilling fänden sich Anfänge der Heimatdichtung; auch Vossens Homer-Übersetzung wird genannt. Die Romantik würdigt er bezüglich ihres neuen Verhältnisses zu Heimat, verzeichnet aber auch eine qualitative Differenz zur Heimatdichtung desjenigen Typs, wie er von Pestalozzi und Hebel ausgeht und dann das 19. Jahrhundert charakterisiert. Man sei berechtigt, „das 19. Jahrhundert wesentlich als Zeitalter der dezentralisierten, der Stammes- und Heimatpoesie aufzufassen“. ${ }^{412}$ Bei allen Vorbehalten gegenüber Bartels' Ideologie und Terminologie muss zur Kenntnis genommen werden, dass er ein zentrales Motiv und Charakteristikum der deutschen Literaturgeschichte des 19. Jahrhunderts als Erster benannt und damit durchaus ins Schwarze getroffen hat. Freilich werden diese literaturhistorischen Bemühungen durch seine unhaltbaren Wertungen, seine Behauptung einer teleologischen Entwicklung der Literaturgeschichte zur ,Heimatkunst', seine Vermischung von objektivierender Beschreibung und forciert subjektivem literaturästhetischem Ideal sowie durch seinen aggressiven Antisemitismus vollständig diskreditiert. Mit der zweifelhaften ,Periodisierung ${ }^{6}$ nach dem Kriterium der Heimatkunst werden zudem andere literarische Entwicklungen vollständig übersehen oder auf groteske Weise marginalisiert.

Welches ist nun aber Bartels' ästhetisches Ideal der Heimatkunst? Kurz gesagt: Es gibt bei Bartels nur eine sehr widersprüchliche Ästhetik und diese Widersprüchlichkeit ist Ausdruck der vielfältigen Funktionen, welche die Heimatkunst übernehmen soll: eine integrative Funktion (nämlich bezogen auf die ,Moderne'), eine Funktion der Platzhalterschaft (in Bezug auf die ,Nation`), eine nach innen ausgrenzende (bezogen auf alles ,Undeutsche‘, Jüdische oder Fremdländische) und nach außen expansionistische Funktion (deutsche Heimat als Exportmodell).

\section{Heimat als Versöhnung der Moderne}

Heimat ist bei Bartels zunächst der Geburtsort oder die Geburtsregion und die mit ihr assoziierte Landschaft beziehungsweise der mit ihr verbundene Volksstamm. ${ }^{413}$ Einerseits hebt Heimat das Individuelle hervor, insofern sich jeder Einzelne durch seinen Geburtsort unterscheidet, andererseits nivelliert sie das Individuelle, insofern sie den Einzelnen als Teil einer Landschaft und als Teil

410 Bartels 1920, S. 43.

411 Bartels 1920, S. 42.

412 Bartels 1920, S. 44.

413 Vgl. Bartels 1909, Bd. 2, S. 544-545 sowie Bartels 1914, S. 8-16. 
eines als Gesamtkörper vorgestellten Volksstammes, gleichsam als Gewächs eines bestimmten Bodens betrachtet. ${ }^{414}$ Solch ein durch die Heimat gekräftigter Volkscharakter ist nur in der Besinnung auf die eigenen „Wurzeln“415 zu erhalten beziehungsweise wiederzugewinnen. Schon hier zeigt sich zum einen die Funktion von Heimat als Synthese von Gegensätzen (hier: individuell - überindividuell) und zum anderen die - zeittypische - metaphorische Umsetzung dieser Funktionalisierung im Bildkomplex des Vegetativen, mit der Rede von der Heimat als ,Nährboden', in dem der Deutsche wurzele. Diese Metaphorik schließt etwa an diejenige des ,Rembrandtdeutschen“ Julius Langbehn an, der von der „Quelle“ und vom „Boden“ als Ursprung des deutschen „Volkscharakters“ spricht ${ }^{416}$ und findet sich in der völkischen Literatur zu Hauf. ${ }^{417}$

Die Heimatkunst greift Bartels zufolge dieses - Einzelnes und Ganzes verbindende - Heimatverständnis auf. Sie ist in Bartels’ Verständnis erst durch den Naturalismus möglich geworden, von dem man sie aber auch abgrenzen müsse. Nicht der mit Radikalismus und Sozialismus in Verbindung gebrachte Naturalismus, nicht der Naturalismus der „hohen ,Allüren““418 wird von Bartels als positive literaturgeschichtliche Entwicklung angesehen, wohl aber derjenige Naturalismus, der das Gegengewicht zur Décadence bilde und nicht wie diese in Ästhetizismus und Individualismus aufgehe, sondern eine „schärfere Beobachtung des Lebens“ lehre. ${ }^{419}$ Bartels kehrt mit der Behauptung, die Heimatkunst sei ein „gesunder“ Naturalismus, das literarhistorische Verhältnis zwischen Hei-

414 „Wie die einzelne heimatliche Mundart ein steter Jungbrunnen bleibt, aus dem unserer hochdeutschen Schriftsprache immer neues Leben zuquillt, so bleibt auch die engere Heimat mit ihrer Stammeseigenart der stete Nährboden, aus dem sich unser ganzer deutscher Volkscharakter $\mathrm{zu}$ immer neuer Kraft, zu immer reicheren Entfaltungen und zu immer vielseitigerer Einheit emporgestaltet.“ Bartels 1909, Bd. 2, S. 545. Bartels gibt hier zustimmend den mit Gedichten in Mundart und Romanen wie Jost Seyfried (1905) bekannt gewordenen Schriftsteller Cäsar Flaischlen wieder.

415 Bartels 1904, S. 18.

416 Langbehn fordert die Wiederherstellung eines „organischen Zusammenhang[s]“ (Langbehn 1890, S. 17) in allen Lebensbereichen, sucht von „der lebendigen Quelle des heutigen deutschen Volkscharakters“ (Langbehn 1890, S. 18) und glaubt, die „irrende Seele der Deutschen“ müsse „sich wieder an den heimatlichen Boden binden“ (Langbehn 1890, S. 19).

417 Vgl. exemplarisch Hans Grimms im Nationalsozialismus zur Schulbuchlektüre aufgestiegenen Roman Volk ohne Raum von 1926: „Sinn und Seele nähren sich“ hier „aus dem Wurzelboden der Heimat“, Grimm 1933, S. 16. Heimat ist bei Grimm aber mit ,Enge‘ konnotiert: Volk und Nation sind insoweit der Heimat überlegen; um ihrer Expansion willen gelte es diese Verwurzelung zu übersteigen.

418 Bartels 1909, Bd. 2, S. 545.

419 Bartels 1909, Bd. 2, S. 570. 
matkunst und Naturalismus kurzerhand um, so dass der Naturalismus als Teil der neuen Heimatkunstbewegung erscheint. ${ }^{420}$

An anderer Stelle wird die Heimatkunstbewegung eher als Vermittlerin zwischen den gegensätzlichen Entwicklungen der zeitgenössischen Literatur präsentiert. Sie vermittle zwischen dem zu Sozialen des Naturalismus und dem zu Individualistischen der Décadence. ${ }^{421}$ Sie verbinde „altes Volkstum“ und „alte Landschaft“ mit modernem Geist und modernen Darstellungsmitteln, verbinde Land und Stadt, Vergangenheit und Moderne. ${ }^{422}$ Einerseits wird die Heimatkunst durch die Abgrenzung von anderen literarischen Strömungen charakterisiert, insofern sie ,gesünder', ,natürlicher' und ,authentischer' sei, andererseits ist sie Bartels zufolge gar nicht als eine Vertreterin irgendwelcher „Richtungen“ zu verstehen. ${ }^{423}$ Heimatkunst, so legt Bartels immer wieder nahe, soll alle Literatur umfassen, jedenfalls alle, gesunde‘ Literatur. ${ }^{424}$

Dementsprechend bleibt auch die Charakterisierung der Formen und Inhalte der Heimatkunst denkbar offen: Die Art des Stoffs sei nicht bestimmbar, heißt es, auch Sprache und Darstellungstechnik seien nicht festlegbar, aber Stoff, Sprache und Darstellungstechnik gingen Hand in Hand, und mit ihnen das ganze Wesen des Dichters: Auf dessen „Wesens-Erneuerung“ und „Geistes-Auffrischung“ komme es an. ${ }^{425}$ So diffus wie die Anforderungen an den Künstler, er solle einfach nur ,er selbst', gesund und natürlich sein, so diffus ist auch das ästhetische Programm, das keines sein will.

Zwei Begriffsfelder tauchen sehr häufig im Zusammenhang mit Fragen nach der Behandlung des Stoffs und in der Beschreibung des ,Wesens' des Heimatdichters auf: das der scharfen Beobachtung und das der Liebe - Gegensätze also, insofern das erste Distanznahme, das zweite Zuwendung erfordert. An dieser Verbindung von Distanz und Zuwendung habe schon der poetische Realismus gearbeitet, nach Bartels aber mit zu viel verklärendem und $\mathrm{zu}$ wenig scharfem Blick. Gefordert wird eine ,schärfere Beobachtung des Lebens und eine charakteristischere Darstellung“, diese sei möglich „dank dem Naturalismus, der wieder den Respekt vor dem Leben gelehrt“ habe. ${ }^{426}$ Wiederholt wird der durch den

420 Vgl. Bartels 1909, Bd. 2, S. 545. Zum Verhältnis von Naturalismus und Heimatkunst vgl. Beßlich 2011.

421 Vgl. Bartels 1909, Bd. 2, S. 568.

422 Beide Zitate Bartels 1909, Bd. 2, S. 569.

423 Bartels 1904, S. 3 und S. 20. Vgl. auch Bartels 1909, Bd. 2, S. 569.

424 Vgl. Bartels 1909, S. 3.

425 Beide Zitate Lienhard: Tagebuch, 1900, S. 182.

426 Beide Zitate Bartels 1909, Bd. 2, S. 570. 
Naturalismus erneut gestiftete „Zusammenhang mit dem Leben“ beschworen. ${ }^{427}$ Das Kunstwerk solle dem Leben abgerungen werden, Natur und Leben gälten mehr als die Individualität des Dichters. Dies kann man zum einen im Kontext der lebensphilosophischen Ideen der Jahrhundertwende lesen (zeittypische Topoi des Organischen verweisen auf einen Lebensbegriff, der sein metaphysisches Bedürfnis nicht mehr im Christentum befriedigt; bei Bartels verbindet sich der Lebensbegriff zudem mit einem darwinistisch interpretierten ,Leben', das nur dem ,Gesunden` Überlebensrecht einräumt), zum anderen im Kontext der vielfältigen zeitgenössischen Bemühungen um Theorien und Techniken der exakten Wahrnehmung und des genauen Blicks. Heimatdichtung wolle nicht sentimental sein, betont Bartels. Dem Ideal des Unsentimentalen wird nun aber der Begriff der Liebe an die Seite gestellt, ohne dass Bartels auf mögliche Widersprüche zwischen beiden eingeht: Er bestimmt an mehreren Stellen das „Prinzip“ der Heimatkunst geradezu als „die Liebe, das Mitfühlen“, ${ }^{428}$ teilweise in Abgrenzung zur Kunst der Décadence, teilweise in Abgrenzung zum Naturalismus. Diese gerade beim besessenen Antisemiten und erklärten Humanismusverächter Bartels, der das Christentum durch einen „germanischen Transzendentismus“429 ersetzt sehen möchte, diese für Bartels also bemerkenswerte Vokabel der Liebe hatte schon bei Julius Langbehn, dem Ideengeber eines „Lokalismus der Kunst“, eine Umdeutung erfahren, die die Reichweite der Liebe auf das als richtig Befundene einschränkte. ${ }^{430}$ Die aus christlicher Perspektive abwegige Idee einer aufs Gesunde beschränkten Liebe findet sich auch im Umfeld von Bartels wieder. ${ }^{431}$

Hier mag einer der Gründe für den Erfolg der Idee der Heimatkunst bei vielen zeitgenössischen Autoren liegen: Sie ist nicht einfach antimodernistisch, sondern sie vermag es, moderne ästhetische Programme zu integrieren, etwa die naturalistisch inspirierte Ästhetik des präzisen Blicks. Sie besetzt diese Ästhetik der Naherfahrung zugleich mit positiven Emotionen. Indem sie mit der Zusammenführung gegensätzlicher Charakteristika Widersprüche scheinbar überwindet

427 Bartels 1909, Bd. 2, S. 571.

428 Bartels 1909, Bd. 2, S. 544 und S. 569.

429 Bartels: Das Weimarische Hoftheater, 1906, S. 32.

430 Langbehn 1890, S. 15. „Keine Liebe ohne Haß; zu dem sanften gehört stets der strenge Christus; sonst ist das Bild nicht vollkommen. Mögen darum auch die jetzigen Deutschen lernen, zu hassen. Wer Haß sät, kann Liebe ernten.“ Langbehn 1890, S. 305.

431 Programmatisch etwa in einer Besprechung des zur Heimatkunst gezählten Schriftstellers Timm Kröger in der Zeitschrift Heimat. Vgl. Berger 1900. Karl Berger hebelt aber mit dem Paradigma von Gesundheit und Krankheit das christliche Konzept der unterschiedslosen Liebe aus, indem er es nur auf das Gesunde angewendet wissen will. Diese These lässt sich auf den Heimatgebrauch der Literatur und Literaturkritik um 1900 insgesamt ausweiten, vgl. auch MoellerBruck 1900, S. 5-6. 
oder aufhebt, stellt sie ein Integrationsangebot für die gegenläufigen Tendenzen der ,Moderne“ dar. Heimatkunst sei als Garant gegen das „Bazar- und Modewort“ ,modern' zu verstehen, heißt es ausdrücklich - und zugleich, Heimatkunst beanspruche, „noch ,moderner“ zu sein als der modernste [Hermann] Bahr“ ${ }^{432}$ womit eine charakteristische Überbietungsfigur der ,Modernen“ um 1900 bedient wird. Gegenwart soll nicht rückgängig gemacht, sondern transformiert werden, Oberflächenkultur soll in Tiefenkultur verwandelt werden. ${ }^{433}$ Heimat ist eine Vokabel, die solche Vorstellungen von ,Tiefenkultur' auch in dem Sinn als Überwindung von Gegensätzen versteht, als sie sich in ihrer literarischen Darstellung zugleich dem Irdischen und dem Geistig-Transzendenten zugehörig zeigt. „Vor der Einfalt und Einheit solcher volksmäßigen Dichtung verschwindet Bekenntnis, Partei und Bildung, trennende Gewalten, die der künstlerische Ausdruck deutscher Weltsicht in der durchgeistigten Darstellung irdischen, zumal heimatlichen Lebens bezwingt. “434 So formuliert Ernst Wachler, Begründer des als neuheidnische ,Weihestätte' konzipierten Bergtheaters Thale und Mitglied der völkisch orientierten ,Germanischen Glaubensgemeinschaft‘. ${ }^{435}$ Auch Julius Langbehn verwendet Heimat als Integrationsformel zur Überwindung der Gegensätze zwischen den gesellschaftlichen Klassen, aber auch zwischen Nähe und Ferne, Realität und Ideal: „Künstler Bauer König stehen und fallen gemeinsam mit dem, was der Mensch Heimath nennt; und was ihm das Theuerste auf der Welt ist. Kranke Naturen halten es für eine Eigenthümlichkeit des Ideals, daß es unendlich fern sei; und es ist doch unendlich nah: die Heimath ist das Ideal.“436

Festzuhalten bleibt, dass die völkische und antisemitische Heimatkunst eines Bartels nicht als reaktionär einzustufen ist in dem Sinn, dass Moderne hier schlicht rückgängig gemacht werden soll. Vielmehr wird in einer wie scheinhaft auch immer einzuschätzenden Synthesebemühung ein Versöhnungs- und Harmonisierungsangebot an diejenigen gemacht, die unter den Widersprüchen der Moderne leiden. Damit reiht sich Bartels ,Heimatkunst“ zeittypisch in eine ganze

432 Lienhard: Hochland, 1900, S. 3. Vgl. auch Lienhard: Vorherrschaft Berlins, 1900, S. 20 oder Bartels 1904, S. 19. Zu Lienhards Modernitätsanspruch der Heimatkunst mit vielen weiteren Nachweisen vgl. Kramer 2006, S. $43-47$.

433 „Kein Flüchten vor dem Geiste der Gegenwart, aber seine Nationalisierung, seine Konkret-, seine Heimischmachung, die Verwandlung der Oberflächenkultur in Tiefkultur ist die Aufgabe, und ihr dient auch, und sei es zunächst noch in bescheidener Weise, unsere Heimatkunst.“ Bartels 1904, S. $19-20$.

434 Wachler 1897, S. 27-28.

435 Ernst Wachler wird in Karlheinz Rossbachers Studie als Programmatiker der Heimatkunstbewegung besprochen, vgl. Rossbacher 1975; allerdings hat sich Wachler nicht explizit als solcher verstanden.

436 Langbehn 1890, S. 128. 
Reihe von kulturtheoretischen Entwürfen, die in Antinomien dachten und diese in Synthesen zu überführen suchten. ${ }^{437}$

\section{Heimat als Platzhalter der Nation}

Man kann die aporetischen Argumentationsmuster Bartels' als Versuch der Synthese lesen, wie oben entwickelt. Man kann sie auch als den Versuch lesen, eine Leerstelle zu schaffen, die als Platzhalter für etwas anderes fungieren kann. Diese Lesart soll hier ergänzend zur obigen angeboten werden. Denn es bleibt zu konstatieren, dass Heimatkunst vorrangig als Negation erscheint. Sie wird als das charakterisiert, was sie nicht ist: Sie sei nicht notwendig Literatur mit örtlichem Charakter, denn solche Regionalliteratur könne durchaus im Gegensatz zum Allgemein-Nationalen stehen und sei dann nicht mehr im Sinn der Heimatkunst zu verstehen. ${ }^{438}$ Sie sei nicht gleichzusetzen mit der Volkskunst, denn diese mache Heimat nur zu einem Mittel pädagogischer Zwecke. ${ }^{439}$ Man solle sie auch nicht mit der Dorfgeschichte verwechseln, da hier Heimat ebenfalls nur Mittel zum Zweck, wenngleich einem ästhetischen, sei. ${ }^{440}$ Die Beobachtung, dass Heimat sich über das Prinzip der Negation charakterisiert, heißt nicht, dass sie in ihrem Selbstverständnis das Gegenteil des Abgelehnten wäre. Sie opponiert gegen die Großstadt, will aber auch nicht einfach mit dem Ländlichen identifiziert werden: Auch die Stadt, sogar die Großstadt könne Heimat sein. ${ }^{441}$ Heimat meine gerade nicht Enge und Beschränktheit, meine nicht Rückwärtsgewandtheit und Weltfremdheit, meine nicht Idylle oder ein simples ,Zurück zur Natur ${ }^{442}$ Insofern versteht sich Bartels ähnlich wie Friedrich Lienhard nicht als Verfechter einer

437 Vgl. etwa Hein 1992, S. 88.

438 Vgl. Bartels 1904, S. 6.

439 Vgl. Bartels 1904, S. 7.

440 Vgl. Bartels 1904, S. 8.

441 Vgl. Bartels 1904, S. 15; Bartels 1909, Bd. 2, S. 569. Vgl. auch Lienhard: Vorherrschaft Berlins, 1900, S. 20 - 21 und dessen Vorwort zur zweiten Auflage. Ein eher seltenes Beispiel für den literarischen Versuch, Großstadt und Heimat zu assoziieren, ist Ernst Schurs Gedicht Heimat in seinem Gedichtband Die steinerne Stadt (1905), das so beginnt: „Heimat! / Ist Heimat nur Dorf und Land? / Nur die kleinen Städte? // Auch über dem Meer der Mietskasernen / wölbt sich der Nachthimmel mit all den Sternen." Schur 1905, S. 27-29, hier S. 27. Karlheinz Rossbacher interpretiert das (allerdings bei ihm nicht ganz korrekt wiedergegebene) Gedicht überzeugend als den scheiternden Versuch, Vorstellungen organischer Verwurzelung und eines biologisierten Lebenskreislaufs vom ländlichen in den städtischen Raum zu übertragen, ohne Bewusstsein dafür, dass die Metaphern nicht mehr stimmen; vgl. Rossbacher 1975, S. 33-34.

442 Vgl. Bartels 1900, S. 14. 
Antimoderne, sondern als Kämpfer gegen „die ,schlechte“ Moderne“. ${ }^{443}$ Ist Heimatkunst nicht positiv bestimmbar, dann bleibt ein weiter Raum für das, was sie sein könnte. In jede Leerstelle will etwas eingetragen werden. Im Falle von Bartels' Heimatbegriff ist es die Utopie der nationalen Größe.

Bartels greift deswegen dankbar den von Friedrich Lienhard in die Heimatkunstprogrammatik eingebrachten Begriff der sogenannten Höhenkunst auf. ${ }^{444}$ Die Höhenkunst wird als der noch uneingelöste, utopische Zielpunkt einer literaturgeschichtlichen Bewegung entworfen, die in der Zeitgenossenschaft Lienhards und Bartels mit der Heimatkunst ihren Anfang genommen habe. Mit organologischer Rhetorik wird eine literaturhistorische Teleologie entworfen, nach der aus dem ,gesunden' Boden der Heimatkunst die ,stolze“ nationale Höhenkunst erwachse, Heimatkunst also Vorbereitungsstufe für eine höhere, noch zu erwartende Stufe der Literatur sei. Lienhard gestaltet dieses Prinzip der sich ergänzenden Pole von hoch und tief geradezu programmatisch auch in seiner dramatischen Wartburg-Trilogie (1903-06). ${ }^{445}$ Dabei ist, im Anschluss an einen seit Beginn des 19. Jahrhunderts topischen Antagonismus von Heimat und Nation (vgl. I.2.1), die regionale Heimatkunst dem Leiblichen, Vegetativen, Weiblichen oder auch Kindlichen, dem Boden, der Landschaft zugeordnet, während die nationale

443 Bartels 1909, Bd. 2, S. 516.

444 Vgl. Bartels 1904, S. 19 - 20 oder Bartels 1909, Bd. 2, S. 592. Gleichwohl ist das Verhältnis von Höhen- und Heimatkunst nicht immer so harmonisch, wie die Programmatik nahelegt. So wollte Lienhard die Zeitschrift Heimat. Blätter für Literatur und Volkstum eigentlich unter dem Titel Hochland erscheinen lassen, konnte sich aber gegenüber dem Verleger nicht durchsetzen. Schon nach Erscheinen des ersten Heftes zieht sich Lienhard aus der Leitung zurück, da er die vertretene Konzeption nicht mittragen will. Er selbst äußert sich dazu in Lienhard 1901, S. 193. Vgl. auch Châtellier 1996, S. 121. Die 1903 vom Reformkatholiken Carl Muth gegründete Münchner Monatsschrift Hochland nimmt Ideen von Lienhard auf.

445 Lienhards Wartburg-Trilogie (1903-06), bestehend aus Heinrich von Ofterdingen, Die heilige Elisabeth und Luther auf der Wartburg, enthält in allen Teilen eine auffällige Hoch-tief-Metaphorik, die zwischen Burg und Volk vermittelt. Ofterdingen muss die Burg mit seinem Gesang erobern, ohne seine Verbindung mit dem Volk zu verraten. Elisabeth holt die Armen und Aussätzigen erst zu sich in die Burg und steigt dann ganz hinab, um dem Volk zu dienen. Und Luther bringt seine Bibelübersetzung in Lienhards Version als Erstes den Eisenacher Bürgern, von der Burg hinab ins Tal. Alle drei Heldenfiguren werden durch ihre Nähe zum einfachen Volk charakterisiert. Während die Bewegung von Ofterdingen im Stückverlauf von unten nach oben verläuft, ist die Bewegung von Elisabeth und Luther eine von oben nach unten. Wichtig ist, dass alle drei eine Verbindung von beiden Polen herstellen. Alle drei, so Lienhard, ,sind voll von Geistesbildung der Zeit und halten sich gleichwohl zum natürlichen Empfinden des Volkes. [...] So stellen sie die Verbindung zwischen Höhenkultur und Wurzelkräften der Volksseele dar.“ Lienhard 1918, S. III. Vgl. dazu Oesterhelt 2019. 
Höhenkunst vaterländisch, geistig, heldisch, männlich konnotiert ist. ${ }^{446}$ Beide stehen also in einem Bedingungsverhältnis, das die (potentiell unendlich erweiterbare) Scheindialektik von Heimat auf eine weitere Stufe transponiert. So wie die Heimatkunst aus weiblichem und männlichem Anteil besteht, bleibt sie doch immer noch Frau und bedarf des vaterländischen Prinzips der Höhenkunst, das seinerseits ebenfalls beide Anteile in sich birgt (vgl. I.2.3).

Bartels muss nach dieser Logik dann auch keine herausragenden Repräsentanten der Heimatkunstbewegung benennen, vielmehr kann er eingestehen: ,[Z]u hoher Kunst kam es nur selten.“ Verhehlen könne er nicht, „daß ein vollständiger Sieg der Heimatkunst trotz der großen Erfolge, die einzelne Werke errangen, nicht erfolgt ist“. ${ }^{447}$ Mit diesem Eingeständnis stellt er die von ihm proklamierte Bewegung aber nicht in Frage, insofern sie sich aus ihrem vorbereitenden Charakter rechtfertigt. Die stets Leerstellen produzierende Rede über Heimat findet in der Erwartung einer nationalen Höhenkunst einen Platzhalter für das Charakteristische, Herausragende, Bestimmte, das ihr selbst fehlt. Heimat und Nation, Heimatkunst und nationale Höhenkunst funktionieren also bei Bartels ähnlich, insofern beide auf etwas noch Einzulösendes verweisen. Dabei enthalten beide Antagonisten jeweils selbst ihr gegenteiliges Prinzip: Heimat bedeutet Konkretion und doch soll die Heimatkunst den allgemeinen Nährboden bilden für die nationale Höhenkunst; Nation bedeutet Abstraktion und doch soll die vaterländische Höhenkunst gerade die exzeptionellen, einzigartigen Dichter hervorbringen. Den Widerspruch, in den sich die gesamte auf ein Nationales zielende Rede von Heimat im beginnenden 20. Jahrhundert begibt, dass nämlich gerade ein forcierter Regionalismus zum Bürgen für die Größe der geeinten Nation wird, löst der Verweis auf die Verwobenheit von allem mit allem nur scheinbar auf.

\section{Heimat, Kulturkritik und Kolonialismus}

Das Prinzip der Negation erschöpft sich bei Bartels allerdings nicht im Platzhalterprinzip für ein abstrakt Nationales, sondern besitzt auch eine sehr konkrete, aggressiv-abgrenzende Implikation. Denn wenn Heimat bei Bartels alles ,Gesunde' einschließt, so muss in der Konsequenz gleichzeitig alles ,Kranke‘ abgetrennt werden. ${ }^{448}$ Ist Heimat aber alles, was gesund ist, so gibt es das aus der Sicht der

446 Vgl. Lienhard: Hochland, 1900, näher nachgewiesen in Oesterhelt 2019.

447 Beide Zitate Bartels 1909, Bd. 2, S. 588-589.

448 Vgl. Bartels 1904, S. 17-19. Heimat und Gesundheit bzw. Nicht-Heimat und Krankheit gehen um 1900 eine topische Verbindung ein; vgl. exemplarisch die andernorts in dieser Studie zitierten Passagen aus Langbehn 1890, S. 128; Dieterich 1902, S. 3- 4. Auch in Heinrich Manns begeisterter Besprechung von Friedrich Lienhards Liedern eines Elsässers (1895) und seinem Plädoyer für 
zivilisationskritischen Heimat-Fraktion kaum noch. Denn die Gegenwart sei bestimmt von Rationalismus, Nüchternheit, Materialismus, Großstadt, Kapital, Dekadenz, Feuilleton, Sensationsgeist, Internationalismus, Ästhetizismus - um einige besonders häufig angeführte Schlagworte zu nennen. Diese Erscheinungen der Moderne sind in Bartels’ von Anfang an völkisch gefärbter Kulturkritik ${ }^{449}$ eng assoziiert mit dem Jüdischen: Dieses sei die Verkörperung des materialistischen Denkens, des geistreichen, aber kalten Witzes, des kapitalistischen Kalküls, des sensationsgierigen Journalismus und so fort. Die Juden werden nicht nur als eine fremde Rasse aufgefasst, sondern auch als minderwertige, weil sie - ganz in der Tradition des Ahasver-Mythos - keine eigenen ,Wurzeln' habe, selbst heimatlos sei und deswegen in einem parasitären Verhältnis zum deutschen Volk stehe (vgl. II.1.3.2). Die dem Juden zugeordnete Heimatlosigkeit verbindet sich hier unlösbar mit einer Modernekritik, die durchaus auch ganz anderen Motivationen und Weltanschauungen entspringen konnte als dem Antisemitismus: einer Kritik am Kapitalismus, einer Kritik an den Entfremdungserscheinungen der Moderne, die Georg Lukács 1914 als ,transzendentale Obdachlosigkeit‘ oder auch als ,transzendentale Heimatlosigkeit ${ }^{640}$ bezeichnete (vgl. I.2.4). Während Lukács allerdings alle Menschen dieser Situation ausgesetzt sieht, behaupten zeitgleich nicht nur die Deutschvölkischen, sondern etwa auch der kapitalismuskritische Soziologe Werner Sombart Heimatlosigkeit in Analogie zur Logik des beweglichen Kapitals als spezifisches Charakteristikum der Juden. ${ }^{451}$ Bartels und die

„Heimathsliebe“ und „Bauerngeist“ (Mann 1895, S 351) in der Literatur argumentiert Mann mit einer „Provinzgesundheit“, die wie eine Naturgewalt „über die Hauptstadt“ hereinbrechen und zur Reinigung führen solle (Mann 1895, S. 352). Zu Heinrich Manns Rolle in der Heimatkunst vgl. Kramer 2006, S. 40 - 43 und 47-51; auch zu Thomas Mann, der für die vom Bruder Heinrich redigierte Zeitschrift Das Zwanzigste Jahrhundert zwischen 1895 und 1896 verschiedene affirmative Rezensionen zu belletristischen Neuerscheinungen „aus dem Umkreis der völkisch-nationalen Heimatliteratur“ verfasst, vgl. Kramer 2006, S. 52-57, hier S. 52. Kramers Fazit: „Deutschnationale Heimatkunst wird damit zum Zentrum von Thomas Manns früher politischer Ästhetik.“ Kramer 2006, S. 56.

449 Barbara Beßlich zeigt, dass die wilhelminische Zivilisationskritik keinesfalls immer mit den völkischen Ideologien in Zusammenhang stehen musste, wie es etwa Fritz Sterns einflussreiche Studie Kulturpessimismus als politische Gefahr nahegelegt hatte. Vgl. Beßlich 2000, S. 16.

450 Vgl. Lukács 1920, S. 51-52.

451 In Die Juden und das Wirtschaftsleben (1911) entwickelt Werner Sombart die behauptete Affinität der Juden zum Geld als historische Folge ihres althergebrachten „Nomadendasein[s]“. Durchs fortwährende Exil seien die Juden „,von aller etwa noch vorhandenen Bodenständigkeit und Wurzelfestigkeit abgedrängt“ worden. Im Gegensatz zu anderen unter Zwang auswandernden Völkern hätten die Juden nie „eine Ackerbaukolonie“ gegründet (alle Zitate Sombart 1911, S. 411) und die Juden seien auch vor ihrer vollständigen Diaspora nie „zur heimatlichen Scholle zurückgekehrt, nachdem sie sich ein kleines Vermögen erworben hatten“, wie andere Völker 
Deutschvölkischen gehen so weit nahezulegen, die u.a. durch den Kapitalismus gefährdete Heimat sei wiederherstellbar, wenn man sich von den Juden befreit habe. ${ }^{452}$

Heimat zurückzugewinnen heißt dann, ,Gesundheit‘ zurückzugewinnen. In die antisemitisch grundierten Reinigungsphantasien mischt sich schon 1904 die Vokabel des „Lebensrecht[s]“, das der Heimatkunst zu-, der „decadente[n] Kunst“ dagegen abgesprochen wird. ${ }^{453}$ Die Aggression geht dabei in zwei Richtungen: nach innen, insofern sich das deutsche Volk von seinen ,kranken` Mitgliedern zu ,reinigen' habe, nach außen, insofern der gesundende ,Volkskörper‘ notwendig auf nationale Expansion dränge. Der Heimatkunst fällt die Aufgabe zu, die ,nationale Widerstands- und Expansionskraft“ ${ }^{\star 454} \mathrm{zu}$ heben und die deutsche Kultur „durch die Welt [zu] tragen“. ${ }^{455}$

Somit zeigt sich auch in Bartels’ Heimatprogrammatik jene Verkopplung mit dem Kolonialdiskurs, die Rolf Parr für die Zeit um 1900 in seiner Studie zu Heimatkunst, Kolonialismus, Expeditionen beschrieben hat. ${ }^{456}$ Die Affinität zwischen

(Sombart 1911, S. 412). Zum Zusammenhang von Kapitalismusdebatten und Antisemitismus um 1900 vgl. Berg 2011.

452 Zur Verbindung von Kapitalismuskritik und Antisemitismus bei Adolf Bartels vgl. Bartels 1913, S. $10-11$ und S. 29.

453 ,[U]nsere Heimatkunst [...] hat [...] ganz anderes Lebensrecht als die zeitgenössische decadente Kunst, die denn zuletzt doch auf falscher Genialitätssucht, ja, auf einer bestimmten Unverschämtheit beruht. Was gehen denn ein großes Volk die Nervenzuckungen und unnatürlichen Gelüste seiner kranken Individuen an? [...] Nun können wir zwar die Decadents, wenn sie einmal da sind, nicht einfach totschlagen, aber sie allzu sänftiglich anzufassen, haben wir auch gar keine Veranlassung, wir glauben eben, daß unser Volk noch gesund ist oder es doch sehr rasch wieder werden kann, und sprechen den kranken Leuten einfach ihre nationale Existenzberechtigung ab.“ Bartels 1904, S. 17-18.

454 Bartels 1904, S. 18.

455 Die Heimatkunst sei „Teil jener großen nationalen Heimatbewegung, [...] die das Nationalgefühl auf ein starkes Heimatgefühl gründen, also dem modernen Menschen die Heimat erhalten oder sie ihm wiedergeben will, die die europäische Mischkultur entschieden ablehnt, aber mit der allgemeinen deutschen autochthonen Kultur endlich ernst macht und sie, soweit es möglich, durch die Welt tragen will.“ Bartels 1904, S. 19.

456 Vgl. Parr 2014. Zum Zusammenhang von Kolonial- und Heimatdikurs vgl. auch das Kapitel ,Creating a German Heimat in the African Landscape“ in Sandler 2018, S. 236-242. Das komplexe Gefüge lässt sich an so wirkmächtigen völkischen Kolonialromanen wie Hans Grimms Volk ohne Raum (1926) erahnen, die für die völkische Idee des angeblichen Kolonisierungsauftrags der Deutschen bereit ist, ,Heimat' zu verlassen, um dem, Volk` zu dienen. Im ersten, Heimat und Enge überschriebenen Romanteil werden zwei Optionen für den Umgang mit Heimat im völkischen Sinn eröffnet: „Für die Männer, die hinaus müssen und weg und fort aus dem Tale [...] kann dies auf zweierlei Weise geschehen. Sie können ein Handwerk gelernt haben, damit sie zeitweilig im Tale Beschäftigung finden; dann ist die Fremde ein Zwischenspiel, und Sinn und Seele nähren 
Kolonial- und Heimatkunstliteratur etwa bei Gustav Frenssen, dessen norddeutsche Regionalromane (der erfolgreichste war Jörn Uhl) mit seinem Kolonialroman Peter Moors Fahrt nach Südwest auffällig konfliktfrei zusammengehen, erklärt Parr damit, dass das, was als Heimatkunstprogramm in Deutschland schon lange nicht mehr verwirklichbar gewesen sei - Bauerntum, Bodenständigkeit, ein authentisches Leben jenseits der industrialisierten Welt - in der ein ,besseres Deutschland' in Übersee imaginierenden Kolonialliteratur eingeholt worden sei. ${ }^{457}$ In einer im Exotischen möglich werdenden Doppelperspektivierung wird zugleich ein Blick zurück in die vorindustrielle Vergangenheit und ein Blick voraus auf die koloniale Zukunft geworfen, Industrialisierungskritik mit Kolonialisierungsphantasien verbunden. ${ }^{458}$ Modernekritik und imperiale Ambitionen können auf diese Weise in der auf den exotischen Raum übertragenen Heimatkunst zusammengehen. Obwohl diese Allianz von Heimat- und Kolonialliteratur mit dem Ende der kurzen Geschichte des Deutschen Reiches als Kolonialmacht ihre Funktionalität verliert, werden auch noch später Titel gedruckt wie $D u$ meine Heimat Deutschsüdwest. Ein afrikanisches Farmerleben (Bernhard Voigt, 1925).

Heimat und aggressiver Expansionismus gehen auch jenseits der literarischen Phantasien, die sich um die afrikanischen Kolonien ranken, eine Allianz ein. Im ,Krieg der Geister', der den Ersten Weltkrieg mit vorbereitete und begleitete, ist Heimat allerorten zu finden, ${ }^{459}$ und auch nach dem Krieg ändert sich das nicht. Der Schriftleiter der Zeitschrift Die Heimatkunst des Deutschen Bunds für Heimatkunst, 1922 umbenannt in Germanische Heimat und Heimatkunst, glaubt, dass nur Vaterlands- und Heimatvergessenheit zur Kriegsniederlage geführt habe.

sich weiter aus dem Wurzelboden der Heimat. [...] Die zweite Weise [...] ist also, daß er sich völlig von seinem Wurzelboden scheidet und fortmacht in die Fremde.“ Grimm 1933, S. 16-17. Dass diese Fremde im Kolonialdiskurs der NS-Zeit aber auch immer Heimat sein kann, zeigen Titel wie Ilse Steinhoffs Deutsche Heimat in Afrika. Ein Bildbuch aus unseren Kolonien (1939).

$457 \mathrm{Zu}$ Frenssen als Vertreter der Heimatliteratur vgl. Rossbacher 1975, S. $82-84$ und Dohnke 1996, S. 678. Parr bietet in seiner Darstellung des Bedingungsgefüges von Kolonialismus, Exotismus und Heimatdiskurs ein überzeugendes Deutungsangebot für die Burenbegeisterung der Deutschen während der sogenannten Burenkriege zwischen 1899 und 1902. Die Buren werden im Kolonialdiskurs zu ,niederdeutschen Bauern` erklärt und dienen einem in die Ferne gerichteten Heimatbegriff, der Exotismus und Heimat miteinander verbindet. Zugleich geht es nach Parrs Deutung um die Etablierung einer neuen imperialistischen Diskursposition in Abgrenzung zu England. Nach dem Verlust der Kolonien finde ein radikaler Wandel des Gefüges ExotismusFremde-Beheimatung statt. Vgl. Parr 2014.

458 Vgl. Parr 2014, S. 76.

459 Bartels prognostiziert schon 1909, „daß uns Deutschen nach außen und im Innern schwere Kämpfe bevorstehen, und nicht bloß geistige“ (Bartels 1909, Bd. 2, S. 589). Im Januar 1913 macht er explizit, dass nur ein Krieg zur Gesundung des eigenen Volkes führen könne (vgl. Bartels 1913, S. 42-43). Vgl. auch den Ausstellungskatalog Krieg der Geister. Holler/Wendermann/Püschel 2014. 
„Die Lehre, die ihm jetzt dafür zuteil geworden, sollte ihm endlich vollkommen zeigen, daß die Heimat sein höchstes Gut bildet, das zu verteidigen bis zum letzten Tropfen Blutes eines jeden Willen sein müßte. “460 Ein Volk, „das sich stark genug fühlt, von seinem Überflusse abzugeben““, ${ }^{461}$ will ab den 1920er Jahren wohl endgültig nicht mehr (nur) Richtung Afrika expandieren, sondern hat gleich die ganze Erde im Blick. Und im Sinn dieser Steigerung wird auch gern nicht mehr nur von Heimat, sondern gleich von Urheimat gesprochen - ein Begriff, der sich seit Ende des 19. Jahrhunderts findet und aus dem Umfeld der Indogermanistik, Volkskunde und Linguistik stammt ${ }^{462}$-, etwa 1933 in Josef Nadlers Rede Der zeitliche und der ewige Deutsche. Über die Deutschen heißt es in Nadlers expansionistischer Rhetorik: „Sie ergreifen Besitz von der bunten Vielfalt der Erde. Sie unterwerfen sich den gemeinschaftstrennenden Schicksalen eines neuen Lebens. Aber sie halten die ewige Erinnerung an die Urheimat und die Gemeinschaft ihrer Abkunft fest." ${ }^{463}$ Die Urheimat der Deutschen liegt also nicht wie in den indogermanischen Forschungen in Asien, sondern umgekehrt liegt sie für den die Welt erobernden Deutschen in Deutschland selbst.

\subsubsection{Viebigs Heimaten zwischen Milieu und Scholle}

Clara Viebig, geboren 1860 in Trier, gestorben 1952 in West-Berlin, gehörte um 1900 vor allem als Autorin von Romanen und Erzählungen - weniger als Dramatikerin und Feuilletonistin, die sie auch war - zu den vielgelesenen Autorinnen des Bürgertums. ${ }^{464}$ Die ,deutsche Zolaide ${ }^{6465}$ erlangte durch ihre epischen, teil-

460 Schellenberg 1922. Ernst Ludwig Schellenberg, der Schriftleiter der Zeitschrift, legt den maschinenschriftlichen Durchschlag dieser Annonce einem Brief an Adolf Bartels bei. Der Brief stammt vom 12. März 1922 und enthält auch die Bitte um einen Beitrag zur Zeitschrift.

461 Schellenberg 1922.

462 Vgl. Hermann Hirts Aufsatz „Die Urheimat und die Wanderungen der Indogermanen“, Hirt 1895.

463 Josef Nadler in seiner am 20. Januar 1933 gehaltenen Rede „Der zeitliche und der ewige Deutsche“, Nadler 1937. Ina-Maria Greverus verortet die Idee der ,Urheimat“ im Kontext der „Minderheitenpolitik seit dem ersten Weltkrieg“, sie sei dann durch die „nationalsozialistische „Heim-ins-Reich'-Politik verstärkt“ worden. Greverus 1972, S. 208. Bernhard Waldenfels unterscheidet zwischen „Wahlheimat“ und „Urheimat“ als Herkunftsort, Waldenfels 1994, S. 200.

464 Nach Elizabeth Boa und Rachel Palfreyman, die Viebig in ihrem Buch Heimat. A German Dream ein ganzes Kapitel widmen, gehört sie phasenweise zu den drei meistverkauften Autoren überhaupt: „In the first decade of the century she was consistently among the top three bestselling German authors and up to the mid-1920s her work was published and reprinted in impressions of between 20.000 to 60.00 copies.“ Boa/Palfreyman, S. 41.

465 Vgl. Durand 2004, S. 7. 
weise zyklisch angelegten Milieuromane als sozialpolitische Chronistin ihrer Gegenwart Bekanntheit. Anders als etwa die Schriftstellerkollegin Gabriele Reuter, die mit Romanen wie Aus guter Familie vor allem die bürgerliche Schicht beschrieb, widmete sie sich ausgiebig dem proletarischen Milieu. Zugleich schrieb sie viele mundartliche Texte, die im ländlichen Raum spielen, etwa die hier schon behandelte Novelle Die Heimat, Teil einer Novellensammlung mit dem Titel Heimat (vgl. II.2.2.1). In heutigen Literaturgeschichten wird Viebig daher sowohl dem Naturalismus als auch der Heimatkunst zugeordnet.

Ein Brief von Clara Viebig an Bartels wirft ein Schlaglicht darauf, dass sich diese Zuordnung schon zeitgenössisch in Bewegung befand. Er zeigt, dass Viebig sich als Heimatdichterin sieht und gegenüber Bartels ihre - von ihm zu diesem Zeitpunkt bereits bestrittene - Zugehörigkeit zur Heimatkunst ausdrücklich reklamiert: „[E]s hat mir immer leid getan, daß ich bei einem Hauptvorkämpfer der Heimatkunst für meine, in erster Linie aus der Liebe zur Heimat geborenen Werke nur Ablehnung gefunden habe. “466 Viebigs Brief nimmt Bezug auf drei Besprechungen ihres Romans Das Weiberdorf, eine durch Bartels im Litterarischen Centralblatt und zwei durch Hermann Anders-Krüger in der Westdeutschen Zeitung und in Kürschners Jahrbuch. Anders-Krüger hatte die Prognose Bartels', nach der Viebigs Weiberdorf als Skandal wirken würde, in seiner eigenen Rezension zu der Aussage verkürzt, der Roman sei ein Skandal. Viebig bittet Bartels um eine Distanzierung von der ihm durch Anders-Krüger in den Mund gelegten Äußerung.

Viebigs Brief führt offensichtlich nicht zu einer Annäherung. In seiner Literaturgeschichte von 1909 kommt Bartels zwar nicht umhin, sie unter der Rubrik der Heimatkunst zu behandeln, aber nur, um ihre Zugehörigkeit zur Heimatkunstbewegung anzuzweifeln: Viebig wird unter anderem Berechnung vorgeworfen (also das Gegenteil der geforderten Natürlichkeit) und zu viel Brutalität in der Darstellung des Volkslebens - mithin zu viel Naturalismus: „Ihr liegt oder lag der Zolaische Naturalismus im Blute, und ihr nächster Roman Das Weiberdorf (1900) ist denn wohl das stärkste, was eine Schriftstellerin, die literarisch ernst genommen sein will, bei uns gewagt hat.“467

Den Umstand, dass Viebig selbst nicht zu denen gehörte, die sich abfällig über die Heimatkunst äußerten ${ }^{468}$ - und hier gibt es genug einprägsame Äußerungen, wie etwa Karl Bleibtreus „Höre ich nur „Heimathkunst”, so vomire ich schon“ -, rechnet Bartels ihr nicht positiv an, sondern macht daraus im Rückblick

466 Viebig 1900, o.S. Der unveröffentlichte Brief stammt vom 9.12.1900 und befindet sich im Goethe- und Schiller-Archiv in Weimar.

467 Bartels 1909, Bd. 2, S. 549.

468 Unveröffentlichter Brief Karl Bleibtreus an Friedrich Lienhard vom 22. August 1904. GSA 57/ 296, zitiert nach Beßlich 2011, S. 413. 
noch ein Argument gegen sie. In seiner Thüringischen Literaturgeschichte von 1938/42 behauptet er, die Heimatkunst habe sich nicht durchsetzen können, weil die „Judenheit die Herrschaft über die Presse und das Theater“ gehabt habe. Nur dann sei Heimatkunst nicht „heruntergemacht“ worden, wo, „wie z. B. bei Klara Viebig, Beziehungen zum Judentum bestanden“. ${ }^{469}$ In der Logik Bartels’ soll dies wohl bedeuten, dass die der Heimatkunst affinen Texte Viebigs von einer jüdisch dominierten Kritik nur deswegen nicht negativ beurteilt worden sind, weil ihr Ehemann der deutsch-jüdische Verleger Friedrich Theodor Cohn war. Damit würde er allerdings zugestehen, dass Viebigs Texte doch der Heimatkunst zuzurechnen wären.

Viebigs Brief an Bartels zeugt zunächst von dessen Einfluss: Die von großen Teilen der Kritik anerkannte und bis in die 1920er Jahre viel besprochene, in hohen Auflagenzahlen (in ihrem Berliner Hausverlag Egon Fleischel \& Co auch in nummerierten und signierten Luxusausgaben auf Bütten) verlegte und in fast alle europäische Sprachen übersetzte ${ }^{470}$ Autorin erachtet es als notwendig, Bartels' Äußerungen über ihre Romane öffentlich durch ihn selbst richtigstellen zu lassen. Der Brief Viebigs darf aber wohl nicht nur als Zeugnis für die literaturpolitische Bedeutung Bartels gelten, die es Viebig geraten scheinen ließ, sich der Heimatkunst zuzuordnen. ${ }^{411}$ Der Heimat(kunst)begriff war darüber hinaus tatsächlich auch für Autorinnen wie Viebig attraktiv, allerdings in einem ästhetisch und ideell gänzlich anderen Verständnis als demjenigen Bartels'. Es bleibt deshalb fraglich, welchen Gewinn heutige Literaturgeschichten daraus ziehen, den bartelsschen Begriff der Heimatkunst überhaupt als epochale Kategorie zu verwenden. Und es ist kein Zufall, dass sich Studien zu einzelnen bis heute der Heimatkunst zugerechneten Autorinnen, wie etwa zu Helene Voigt-Diederichs, explizit gegen eine

469 Alle Zitate Bartels 1942, S. 264.

470 Vgl. Richards 1968, S. 236 -237, für weitere Nachweise vgl. Krauß-Theim 1992, S. 29.

471 Bartels betreibt Literaturpolitik - als Literaturhistoriker, indem er die gesamte deutsche Literaturgeschichte quasi als Vorgeschichte der Heimatkunst deutet, als Programmatiker einer Bewegung, die er zu beschreiben vorgibt, deren Existenz aber auch Produkt seiner Programmatik ist. Auch als Literaturkritiker charakterisiert und kreiert er zugleich eine Bewegung der ,Heimatkunst', und das nicht nur in seinen publizierten Kritiken, sondern auch in seinen durch schriftliche Korrespondenzen gut rekonstruierbaren Netzwerken. Der umfangreiche Briefnachlass belegt sein weit verzweigtes Netzwerk in völkische Kreise und seinen Kontakt zur rechten Intelligenz oder deren Umfeld wie Houston Stewart Chamberlain, Paul Schultze-Naumburg oder Elisabeth Förster-Nietzsche. Auch mit vielen zeitgenössischen Schriftstellern pflegt er Briefwechsel, zu den Korrespondenten zählen Wilhelm Raabe, Arno Holz, Peter Rosegger, Rudolf Alexander Schröder, Christine Hebbel (die Ehefrau Friedrich Hebbels), Ernst Wachler, Timm Kröger, Friedrich Lienhard und Clara Viebig. 
Diskussion der Werke in Bezug auf die Heimatkunst entscheiden. ${ }^{472}$ Für Viebig gilt wie für viele andere Autoren der Zeit, dass Heimat eine zentrale Rolle für ihr Werk spielt, sich diese aber nicht sinnvoll in die Programmatik der Heimatkunst überführen lässt. Denn Viebig ist in ihren Erzählungen und Romanen an den Ambivalenzen von Heimat interessiert.

Clara Viebigs heute kaum noch bekanntes, wenn auch nie gänzlich vergessenes schriftstellerisches Werk ${ }^{473}$ trägt Züge der Regionalliteratur, etwa bezogen auf das Idiom ihrer Figuren. Aber im Gegensatz zu anderen Mundartdichtungen sind es jeweils nur die Figuren und nicht die Erzählerstimme, die sich des regionalen Dialekts bedienen, und anders als bei Fritz Reuter, Timm Kröger oder Gustav Frenssen, die mit ihrem Gesamtwerk fürs Niederdeutsche stehen, verwandelt sich die Sprache von Viebigs Figuren verschiedenen deutschsprachigen Regionen an. Insbesondere sind das die ländliche Eifelregion (Das Kreuz in Venn, Eifelnovellen, Das Weiberdorf), die ländliche preußische Provinz Posen (Die Rosenkranzjungfer. Novellen, Das schlafende Heer $)^{474}$ sowie die Städte Düsseldorf (Rheinlandstöchter, Die Wacht am Rhein) und Berlin (Die vor den Toren). Der Bezug auf diese Regionen ist autobiographisch motiviert. Viebig schreibt: „Also von mir möchte ich nicht reden, wohl aber von dem, was meinem Herzen teuer ist: von meiner Heimat. Vielmehr: von meinen Heimaten. Mir geht's, wie es Onkel Bräsig ging - ich habe ,drei Brauten'."“75 Diese (auf Fritz Reuters Ut mine Stromtid anspielenden) ,Brauten“ sind Eifel, Düsseldorf und Posen. „[U]nd wenn ich's recht bedenke, bin ich Bräsigen doch noch über, ich habe eigentlich vier. Die vierte

472 So Meike G. Werner in ihrem Kapitel über Helene Voigt-Diederichs, für die sie im Kapitel „Heimatkunst und Neue Weiblichkeit“ zwar auf Schnittstellen zur Heimatkunstbewegung hinweist, einen Zugriff auf die literarischen Texte aber unter dieser Perspektive nicht für sinnvoll hält. Denn Heimatkunst ist zum einen eher (ideologische) Programmatik als Beschreibung von Literatur, zum anderen kann man damit selten ein ganzes literarisches Werk fassen: „Da eine Diskussion der Einbindung ihrer Werke in die Heimatkunstbewegung zum einen auf die Instrumentalisierung durch deren Ideologen abheben und zum anderen durch die stoffliche Konzentration auf Schleswig-Holstein von Jena wegführen würde [...]“, entscheidet sich Werner daher gegen diesen Zugriff (Werner 2003, S. 205).

473 Clara Viebig verlor ab den 1930er Jahren öffentliche Aufmerksamkeit. Mit ihrem jüdischen Mann in NS-Deutschland gänzlich bedeutungslos geworden, wurde sie als sozialkritische Dichterin in den 1950er Jahren zunächst in der DDR gewürdigt, geriet aber hier wie auch in der BRD in Vergessenheit. Seit den späten 1960er Jahren, verstärkt in den 1970er und 80er Jahren wurde sie teils im polnisch- und englischsprachigen Raum, teils im deutschsprachigen Raum durch volkskundlich und regionalgeschichtlich motivierte Arbeiten wiederentdeckt. Zu neueren Untersuchungen vgl. Krauß-Theim 1992 (hier auch ein ausführlicher Forschungsüberblick bis 1992); Boa/Palfreyman 2000, Neuhaus/Durand 2004; Werner 2009; Aretz/Kämmereit 2010; Bland 2019. 474 Vgl. Wojtczak 2004.

475 Viebig 1920, S. 3. 
Braut ist Berlin. Aber nein, was sage ich denn?! Keine Braut! Mit Berlin bin ich verheiratet. “476 Heimat ist in Viebigs Äußerung emotional und positiv besetzt, sie ist regional lokalisierbar, steht aber im Plural und kann sich auch auf die Großstadt beziehen - und das auch schon vor 1900, als ihre ersten Berlin-Romane zu erscheinen beginnen.Viebig gehört zu den wenigen Autoren, welche die im letzten Jahrhundertdrittel einsetzende Polarisierung von Metropole und Provinz überwinden, die sich um 1900 auch literarisch einerseits im neuen Genre Großstadtliteratur und andererseits in dem der Regionalliteratur spiegelt. ${ }^{477}$ Als Heimatschriftsteller werden zeitgenössisch in der Regel diejenigen Schriftsteller bezeichnet, die gerade nicht über die Großstädte schreiben und auch nicht in ihnen wohnen (auch, wenn Letzteres für viele gar nicht zutraf), wie Hermann Löns, der mit seinen im Ländlichen angesiedelten Romanen wie Dahinten in der Haide. Niedersächsischer Roman (1909) zu einem der erfolgreichsten Autoren dieser Jahre überhaupt avancierte. ${ }^{478}$

Viebig gehört im Gegensatz zu Löns zu den wenigen Autoren der Zeit, die gleichermaßen Großstadtromane und Regionalliteratur (also Literatur, die in ländlichen Regionen spielt und mundartliche Sprache integriert) schreiben. Und auch die Regionalliteratur in Viebigs Verständnis ist anders, wirft sie doch ein Licht auf das, was in der Dorfgeschichte des 19. Jahrhunderts und auch noch des beginnenden 20. Jahrhunderts in der Regel absent blieb: das Leben des Industrieproletariats. Denn wärend die so prominente Gattung der Dorfgeschichte im Jahrhundert der Industrialisierung dem Bürgertum der Städte von einem harten, in irgendeiner Weise aber traditionsverhafteten und authentischen Dorfleben erzählt, blendet sie in der Regel die reale Lebensform immer größer werdender Teile der unteren Schichten aus, eines städtischen Proletariats, dem man

476 Viebig 1920, S. 8.

477 Diese Polarisierung spiegelt sich auch in den zeitgenössischen literarischen Debatten in Deutschland und in Österreich. Für Österreich vgl. die beiden unter demselben Titel - Die Entdeckung der Provinz - in den Jahren 1899 und 1900 erscheinenden Beiträge von Peter Rosegger und Hermann Bahr: Rosegger 1899, Bahr 2010. Zum Verhältnis von Großstadtliteratur, Heimatliteratur und regionaler Literatur um 1900 und Anfang des 20. Jahrhunderts vgl. Nowak 2013, S. $107-162$.

478 Hermann Löns' äußerst erfolgreiche Romane spielen größtenteils in der Lüneburger Heide. Großstädte kommen nur vor, insofern sie als Orte der Verfehlung überwunden werden, wie das Ende von Dahinten in der Haide zeigt: Der geläuterte Held Lüder Volkmann hat erkannt, worauf es ankommt: die „Füße fest auf der Heimaterde“ zu haben, statt „wie so mancher treffliche Mann in dem Wirrwarr der großen Stadt“ in Kauf zu nehmen, „mit der Zeit abgestanden und schal“ zu werden. Löns 1909, S. 210 -211. In späteren Auflagen wurde die Schreibweise abgewandelt: Dahinten in der Heide. Zu Hermann Löns vgl. die Arbeit von Thomas Dupke zum Mythos Löns. Heimat, Volk und Natur im Werk von Hermann Löns. Dupke 1993. 
schwerlich Authentizität andichten konnte. Viebigs Dorfroman Das Weiberdorf (1900), der kurz nach 1871 in der Eifel in dem verarmten Dorf Eisenschmitt spielt, konfrontiert den Leser mit diesen Realitäten, denn das Dorfleben ist dadurch geprägt, dass die Männer abwesend sind: Sie verdingen sich als Arbeiter in der Schwerindustrie und kehren nur zweimal im Jahr für wenige Tage zurück.

Es verwundert nicht, dass der reale Dorfname in der zweiten Auflage in den fiktiven Namen Eisendorf abgewandelt wurde. Dabei gelangte die Romanautorin sicher nicht nur in den Ruf der ,Nestbeschmutzerin' und wurde unter anderem von Vertretern der katholischen Kirche angefeindet, weil die Figur des katholischen Pfarrers nicht gut wegkommt, sondern auch, weil Dorfleben hier in einer Drastik des Drecks, der Verrohung, Gewalt und Sexualität, zudem weiblicher Sexualität, geschildert wird, wie es für die deutschsprachige Literatur der Zeit untypisch ist und auch jenseits katholischer Befindlichkeiten Anstoß erregen musste. ${ }^{479}$

Das Dorfleben des Weiberdorfs ist eine Anti-Idylle: Eine Schlägerei geht in die andere über; man könnte sagen, nahezu alle wichtigen Charaktere des Romans werden mit einer Prügelszene eingeführt und es sind angesichts der meist abwesenden Männer vor allem die Frauen, die schlagen. Gewalt gehört zu den nicht weiter kommentierungsbedürftigen Alltagsszenen und zählt in einer Reihe mit Waschen und Nähen zu den gewöhnlichen Verrichtungen, wie diese dörfliche Abendszene nahelegt:

Hier wusch noch eine, hinter dem mit alten Fetzen verhängten Fensterchen. Da prügelte eine ihren Kindern das ,Artigsein“ für den Vater ein und erstickte das Geschrei, indem sie ihnen das bleischwere Deckbett über die Köpfe zog. Dort saß eine ganz Junge bei unruhig flackerndem Kerzenschein und nähte sich rote Strumpfbändel zum Tanz. ${ }^{480}$

Wenn sich die Dorfbewohner inmitten des allgegenwärtigen Schmutzes ${ }^{481}$ nicht betrinken oder verprügeln, beschlafen sie einander und die christlichen Symbole

479 Dass dieser Roman quer zu den Erwartungen steht, die an ihn herangetragen wurden und werden, mag Teil der Erklärung für die Geschichte seines Vergessens sein. Obwohl ein bemerkenswertes Dokument der Literaturgeschichte, wird er bis heute entweder ignoriert oder für eigene Zwecke vereinnahmt. Wie Marlene Kück beispielsweise darauf kommt, im Roman ein ,auf Unabhängigkeit basierendes Emanzipationskonzept“ zu entdecken, bleibt erklärungsbedürftig. Kück 1998, S. 41. Auch die gegenteilige Einordnung des Romans durch Karlheinz Rossbacher als antiemanzipatorisch - das Frauenbild des Romans reduziere die Frau auf ein „Naturwesen“ erfasst den Roman nicht adäquat. Rossbacher 2000, S. 312. Vgl. auch schon Rossbacher 1975, S. 142. Im gleichen Sinn verurteilt auch Gisela Ecker die Frau bei Viebig als „Figur des zufriedenen Opfers“. Ecker 1997, S. 131.

480 Viebig 1993, S. 160.

481 Vgl. Viebig 1993, S. 40 oder S. 148. 
werden derweil buchstäblich mit den Füßen getreten, etwa während eines „Schäferstündchen[s] in der schmutzigen Stube“: „Das Herrgöttchen lag am Boden, achtlos trat Tinas Fuß darauf.“ ${ }^{482}$ Oft, ebenfalls ungewöhnlich für die zeitgenössische Literatur, stehen gerade die Frauenfiguren für aktive Sexualität.

Der antiidyllischen Darstellung geht es aber nur zum Teil um drastische Milieuschilderung. ${ }^{483}$ Die Darstellung zielt mindestens ebenso auf ein durchaus lustvolles Anarchisches, das die Dorfbewohner von den gebildeten Figuren absetzt. Auch die Sprache der Eifler transportiert diese anarchische Potenz, ja zeigt sie gegenüber den hochdeutsch sprechenden ,Auswärtigen' als überlegen: Der detailgenaue Dialekt, ${ }^{484}$ der den über weite Strecken in direkter Rede verfassten Roman beherrscht, unterscheidet die Eifler von allen Repräsentanten der gebildeteren Schichten, vom reisenden Händler, der sich über die „,arme[n] Teufel“ aus „dieser zurückgebliebenen, unkultivierten Gegend“ amüsiert, ${ }^{485}$ über den Pfarrer, dessen verlogen-weihevolle Sprache das Hochdeutsche ist, ${ }^{486}$ bis zum Gendarmen, der die Eifler für „viel zu dämlich“487 zum Betrügen hält. Dabei ist der Gendarm der Dumme, weil er die Mundart der Gegend nicht versteht und deshalb handlungsunfähig ist. ${ }^{488}$ Auch dem Obergendarmen rücken die obrigkeitsresistenten Dorfbewohnerinnen physisch und mit ihrem Dialekt zu Leibe; auf dessen Forderung „Platz für die Obrigkeit“ erfolgt schallendes Gelächter und es wird geschrien: „,O dau Lappes [...] gieh nor on laoß der dein Rotznaos wischen. Mir peifen uf dein ,Platz for de Obrigkeit‘! [...] Ein ohrenbetäubendes Gekreisch der Weiber erhob sich, in drohender Haltung rückten sie näher und näher.“489 Die Darstellung des widerständigen Frauenpulks weckt archaische Assoziationen: Ein ,kreischender“, erinnyengleicher „Weiberchor“ vermehrt sich, zunehmend unbeherrschbar, von allen Seiten und setzt schließlich seinen Willen durch.

Gleichgültig, ob man die Trostlosigkeit oder die Anarchie der Dorfdarstellung betont - anti-idyllisch ist sie allemal. Innerhalb dieses Rahmens kann Heimat

482 Viebig 1993, S. 40.

483 Zur Belletristik Viebigs als volkskundlicher Quelle vgl. Neft 2004.

484 Vgl. Macha 2004. Zum provokativen Potential der Sprache im Roman vgl. auch Chambers 2007, S. 144: Das Fluchen und Spotten der Figuren sei ,a sign of their subjecthood, and identity that is characterized by banter and direct and spontaneous provocativeness“.

485 Viebig 1993, S. 79.

486 Vgl. Viebig 1993, S. 89, S. 145.

487 Viebig 1993, S. 148.

488 „Der Gendarm verstand den Dialekt noch nicht und witterte immer gleich eine Verhöhnung der Obrigkeit. / Tappert, das war ungefähr das einzige Eiflerische, was er bis jetzt gelernt; es war gleichbedeutend mit dem hochdeutschen Dummes Luder und wurde hier bei den ,dämlichen Bauern“ mit Vorliebe von ihm angewendet.“ Viebig 1993, S. 62-63.

489 Viebig 1993, S. 169. 
deswegen, selbst wo sie Idylle repräsentieren soll, nur mehr gebrochen als solche wahrgenommen werden - Elisabeth und Rachel Palfreyman bezeichnen Das Weiberdorf daher als „almost an anti-Heimat novel“.490 Die Funktion der Brechung zeigt sich an allen drei Spielarten, die Heimat im Weiberdorf durchläuft.

Heimat taucht aus drei Figurenperspektiven auf - nie (bzw. nur einmal mit Einschränkung) aus der Perspektive derer, die Heimat repräsentieren, also der Dorfbewohnerinnen. Sie erscheint erstens aus der Perspektive der fortgegangenen und immer nur kurzzeitig wiederkehrenden Männer, zweitens aus der Perspektive des zugezogenen Städters, drittens aus der Perspektive der Hauptfigur Bäbbi, die fortgehen will.

Die Männer des Eifeldorfes können auf den kargen Böden nicht mehr ihren Lebensunterhalt verdienen, überlassen das Dorfleben deshalb gänzlich den Frauen, Alten und Kindern und verdingen sich in der rheinischen Eisenindustrie als Fabrikarbeiter. Die hergebrachten patriarchalen Strukturen haben sich durch die Industrialisierung, ganz wie es bei Karl Marx und Friedrich Engels beschrieben wurde, aufgelöst. Unter den neuen ökonomischen Bedingungen, so Engels, entstehe eine „heimathlose[ ] Bevölkerung“.491 - In Viebigs Roman sind die Männer nur für wenige Tage im Jahr dort, wo ihre Frauen und Kinder leben: „Zweimal im Jahr - im Winter zu Weihnachten, im Sommer zu Peter und Paul kamen sie heim ins enge Salmtal. “492 Ihr Leben findet fern des Geburtsdorfes im Rheinland statt, „umglüht von Flammen, eingeengt von Mauern, sehnsüchtig des Heimathimmels gedenkend“. 493 Der Roman wird von der Ab- und Anwesenheit der Männer strukturiert, er beginnt und endet mit der Heimkehr der sonst meist abwesenden Männer. Die Handlung setzt mit einer eindringlichen Schilderung

490 Boa/Palfreyman 2000, S. 43. Boa und Palfreyman konzentrieren sich in ihren Textanalysen dann aber auf Kinder der Eifel (1897) und Das Kreuz in Venn (1907).

491 Friedrich Engels schreibt 1877/78 in seinem als Anti-Dühring bekannt gewordenen Text über die frühe Industrialisierung in England: „Mit stets wachsender Schnelligkeit vollzog sich die Scheidung der Gesellschaft in große Kapitalisten und besitzlose Proletarier, zwischen denen, statt des früheren stabilen Mittelstandes, jetzt eine unstäte Masse von Handwerkern und Kleinhändlern eine schwankende Existenz führte, der fluktuirendste Theil der Bevölkerung. Noch war die neue Produktionsweise erst im Anfang ihres aufsteigenden Asts; noch war sie die normale, die unter den Umständen einzig mögliche Produktionsweise. Aber schon damals erzeugte sie schreiende soziale Mißstände: Zusammendrängung einer heimathlosen Bevölkerung in den schlechtesten Wohnstätten großer Städte - Lösung aller hergebrachten Bande des Herkommens, der patriarchalischen Unterordnung, der Familie - Ueberarbeit besonders der Weiber und Kinder in schreckenerregendem Maß - massenhafte Demoralisation der plötzlich in ganz neue Verhältnisse geworfenen arbeitenden Klasse.“ Engels 1988, S. 430.

492 Viebig 1993, S. 16.

493 Viebig 1993, S. $16-17$. 
des Einzugs der Männer in die Täler ihrer Herkunft ein: „Derhäm!“494 brüllen sie schon lange bevor die Frauen sie hören können, „se sein hei, se sein hei“495 die Frauen, als sie der Männer gewahr werden. „[L]eichter Rauch [kräuselt sich] vom heimischen Herd“496 und „nur der Schatz in der Heimat“497 küsst so gut - so die sich der Perspektive der heimkehrenden Männer anverwandelnde Erzählerstimme. Es ist dieselbe Erzählinstanz, von welcher der Leser kurz darauf erfährt, wie schmutzig der ,Herd“ ist und welche Geliebten der ,Schatz' in der Abwesenheit des Ehemannes geküsst hat. Der Effekt dieses Kontrastes ist kein ironischer. Das Pathos der Ankunft wird durchaus nicht beschädigt. Der Kontrast der Außenperspektive der abwesenden Männer, aus der heraus Heimaterfahrung möglich ist, und der Innenperspektive der dableibenden Frauen, die den Begriff der Heimat nie verwenden, bildet zugleich das Verhältnis von rahmender und gerahmter Handlung. Denn zwischen dem kurzen Aufenthalt der Männer und ihrer erneuten Rückkehr ein halbes Jahr später liegt die eigentliche Erzählung - die Zeit, in der die Frauen allein ihr Leben im Dorf auf so wenig idyllische Art führen.

Die zweite Perspektive, in der Heimat gezeigt wird, ist die des zugezogenen Pensionärs Schmitz - eine weitere männliche Außenperspektive also. Er ist „ein reicher Herr“498 nach Ansicht der Dörfler, aus der Eifel stammend, als Knabe ausgewandert und zum Gerbereibesitzer in Köln aufgestiegen, der sich im Salm-

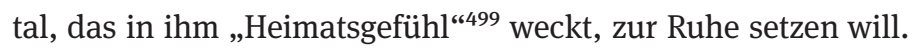

Da stand er nun in seinen grasgrünen Pantoffeln, die Hände in den Schlafrocktaschen vergraben, einen Schal um den Hals, mächtige Tabakwolken in den hellen Morgen hinausqualmend. Mit behaglicher Rührung musterte er die Umgebung. So waren ihm die Heimatberge mit ihren runden Buckeln und den daranhängenden, winzigen Äckerchen manchmal im Traum erschienen! Und da dachte er an das Mus, an Kabes met Grombieren on Griewen, die er sich für heut Mittag beim Krumscheid bestellt, und sein Eifeler Magen knurrte in süßer Erinnerung. ${ }^{500}$

Die ihn umgebende Lebensrealität hat allerdings wenig mit diesen biedermeierlichen Reminiszenzen von Pantoffel und Schlafrock, Tabak und Mus gemein, und so schließt an die zitierte Szene auch unmittelbar eine andere, konterkarierende an: Zeih, die Frau, die Schmitz so anziehend erotisch findet, erscheint mit ihrem

494 Viebig 1993, S. 7.

495 Viebig 1993, S. 10.

496 Viebig 1993, S. 8.

497 Viebig 1993, S. 13.

498 Viebig 1993, S. 131.

499 Viebig 1993, S. 132.

500 Viebig 1993, S. 134. 
„elenden“, kranken Kind und berichtet von ihrem trinkenden und prügelnden Mann. Wieder wird das ,Heimatsgefühl‘ einer Romanfigur, die nicht zum eigentlichen Dorfleben dazugehört, mit antiidyllischer Realität konfrontiert.

Die dritte Perspektive auf Heimat eröffnet sich am Ende der Erzählung und ist parallel zur Eröffnungsszene lesbar. Ging der Blick der Figuren am Handlungsbeginn in Richtung Dorf und ,heimischem Herd', geht sie jetzt von der Dorfbewohnerin Bäbbi Richtung Stadt. Wie am Anfang wird eine figurenbezogene Perspektive gewählt, mit der die Erzählinstanz sympathisiert:

„Wuh ons Pappa es, lao sein mir aach zu Haus, gäl, Lorenzche?“ Sie dachte an die eingeengten Straßen, an die graue Luft, an das Gestampf und Geächz der Maschinen, und für Augenblicke irrte ein Bangen über ihr Gesicht; aber gleich darauf lächelte sie freudig. „Wann hän ons ruft, mir kommen, gäl? Mir giehn zu onsem Pappa on bringen ihm sein Heimat!“501

Heimat ist beweglich, so die Botschaft der Textstelle. Aber der Entschluss, dem Mann in die Stadt zu folgen, wird als heroisches Opfer dargestellt und die Reinheit der Natur wird in deutlich wertender Absicht gegen die ,graue Luft' der Stadt gehalten. Die Zukunft mag in der Stadt liegen, aber die Kraft - auch die Kraft, das Geburtsdorf zu verlassen - wird aus dem ländlichen Boden geschöpft. Es sind nicht die Menschen des Dorfes, die Bäbbi Kraft geben, sondern es ist die Natur, genauer noch die besessene und bewirtschaftete Natur - der zitierten Textstelle unmittelbar voran geht die Beschreibung, wie Bäbbi ihren Acker bestellt. Die Bildlichkeit des Wurzelns in der Heimaterde und des Sich-in-die-Höhe-Reckens wird in ein nun ganz aus der Perspektive der heterodiegetischen Erzählinstanz vorgetragenes symbolistisch-pathetisches Bild überführt, wie es aus der Malerei der Jahrhundertwende (Abb. 39) vor Augen steht: ${ }^{502}$ „Ihre ernsten Augen erhellten sich, ein heiliges Feuer schien sich darin zu entzünden. Höher und höher reckte

501 Beide Zitate Viebig 1993, S. 142.

502 Vgl. exemplarisch folgende Bilder des Symbolismus: Fidus (d.i. Hugo Höppener): Lichtgebet (1894), Max Klinger: Und doch! (1898), Sascha Schneider: Die Glut (1904), Ludwig von Hofmann: Opferschalen (1910). Fidus' Lichtgebet, als Postkarte, Kohledruck und großformatiger Farbdruck um 1900 weit verbreitet, ist eine Ikone der Lebensreformbewegung, aber auch „Leitbild“ des George-Kreises. Hermand 1972, S. 86. Das Bild zeigt in Rücken- bzw. Seitenansicht einen nackten Jüngling, der, auf einem Felsen stehend, mit ausgebreiteten Armen die Sonne begrüßt. Mit den kultischen Zügen eines Naturgottesdienstes, in dem eine unvermittelte Beziehung zwischen Mensch und Natur möglich ist und in dem unten und oben, dunkel und hell, Fels/Boden und Himmel/Sonne in eine Einheit verschmolzen werden, ist die Bildidee ebenso anschlussfähig an Friedrich Lienhards Programm der ,Höhenkunst', vgl. Rossbacher 1975, S. 59-60. Auch bei Clara Viebig ist es ,Felsboden', auf dem die hochgereckte Gestalt der Protagonistin steht, und auch hier werden dieser Felsboden und die Höhe und Weite darüber in ein kultisch-religiöses Bild der Verbundenheit von Mensch und Kosmos gefasst. 
sich ihre aufrechte Gestalt; wie die Wurzeln eines starken Baumes standen ihre Füße fest im heimischen Felsboden, aber ihr offener Blick ging ins Weite. “503 Mit der Beschreibung der Figur Bäbbi, die hier zur Priesterin überhöht wird, wechselt Viebig den Ton in einer Weise, der zu den drastisch-beschreibenden Zügen ihres Romans quer steht. Die kritische Korrektur der bisher nur von einzelnen Figuren formulierten positiven Einstellung zu Heimat (der heimkehrenden Männer, des Pensionärs Schmitz) bleibt an dieser Stelle aus. Stattdessen wird eine Vorstellung von Heimat entworfen, die Natur, genauer noch den bewirtschafteten, ländlichen Grund und Boden zur Urzelle menschlicher Kraft erklärt. ${ }^{504}$ Diese dem ,Heimatboden' entspringende Kraft strebt hinaus, in die Höhe, ins Weite. Bäbbis ,Schollengebundenheit‘ wird so zugleich überhöht und vertieft und partizipiert am um 1900 weitverbreiteten Topos eines Heimatverständnisses zwischen ,Erde und Himmel ${ }^{6}{ }^{505}$ Die damit einhergehende positive Assoziation von Heimat mit der solchermaßen aufgewerteten ,Scholle‘ - als Begriff erst später in Viebigs Romanen $\mathrm{zu}$ finden - ist ein werkimmanentes Motiv der Schriften Viebigs, das sich verstärken wird - auch und gerade in ihren Berlin-Romanen.

Zwischen 1897 und 1935 hat Viebig sechsundzwanzig Romane geschrieben; die Hälfte davon spielt in Berlin. ${ }^{506}$ So auch Das tägliche Brot (1900), das im selben Jahr wie Das Weiberdorf erscheint. Das tägliche Brot erzählt die Geschichte von den ungleichen Mecklenburger Dorfmädchen Mine und Bertha, die in den 1890er Jahren ihre Familien verlassen, um in Berlin Arbeit als Dienstmädchen zu finden. Die ungebildete, unansehnliche und phlegmatische, dabei aber redliche und bis zur Selbstaufgabe arbeitsame Mine kann trotz aller Anstrengungen und völliger Anspruchslosigkeit kaum die eigene physische Existenz sichern und bleibt auch Jahre später als Ehefrau und Mutter von zwei Kindern von Armut und Hunger bedroht.

Die hübsche und agile Bertha, die es zunächst besser zu treffen scheint, treibt die Sehnsucht nach einem besseren Leben schließlich in Alkoholismus und Prostitution. Das Scheitern beider Frauen wird nicht moralisiert. Berthas Verderben ergibt sich nicht aus sittlicher Verkommenheit, sondern aus einer unglücklichen Mischung charakterlicher und milieubedingter Dispositionen, ihrer

503 Viebig 1993, S. 144.

504 Zur Rolle der Natur bei Viebig und speziell im Weiberdorf vgl. Guntermann 2004.

505 Langbehn über den idealen Künstler: „Sein Fuß haftet fest auf der Erde; aber sein Blick richtet sich dabei frei gen Himmel.“ Langbehn 1890, S. 20. Lienhard über den Heimatkünstler: „Aus der Heimaterde gen Himmel wachsend, in Sturm und Sonnenfreude!“ Lienhard: Vom Reichtum deutscher Landschaft, 1900, S. 140.

506 Zur Einordnung Viebigs innerhalb des Genres Berlin-Roman um 1900 vgl. Durand 2004. 


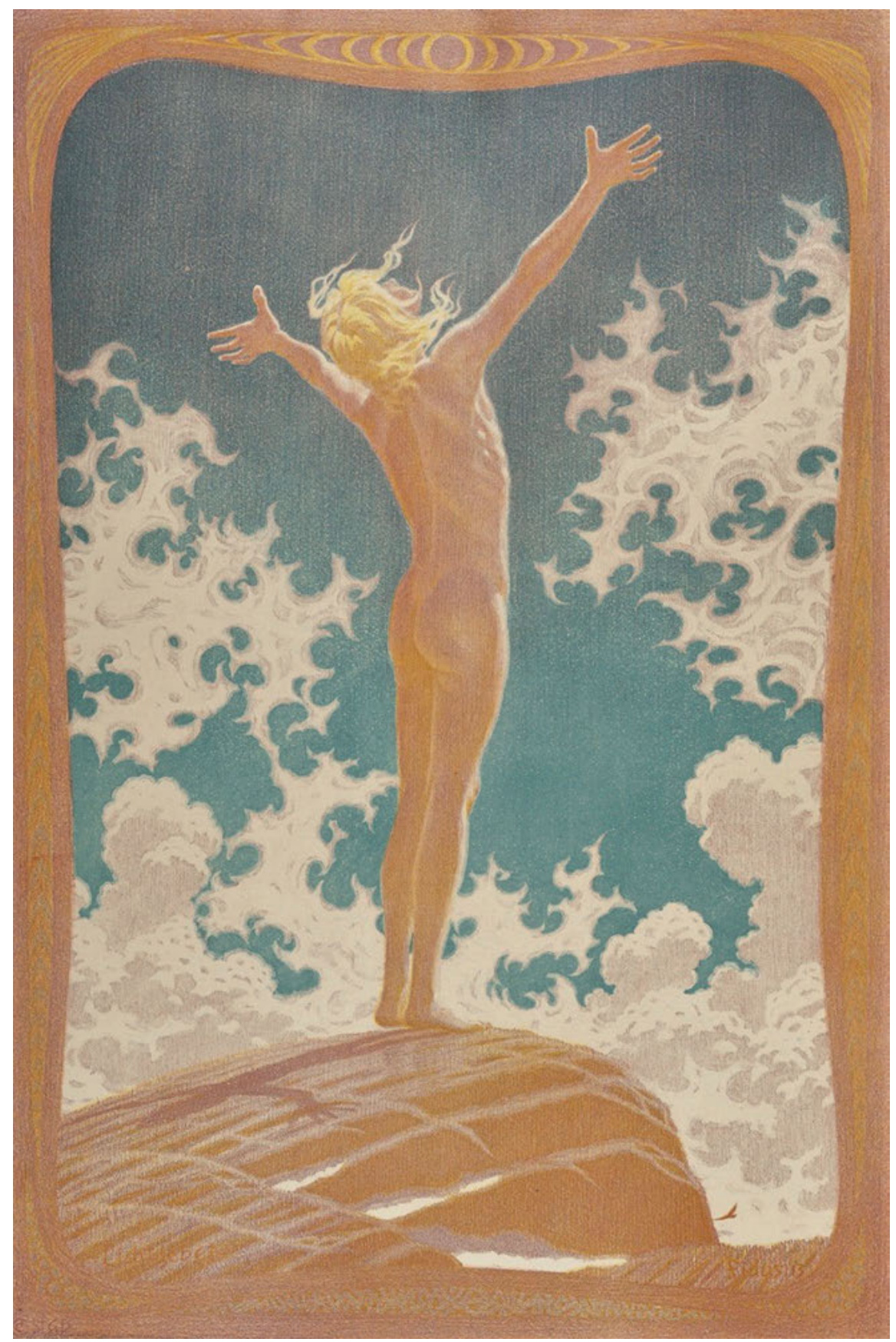

Abb. 39: Fidus: Lichtgebet, Farblithographie. 1913 (gemeinfrei über Wikimedia commons) 
„Gier nach Leben“, ${ }^{507}$ die nicht zu ihrer gesellschaftlichen Stellung und ihren ökonomischen Voraussetzungen passt.

Mine ist fleißig, anspruchslos und selbstlos; dies bewahrt sie aber nicht davor, nach den moralischen Kategorien ihrer Zeit schuldig zu werden. Die Aussicht auf eine bessere Zukunft, die sich für sie am Ende zu eröffnen scheint, bleibt mehr als zweifelhaft. Der Leserin des Romans Eine Handvoll Erde, der Fortsetzung von Mines Geschichte, bestätigt sich dieser Zweifel. Nicht eine moralische Absicht strukturiert die Handlung wie bei den Realisten Dickens oder Freytag, sondern eine durch die Milieutheorie beeinflusste Versuchsanordnung wie bei Hauptmann oder Zola, innerhalb derer soziale und ökonomische Verhältnisse die Spielräume des Einzelnen derart eingrenzen, dass die Möglichkeit autonomen Handelns grundsätzlich fraglich wird.

Als Produkt ihrer Verhältnisse erweist sich in Das tägliche Brot auch die Familie Reschke mit ihrem ,Grünkramladen', die mit vier Kindern in einem feuchten und dunklen Berliner Keller haust: Arthur, der nach dem Willen seiner Mutter etwas Besseres werden soll und an dieser Überforderung scheitert, Trude, die von den Eltern an eine vermeintlich gute Partie verschachert wird und schließlich in die Prostitution abgleitet, die fidele Elli, deren Zukunft am Ende des Romans ebenfalls in düsteres Licht getaucht wird, und die von ihrer Familie vernachlässigte behinderte Grete, die noch als Kind stirbt. Familie Reschke ist entfernt mit Mine verwandt und nimmt sie zunächst auf, bis sie eine Dienstbotenstelle bekommt - nicht aus Menschenfreundlichkeit oder familiären Bindungen, wie sich bald herausstellt. Die Figurendarstellung arbeitet präzise die Ambivalenzen der Handelnden heraus, die in ihrer Gehässigkeit und Gleichgültigkeit genauso wie in ihrer - meist nur kurzfristig aufwallenden - Herzlichkeit und Mitmenschlichkeit gezeigt werden. Nur Mine und Grete fallen aus diesem Darstellungsmodus heraus. Sie scheinen mit ihrem mangelnden Egoismus nicht ganz dieser Welt zuzugehören.

Heimat übernimmt im Roman verschiedene Funktionen: die der Selbstversicherung, die der Versorgung und die des Glücks-, ja Erlösungsversprechens. Im Lauf des Romans erweisen sich diese Erwartungen - verstanden als soziale und religiöse Kategorien - als nichtig. Jenseits einer Heimatvorstellung, die sich an Menschen oder an einen Glauben knüpfen würde, hat eine andere Vorstellung von Heimat für die Figur Mine bis zum Ende Bestand, nämlich die der seelischen Verbundenheit mit der kultivierten, ökonomisch versorgenden Erde: ein „Stück-

507 Viebig 1950, S. 327. 
chen Acker, an dem die Seele hängt““.508 Die Fortsetzung des Romans, Eine Handvoll Erde, trägt diese Idee dann schon im Titel.

Überwiegend benutzen Mine und Bertha das Wort Heimat, wenn sie sich ihrer selbst und der Beziehung zueinander versichern wollen. Bertha ist für Mine „ein Stück Heimat“. ${ }^{509}$ Mine rechtfertigt ihren Besuch bei Bertha mit den Worten: „Ich bin aus ihre Heimat. “510 Als Mine bedrückt darüber ist, dass sie Berthas Mutter keine Nachricht von deren Tochter bringen kann, kommt es ihr so vor, „als wenn man gar nicht ein und dieselbe Heimat hätte!"“511 Als sie aber Bertha bei einer neuen Herrschaft einführt, fungiert der Verweis auf die gemeinsame Heimat als eine Art Empfehlungsschreiben: „Vor der brauchen Se keene Bange zu haben, die is aus meine Heimat."512 Und nichts hat zwischen den beiden größeren Verpflichtungscharakter als die gemeinsame Heimat: „Du, Mine, verlaß mer nich, wir sind ja aus einer Heimat!“513 Die komplementären Figuren werden also zusammengehalten über ihre Rede von der gemeinsamen Heimat - einer Heimat, mit der sie andererseits nichts Gutes verbinden und nach der sie sich nicht sehnen: „Noch nie hatte Bertha der Heimat gedacht. “ Berthas alleinstehende Mutter trinkt und ist selten in der angemieteten Wohnung. Mines Familie besitzt, was Berthas Mutter vermisst, das „Stückchen Acker, an dem die Seele hängt“.514 Aber im beengten Bauernhaus der Familie kann auch Mine nicht bleiben, da es zu viele Mäuler zu stopfen gibt. ${ }^{515}$ Im Romanverlauf gibt es vier charakteristische Bezugnahmen auf Heimat durch Mine, die zeigen, dass die Funktion der Selbstversicherung, jedenfalls als soziale Kategorie, keinen Bestand hat.

Unmittelbar bevor Mine ihren ersten Dienst antritt, unterhält sie sich im Keller der Reschkes mit Grete. Heimat ist hier für die frisch in Berlin Eingetroffene ein Inbegriff des Versprechens, immer satt zu werden:

„Du solltest mal bei uns kommen, Grete, da wirste groß un dick!“ Und von einer Sehnsucht ohnegleichen gepackt, erzählte sie dem still zuhörenden Mädchen von dem Vaterhaus mit dem Strohdach, drauf alle Frühjahr ein Storch nistete, von den Pantoffelblumen am Kam-

508 Viebig 1950, S. 353.

509 Viebig 1950, S. 82

510 Viebig 1950, S. 135.

511 Viebig 1950, S. 232.

512 Viebig 1950, S. 316.

513 Viebig 1950, S. 353.

514 Beide Zitate Viebig 1950, S. 353.

515 „,Was willste denn ooch derheeme?‘ sprach der Vater. [...] Es waren der Mäuler gar zu viele für Barthel Heinzes Acker; das Haus war eng, man konnte doch nicht so aufeinander hocken. Wenn nicht der Peter und die Lisa, die nach ihr im Alter kamen, schon als Kinder miteinander im Entenpfuhl ertrunken wären, hätte sie längst fortgemußt.“ Viebig 1950, S. 7. 
merfenster, dem Schweinekoben, den Hühnern auf dem Mist, von dem Dorf mit dem Entenpfuhl, von dem Kartoffelacker und dem Roggenfeld. Die dunklen Kellerwände wichen auseinander, sie sah weit über hellbeglänzte Fluren. [...] „Aber derheeme, da sollste kucken! Un en Butterschmier“ - sie zeigte vier Finger - „so dick! Ju, ju, da hammers sehr gutt!“516

Was hier vermeintlich in Erinnerung gerufen wird - immerhin war der Grund, das Vaterhaus zu verlassen, dass es nicht alle Kinder ernähren konnte -, ist die bäuerlich genutzte Natur, sowohl in Form von kultivierter Landschaft (,hellbeglänzte Fluren') als auch in Form ihrer Produkte (,Butterschmier') - der Boden also, der seinen Besitzer ernährt. Die dazugehörigen Menschen spielen keine oder doch nur eine sehr abstrakte Rolle (,Vaterhaus'). Auch die sich in die Perspektive der zuhörenden Grete versetzende Erzählerstimme betont diesen Aspekt - Grete habe „noch nie grünende Saat, noch nie ein wogendes Kornfeld gesehen“. Es geht in der Heimaterinnerung von Mine also um ein glückhaftes Naturerlebnis, aber auch um den Aspekt der Versorgung. Das Schwelgen in der Heimat wird unterbrochen, weil die Ökonomie der Armen in der Stadt anderen Regeln unterliegt; Miene sucht Herrschaften, bei denen sie als Dienstmädchen arbeiten kann: ,', $\mathrm{s}$ is eene da, die dir mieten will.‘ Fort war die Heimat mit einem Schlag!“5517

Am einzigen unbeschwerten Tag Mines, den der Roman schildert, verbindet sich Heimat mit einem Naturerlebnis, in dem sich Erinnerung und Glückserfahrung überlagern. In dieser Szene wird ihr Kind gezeugt. Drastisch assoziiert Viebig hier Heimat und Koitus miteinander. Mines und Arthurs Ausflug in einen Vergnügungspark in Wilmersdorf, dem damaligen Rand der Stadt, endet aus Scham, kein Geld fürs Amüsement zu besitzen, außerhalb der Vergnügungsanlage: „Eine unabsehbare Fläche breitete sich aus; keine Wiese, kein Wald. Brachliegende Felder, schon zu Bauplätzen bestimmt, rechts und links. “518 Keine schöne Natur also, aber die freie Weite beglückt Mine: „Eine große Freude machte ihr Herz zittern; sie wähnte sich daheim auf der grünen Golmützer Flur, daheim und - mit ihm! Sie hätte jubeln mögen." ${ }^{\text {"519 }}$ Die Erinnerung an die Heimat wird überblendet mit der gegenwärtigen Zweisamkeit, weitere Überblendungen dieser Art folgen: Mine ,dachte an daheim; und doch hätte sie jetzt nicht mehr dort sein mögen, um alles in der Welt nicht, denn - sie lächelte und seufzte leise und strich mit ungeschickter Zärtlichkeit über die schön pomadisierten Haarwellen an Arthurs Hinterkopf.“520 Als Arthur sie küsst, tat sie „ihm den Willen, sie selbst war ganz

516 Viebig 1950, S. $43-44$.

517 Viebig 1950, S. 43-44.

518 Viebig 1950, S. 114.

519 Viebig 1950, S. 115.

520 Viebig 1950, S. 117-118. 
willenlos. Immer die schöne Musik, und der Hauch von den Feldern, der sie gedankenlos froh machte wie ein Kind auf der Heimatflur. “521 Wieder wird Heimat mit Natur und Ackerbau verbunden - Erde, Felder und Kartoffelkraut -, nicht mit Menschen. Aber in der eigenen Gegenwart wird noch etwas anderes, Schöneres gefunden, Zweisamkeit, und Mine möchte ,um alles in der Welt nicht daheim sein. An diesem Tag wird sie schwanger.

Das dritte Mal wird Heimat für den Erzählverlauf wichtig, als die werdende Mutter ahnt, dass ihr Kind von den Eltern nicht anerkannt werden wird. Die positiven Gefühle zur Heimat werden durch eine Vorahnung überschattet. „Einer Vision gleich sah sie durch die frühlingsfeuchten Äste hindurch, die Laternenschein silbrig beglänzte, weit, weit die Heimatflur. Da tat die Erde jetzt ihren Schoß auf, da roch der Acker kräftig nach Nahrung und Gedeih'n. “522 Wieder wird das Kompositum der Heimatflur gewählt und wieder übernimmt es die Funktion, zwischen einer sozialen Heimat, die in Frage gestellt wird, und einer Heimat des Ackers, der kultivierten, ökonomisch versorgenden Natur, zu unterscheiden. Nicht an die Familie, sondern an die Flur binden sich positive Gefühle: ,Erde‘, ,Acker‘, ,Saat‘ als Symbole der Fruchtbarkeit werden hier mit der eigenen Schwangerschaft verknüpft. Heimat ist damit weiblich konnotiert als Gebärende (vgl. I.2.3). Das Gebären ist als natürlicher Vorgang gedacht - menschliche Empathie und Solidarität schließt das nicht ein, wie sich bestätigen wird, denn ,ihre Saat würde niemand mit Freuden begrüßen“. ${ }^{523}$

Das vierte und letzte Mal im Romanverlauf verknüpft sich für Mine der Ort der Herkunft mit Hoffnung und Freude, als sie sich entschließt, das inzwischen geborene Kind zu den Eltern zu bringen: „Es war an einem schönen Septembermorgen, als Mine, das fest in ein Tuch gepackte Fridchen auf dem Schoß, der Heimat zufuhr. Jetzt regte sich doch ein Gefühl der Freude in ihr, und eine lebhafte Neugier dazu [...]. “524 Ohne anerkannten Vater muss sie ihre Mutterschaft vor ihrer Herrschaft verheimlichen, das Neugeborene in Kost geben und kann das Kind nur zwei Mal im Monat für einige Stunden sehen. Sie möchte ihr Kind deswegen zu ihrer Familie nach Mecklenburg geben. Aber Mine stößt in ihrer Familie auf Ablehnung und gänzliches Desinteresse. Das uneheliche Kind wiegt dabei weniger schwer als die ausgebliebenen Geldsendungen, die sich die Familie erhofft hatte. Die Familie weigert sich, das Kind aufzunehmen. „Und dann ging sie plötzlich, ohne Adieu, ohne der Mutter die Hand zu bieten, zum Hause hinaus. Draußen sah

521 Viebig 1950, S. 119.

522 Viebig 1950, S. 172.

523 Viebig 1950, S. 172.

524 Viebig 1950, S. 230. 
sie nicht mehr zurück - sie hatte ihre Heimat verloren. “525 Ab diesem Zeitpunkt, dem zweiten Drittel des Romans, ist Heimat keine Bezugsgröße mehr für Mine, sie nimmt das Wort nicht mehr in den Mund. Als soziale Kategorie der Selbstversicherung und der Versorgung hat sich Heimat nicht bewährt.

Auf eine andere Heimat, die Einheit mit Gott, hofft das zurückgebliebene und ungeliebte Kind Grete, das bei der Heilsarmee Trost findet: „Ich habe die joldene Heimat jesehn und das lichthelle Land - komm, laß uns dahin jehn!“526 Grete hat sich ganz dem Jenseits verschrieben und stirbt schließlich. Die vorher durchlebten ekstatischen Visionen des Kindes sind ins traurige Licht der Verzweiflung gehüllt, mehr Ausdruck des Scheiterns am Leben als der Spiritualität. Ihr Tod steht für das Versagen ihrer Umwelt, nicht für eine Einkehr in Gott, und so ist Gretes ,joldene Heimat' nicht nur eine persönliche Illusion, sondern Ausdruck einer Gesellschaft, die nicht für ihre Armen sorgt und in der die Religion mit Marx das ,Opium des Volks‘ ist. Der Glaube an eine himmlische Heimat (vgl. II.1) wird somit aus sozialer Perspektive der Kritik unterzogen.

Auch wenn Heimat als soziale und Heimat als religiöse Kategorie im Romanverlauf scheitern, hat ein anderes Glücksversprechen von Heimat Bestand: das der seelischen Verbundenheit mit der kultivierten, also ökonomisch versorgenden Erde. Der Roman entwirft ein weit über die einzelne Figurenperspektive hinausgehendes Positivmodell von Heimat, das auf den bäuerlichen ,Grund und Boden' setzt. Es ist hierbei nicht ein beliebiges Naturerlebnis, es ist nicht einfach die Landschaft der Kindheit, sondern der bewirtschaftete Boden, der zum kraftspendenden Erinnerungsbild für Mine wird. Berthas Beziehungslosigkeit zur Heimat wird von der Erzählinstanz unter anderem damit erklärt, dass ihre Mutter eben nicht „ein Stückchen Acker, an dem die Seele hängt“ habe. ${ }^{527}$ Auch Gretes Verhalten wird von der Erzählerstimme dahingehend kommentiert, sie habe „noch nie grünende Saat, noch nie ein wogendes Kornfeld gesehen“. Im Moment des Glücks verbindet sich Mines Natur- und Liebeserlebnis mit der Erinnerung an

525 Viebig 1950, S. 240.

526 Viebig 1950, S. 51-52.

527 „Noch nie hatte Bertha der Heimat gedacht. Berlin war ja so viel schöner. Aber als sie jetzt so einsam am zugigen Tor stand und mit unruhigen Blicken die Straße hinauf und hinab spähte, dachte sie an daheim. Aber hatte sie denn ein ,Daheim‘? Kein Stückchen Acker, an dem die Seele hängt, zu eigen; im Häuschen wohnten sie zur Miete. Die Mutter, halb Bäuerin, halb Städterin, war ewig aus dem Haus! Und wenn sie wiederkam und überwacht, angestrengt, durchfroren, durchgerüttelt vom Bauernwägelein stieg, mußte sie eins trinken zur Beruhigung, und dann schlief sie ein, und dann trank sie nach dem Erwachen abermals, um sich wieder zu beleben, ,Mumm` zu kriegen für eine neue Verantwortlichkeit, die ihr Gewerbe mit sich brachte. Bertha schüttelte sich; nein, nicht nach Haus! Aber wohin denn, was wollte sie denn eigentlich?!“ Viebig 1950, S. 353. 
die ,Heimatflur‘. Es findet keine Verklärung einer ländlichen Heimat im Sinne des Sozialen statt: Die Familie von Mine ist arm, aber deswegen nicht natürlichmenschlich, im Gegenteil ist sie roh, selbstsüchtig und ohne Erbarmen. Auch das Dorf wird nicht als funktionierende menschliche Gemeinschaft dargestellt. Es bleibt die gewissermaßen menschenlose ,Heimatflur'. Es ist aber wichtig, dass der Begriff der Heimat, nachdem Mine von ihrer Familie verstoßen wurde, kein einziges Mal mehr im Roman verwendet wird. Ohne das Soziale, so kann man schließen, bedarf die seelische Verbundenheit mit der Erde auch nicht mehr des Begriffs der Heimat.

Dies bestätigt die fünfzehn Jahre nach Das tägliche Brot erscheinende Fortsetzung der Geschichte von Mine Reschke mit dem Titel Eine Handvoll Erde (1915). Mines Sehnsucht nach einem Stückchen Grund und Boden ist das Handlungszentrum des Romans. Die ,Scholle‘ (anders als in den zuvor besprochenen Romanen nun als Begriff präsent), die ,Handvoll Erde‘, ist das zentrale Motiv und zugleich das Surrogat von Heimat. Das Wort Heimat wird demgegenüber kein einziges Mal im ganzen Roman verwendet, denn Langbehns Diktum - „Eine wahre Heimat hat der Mensch erst, wenn er Grundbesitz und insbesondere Landbesitz hat" ${ }^{428}$ - kann in der Großstadt nicht mehr gelten.

Der Roman Eine Handvoll Erde spielt um 1910, etwa zwanzig Jahre nach Das tägliche Brot. Zwei Kinder Mines sind gestorben, zwei groß geworden, die Eheleute Reschke wie eh und je ohne feste Stelle. Reschkes pachten Boden für eine kleine Laube, um der Mietskaserne wenigstens in der kurzen freien Zeit zu entkommen. Das Laubengrundstück liegt in einer armseligen, trüben Gegend vor den Toren Berlins; hier laufen die dunklen Handlungsfäden eines Kriminalplots zusammen, in dem es um einen falschen Liebhaber und einen Doppelmord, Bodenspekulation $^{529}$ und Raub geht - am Ende wird ein Irrenhaus an diesem Ort errichtet. Das Bedürfnis von Mine nach „dem Stückchen Erde, dieser armen Scholle“ kann das aber nicht brechen, auch wenn das Grundstück nur gepachtet ist: ,,'ne Handvoll Erde, wo ich zu sagen kann: ,du bist mein“."530

Korreliert wird der im Schrebergarten gewonnene Lebensmut mit den Auswanderungsplänen des Sohnes Max nach Amerika: „Eine Handvoll Erde genügt da oft schon, um reich zu werden. "531 Die Hoffnung des ausgewanderten Sohnes bestätigt sich nicht und die Hoffnung von Mine auf eigenen Grund und Boden

528 Langbehn 1890, S. 128.

529 Der Bodenspekulant Hippelt beutet das Bedürfnis der kleinen Leute nach „eigenem Grund und Boden“ aus: „Hippelt rieb sich die Hände: nur auf eigenem Grund und Boden fühlt sich der Mensch glücklich.“ Viebig 1952, S. 221.

530 Beide Zitate Viebig 1952, S. 255.

531 Viebig 1952, S. 241. 
wird bis zum Äußersten auf die Probe gestellt. Ihre Pacht läuft aus und die Verzweiflung über das Scheitern des Sohnes vermischt sich mit der über den Verlust der Laube: „Ach, sie war ja hier schon so angewachsen - nein, sie konnte, sie konnte hier nicht fort! Ihre Finger krallten sich förmlich ins Erdreich, wie Wurzeln, die eindringen, die tief hinabgreifen. “532

Der Deus ex machina, der im Folgenden in Gestalt des Dr. Hirsekorn auftritt, verspricht Mine, ihr die ,Handvoll Erde‘ zu erhalten und ihr ein Häuschen mit Garten in der Gegend zu kaufen. Wie schon beim hoffnungsvollen Romanende von Das tägliche Brot wird die hier hergestellte ,poetische Gerechtigkeit‘ allerdings deutlich als Abkehr vom realistischen Szenario markiert. So ist es Mine, als sie Hirsekorn trifft, ,als blicke sie in Gottes Angesicht“. ${ }^{533}$ Der Roman endet melancholisch mit einem inneren Zwiegespräch des Doktors mit seiner verstorbenen Frau Marianne: „Eine Handvoll ist's, um die wir ringen, wir mühen uns darum unser Leben lang: eine Handvoll Erde. Aber siehe, einzig die letzte, sie, die uns deckt, macht uns ganz glücklich - nur sie allein! Und sie nur gehört uns ganz!“534

Auch mit dieser letzten Wendung der Metapher zeigt sich die ,Handvoll Erde“ als Surrogat einer Heimat, die sich nicht jeder leisten kann: So wie die ,Handvoll Erde‘, die bewirtschaftet wird, Heimat ersetzt - aber eben nur unter den ärmlichen Bedingungen der gepachteten Laube in einer trüben Gegend -, ersetzt die das Grab deckende ,Handvoll Erde“ die Vorstellung der ,himmlischen Heimat‘. Die Jenseitsvorstellung wird vermittels der physisch-materiellen Bildlichkeit der Erde in die Immanenz überführt. Umgekehrt gilt aber auch, dass die ,Erde' im Roman immer wieder emotionalisiert wird, etwa in der Szene, in der die alte Mine sich auf ihr Stück Boden fallen lässt und ,ihr heißes Gesicht in die kühle Erde“ drückt. Die eigene Scholle ist in Viebigs Texten die Urzelle menschlicher Kraft, die auch in der industriell geprägten Moderne nichts von ihrer Bedeutung verliert, im Weiberdorf repräsentiert durch die in die Stadt ziehende Bäbbi, in Eine Handvoll Erde durch die zur Städterin gewordene Mine. Während Heimat als soziale Kategorie in den behandelten Texten in Frage gestellt wird, fungiert die menschenleere ,Scholle،

532 Viebig 1952, S. 252.

533 Viebig 1952, S. 253. Der Bruch des Romanendes wird genauso wenig wie die Tatsache in Rechnung gestellt, dass das Wort ,Heimat" hier gar nicht vorkommt, wenn Gisela Ecker das Frauen- und Heimatbild des Romans mit Bezug auf diese Textstelle aus feministischer Sicht verurteilt: „,Heimat‘ ist für Heldinnen wie sie ein Ort, an dem frau wartet, mehr als alle anderen arbeitet, Kinder bekommt, sich für alle aufopfert und die entsprechenden Zeichen sichtbar am Körper trägt. Die paradoxe Figur des zufriedenen Opfers enthält sowohl die Leistung, die zu erbringen ist, damit ein so stabiler, begehrter Ort (vor allem für Männer, aber auch für Frauen) erhalten bleibt, als auch die Gratifikation und partielle Macht durch Idealisierung, die nötig ist, um die Bewahrerin von ,Heimat‘ an diesem Ort zu halten.“ Ecker 1997, S. 124.

534 Viebig 1952, S. 260. 
als pathetisches Gegenprogramm. ${ }^{535}$ Aber die Scholle wird bei Viebig nicht, wie zeitgenössisch üblich - etwa bei Hermann Kurz (vgl. II.2.2.3), Theodor Herzl (vgl. II.1.3.2) oder Josef Nadler (vgl. II.3.3) - mit dem Begriff der Heimat verbunden. Viebig wurde von der zeitgenössischen Literaturgeschichtsschreibung entweder nur dem Naturalismus oder nur der Heimatkunst zugeordnet. ${ }^{536}$ Dass es eher um eine Verbindung von beidem geht, ${ }^{537}$ hat sich inzwischen - vor dem Hintergrund der Annahme eines Stilpluralismus in der Zeit um 1900 - als Einschätzung durchgesetzt. ${ }^{538}$ Fraglich bleibt allerdings, wie sinnvoll überhaupt von ,Heimatkunst‘ als literaturhistorischer Bezugsgröße ausgegangen werden sollte. Die ,Heimatkunst“ ist, jedenfalls zum Teil, ein literaturpolitisch äußerst wir-

535 Die Rede von der ,Scholle‘ war im späten 19. Jahrhundert oft, aber nicht notwendig mit der völkischen Ideologie verknüpft, die sich ab Anfang der 1920er Jahre dann mit dem Begriff von ,Blut und Boden' verband. Oswald Spengler gebraucht die Begriffe von Blut und Boden im Untergang des Abendlandes als Gegensatzpaar. Max Wundts Verwendung des Begriffspaars in seiner Schrift Was heißt völkisch? ist dann einschlägig, vgl. Wundt 1924, S. 32. Schon Ende des 19. Jahrhunderts tritt die Scholle als völkisches Konzept im fiktiven Rahmen etwa in Wilhelm von Polenz' Roman Der Büttnerbauer in Erscheinung: Mit sozial- und ökonomiekritischer Präzision wird die zeitgenössische Umstrukturierung der extensiven in eine intensive Landwirtschaft und werden ökonomische Abhängigkeiten der Landbevölkerung in eine panoramatisch-analytische, an Zola erinnernde Gesellschaftsdarstellung gefasst: „Das Verpfänden und Belasten des Grund und Bodens ward in ein System gebracht, das den Urgrund aller menschlichen Verhältnisse, die Scholle, einem Handelsartikel gleichstellte“ (Polenz 1895, S. 278). Die Kapitalismuskritik wird völkisch gewendet, indem sie das Leiden an den Umstrukturierungen an die vermeintlich erdverbundene germanisch-nordische ,Rasse‘ bindet, während die kapitalistische Logik durch die Juden vollzogen wird, die bei Polenz nicht nur unfähig zur Erdverbundenheit sind, sondern diese durch Spekulation in ihren Grundfesten untergraben. Am Ende nimmt sich der seines Landes enteignete Büttnerbauer das Leben; von der Scholle kann er nur über seine Leiche lassen: „Die weit aus ihren Höhlen hervorquellenden Augen starren die Scholle an; die Scholle, der sein Leben gegolten, der er Leib und Seele verschrieben hatte“ (Polenz 1895, S. 427). Der erhängte Körper hat dann auch im wörtlichen Sinn den Boden unter den Füßen verloren. - Auch in Viebigs Texten wird Bodenspekulation als Ausdruck inhumaner wirtschaftlicher Interessen gegen die Bodenverbundenheit des einfachen Volkes gesetzt, aber die völkischen und antisemitischen Motive eines Polenz fehlen in den hier besprochenen Romanen völlig. Für Viebigs Texte ab den 1920er Jahren mag gelten, dass zunehmend konservative Wertmaßstäbe mit ästhetischer Mittelmäßigkeit korrelieren und Heimat dort dem völkischen Verständnis als, deutscher Scholle‘ bedenklich nahe rückt, so KraußTheim 1992, S. 249.

536 Vgl. Gubisch 1921; Scheuffler 1927; Mahrholz 1931, S. 145-147; Meyer 1921, S. 554.

537 Dies wurde schon von Zeitgenossen so gesehen, etwa von dem Schriftsteller und Publizisten Ludwig Jacobowski; vgl. Jacobowski 1897, S. 717.

538 Die Annahme, Literatur ,um 1900‘ sei als Entfaltungszusammenhang nicht diachron sich ablösender, sondern sich nebeneinander entfaltender und sich wechselseitig beeinflussender Strömungen zu verstehen, wird so diskutiert seit Rasch 1967. Vgl. auch Krauß-Theim 1992, S. 38 mit einem Forschungsüberblick zum Verhältnis von Heimatkunst und Naturalismus. 
kungsvoll installiertes Privatprogramm Adolf Bartels', der sie als literaturhistorische ,Epoche“ überhaupt erst einführte. Die sich zur ,Heimatkunst bekennende Viebig ist, schaut man auf die ästhetisch innovativen Texte um 1900, denkbar weit von dem entfernt, was Bartels mit der Heimatkunst verband: Viebigs Texte setzten aufs Regionale, aber nicht nur aufs Ländliche, sondern auch aufs Städtische. Sie bedienen sich der Mundart, aber dazu gehört auch der Berliner Dialekt. Sie haben das ,einfache Volk' zum Gegenstand, aber die Schilderungen des Landlebens zeigen nie eine intakte oder gar idyllische Welt. Sie führen den Begriff der Heimat mit sich, er zeigt aber nur ein Bedürfnis an, das nicht befriedigt werden kann. In welcher Weise überhaupt sinnvoll von Heimatkunst um 1900 als einer in sich kohärenten literarischen Bewegung gesprochen werden kann, bleibt, wie man an Clara Viebigs Texten sieht, fragwürdig. In dieser Perspektive wäre die Literaturgeschichtsschreibung einem mehr oder weniger solitär stehenden Programmatiker wie Adolf Bartels bis heute in gewisser Weise aufgesessen. Die Existenz von Heimatkunst erweist sich als genauso zweifelhaft wie ihr Gegenstand. 